\title{
COLECCIÓN DE ESTUdIOS Árabes
}





\section{DECADENCIA Y DESAPARICIÓN}

I) LOS

ALMORAVIDES EN ESPAÑA 



\section{DECADENCIA Y' DRgapariOIÓN}

J) $\operatorname{LOS}$

\section{ALMORAVIDES EN RSPAÑ}

Pok

\section{FRANCISCO CODERA}

de ia R. A. de Ia Historia

ciatedrático de Lengua Árabe en Ia Universidat

Centr:il

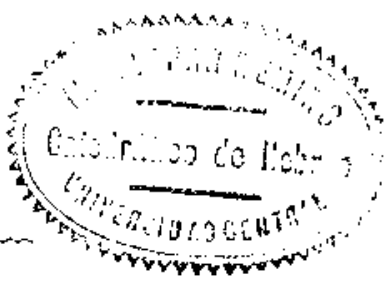

$2,1 \cdot 103.822$

\section{ZARAGOZA}

TLP. TE GOMAS HEMSANOS, PllaR, 1 



\section{INTRODUCCIÓN}

lis cosa corriente y admitida por cuantos se dedican en seria al cultivo de nuestra Hisloria, que la dominación de los f́rabes en Espeña está por escribir; pues si tenemos una obra buena, en cuan lo podía pedirse liace 40 años cuando Dazy escribió su IIstoria dr. los musulmanes de España hasla la compuisin de los ntmaraxites, el antor holandés, como indica el título de st obra, suspendíb la narración al terminar el períouo die los reyes de Taifas, dejando por historiar los períodos de Almoravides, Almohades, Benimerines y Na- 
saríes de Granada, prescindiendo de otras dinastías, espeñolas 6 a fricanes, que por poco tiempo dominaron parte de la Península.

Ls verdad que ya antes había eserita don José Antonio Conde su Historia de la dominaciou de los úrabes en España, libro que en un principio se crejó en toda Jiuropa que llenabe el vacío de nuestra historia; pero la obra de Conde cayó pronto en descrédito para los intelicrentes nacionales y extranjeros, hrbiendo sido objeto fuera de España de acerbas críticas, que un mal entendido patriotismo ha hecho creer infundadas, cuando en realidad sólo resultan exageradas; pues se atribuy 6 á ignorancis completa de la lengua lo que en mi sentir ( $y$ en esto creo ser más duro con Conde) es debido á lo que pudiéramos llemar mala fe literaria, porque el autor, cuando excontraba una dificultad insoluble, como tedía que encontrar muchas y se encuentran aún hoy, corteba el nudo en vez de desalarlo, $\delta$ de confesar su ignorancia en puntos concretos por fulta de datos.

En prueba de mis spreciaciones citaré dos hechos muy importantes de nuestra his- 
toria árabe, que Conde no podía entender, $y$ que le llevaron, el uno á multitud de erroses, y hasta falsiūcaciones, $y$ el atro á cambjar una fecha, alierando la unidad, deceza y ceutena para hacer entrar el hecha, á que parecía referirse, en la cronología recibida.

Habiendo encoutrado en varios autores árabes que el centro de la rebelión de Omar Abenhafsún, fué gä́r? que tomó por Barbastro, en la provincia de Huesca, cuando en realidad era Bibaster, eu la provincia de Málagya, cerca de Anlequera, trasladó á Barbastro el centro de operaciones, é liizo girar á Omar en torno de esta ciudad, cambiando los nombres de Archidona, Antequera, Elyira, Granada, Málaga y otras, por los do las poblaciones, a que se podía llegar desdo Barbastro, como son Monzón, Tamarite, Lérida, Roda, Huesca, Zarogoza, Alonñiz, etc.

Comprendo que este cargo es gravísimo y que habrá quienes lo tacharán de exageración mía: no lo dirán los arabistas: éstos podrán decir que corgos tan graves, aunque sean fundados, no deben bacerse por un español, máxime cuando Conde está bestante 
$\mathrm{X}$

desacreditado: á esto diré, que ni creo á Conde basiante desacreditado entre nosotros, puesto que muchos siguen citándole y tomándole como guía, ni entiendo ei patriotismo de este modo tan estrecho.

Podría suponerse en defensa de Conde que en elgín. manuscrito árabe leyó las grueras de Omar A benhafsún cono las aarra en su libro: no podemos asegurar que así no fuera; pero de todos modos es indudable que Conde leyó la narración da estas guerras como la leemos boy en los autoros publicados, muchos de los cuales leyó, y en el mero hecho de diferir esencialmente la narración de como se encontraba en el supuesto manuseristo, que nadie ha visto, tenía obligación estricla de advertirlo, so pena de autorizarnos á tacliarle de falsario.

Hemos admilido la suposición de que Conde viera un mauuscrito ctiya narración en este punto difiriese de la de otros; pero estamos seguros de que no hubo tal cosa, y ésta es en último término la opinión de los arabistas, aun la de aquellos que procuran atenuar los cargos contra Conde. 
F) otro hecho á que hemos aludido es el siguiente: Conde llegó a leer hastante bien las monedas árabes españoles: vió sin duda muchas de las acuñadas á nombre de llixem II, bastantes años después de muerto, y no pudiendo entonces comprender esto, que se explica hoy perfectameute por el reconacimiento del falso Hixem li, por el cadí de Sevillu y demás reyes de 'l'uifus que podríamos llamar del pertido legitimisia, sulió de la dificultad, ó se alucinó, al describir una moneda de Sevilla del año 438 , leyendo en alla la fecba 382: y nótese que la moneda estaba bien conservada, según resulta del grabado

No todo lo arue escribió Conde, ni mucho menos, es disparatado; pero bay en su obra muchos errores, y los no arabistas no están en condiciones de distinguir lo bueno de lo malo: por tanto no deben hacer uso de tat obra: entre los arabistas dudo que haya uno que so atreva á aceptar, por la sola autoridud de

I Memorlas de la Real Acastomin de la Historia,

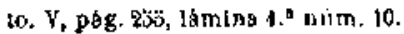




\section{XII}

Conde, una noticia que le interese para sus trabajos y que él mismo no hayu encontrado en los autores árabes.

La desconfianza absoluta que debe tenerse de la obra de Conde, alcanza lo mismo it la de Tiardot, mero trasunto de la de Conde, á las obras de Romey, D. Nodesto Lafuenie y á olras muehas que para la parte árabe son en general meras paráfrasis de las de Conde 6 Viardol, con la particularided de que en muchos cesos, por no copiar las palobres del original, al querer retocar el cuedro por su cuenta, le dan más colorido, y con esto el cuadro resulta más fulso: no to hacen así los autores árabes, que casi siennpre copian las palabras de los autores apieriores.

Adernás de las historias de Dozy y Conde, tenemos la Mistoriat de las Dinastias mahometanas en España por auestro querido maes-

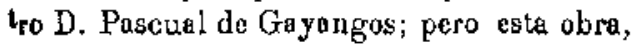
escrita en inglés, sin que se haya lecho versión castellana, no es orjgina], di el autor lo pretendió, sino traducción-arrerrlo de una obra de autor árabe-Inarroquí de principios del siglo xva, con muchas ilustraciones to- 
mudas por el Sr. Gayaugos de otras obras, inéditas muchas de ellas.

Is obra escrita en estos úllimos años por Mercier 1, por su contenido generul podrín servir nucho para ilusirar nuesira historia árabe, ya que entre ambos países musulmanes hubo siempre gran comunicación, aun cuando no existía identidad de gobierno, como sucedió en períodos más ó menos lergos: pero como probamos en las Aclaraciones, en lo referente á los acontecimientos de la dominación árabe ocurridos en Fspaña el autor incurre con lista frecuencia en graves errores y debe por tanto comaltarse con desconfianza, y es que MIr. Mercier se propiso una cosa imposible, escribir la historia de las dinastías africanas, que no han sido áu objeto de estudio especial y completo por parte de ningín europeo, $y$ mientras no se haya hecho la historia de cada dinastía, no es posible que uno escriba bien la de todas ellas.

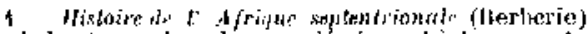

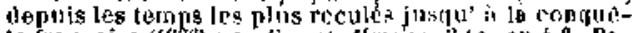

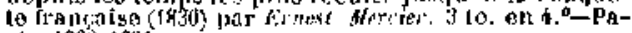
ris, $1898-1894$. 
Si hasta ahora no se ha escrito una buena Listoria árabe de España, öse estả en condiciones de escribirla? Creo que no: los estudios árabes no están suficientemente adelantados para que se pueda sintetizar la historia: aunque se hen publicado durabte los cincuenta вños últimos muchos textos referentes $\{$ cosas de España, otros muchos, $y$ quizá los más importantes, están aún sin publicar, y por muy buena valuntad $y$ constancia que supongamos en los arabistes, no es lo mismo estudiar cómodamente en su gabinete un libro impresa, quo hojear un manuscrito de mejor ó peor letra en el depurtamento de una biblioteca, con las molestius y deficiencias consiguientes: mientras no se hayan publicado previamente los muchos libros que se conocen de nuestra historia, nos parece muy difícil, por no decir imposible, que pueda salir un genio, quo después de cxaminar por su cuente lo mucho que existe espurcido en bibliotecas públicas y privadas, pueda abarcar de un gelpe la historia general de los árebes en España.

Hoy por hoy, quizá lo único que debiera 
hacerse, es lrabajar monografina, dilucjdando puatos especiales; monogn jias que rehechas ó complelaclas por el raismo autor, 6 por autores posteriures, preparacen los elementos para trabajos de covjunto.

Dicho lo que precede, su comprenderá que no tenemos la pretensión de escribir la Historia de los almortaides, propiamente tal: el preseute trabajo fué escrito hace bastantes años cono Estudio memismático del jucriodo intermedio entre .tmorades $y$ imohrdes: publicadas luego por nuestro anigo I). Antonio Vives lodas las nouedas árabos españolas canocidas, auque sin discutirlas ai aprovechar sus datos, pues eslo: no unlrabe en su plan, ya nuestro trabajo primitivo babía perdido una buena parte de su importancia, y lo redactamos de nuevo, discutiendo Jos liachos à la luz de todos los dutos conocidos, muclios de los cuales aparecían baslante más claros en vista de los datos que nos habíun proporcionado libros antes no conocidos, $y$ que hoy posee la Real Academia de la Historia.

Acordada la publicación de la Colección de 
estudios icrabes, como nuestro trabajo no resultaba de fácil lectura para los no arabistas, pues los tex tos árabes estaban discutidos en el cuerpo del trabajo, y el objeto de la Colcción es vulgarizar los resulıdos de los estudios arábigos, lo hemos redactado de nuevo, historiando el poriorlo de la dectedenira y desaparición de los Almoracides en Esparia, refiriendo los hechos como nos han parecido. resultar de nuestras investigaciones; pera no pretendiendo que se nos crea por nuestra pulabra, en notas é ilustraciones nos referinos á los lextos, en que nos apoyamos, y como no pocas veces los autores están discordes, hemos discutido los textos en comprobación de la opinión que seguimos: alguna ver, sin emhargo, hemos dado en el texto las diferentes versiones respecto á ciertos sucesos, cuando por ser las noticias poco abundeates, no hemos encon lrado razón especial para decidirnos por una versión más bien que por otra. El púmero y extensión de las notas é ilustraciones parecerá quizá excesivo; pero téngase en cuenta que los puntos tratados lo son casi por primera vez para el público y 
había que indicar todas ó la mayor parte de las fuentes ó de las razones que nos habían guiado en nuestra investignación.

Fuenles. Como podrá ofservarse fãcilmente, para nuestro estudio nos servimos en primer término de los autores árabes publicados 6 inćditos: no pocas reces nos guiamos por lus Cronicones, cuyos datos son ea general de la mayor imporiancia y deben teuerse muy en cuenta, aun en los cusos. pocos por cierto, en que parecen en contradicción con los textos árabes: sisuiendo la marcha que indicamos al escribir nuestro biscurso de recpcion en la Real Aerdemia de la Hintoria, apreciamos en mucho los datos de los cronicones y Necrologias de monasterios, al paso que prescindimos por completo de lo gue digan respecto á un pubto especial los historiadores generales 6 particulares desde el siglo $x v$ en adelante, porque de las cosas árubes sabían casi siempre muy poco $y$ los encontramos disparatados con harta frecuencia, extraviados por las tradicciones locales; y como en general no citan las fuentes, no tenemos la pretension de acertar á separar lo poco que Axmontyons 
pueds haber de aceptable de lo mucho que indudablemente es disparatado.

$Y$ esto merece alguna explicación. No hacemos á nuestros historiadores clásicos de los úlitimos siçlos la ofensa de suponer que se fingieron los hechos relativos á los árabes: de ordinario sólo conocian nuestros Cronicones 8 ntiguos, que se esfuerzan en aclarar lucliapdo con la escasez de datos: alguna rez se vislumbran en sus palabras trasuntos de textos árabes mejor 6 beor traducidos '; pero siempre resulta que muchas cosas evidentemente están nuy mal entendidas, incurriendo casi todos allos an muchos anacronismos é incongruencias manifiestas, de donde resulta que la moyor parte, ó muchas de las noticias, que se encuentran en puestros historiadorés particulares eslán lergiversadas: de aquí la gran desconliauza que tienen quc inspirar las que no constan hoy por otro conducto, aun en el supuesto de que no estén

1 Es casi seguro (ue varios ubras arobes, como

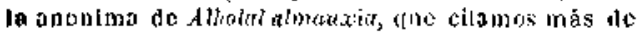
una vez, fueron traducitas al caslellano, y prohablemente serían ulilizadas por nuestros listoriadores. 
en contradicción con lo que se tiene por averiguado.

Creo que las noticias de esta clase sólo podrán ser aquilatadas en su justo valor por algún arabista que estudie de un ruodo especial la historia particujar de la recrión ó población á que se refiera; el escritor recrional, como más enterado por lo común de los detalles de todo género referentes á su región, está en mejores condiciones para apreciar bien pequeños detalles, 9 podrá dedicar su atención á investigar lo que pueda haber de verdad en las trudiciones locales consignadas por nuesitas listoriadores de los siglos xy y posteriores, porque pra él tendrá gran importancia el aclarar un hecho más, aunque no la tenga para la historia geaeral; pero creemos que sicmpre ha de ser larea difichl, y casi imposible, si el erítico no es arabista.

Aunque pueda parecer parcialidad de profesión y exegerada insistencia, me atrevo á recomendar muy particularmen te á cuantos se dediquen á estudios de Historia de lispaja, general 6 particular, que en lo referentc a los árabes, 6 relaciones de éstos con los 
cristianos, no acepten kecho ni apreciation que no encuentren en los autores árabes, en los Cronicones antignos ó en los autores modernos, que no sean trasunlos más ó menos directos do Conde, como los hay aún muchos.

No tenemos la pretensión de que nuestra historia de este periodo sea completa y perfecta, ni mucho menos: nos hemos limitado a exponer la historia exlerva, prescindiendo de la interna, ó sea de las institocioncs, costumbros, comcrcio, industria é ideas del puoblo inusulnán español durante este período, no por principio y porque crenmos que todus estas muterias no sou parte esencial de Ia histaria, sino por igzarancia: de todo esto poco ó nada sabemos, teniendo además lu convición de que nadie sabe mucho de ello, aunque habría medio de saber bastant, si alguien pudicra estudiar los muchos libros dunde con segurided se encontrarían noticias interesantes acerca de estos puntos, como son los libros de administración árabe, colecciones de consultas de abogados á alfaquíes tan notables cono el Abearoxd, abuelo del filósolo Averroes, Abeniyad y otros, de quienes 
se conserva y es muy aprecibda una colección de consultes en seis grfuesos ralímenes, y los libros de consejos acerca del modo de gobervarse en la vida $\mathrm{y}$ otros; pero por descracia es de temer que tales libros tarden mucho en ser utilizados, dada la escasez de los arabistas $y$ am el poco estímulo que el público presta á ostos estudios.

Es tan grande la convicción que tenemos de que hoy no puede pensarse en escribir la histaria de los árabes de España, que sólo cediendo algo a la opinión greneral, inlentamos dar un bosquejo de la dominación árabe en sus diferentes períodos: por uuestra parle creemos más útil al progreso de la historia patria la publicación de los datos que hubiéramos podido reunir, y había pensado poder publicar como Aparato histónico la colección de papejetas que tenemos hechas, en cuya publicación hubiéramos discutido los datos que teuemos anotados referentes á cada suceso, sin tratar de llener laruas ni de aclarar á todo trance los hechos de los que hay pocos datos; pero esto nos compromelía ante el público a un trabajo superior á nuestros medios. 


\section{XXII}

Una publicación de esta índole tendría la ventaja de que en ella cabe perfectamen te la diferencia de extensión en los detalles: se darián los noticias como se tuvieran: á veces de sucesos muy imporlantes no hay inás noticia quo una línea, y olros de escaso interés b́que sólo lo tieneu para la historia local, están nasrados de un modo muy minuciaso: de éstos hay que prescindir en narración seguida, exponićudose el autor en otro cuso á dar importancia á lo que no la tíne: es scguro que nuestro plon predilecto no hubiera sido del agrado del público: es muy posible que tampoco le agrade lo que brcemos y que noconsigamos ni aus la escasa acogida necesaria para poder continuar la presente Caleceión, con la cual aspiramos á difundir un poco entre nosotros el conocimiento de nuestra historia árabe, ó al mezos á desterrar de ella errores, que pasan como verdades sancionadas por asentimiento de los historiadores.

Las mismas causas que nos novieron de un modo especial al esludio de la hisioria de este período, nos han movido á reunir con 
especial empeño datos para estudiar el periodo histórico eutre Almoliades y Kenimoriues; pues también cristen de él monedas dificiles de explicar, por referirse á liechos paco o nada conocidos: seguiremos reumieaclo cuantos datos nos sea posible, yor si podemos ilustrar con ellos nuestra histurit arabe en sus diferentes períodos: para el trabyjo de estudio no vecesitamos estímulo alguno, ni protección de nadie, sino frojlidades de parte de quier posea documentos árabes de cualquier género: pero como el trabaja de redocción, aun desputés de remidos los datos, nos cansa mucho, y satisiace puco, por no tunor la ilusión de hacerlo bien, es nuy posible que nos coja la pereza por el cansarcio inherente al disguisto en la redacción $y$ quede la tarea para que la lleve á cabo otro, quiź alguno de nuestros arahistas que quiera aprorechar nuestras numerosas papeletas, ledradas al predilecto de nuestros discípulos, quien con seguridad, siguiendo las tradiciones del insigne restaurador de los estudios arabigros en España, que fignura al frente del primer tomo de estu Colccción, las comuni- 


\section{XXIV}

cará generosamente á cuantos estén en condiciones de aprovecharlas.

Transcripción. La éste, como en los demás towos de la Colección, seguimos el sistema de transeripción expuesto en el primer tomo de la misma por el Sr. D. Eduarda Saaverira; pero para este tomo $\mathrm{J}$ los demás que puedan seguir de la misma índole, necesitemos hacer alguna aclaración.

Ln obras históricas árabes hay que hacer mención de uuchos nombres propios, no sólo desconocidos por completo de nuestros antores hispancmcristianos, sino aponas citados más que por uno ó dos autores árabes do los conocidos hasta hoy, resultando con harta frecuencia que un autor lo cita de un modo y otro de otro modo: no es esto sólo, sino que por la índole de la escritura árabe, de muchas nombres propios no constan las vocales, ni hay medio de averjguarlo, cuando el nombre propio no es de procedencia árabe, como sucede en muchos cusos en nuestra historia; por tanto no hay medio de averiguar wi de un modo aproximado cual fuera la pronunciación de tal nombre; de aquí que, no siendo 
posible en obras de esta clbse, poner sólo las consonantes, como quizá debiera bacerse, les hayamos supuesto, casi á ciegas, vocales determinsdas, $y$ hemos transcrito el nombre en virud de esta supuesta vocalización; y como para ésta apenas teníamos fundamento alguno, nada tendrá de extraño que el mismo nombre resulte transerito de diferente modo.

Feckas. Como la narración está tomada casi siempre de los autores arabes, of recía graves dificultudes el poner siempre la correspoudencia cronológica unestra, prescindiendo de la árabe, $y$ par eso de urdjuario hemos consigaado ésta, aunque poniendo casi siempre la cortespondeucia con la nuestra.

Cuando los autores árabes fijun oño y día del mes, es fácil y hubiera sido mejor, si estos detalles se fijaran sjempre, el poner s6lo la feclie en nuesiro cómputo: pero cuando no cilan el díu del zoes árabe, ó sólo citan el ano, sería muy vago poner la fecha en uuestro cómputo, pues casi siempre el año áratio corresponde á parte de dos nuestros, y liubiera sido preciso siempre que se tace mención del año 540, por ejemplo, decir dessle 
$x \times v i$

I4 de turio de $114, ;$ a 12 de Jurio de $1136, \mathrm{y}$ lo mismo respectivamente cuando se cita el mes, pera no ol dia, ya que el mes árabe casi siempre corresponde á parte de dos meses nuestros.

Como no siempre liemos puesto la corespondencia al citar fechas. que se repiten mucho, $y$ en el cuadro crosolóśco que ponemos al lin, no cabía tampoco hacerlo por las razones indicadas, nos parece oportuno poner a continuación los nowbres de los meses árabes y el cuadro dc los prizcipion de los oños árabes, que ubarca este estudio, previas unas indicociones cronolóngicus respecto al computo mahomelavo: con esto podrá el lector comprobar las correspondencies anotadias en el texto, que pucden estar equivocados y no la yamos corregido.

\section{Filancisco Codera.}

Medrid, 11 de beto do l890. 


\section{COMPUTO ARABE I}

Los musulmanes cuentin sus fecluas por su Era, llamada Hripira (huida) por la fuga de Mahoma de la Meca a Mrdina en lo nocbe del jueves 15 de dulio def ano 622 de J. C.; Ja Era, sin embargo, covieaza á contarse el dia 16, suuque no pocos lan creido que comenzó ol 15, y esta es la causa de que haya diferencia de un dia mas lad relación á nuestra Ẽra sexín el cómputo que hoga servido de punio du partida?.

El año para los musulmenes consta de 12 meses luares do 30 y 29 dios altornativamenle; pero como el año lamar, $\delta$ las doce

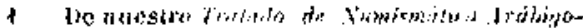

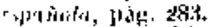

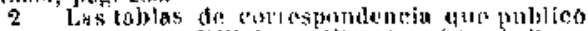

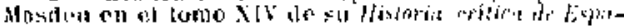

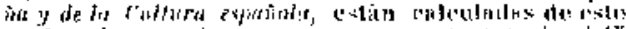

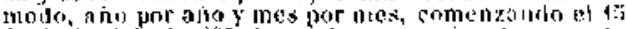

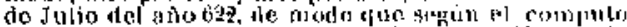

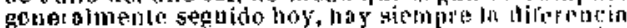

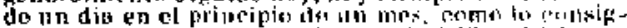

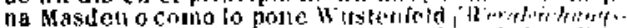

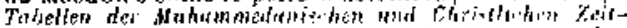

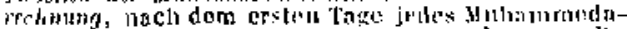

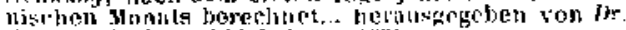

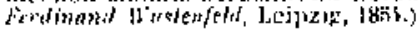


lunaciones hacen $3 \overline{4} 4$ días, 8 horas, $48^{\prime} 45^{\prime \prime} \mathrm{J}$ $30^{\prime \prime}$, hay necesidad de iutercalar un día cada dos ó tren años, para que resulte, ya que no exactitad rnotemálica, hprositnada; el día se añade al último mes, que tiane 29 días y 30 cuando es intercalar: en cada ciclo de 30 āios sou intercalares los años 2, 5, 7, 10, 13 , $16,18,21,24,26$ y 29 , comenzando el ciclo con el primer ano de la hégira.

Siendo el año nusulmán de 354 ó 355 días, es claro que no puede guardar relación constante con nuestros años, que son 1] días más largos y por consiguiente el comienzo del aña árabe ticne que adelantas 11 días de un año á otro con relación al nuestro; pero como aun esto no es completamente uniforme, pues hay que lence cn cuenta la existencia de nuestros años bísiestos, y la diferencia puede ser de 10,11612 días, resulta una grrar complicación que los cronoJogos han salvado formando tablas, que señalan el primer día de cada año musulmán con relución al nuestro.

De esta tabla ponemos a continuación la parte correspondiente al período comprendi- 
XX]X

do en este libro, advirtiendo respecto a sa usa, que sólo se indica el primer día de cada año de la téfira: los números de Ja curita columa indican el día do la semara, teniando on cuenta que los árabes lianan al flominso, dia primero, al lunes, diu seytuds, etc. $\mathrm{y}$ aunque al vicrics y scibalo llaman respectivamente dict de la remión y sidha!, se indican con los números 6 y 7 an la primera columna los áros intercalares van marcados con la jetra $B$.

Los nombres de los meses son: 1.0 "

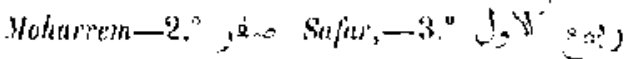
Rebi of mimero, -4."

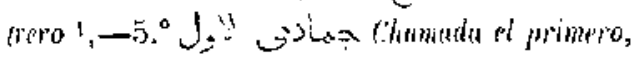
6."

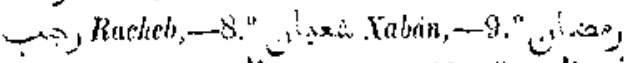

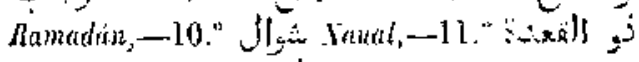

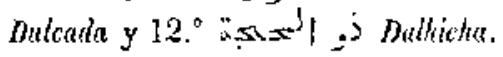

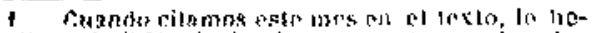

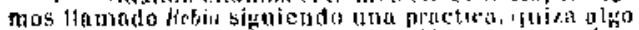

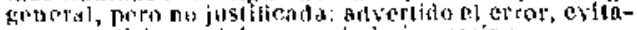

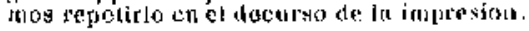


TABSA

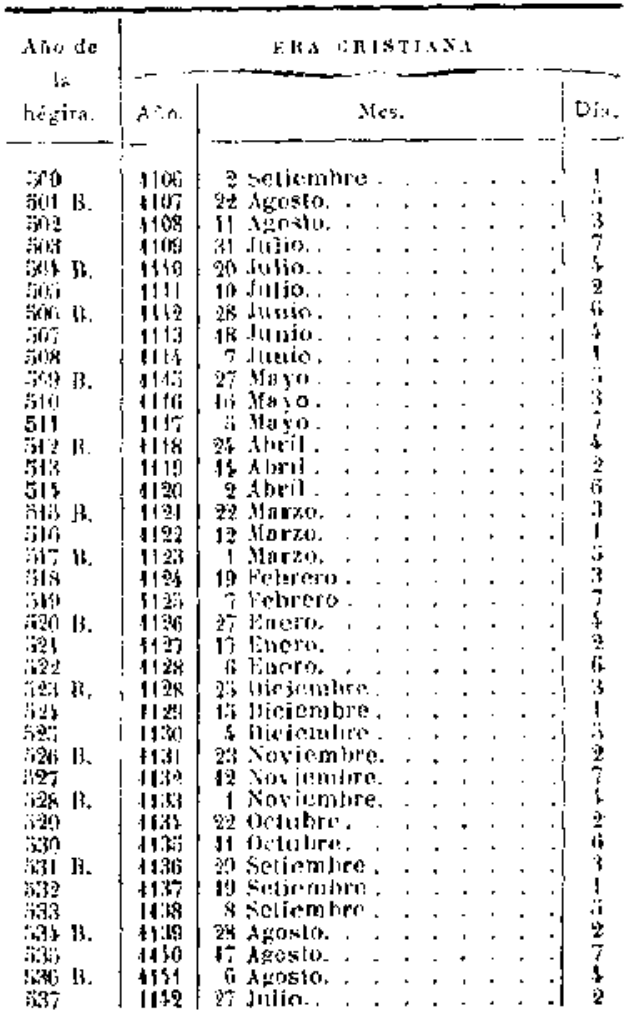




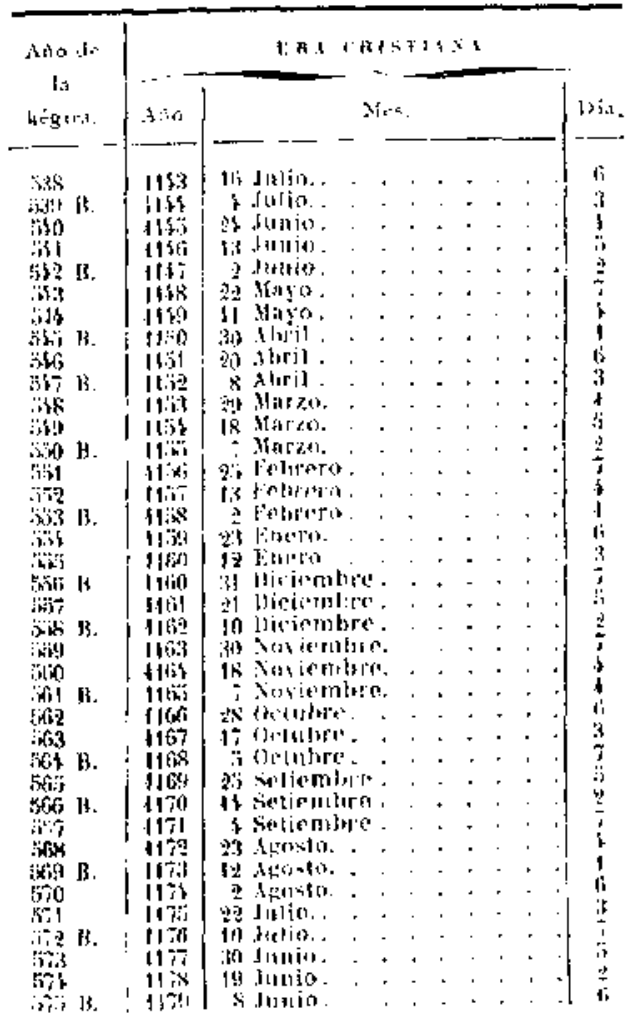


XXXII

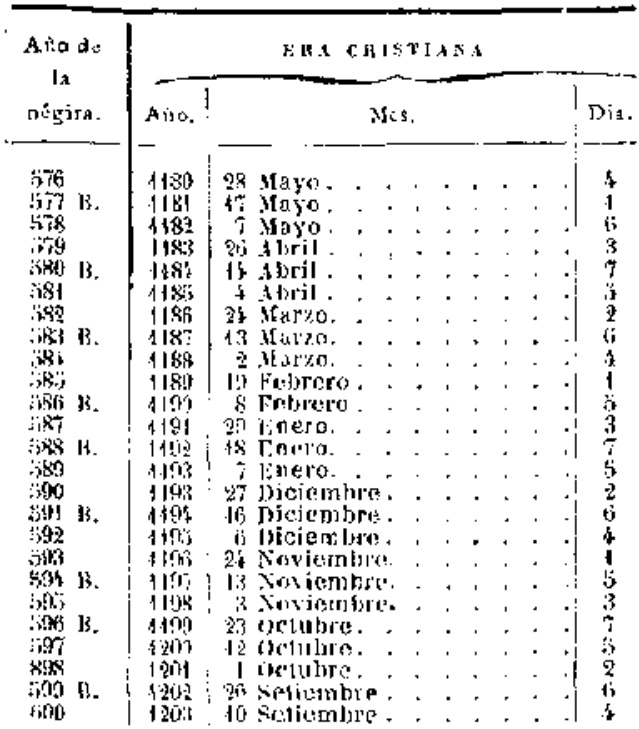




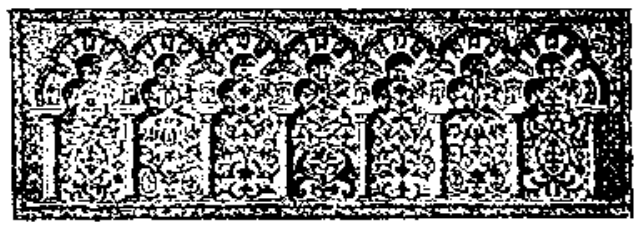

REINADO DE YISTY

La dinastía de los Almoravides, cuyo fundador Yúsuf, lijo de Texufín, había sido llamado por los reyes de Taifas, principalmente por Almotamid de Sepilla y Almolasáquil de I3adajoz, para contrarrestar á las armas victoriogss de Alfonso VI, que amena7.aba acabar con el dominio do los muslimes españoles, si en los primeros momen tos contuvo al conquistador de Toledo, humillándole el 23 de Octubre de 1086 en la batasla de Zalaca (1), pronto emplé́ sus fuerzas ALMORAVIOES 


\section{$-2-$}

en contra de los reyes, que con imprudencia suma habían llamado en su auxilio unas gentes que, cual previera lsmail Arraxid, Príncipe heredero del roy de Sevilla, se habían de convertir en terribles encmigos, que los despojaran de sus estados.

Fortuna fać para los crislianos el que Yúsuf, vencedor en Zalaca, recibiera á seguida la noticia de la muerte de su hijo el Príncipe hesedero Abubéquer Sir, y hubiera de volverse á Marruecos, abandonando la idea de perseguir al derrotado ejército cristiazo, y de obteser el fruto que pudiera prometerse de tan brillante victoria, apoderándose de Toledo, idea que parecía nainral, y que, sin embargo, no consta rue Yúsufllegara a abrigar en su mente de un modo concreto, si bien los antores árabes indican que, a no ocutrí la muerte de su hijo, Yúsuf no hurbiera abandonado inmediatamente el país de Alandalus. Aunque los autores afirman que la derrota sufrida por Alfonso VI fué terrible, y que á duras penas pudo escapar con mug poca gente, su poder $p o$ qued 6 tan quebrantado como so supone, ya que muy pronto 


\section{$-3-$}

esturo en condiciones de tomar la ofensiva: pero la fortuna ya le fué siempre adversa.

Vualto Yúsuf a Marruecos, pronto pudo Alfonso rehacerse, y los Príucipes andaluces hubieron de Llamar de nuevo al almoravid, el cual viene á Espeũa por segunda (2) vaz y sitia el fuerte castillo de Aledo entre J.orce y Murcia, desde dande valientes guerreras do Castilla molestoban con incursiones las comarcas pertenecientes al dominio del reino de Sevilla: Yúsuf permanece cuatro meses. en el sitio, al cabo de los cuales, disgustado ga de los Príncipes españoles, al acercarso Alfonso en auxilio de los pocos guerreros que queduluan en Aledo, se retira á Almería por Lorca, y desde allí se embarca para Marruecos, con el propósito, sin dude, de ir preparando las cosas para apoderarse de la Espana musulmara, idea que comienza a realizar personalmente en su tercera venide, en el año 483 (6 de Marzo de 1090 a 22 de Febrero de 1091), destronando al rey de (iranada, Abdala, después de un silio de dos. meses, y luego á su hermano Temin, rey de Málaga. 
Vuel to Yúisuf á Marruecos, dispone las cosas para apoderarse de los demás reinos musulmanes, menos del de Zaragoze, encomendando cstas empresas á varios de sus generales, que sucesivamente se van apoderando, sin gren resistencia, de los reinos de Sevilla, Badajoz, Almería y del oriente de la península, respetando la independencia de Almostaín II de Zaragoza, fuera por las relaciones especiales que entre ambas mediaban, fuera por la idea, que recomendó á su bijo Alí (3), de que el territorio de los Benihud sirviera como muro de separación entre el dominio de los cristiznos y el de los almorasides. 


\section{$-5-$}

\section{REINADO DE AIÍ}

A primeros de Moharrem del año 500 (4) (2 de Septiembre de 1106) muere Yúsuf después de un reinado de 47 años g 100 de vida, según algunos autores, y le sucede su hijo menor Alí, proclamado Príncipo heredero en los últimos años del reinado de su padre. Alí, hijo de Yúsuf y de una esclava cristiana (5) (probablemente espaũola), tenía 23 años cuando subí́ al trono, y en su largo reinado hubo de ser iestigo del mayor esplendor á que llegro el imperio de los almoravides (6), y bubo de ver su casi complete ruina, teniendo que declararse impotente para ayudar á los musulmanes españoles contra los ataques de tres Alfonsos, del joven Alfonso VII, que en el año 1126 sucedía a su madre D." Urraca en el trozo de Castilla 1 , de Alrouso de Portugral, que eu el año

1 Alimso Vll subió al trono el dia \& de jurzo

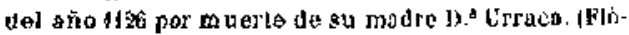
rez. Esp. Sag. tomo XXI, pag. 313.) 
anterior so había armado caballero á la edad de 14 años, y de Alfonso el Batallador, que por este mismo tiempa paseaba sus victoriosas huestes por toda la Andalucía: pero hay que confesar, que el abatimiento del poder almoravid no se debe sino en pequeña parte al esfuerzo de los guerreros cristianos: débese casi por coupleto á los almohades, que con Abdelmumen lanan contra los almoravides numerosas huestes fanatizadas con el entusiasmo de rerdederos né́fitos.

Instalado Alí en el trono, y després de someter á la obediencia a su sobrino Yahya, hijo de su hermano Abubéțuer (Sir?), que se había negado á reconocerle en $F e z$, pasa a Alandalus, a fines del nismo año 500, con abjeto de ordenar las cosas del gobicrno, y probablemenle con el de iniciar las cumpañas que, 6 personalmente (7), 6 bajo la dirección de sus parientes $\mathrm{y}$ trenereles, hizo durante casi todo su reinado, con próspera fortuna a]gunas, con dudosa otras, y sin que nunca obtuviera un resultada práctico importante, ann de las dos más notables en que mueren los Príncipes cristianos que las mandan, co- 
mo son la batalla de Ijclés, en la tú muero el Infante D. Sancho, hijo de Alfonso VI, y la de Fraga, donde es derrolado $y$ quizá he rido de muerte D. Alfonso el Batallador.

En los primeros aũos del reinado de Alí, Jos diferentes estados cristianos estaban en condiciones inuy diforentes para sostener el prestigio de las armas contra las incursiones de los almoravides, entonces en su major pujanza: Costilla estaba robernsda por el anciano $\mathrm{g}$ achacoso Alfonso VI, que muere muy pronto, sentádose en el trono de Castilla au hija D." Urraca; en el occidente, el nuevo condado de Portugal estaha recrido por la Infanta D. Teresa, vinda de Earique de Borgona; los estados orientales, Aragón y Cutaluña, eslaban en condiciones muy diforentes: ambos estaban golucrnados por príncipes esforzados y en la plenitud de su vigor, Alfonso, llamado el Batalador, y Ramón Rerenguer III, Conde de Barcelons: si á esto se agrega que la frontera de los almoravides con Castilla y Porlugal era mucbo más extensa que con Aragón y Cataluña, no causará extrañeza el ver que los almoravides empren- 
den menos incursiones contra estos estados, que contra los dos primeros.

EDtre Castilla y Portugal y los almoravides pueda asegurarse que en este período la guerra fué constante, llevándose á cabo incursiones por uma y olra parle, quizá todos los años, aunque ni por los autores árabes ni por los cristianos tengamos noticias concretas sino de muy pocas relativamente.

Habiendo venido Alí á Alandalus á fones del año 500 , al regresar a su país, dí el mando de Jos ejércitos muslimes de España á su hermano Temim, que hasta entonces labía estado de crir en Marruecos, y le estableció en Granedu, que parece ser en este liempo el asiento del gobieruo de los almoravides en la península; así que en Granada veremos que lambién se establece Texufín, hijo de Alí, $\mathrm{g}$ sucesor de su tío Temim en el gobierno general de Fspaña.

Temim, a los pocos meses do haberse encargado del gobierno de la España nousulmana, reuní́ un numeroso ejército y al frenle del miszono se dirigió a Uulés, ciudad que sitió y tomó á viva fusrza, teniendo la guar- 
nición que relirarse á la alcazaba, en la que opuso resistencia: lleggoda á oídos de Alfonso VI la nuava del ataqua, por indicaciones de su esposa, al decir de los cropistas, desiste do ir al frente de la expedición que se proponía enviar en auxilio do los sitiados, $\rho$ envía en su lugar á su hijo Sancloo, joven de pocos años, que acabaha de ses armado caballero: como es consiguiente, el joren príncipy no era el jefe efectivo del ejército cristiano: avistados cerca de Uclés, los almoravides mandados por Temim, y los cristianos por el Infante D. Sancho, el almoravid intenta levantar el sitio; pero los jefes le contienen y, trabada la batalla, sin que lemin desisticra de su propósito, que no tuvo ocasión de realizar, son rencidos los eristínos con mucrte del Infante D. Sancho, de siete Condes (por lo que se llamó la Balalla de los Sieve Condes) y 23.000 cristianos, según el autor del Cartás, que confiesa el martirio de muchos muslimes, lo cual indica que la victoria fué muy disputeda: añade aste autor que D. Alionso murio de pesar a los 20 días; mas en esto no está bien iuformado: la Balalk de Volés, Hamada 
también de los Site Condes, tuvo lugar el $30 \mathrm{de}$ Mayo del año 1108 (8) (17 de Xaual de 501). Para algunos historiadores, la derrota de Uclés no podía quedar sin reparación inmediata, $y$ buponemos que a ellos ó a la fantasía popular se deba la reunión de numeroso ejército gallego, al mando del obispo Gelmírez, con el que se refinerza el de León, que sale ea busca del encmigo, cl cual no se atrevi 6 á esperarle 1.

No reinte días, como dice el autor del Cariás, sino poco más de un año había transcurrido después de la batalla de Uciés, cuando el miércoles 30 de Junio de 1109 bajaba al sepulcro el anciano conquistador de Toledo, sucediéndole en el reino de Castilla su hija D. ${ }^{\mathrm{R}}$ Urraca, la cual ocupa el trono desde $1 .{ }^{\circ}$ de Julio de 1109 á 8 de Marzo de 11262 .

Era natural que, ea tales circunstancias, los almoravides intentaran rechazar de sus

1 Sancher Cosade en stes Elrmentos de Fistoria

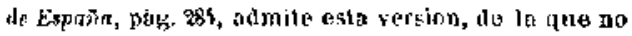
encuentro indicio en los autoros antiguos.

y Flóre, Espaila Sugradx, to. XXI, pág. 313. 


\section{$-11-$}

fronteres á los cristianos, haciéndolos retroceder hasta el Duero; pero aunque vina Alí con numeroso ejército on el año 503 (de 31 de Julio de 1109 a 20 de Julio de 1110 ) y devestó la comarca de Toledo, tomando varios castillos, entre olros, Hadrid y Gundalajara, después de sitiar la capital duranle un mes, hubo de regreser á Córdoba, sin haber couseguido en intento 1.

Con la experición de Talequéa é incursión en liersa de Toledo, había Alí quebrantado las fuerzas de Castilia y necesituba cmprender alguna contra el naciente condado de Portugal: la empresa fué cncomendada al emir Sir, hijo de Abubéquer, quien en el año 504 se apodera de Santarén, Badajoz, Portucal (Oporto), Evora y Isishoa (9).

En los años siguientes se repiten, casi de un modo normel, las expediciones de una y otra parte, siendo siempre Toledo el blanco de los almoravides, pero sin que nunce llegaran á cooseguir su objeto.

1 Vensa jos detalles y diseusion de esla camparia en la jlastracion num. T. 


\section{Aragon: Tulela, Faragroza, Cutunda.}

Si las armas cristiunes del centro $y$ occidente, Castilla y Portugal, hacian no poco con sostenerse contra los musulmanes, en oriente, Araghon y Calaluña, era a por do pronto mis afortunadas, pues Alfonso el Batallador mata en Valtierra al rey de Zaragoza Almostaín Il, el 24 de Linero de 1110 (10); más adela ate silia á Zaragoza, y después de alejar de sus muros al pusilánime Temim 1, el héroe por fuerza de Uelés, hermano de Alí, se apodera en 512 de Zaragoza (II), de donde los naturales, ayudados de los almoravides, habían echada al último rey de la dinastía de los Benihud, Abdelmélic Imadodaula (12), que hubo de refugiarse en Rueda, último baluarle del reino de Zaragoza (13).

Nio conformándose los almoravides con la pérdida de Zaragoza, que apenas había esta-

1 De esto hecho te nuestra historia do Aragón, ua comprobato antes por los autores firabes, traté on al toma X.X.II, pag. 103, del boletín de ha has Arademia de la Historia. 


\section{$-13-$}

do en su poder nueve ar̆os, intentan recobrarla, enviando us ejército á su conquista; pero Alfonso sale al encuentro al Príncipe Ibrahim, hermazo del Sultin Alí, y obtiene en Cutanda una brillante victoria, que debió de ser muj sentida por los rnusulnages, quienes, al nencionar el año 5l4, recuerdan con frecuenciu la célebre derrola, haciendo referencia de algunos de los célebres alfaquíes que en ella murieron (14).

\section{Gxpediclon a Andalucin}

Como consecuencia de la toma de Zaragoza, ó de un modo más inmediato, de la vietoria de Cutanda, D. Alfonso conquista en poco tiempo á l'urazona, Alagón, Epila, Ricla, Borja, Megailón, Mallén, Calutayud, Bubierca, Ariza y Medinaceli, y por oriente Daroca y Honreal, que Fortifica como amenaza y defensa contra los moros de Valencia.

A penas transcurridos siete años desde la toma de Zaregoza, Alfonso emprende una expedición, que pudiera tacharse de cuballeresca, y cuyo objeto desconoceríamos por 


\section{$-14-$}

completo á no ser por los autores árabes, alguno de los cuales nos da bastantes delalles 4.

Los mozárabes de Granada, de scuerdo probablemeate con los de otros purtos, piden con insistencia la protección de Alfonso, quien, despues de largas negociaciones, reunido un brillonte ejéreito de 4.000 caballeros, sale de Zaragoza á principios de Septiembre de 1125 siu manifestar el objeto de la expedición: pasando por cerca de Valemcia, Alcira, Denia y Murcie, llega en Diciembre á Guadix, que a taca sin resultado; ol 8 de Lnero llega a la vista de Granada, de la que no puede apoderarse $y$, después de un combate en sus inmediaciones, levanta el canpamento. no sin haberse quejado al jofe de las mozárabes de haberle compromelido á una empresa temereriu é inútil, de los cuales crirgos pudo éste sincerarse muy bien diciendo que la culpa era del mismo Alfonso, por haberse

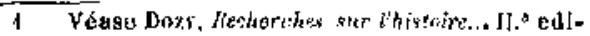
ción, 10. 1, pag. 3ta y III.* cilic, to. 1, pák. 3t8, a quien seguimos en este punta. acorea lel cunl nada julporlante hemos encontrado que no haya aprovectado el subjo profesos do Loiden. 


\section{$-15-$}

deterido tanto en las primeras ctapas, dendo liempo á que los almoravides se prepararan: molestado frecuentemence por el ejército crrezadiuo á las órdenes del Príncipe Tenim, Alfonso se dirige á Córdoba, pasendo por Luque, Bzena, Ecija y Cabra, deteniéndose en Arinsol, cerea de Lucena, donde, atacado por los almoravides, que obtuvieron alguna ventaja al principio, lubo de organizar las buestes para una batalla formal: como los almoravides estabar desordenados y poco prevenidos, Alfonso consiguió ua brillante victoria, que se hizo mayor por la imprevisión ó cobardía del Príncipe Temim, el cual, con hacer trasladar su tienda durante la noche, infundí sospechas on los suyos y cundí́ tanto el pávico. que una gran parte louyeron 6 la desbandada: la batalla de Arinsol ocurrió el 9 de Marzo de 11261.

1 Las analos Toledanos dan cuenta lo osla liatallá cor estas palabras: «Bntró ol they do Arogon rom tron hueste en lierra de Moros, b lidió es vencio a XI Reyes de Mlocos en Aranzuel, Era $1161 .:$ La Lisa ostá equivoeada, porculpa sin tuda de los manuscritos: Ios $X I$ reyes noros han de cutetdorse jefes 0 magna. tes o gonerales. 


\section{$-16-$}

D. Alfonso no pudo aprovecharse de la victoria por no tener elementos para apoderarse de Córdoba, y dasde trinsol se diri. gí á la costa de Salobreña, atraresando las Alpujarras; allí comió pescado que hiza coger en el mar; y luego se volvió casi por el mismo camino.

Quince meses invirtió en la expedición, durante la cual hubo de librar muchos combates parciales; con esto y la peste perdió muchos de sus caballeros, $y$ si bien recogió mucho bolín é hizo mucho daño al enemigo, no pudo conseguir opoderarse de ninguna población impartante.

La sjtuación de los mozárabes se agrav $\delta$ por efecto do esta expedición, pues enterados los almoravides de su connivencia con D. Alronso, el cadí de Córdobe Abulualid bijo de Rloxd (abuelo de Averroes), se trasJadó á Marruecos para conferenciar con Alí, y éste decretó la expulsión de los mozárabes, los curles ea gran parte fueron trasladados á Marruecas: muchos, previendo esto, se hubían unido al ejército de D. Alfonso y se babían trasladado a Valeucia. 


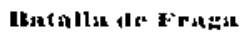

Ocho años habian pasado desde la expedición á Aadalucia, cuando Mlfonso ol Batalatior se apoderuha de Meyuluenza tros sangrienta malauza b casliero $y$ sitiaba á Trogg, enya marmoión estaba a junto de sucumbis, enando los sitiados recibieron oportuno y efice\% muxilio, que saad Abenmerdanix habín pedido al gobernador trenernl do la Ispaña musulmanta, el Drincipe lexufiu: deste Córdoba envió siste th pran comvoy y mil rinetes á las órdenes de latreir liajo de Amru, (el Arued de mestrus crónicas); d gowerabetor do Muroin y Volencia, Yabya Abongano (Alesstrania de nuestras crónicas), reune soo rinetes y se iucorpora con lus tropess de Córtola, le cuyo mancto debió de encaryanse l lo mismo que de los 200 sinetes

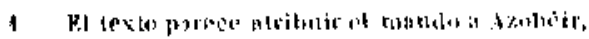

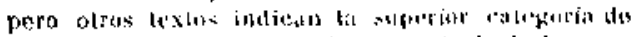

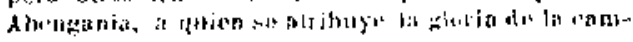
คดทัล. 


\section{$-18-$}

que aportó el gobernador de Lérida Abdala Abeniyad.

Al acercarse á lirga, Abengania organiza su lueste poniendo en la rasguardia las tropas de Letrida á lus cirdenes de Abeniyed; el ocapa el ceotro con lus de Murcia, y en la retagnardia deja á Axbéis, protegiendo el conroy.

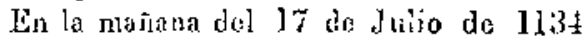
(15), el ciercito sitiador ve llegrar al auxiliar, y Alfunso, que había licezciado parte de sus fuer $\iota$ as, coratado sin duda con que el do Lérida acometia con sulas las suyas, le desprecia, y envia coulru dil un rroteso destucanealo á recibir ul tegalo que, serín dice el autor, les coviaba los musulmanes: $A$ beniyad acomete con brío al desiacinento cristiano, al que cousigue romper y decordenar,

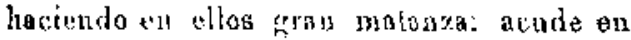
gu auxilio el mismo Alfonso con todos sus tropas, contiado en sla número y bruyura, pero llerga ol nistuo liempo el centro del ejércilo a les inmodiatas ódeses de $\lambda$ bengrania, $y$ se traba un terrible combato genera], en el que toman parte lodos las fuerzas. 
de uto y otro bando: en e? acto, los sitiados se enteran de que llegra el consoy $1, y$ salea de la ciudud hombres y mujeces, frandes y pequeños, $y$ acometen el cur!unento: los

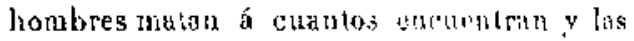
mujeres roban euaulo hulluas: Alistso y dicsgania entre tanto luchiban kemamente, l'evando ya la peor parte los cristiauns do .llfooso, quien al llegar la retnguarelia á las órdenes de 1 zobéir cun sus lropas de refresco, se retirn con los puras fue zats atue lo que-

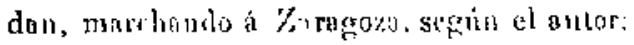

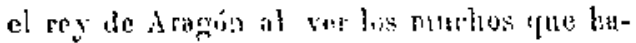
lian naterto, a los peinte dís murió de pesils.

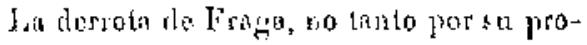
pis impontam con por la muerte de don Alfomso (nje si no sobrevino a los 20 díns. tarkí poeo ed aspecer), fuí de gran transietedencia jara hrarón, pues por la muerle de I). Alfonso y por su extróno testamersto encontrós el reino al horde dal abismo, tel que

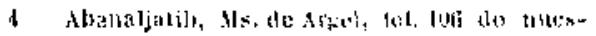
ura copia. 


\section{$-20-$}

sólo la prudencia y buen sentido del pueblo pudieron salvarle.

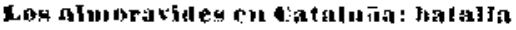 de martorelt $(16)$.}

Hacia el mes de Jauio del ano 1114 salía de Zaragoza una cepedición mandada porsu gobernador Abuabdala Mohámed Abeculliach, quier yu autes, siendo goberador do Yalencia, liubía henho muchas incursiones en el país de los cristianos: reunidos, «uizt en J,érida, Abenaltaroh y el Príncipo Abuabdila valgarmente conocido por Atjonaixa, hermano del stitân $\lambda$ li, pasan por Cervera $y$ llegan hasta Kurcelona, desolando el puis y cogicndo ricos despojos; Abenalhach, jefe efuctiro sin dusla de la expedición, etivía el botía por una puste, por el camino grande (vía romana\%), mientras toma él ofra dirección por un camino próximo a] país de los muslimes, por terseno quebrado, á propósito para sorpresas del enemigo, pues neceseriamente había que pasas por ub jestrecho? (canal): cuando se hubo internado en él, encon- 


\section{$\rightarrow 21-$}

tróse coo ios citislianos, que había preparado una emboscada en uro de sus lados. Abenalbach y los capitaces que le acompañaban, pelearon con los cristianos con el denuedo de quien está seçure de la muerte y de alcanzar el marlirio, ya que no había puien les pudiera librar, pues la mayor parte de la gente iba con el botín. Mbenallach murió mártir con suaititud do voluntarios, solvándose con way jocos al Principe, jefe thonorario? de la expedición, Joliúncal sbenoixa ".

Isa cuanto Alí tuvo nolieia de la derrota, ent:-isteciclo por lia marle de Abenallach y dal esiado mevtal de su íermano ol I'ríncipo

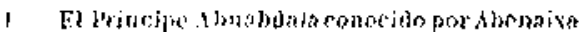

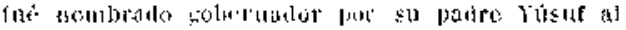

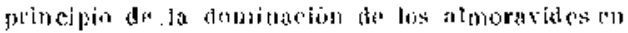

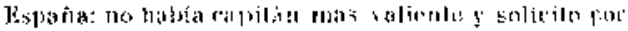

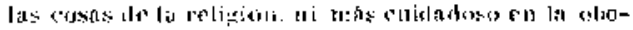

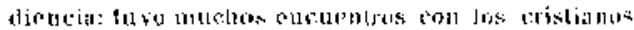

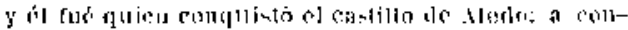

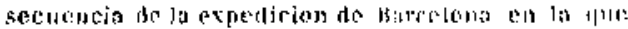

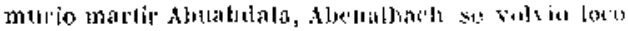

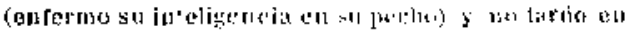

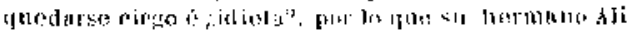

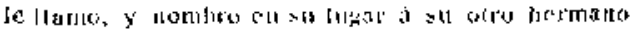

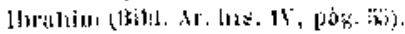


A benaixa, nombró, para reemplazar á éste, á su cuñado Abuhéquer hijo de Thrathim $A$ benteflut? (17): que era gobernador de sturcia; éste inmediatamente de recibir su nombramiento de goberrador de Valercia, Turtosa y sus dependencias, salió para Valencia, donde se le unieron las tropas que aili liuj,ía, $y$ con ellas continuó su marcha hasta Barcejova, á la que sesitió durante 20 díos, talando $y$ saqueando sus alredulores: hahiendo llegado (probablemente descle Mallorca) D. TRamón Terenguer con las tropas del llano de Barcelona y del pais de Narbona, trabóse entre ambos ejércitos un sangriento combate, eu e) que murieron uuchos cristianos, no sin que sufrieran el martirio cerca de selecientos muslimes.

\section{E*ortumat y Castilla}

Tócaba á su témino la debjilidad relativa de Portugal y Castilla; pues en el año 1125 de J. C. (öl8 y 519 de la héfrira), el írciito Iufuete D. Alfouso, hijo del Conde D. Earique y de la Iofuula D." Teresa, hija de Al- 
fonso VI, se srma caballeróa la edad de 14. años, $y$ en Castilla, muerta la Reina dona Urraca el 8 de Mismo de 1126 , le sucede en el trono su hijo Alfonso, que habia de temar y lievar con glocia el titulo de limperator.

Casi por el mismo liempo, en que las reinos de Castillis y Portuşal cou sus jóvenes y vilien les $A l f o n c o s$ entraban en condiciones no sólo de resistir las acometidas de los musulmanes, si que tumbián de tomar la ofensiya contra los almoravides, éstos, con la uparición de los almalarles, en el ajo 5ia, entrabon en el período de una decadencia que los labía de llevar pronto í la completu ruina; pues ocupados en la glesera contra Almehdi, y lnegro contra Abdelmunen, verdadero fundador militur dul Imperio almohade, no tuvieron fuerza para prutiger á los musulmanes españoles coutra las afmas de los dos Alfonsas ${ }^{1}$.

Verdad es que aum intenten varias veces apoderarse de Toledo, y más de luna vez de-

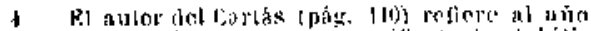

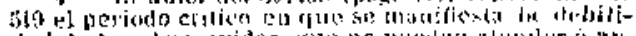

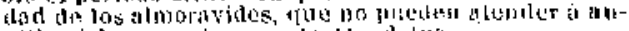

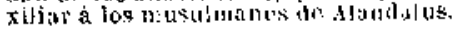




\section{$-24-$}

rrotan á los cristianos, apoderáuduse de ulganos castillos; pero otras veces son derrotados, y de todos modos nunca consiguen una victoria decisiva.

Eu ul añy 1132, en el mes de 310yo. bas milicias de Toledo llevaron á cabo, en lierra de Sevilla, con foliz éxita, ina incursión, la cual dobió de causar gran entusiasmó entre Jos cristianus; que Jlegaron á las jetertas de Sevilia dando muerte a se palyernador Omar con muchos peincipanes $y$ capilanes, como dice la Cúnica del Limapeador y coslirmau los autores árabies (18).

Por estos tiempos (ano 1131 525 y 526 de ta Trúgiroh, Kaladola, desceudiento de los reyes de zistagroza, de cuyn dominio solo conservalja el castillo de hota (liueda de Jalón, 6 el fuluro Mouasterio de liuedu), oídas los vichories del rey Afronso Kill, al decir de la Cronira de este Limperador, Jamó a sus lijos y mujeres $y$ les propuso entregarse a Alionso: conformes tados en ella, envió legados, prometiendo presentarse personalmentc, si por aiguno de sus maguales lo enviaba salvo-conducto, como así to hiso. 
Recibido Zafadola por D. Alfonso, le hizo entrega de su castillo de Rola, recibiendo en carnbio castillos y cindudes en tierra de Toledo y Lxtremadura (19): dos años después, habido consejo con Zafaclola y los maguates, Alfonso delermina tomar venganza del Príncipe Texufín y demás reyes lacabitos (jefes almoravides) que, puestos sobre Toledo, labbían muerio a muchos cristianos y destruido el castillo de dzeca.

Reuniclo el cjército en T'oledo, salió el rey v. Alfonso con Zafadula cutrando en lierra del cnemigo pas Portum Regern (Puertallanc\%, y lo zestanto del ejérci to entró por.3ruradal, etcoustriturose despuís de quince días de marclaten Gallellog desde alli alravesaron la campiña do Córsoba, llegando las ta Cádiz.

Yicndo los muslimes españoles, añade la Crónica, los estragos causadas por los cristianos y que los almoravides eran impolentes para prolegerles, entraron en tratos con Zafadoli, pasa que, de acuerdo con el Emperador y pagindole tribizto, se nusiese al frente nel movimiento general para echur á los almoravides: no sabemos lo que Zufadola diría 
al Limperador y los propósitos de ćste; pero Ia expedición no tura resultados práclicos, y debió de limitarse á que los expedicionarios volvieran carrados de botín.

De esta expedición, tan prolija $y$ retóricamente narrada en la Crinier rel Emperador, dan cuenta los tnales Toledanos con estas concisas palabras: «Éntró el Emperador con el Rey Cefadola en tierra de moros. L'ra 1171, (1133 de J. C. ó 527 de la héryira).

Aun hizo el Emperador otra eutrada ea tierra de muros en vida de Alí, llegando hasta el Guadalquivir, $y$ á sa vez los almoravides hicieron varias ivchrsiones en la comarca de Toledo, intentando apoderarse de la cupital; pero siempre en vano.

A una de estas expediciones y mientras - el Ismperador estaba sitiando el fuerte castillo de Anrelia ú Oreja, que tomó en Septierubre de 1177 (533) do la hegira), se refiere la anécdota caballeresca de haber desistido los almoravides del silio de 'loledo, por haherse presentado en la muralla la Bmperatriz y haber manifestado á los sitiadores que su marido los esperaba en Oreja. 


\section{REINABO IUR TEXTIS}

'Tueaba â su téraino el largo reina lo de Alí y con su muerte phiede decilse yue termina ef Imperio de los ulmorevides, pues, muerto el 28 de Enero do 1143 (8 de liacheb del $33 \%$ ), le suecde su lijo Texufiu, curado ya los almoluades so labían apoderndo de gran parte del territorio del actual Imperio de Marsuctos, qua labía sido la cunta del Imperio do tos almoravides.

In mes justo habia trasscurrido deste la muerte de Alí, cuazdo morian en cumpal balalla conter los cristianos de Tuledo dos jefes alworavides, Azuel y Abencetw, grabernadores de Córdobr y Sevilla, quiesues por largos años habían sostenido el hovor da las armas musulmanas en Andalas: esta victoria debió de ser de las más celebradas por los cristianos, según lo que nos dico la Crúrnica del Emperador, que cuenta estos hechos con gran prolijidad, auuque con poca jurecisión ".

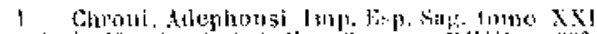

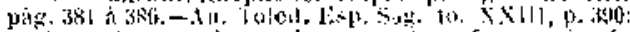

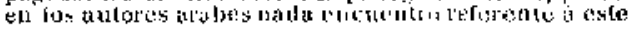




\section{$-28-$}

Ul jefe cristiano, Munio Alfunsu, que ton señaltada victoria líbíu obtenido en la Mata de Muntellos zoz.6 por pocos meses de la gloria alcanzada con tan celebrada victoria, pues en Arosto del mismo año fué vencido y mierto en otro encuentro, sievdo uno de sus brazos lievado á Córdoba.

Pudierá decirse que con el reinado de Texufí comienza el importunte perínto entre almoravides y almohades, que en los copítulos siguientes nos proposemos estudiar de un modo especial á la luz do los da stimivistraclos por los autores áralses, conocidos sin duda los más, pero no aproveclados hasta alora con relación á esios succsos, desconocirlas otros, rftizá los más inporluntes: lawbién las monedas dan no poca lnz para aclarar csile período.

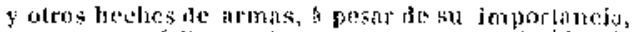

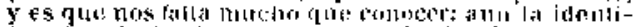

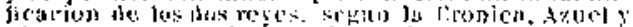

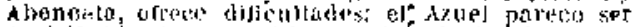

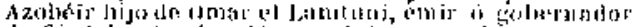

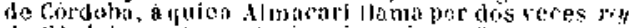

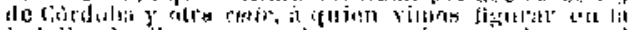

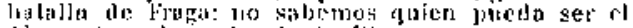
Aberceta, goberuados de sovila. 


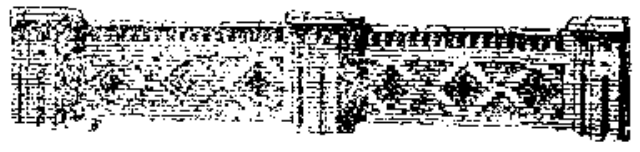

\section{REBELUYN DE TOS ESPANOLTS}

No es fäcil delerminar cuáles fueron las causas de la subleración general de los musulmanes espoñules portra los almoravides, cuyo gobierno, si dt algo pecaba, cra de debilidad: es cicrto chie sus ageotes be serian intachables en su conducta, pero esto no ert ni nuevo ni extraordinario, y los moros espazoles vieron pronto que, si habian rambjado de gobierno, poco ó nada habían ganado, y que lus jefes ó gobernadores almohartes, sucesores de los almoravides, grubernaban peor: una de las causas que quizá determiná 


\section{$-30-$}

más el descontento de las moros españoles fué la tolerancia, 6 mejor dicho, la predilección con que Alí y después su bijo 'l'tufín miraban á los cristianos incorporados un los ejércitos de Fez á las ordenes del cristiaro IRevertes ", tolerancia 6 protección, que debió de exacerbur el odio de los, más que piadosos, fanálicos nnfies, cuya secta, transiormarka en dandalus eo la de los homanns moritir ó artuptes, es indudable que turo gran parte en la rebelión, pues los hermanos adeptos fueron los que da prepararon y llevacon a cabo en los primeros momentos, si bien prunto tomó ot ro caráter, no religrioso, sino polílico aristocrático.

Tres liombres podemes admitir eque perscuifican la marchu de la rebelión en esto

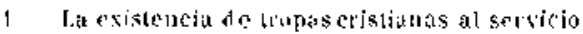

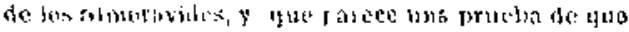

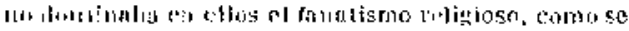

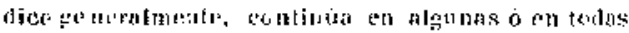

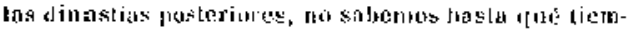

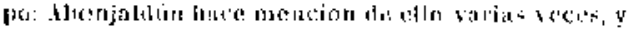

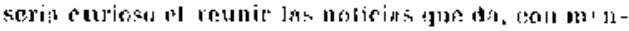
cion te los jefes que las mandalyan y su intelsweion en jas chiscorios y gucruas civiles, prificipalnuento en lioming de jos benjmerincs. 


\section{$-31-$}

primer periodo entre almoravides y almohades, 6 sea desde que los primeros (con sus P'rimejues Texulin, hijo de Alí, IJrahim, hjo de l'exufín é lshas lio do este últisno) aporecen impolenles para resistir a los alunohades y á los cristianos, lastia que los almohades quedain Lutinos de la España musulmano: estos tres personajes son Abenerie de Mérlola, Wenhandin de Córdtiba y Abenhud linosiriair ó sea el Zajorlola de nuestras crónicts; A bencasi dirige la insurreceión en el Algarbe ó sea el occidente, A luenhatndín en el restro, ets Córdoda, y Zafarlola en el oriente de Alnudalus ó sea en Murcia y Falencia; la rebelión se desarcolla en los dos puntos casi simultineamente, girsndo en torno de cadia uso de eslos tres persougies otros varios poco conocidos y crue merceen serlo, siquiera sea por el hecho de liaber sido vordaderos reyes independierics con pratensiones manifestadas en tílulos pompocos, que aratecen et las monedus; por lo cual este período podría llomarse Sefjuato periodo the reges de Taifas, pues fucron verdaderos rejes de bonderias. 



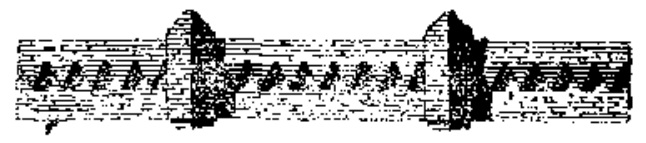

\section{LA REBELION EN BLA AIGA IBBE}

Fil alma de la rebritión en el Atgarije fué Abuloásin Ahmed lijo lo Alhosín, conocido más comúnmente jor Altrithis, enturno del cual eriran al principio casi ludus los rebeldes del $\Lambda$ tgatbe, aurue mís de ma ver. se separan y le liacen grinerra, hasta el punto defraguar su miturte uno do los que le habían sido más adiclos.

De origen cristians ó espā̃ol, y natural de Silves, doude pasó parie de su juventud en las oliciuas de hacienda ", á derrochaudo parto de su fortuna, como dice olro autor, se inició en las doctrinas de los sulies y, ha-

- Dozy, Nolices ele, pàg. 199.

ALATORAYIDES 
biendo viajado por Lispaña, entró en relaciones con el jeque Abulabás Abenalarif, que en Almería era el jefe de los sufíes, secta que ya debía de estar cxtendida en esta ciudad durante el reinado de Alí hijo de Yísuf, pues que habiendo tenido noticia de ello, llamó á Marruecos á Abulabás A benalarif, á su compañero Abalhíquem Abenfarchíln $\mathrm{J}$ otros adeptos, á yquiezes deluvo honoríficamente en Marruecos, donde murieron en al aกิo 537 !.

Desde esta fecha ó antes debió Ahencasi de quedar reconocido de hecho como jefe de los sufies, dando á la stela giro especial, pues parece fué él quien dió a sus sectarios el tílulo de moriden, que llamaremos aleptos, siendo conocida la rebelión de ifue fué el alma, con el nombre de ta Riblim de los $\mathrm{mo}$ ridin, como lo atesligoa, además del aserto terminante de abevaljatib, el hecho de que el historjador llamado Sálibasala escribió un libro que litutó Rebelión de los morialin.

De vuelta á su país, el Algarbe, Abcucasi

1 Abenaljsib, Ms. dr. do to Acad. ‥ 37. 
se puso á explicar en público los libros del filósolo Abuhámid el Graelí y, atrayendo á sí á los cue profesaban sus doctrinas, cn secrelo les excitaba á la rebclión.

Encoluldu la nucva secta en Abencasi, se extendió mucho jor el Alrrarbe, principaimente en Silves, Niebla y la regín de Mértola: habiendo construído en la costa, en las inmediaciones de Silves, un monnsterio, que los musumanes llaman ribita ${ }^{t}$ on la que se reunías sus adeptos, desde ella debieron éstos propalor los fulsos milagros

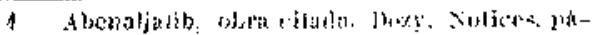

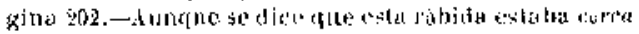

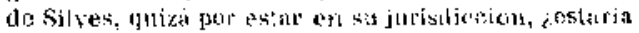

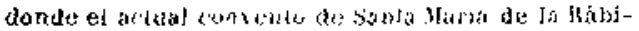

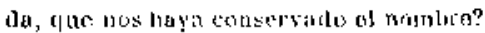

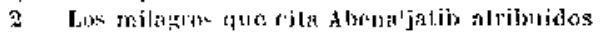

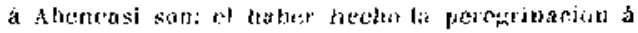

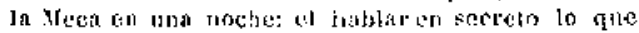
queria: $y$ el gestar del teripto sohrnatural: pues daba á manos tients; docian las gentes que culuko se concluit el disom, se bacla en su casil, y que uno te

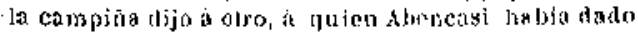

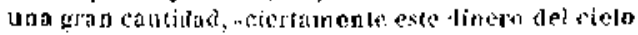
que ala ol Imam, k hace el tesorero de los aluoraxides, pues no hay otlo the acurip-: esto se l'eferita á

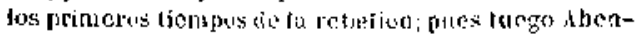
casi llegó a denìar moneda con sut nombre. 


\section{$-36-$}

a Abeneasi atribuyc Abenaljatib, projagán dose con esto la secta del mal (dice), por toda Alandalıs, formandose un vúcleo de devotos fanálicos dispuestos á obedecerle co todo.

No pasaron inadvertidos los trabajos reyolucionarios de los adeptos, principalmente las predianciones de tbencesi, á quien so quiso prender; pero pudo ocuitarse, siendo detenidos alginos de sas partidarios, que fuerur llovades á Sesilla: lono do éstos fué Abu:utlid llukinet hiju de Omar Aluenalmúndir, de quajen labremos de labiar más de una vez por el papel, muy importinte, que deserryonó er astos acontecimiontos 1.

Los an lores rolieren el levantamiento contra los almoravides al a ̃öo 539 ( 1 de Julio de 11.14 a 23 de Jutuio de 1145$), y$ an hasta cierto purto a lamuerterle l'cxufin, que gene-

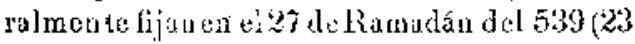
de Warzo de 11 fí) (20); pero aun suponiendo esto exacto, la sublevación comenzó antes de la mucrte do Texufín, pues que en Xaual

1 lonzy. Nulices, pós. 202. 
del año 538 ıno de los partidarios de Abencasi se apoderó del castillo de Yonte-Agudo?, si bien, acometido por los almoravides y no habiendo sido auxiliado por Ahencasi, ni por sus partidarios, lapbo de capitular y fué muerto: para respondes á los reproches de los amigos del rae había sido ríctima de su imprevisión, decía Abencasi que había sido como la fa!sa aurora, después de la cual se levauta la verdadera, umuneciendo en realidad: en vista del castigro de su partiderio, Abencasi, no creýndose segnro, salió hacia la región de Mértoda, pertraneciendo entre unas gentes en la alquería de klelnuza: co el distrito de Mértola.

Había cntre sus jarlidarios an hombre llamado Mohámed liijo de Yahya conocido por Abenalicubila el de Saltis, el hombre más bravo, astuto y valeroso de su tiempo, al par que literato, de quien Abenaljatib añade que cra célebre por la elegancia de sus epístolas y famoso por su elocuencia: este Abenalcabila, hourado por $A$ bencasi con los títulos de Rsparia de su rebetión, Braso de su estato y victo. via y Almostrifa (el Elegido), fué designado 
para apoderarse de Mértola, á donde se dirigió desde lu morada de Abencasi en compañ́a de setenta hermonos adeptos.

Yor la astucia ó por la fuerza consiguió Abenalcabila apoderarse de la furtaleza ${ }^{1} \mathrm{y}$ aunque los almoravides acudieron á cornbatirle, nada pudicron contra él y huthieron de retirarse, no sia baber devostado la región de Mértola.

La toma del castillo de Mértola tuvo lugar en la noche del 12 de Safar de 5392 (14 de Agrosta de 1144), y propagada la noticia por el $A \lg a r b e$, varios pueblos se adhirieron al movimiento, que pudićrauros llamar cantonal, proclamando sin duda como jefe al personaje más importante de encre los iniciados, aunque bajo la obediencia de Abencasi, quieu ol 1." del mes siguiente se

1 lieflerc Abeua'jatib que el jefo de la fortaleza hobla convenido con uno en que irja to noche á velic, y ul etecto, día orden al portero de atto le franyuejse el poso sin inrestigar más, j que habiéndose prosentado ahonalcabila con los seleata hormanos adeplos; no dudo en uhriclos la puerta: Abenajabar, (bozy, Notices, pag. 109) dice due mataron a los porteros.

2 Nhomalabar, pag. 108. 


\section{$-39-$}

presentó en Mértola, acompañado de muchos adeptos, é, instalándose en la alcazalja, se cituló Imam dMehdi biln.

Desde la alcazaba de Hértola, como desde su corte, escribió á los pueblos, inviláudoles a la rebelión, y entonces debí de comenzar a ejercer sus larguezas con el dinero de los hermanos adeptos, que suponia bajado dol cielo, pues que no percibía tributos.

Abumolámed Sidrey Abenuazir, que se babía rebelado en Evora y 13echa, y Abulualid Molámed Abenalmóndir, que había hecho lo mismo en Silves (20), se presentaron en Mértola a prestar lomenaje á Abencasi por los mismós días en que éste se instalabe en su corte: hecha por estos dos rebeldes la visita de cortesía al sejior que hebían reconosido como jefe, y confirmados en sus gobiernos, Abenuezir se retiró á Becha, que perece era su capital, y Abenalmóndir se detuvo algunos días en Mértola: como entre éste y Abenuazir habían surowido diferencias, á pesar de la amistad íntime que los unía, es de sospechar que Abenalmóndir aprovechase estos días para sembrar en Abevcasi la des- 


\section{$-40-$}

confiana contra $\Delta$ benuazir, la cual pronto se hizo manifiesta.

Vuel to A benalmóndir á Silves, cuado hubo reunido las tropas do ocsonova, que se, unieron á la geute del Silyes y â los hermanos adeptos, se presentó de nucyo á Ábensasi, dispuesto á ayudále con sus tropas en el proposito de lacerse reconocer como jefe del levantamiento por aquella reçión: apradecido Abencasi, le ruovó la investidura de lo que ya estaba eu su poder y le confirió el tílulo, hasta entouces desconocido, que sepemos, de Alazizbila fol iltesire por Alal.

Abenalmbndir, al fronte dei ejército que labía reunido, pasa el Guadisna en direccióná Huelva, que le abre las puertas, y desde alii se exlendió á Niebla, de la que se apoderó gracias al auxilio de Yúsul el Petrochi, uno de los valientes adeptos que habían sitiado á los almoravides, quienes se habían defoodido en sus torres.

Lia Huelva tuvo Abenalmóndir noticia de que Sevilla estaba sin goberuador almoravid que la guardase, $y$ le entraron deseos de apoderarso de población tan importante 


\section{$-41-$}

para la causu de los rebeldes: saliendo de Niebla en dirección de Sevilla, entró en las fortalezns de Alcázar y Tejada y lrabiendo llegrado á Azahir ze apoderó do ella.

Yá á la vista de l'riano, le alcanzú Abuzacaría Yuhya Abengania, quien al tener noticia de lo ocurrido ca Niebla y el Alerarbe - hubía salido precipitadamente de Sevilla pare sormeter á los rebeldes; pero lislo de acudis a la deferisa de la capital amenazada por A beralmóndir, á quien sorprendió cuando estaba meroderndo en sus inmediaciones: A beinguija designó de entre los suyos, quien siguiese á los de $\Lambda$ beualmóndir, que lué derrotaklo con grandes pérdidas, por cuyo notivo empreadió de uoche la retirada hacia Niebla, donde se deturo dos días, y dejando en ella a Yísuf el P’etrochí, él se réfugrió en Silves.

Abengania, que desde Sevilla habja seguido á Abenalmóndir en su retirada, sitió á Yúsuf el Pelrachí, que defendió á Niebla duranle tres meses (lo fuerte y fin del in-

1 Dozy, Nolices, pug. 203. 


\section{$-42-$}

vierao), hasta quo le llegó la nolicia del alzamiento de Abenhamaín en Córdclya.

Por su parte Abencasi, al tever noticia del aizamien to de Córdobo, dió órden a Abenalmóndir paca que reuniendo su ejéccito saliese contra la antigua corte de los Omayas, aconpañado de Abenalcabila, su secrefario, dándoles cartas para los partidarios que tenía en ol arrabal oriental, a quienes excitaba á que le reconociesen: solieron cfectivameute los expedicionarios con las tropas de Silves y Nuebla; pero al llegar á Córdoba se encantraron con que se les hubía adelantado Zafadola, á quien sus purtidarios de la cupital habían llevado desde la Frontera $\mathbf{~}$

Durante la expedición de Abenalmóndir á Nieblo, IIuelva y Sevilla, Abencesi se había reconciliado con Sidrey Abenuazir, de. volviéndole el gobierno de su pequeño esiado, reconciliación que duró poeo, pues al regresar de Córdoba Abenalmóndir de la fracasada expedición contra $A$ benhandín, Abencagi llam6 á Sidrey para que se le unie-

1 Dozy, Nolices, pag. 203. 
se: dudú en presentarse, pero por fiu, recorditudo cue ya una vez labía sido eocarcelado en Mértola y temicudo por su persona, se rebeló on Badajoz 6 en Silves, como dice Abenaljatib ó hicieron lo mismo atros, citándose sólo al hermano de Sidrey que se rebeló en Jecha, proclamando á Abenhaudin de Códoba ': liegado esto á conociniento de Abencasi anvió contra Sidrey á Abeualmóndir', cuien derrotado y prisioucro fac mauiatado $y$ eucarcéado en Bechas so se coutertós Sidrey con teuer ahcrrojado á su entances mortal enemigro, sino que al poco tiempo, cuando ya lué señor de Badajoz y su distrito, dic orden a Abdala A bemesomáil de que presentándoséen Beclun, le sacase los ojos, como lo hizo: allí siguió thenalmóudir hasta que

1 Esto explica la txistencia de monedas de Sid-

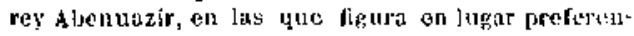

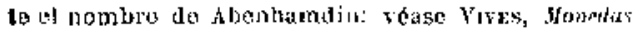

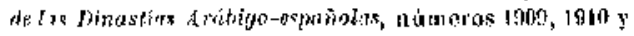
1013, a unque en este viltima no tigura el rombro te Ilametio, porosi al títalo Almabsurbila, que si bien pudiern refarise al mismo sidrey, no consta por documento alguno que llegaso á lemar ta\} litulo, si blen osta moneda nos lo haco sospocliar. 
$-44-$

los almolades se apoderaron de esta ciudad. Derratado y prisionero Abenalmóndir, Abencasi quedó sin medios de defensa, de modo que Sidrey pudo pasas de agredido á ngresor y en el mes de Xabán clel mismo año 540 ( 17 te linero de 1146 á 14 de Febrero) se apoderó de Mértola ', liuyeado sin duda Abencusi, quien al menos desde este momento parece debiera litser renunciado a sus ridiculas protensiones; peruaun ten jendo que acudir á la hmillación de pedir protección á los almohades, no se despojó del pomposo titulo de Almehdi, con que al principio de Ja rcbelión se había proclamado cn Mćrrola: así al menos lo indica Abenjoldún al decir que lishiendo envíado como mensajero á Aludestmumen á Abuhéruer Abenhabís, no recibió contestución a causa de que Abdetmumen se inconodó poreque el enviado daba á su scinor el tílulo de Almchdi , pero paca

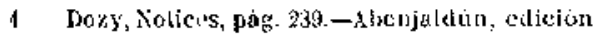
del Cairo, 10. IY, pag. $106 \mathrm{y}$ to $\mathrm{Vl}$, pán.

2 la raguedad del uso del affa an en aralwe $\mathrm{Y}$ lo ridículo do due aboncasi tomara ti pempeso títi-

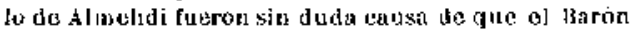
do slate al traducir este texto creyern que el emba- 
despué; pon inicialiqu de Alí hijo de Abenwaimún, seūot the Cúdiz, Abencasi solvió visilar persomulmenle a Abdenmur para invitorle á apoderarse de $A$ landalus entonccs abandonó stus pretensiones: ob: quiado por el gobernador de Ccula, Yú Abentuajluf, que le dió una escoltu, en lie. postrero de $540^{1}$, Muencasi se presentó á : delwumen, que le recibió en Salé: sin di le expondría el estado de Alandalus, $F$

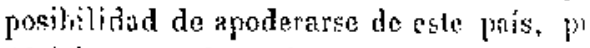

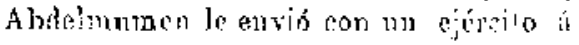

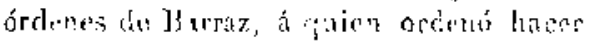
guera a los almoravides y a los rabeld

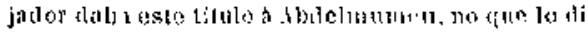

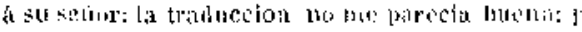

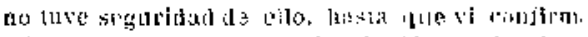

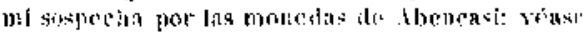

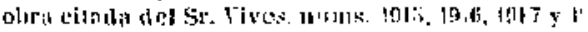

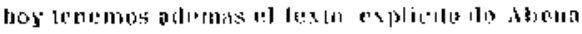

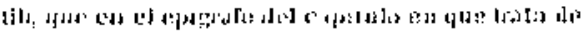

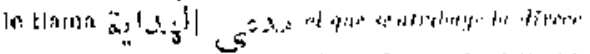

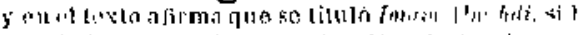

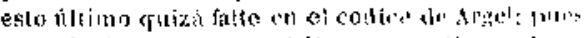

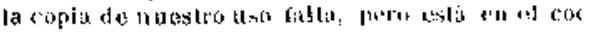
de la Rital deatemia de la tTistoria.

1 boxy, Soljexts, pirg. 200. 


\section{$-46-$}

lueso liarraz fuó auxiliado por otros dus ejércitos, uno á las órdenes de Muza Abensáid y otro á las de Onar thensálits.

El ejércilo almohade, que pasó á Alandulus á las órdenes de Barraz', tomadas 'Tarifo y Algeciras, sometió urio tras otro a Abulgomar $A$ benozrán, rebelde en Jerez, luerro á Yísuf el Petrochí, que prestó abediencia en Kiel,la, y paranto por Mértola, recolbrada sin dida entonces por los partidarios de Abencasi, se dirigrió a Silves, c[ue fué couquistada, y puesta lajo la obediencia de ciste: el ejercito salíó luego de Silves y habiendo pasado por lberda y Badajoz, ducude prestó uhediercia Sidrey Ahenuazir, incorporados todos al ejercito invasor a auxiliar, asistieron ul sitio de Sivillan, que fué tomada el dore ó trece de Xubán de 54l (17 ó 18 do Linero de $11.47)^{2}$, luyed do los almoravites it refucriar-

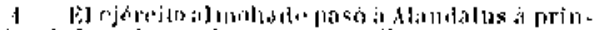

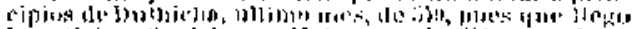

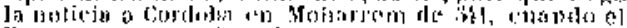

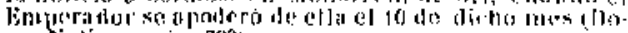

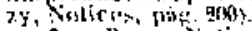

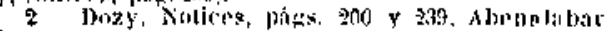

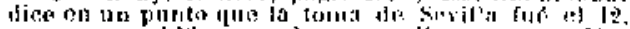

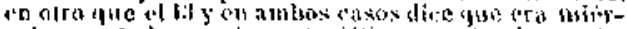
enlex: an Indos nowlos exto viltimo tresulta incexacto, pues eit 12 fut viornas. 


\section{$-47-$}

se cu Carmona, no sin rue Cuerau muertos cuantos fueron alcanzados.

Aunque todo el Alrgabo de Alandalus quedó sometido en esla fetha al proder de los almohades, no debió de durar inucto esto estado de cosiss.

Se habian instalado en Sevilla, andque al parecer sin cańcter oficial, pero sí con gran iulluencia, parecida al mudo, dos persouujes que por sus abusos fueron funeslísimos á la dominonión almohade, sicado causa inmediala de que so vertiese mucla sangre: eran islos Abdelaziz \& Isa, hermanos del Almehdi, fundador de la secta almoliade, quienes se pernitieron el derramamien lo de a ugra $y$ se apoderaron de riguczas que no les corrospondion: habiendo tenislo noticia Yúsuf el l’etroclú. 'gaberaador o rey fendetario de Niebla, de que intentaban ecluarse sobre ét, se refugí́ en su país, echando de Niebla 4 los almohades y uecrando la obediencia: no se necesitú mâs para ine se produjerá una sublevación cosi grencral, rue secundaron Abencasi en Silves, Alí Alemmamúu en Catiz, y Johámed Abenalhachem 
en Badajoz: sólo Abulgomar Abenazrún, señor de Jercz y Ronda, siguió fiel á la dominación almohade.

Thl almoravid thenganin, que había vuelto a apoderarse de Cárdoba con el y.joyo de Alfonso VIJ, tomó a su vez la ofeasiva y se apoleró de $\Lambda$ tgerciras, entrando en reluciones con los de Ceuta, que también sucudieron la obediencia almoliacle.

lostrechados en Sevilla los almohades, Ios causantes de la rebelión, Abde?nziz é Isa y un primo de ambos, Íalsatín, hubieron de relirarse al castillo de Bobastro, donde se les uuió Abulgomar Abena\%rúu, quien con las pocas luerzas que giadabran a los de Scvillo unidas á las suyas, sitió y tomóa Algeciras, clando muerte á los almorivides que allí encontró.

Los hermanos del Almelidi, desde Bbobastro se retiraron a Marruecos, y Abrelmumen envió á Sevilia de goberuador á lísut, hijo de Soleimau, dejando de recauducior de impuestos al poco a fortunado gemeral Barroz:

- cl nuevo gobernador pudo tomar la ofensiva y sometió los distritos de Yúsuf el Petrochí, 


\section{$-49-$}

Niebla y Tejada; y el de Ábencasi, Silves: Alí hijo de Isa Abenmaimún 4 prest 6 obediencia en Santa María, haciendo lo mismo Mohamed hijo de Alí Abenalhacham ${ }^{2}$ de Badajoz, quien en prueba de sumisión equí regalos, que faeron aceptados: recobrada do éste una buena parte del Algarbe, el gobernador Yúsuf hijo de Sulciman se volvió á Sevilla.

Poco antes de este ticmpo, estrechado Abengania por las crecientes exigencias de D. Alfonso VII, en una entrevista que tuyo en Iscija con Barraz, pactó alianza, abandonando Córdoba a los almohades, de la que parece que se apoderó D. Alfouso, si bien los almohades de Sevilla la recobraron pronto, gracias al auxilio de Abulromar Abenazrún, de Yúsuf el Peirochí de Niebla y del ejérecito enviado por Abdolmumen a les $6 \mathbf{r}-$ denes de Yahya Abenyugrnor, á quiea los rebeldes so apresuraron á pedir el amin (la

1 El texto do Abenjaldún (celic klol titira, bomo Y mos serd ol misono que anles tigura on Cáliz.

2 a veces se le Jlama Alhacis.

MLMTOBMUES 
seguridad ó pertón), que les fué concedido por Yahya y ratificado por Abdelmumen.

En el 8ũo 54j el Sultán llamó á Salé á los jefes espenoles, quicnes acudieron al llamamiento $y$ reconocieron á Abdelmumen, renueciando el mando de sus respectivos disfrito: ': usistieron á Ja cita Sidrey Abenuazir, señor de Isecla y Evora?, el Petrochí, señor de Nitbla, Abenazún, señor de Jerez y Jionda, Abenallacham, señor de Badajoz y Amil Abennolríjb, seĩor «le 'Tahira ": sólo Albencasi con los de Silyes se opuso á esle reconocimiento, lo que desjués fué causa de su nuerte.

Declusado Alencasi en rébeliún conera los ulmohades en 545, chando todos los demás jéces lialbían prestalo obedieucia, se alió con los cristianos del naciente reino de Porluigal, enviando un mensaje i $D$. Alfonso

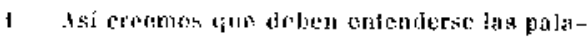

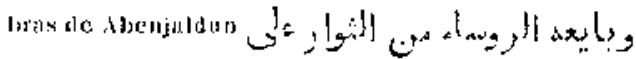
$y^{*} \mathrm{H}^{2} \mathrm{C}$

2 El lexta do Alienjaldun en la edicion der Cai. so pone Thlatra: la edicion de Argel Tativa. 


\section{$-51-$}

Licrícquez, á qquiea thedaljatib llama señor de Coimbra: el monarca porlugués recibió al mensajero de Abencasi, regatandole un cuballo de stıs cacros, ma adioran y una lan7.a: la grente de Silves, disgustada de esta alianza, on especial el ciego Abcnolmóndir que desde la ronciuista de Bechn por los aimohades había vuelto a su antigua cortc. prepararon una conspiración, es la gue fud muerto A bencast en Clicumada $1 .^{\circ}$ del aĩo 540 (16 de Agrosto a 14 de Septiembre de 1151) 4, siendo clavada su cabeza en ln purnta des la lanza que, cotno regalo, le lialía enviarios $\Delta$ beneurique, romo llaman, los musulmane á los reyes de Purtugral.

Abevalnóndir, aunçue ciccro, volvió a encargarse del mando de la ciudad hasta rue la entrecró á los almohades con hisloria larga, como dice Alienaljatib y que en porlo jndice otro autor diciendo que lemitiulase de él que se rebelace por tercera ve\%, fine Irasladado a Sevilla después de ser itr putesto por $A$ benuazir, que golsernóa Silves con exclusión de él con historia que cuenta cl lis-

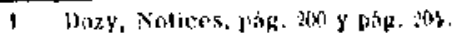


toriador Abeusálibasala en su libro Retation de las moridin.

Pasan algunos años desde la muerte de Abencasi sin que los historiadores nos den noticia referente á los rebeldes del Algarbe. haste que en el año 55 \} los de Sevilla piden á Abdelroumen que les dé por gobernador alguno de sus bijos y habiendo sido designado para este cargo el Lríncipe (Sid) I Ábuyacub, hubo de comenzar su gobierno sometiendo alirunos rebeldes, personajes nuevos unoe, ya conocida nigín otro: acompañado del visir Abuha Ás Abenatía, e] Príucipe Abuyacub salió para Tabira, donde se labía rebelado Aluasivi, que hubo de prestar obediencia; luego se apoderá del distrito de Abenuazir ? y en ol año 552 desalojo de Mórtola á Toxufín e) Iambani, quedando con esto terminada la conquista del Algrube por los almohades.

1 Dasle osto tiempo lus hijos spe los sultames

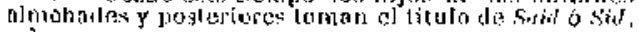
sentor.

2 Eil tuxin añado "y de Alsencasin peto eren sea

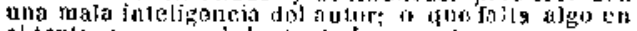
el toxto, eil genera], bestaute Incorrecto. 


\section{LA REBBLIÓN LE CORDOBA}

Si la rebelión en el Alrarbe puede considerarse simbolizada por A hencasi, la de Córdoba y centro de la Fepaña musuluasa lo esta por dos personajes, calla uno de los cuales uvo sus partidarios y gobernó eu Córdoba par más ó menos tiempo, siendo recouocido como jefe no sólo por los de Cóndoba, sino por lodos ó la mayor parte de los rue on el centro y orizule the Aladialus se rebelan contra los almoravides: los personajes aludidos son Abrthamdin de Córdoba y dienturd Almostinsir, á quien los cronistas cristianos conocieron sólo por el lítulio de Scifodaula, que transformaron en Zafatiola, con cuyo 


\section{$-54-$}

nombre ó con el de Abenhud le desiguaremos.

Hamalin, hijo de Mohámed, hijo de Ali, hijo de Mohámed, hijo de Abdelaziz, Abeuhemdín, natural de Córdoba y oriundo de Pego de Abenlailáx del distrito de Granada, fué cadi de Gúrdoba, primero desile el aña 527 ó 520 al 532, en cuya lecla fuć destituído por Alí bijo de Yúsuf, siendo reemplazado por Abulcásim Abeuroxd, á quien á su vez reemplazó en 536 por umbramiento del pueblo, á quieñ ol P'ríncipe concedió este derecho después de un año do la dimisión ó resuncia presentada por Abenroxd: Abenhawdín seguía de cadí de Córdobn cuando en el año 539 estalló la rcbelión en el Alrarbe, alzándose en Mértola Abencasi con el pomposo título de Amchdi biumria pel dirigido por mandato de Alij.

No sahemos si las predicaciones de Abencasi habían encontrado eco en Córdoba: prosćlitos ó amigos tenía, según algrín autor, pero no serían muchos, 6 al menos no supicron aprovechar la acosión de proclamarle.

Respecto á Abenhamdía no encontramos 


\section{$-55-$}

indicios de que al principio deseara y trabajase par alzarse con el mando ', como vere-mos que lo hixo su rival Abenhud: pero es lo cierto que por dos veces ac hizo rarivo del gobierno de Cordoba y que la segunda proclamación fué preparada con partici pación suya y de un modo trazicico?

Ni en los autores árabes ni en los cristiunos encontramos la narracióc serguida de estos suceses: las fochas mas importantes de la vida política de Abenhamdín no so encunntran en las biografías suyas, pue nos han dejado varios autores 3: hay que recogerlas,

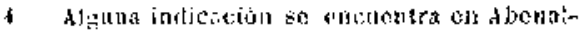

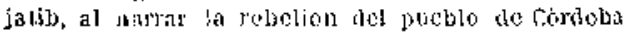
contra el cadi Abulasioim Abenroxd: fue hubo do

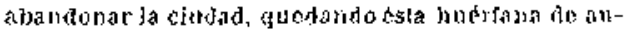
toridod aurabte mós de un mes polutue el britacipo

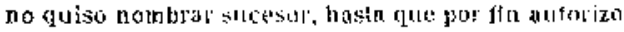

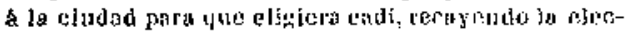
cion en Aljectitamdin.

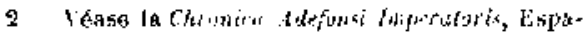
ha Sog. Lo. XXI, pag. 39k.

3 Adabi y Alsenalabar pollen sul Jiogratia, pur-

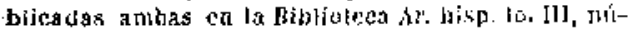
mero 38", 10. Y, mim, 119, donde se hitlat lombist las de sn padro y de dhmed 5 Ali, hermanos do dhennamdin. 


\section{$-56-$}

no bugcarlas, en las biografias de otros personejes, en las sumarios 0 compendios do los acoulecimienlos de este período ó donde se encuegtren, $y$ muchas veces las noticias concretas se encuealran donde menos podrían esperdrse.

Proclamado Ábencasi en Mértola á principios de Rebia primero del año 539, como hemos vista, Yabya Abengauia goberuador generul de la Espana musulmasa, al icner noticia del alzamiento $y$ de que Abesulinóbdir, lugarteniente da $A$ bencasi, eslaba sobre Niebla, salió de Sevilla (ó Córdoba) con objeto de combatir a los robeldes, a quienes sití eu Riebla darante tres raeses: en este intermedio, los de Córdoba proclaman í Abenhandín, yor to que Abengania the bo de aliandonar el sitio de Nielbia y volversa a Serilla con intención sin duda de asegurar la copital y eu su caso prepararse pora recobrar á Córdoba.

La sublevación de Abeuhamedín debió lleyarse a caho en el mes de Rucheb del mismo eña 539 (28 de Diciembre do 1144 a 26 . de Enero de 1145) (22), lomaudo el zoodesto. 


\section{$-57-$}

título de calli y lugarieniente, quizá porque obrara de acuerto con tbenhed, que so presentó en Córdoba á los 12 ó lit dias, y se apoderó del nando (23); pero Abentud, ó sea Zaladola, debió de gobernar muy rool, pues los autores suponea que los de Córdoba le ecluarona los doce días, dando muerte á su visir $A b e n x a m a j '$ y á una porción do sus partidarios 6 satélites: creemos, sin erabargo, que no fué lan efímero el reinado de Abcrihud en Córdoba y que duró bastaules dias más, como dicen otros, hasta el sábado cinco de Runnadin ó sea primero de Marzo de 1145, lecha lijadu por los Auales Toledauos, de modo che el gobierno de Zafudola duro de uno á dos meses, siendo restublecido A benhandin, que esta vez tomó los tílalos de Aimanser bille, amir almustimin, dándose desde esta facha aires de yerdadero Príncipo, teniondo oficinas, relsuiculo ejorcitos y escribiendo it los rebeldes de otrus poblaciones, algunos de los cuales le reconocieron.

Consta que asi lo hicieron, Sidrey A ben-

1 1302y, Xstices, port y 225 . 
uazir, de quien lasta se conocen monedes con el nombre de Abenhamdín I, y Atucliáfar Abderalimen de Murcia, quiten hizo la oración pública por él durante algunos días de los meses Thamadán y laval del año 589 , es decir, en los mismos meses on que thenhamdín fué proclamado en Córdoha yor seguoda vez: también coneta, ó al menos lo dice Abenaljatih, rue en (iranada toé reconocido por Abenadha, y en Jerez y Arcos por Abulgomar, hijo de Asáib Abenazrin s; es de suponer que además Abculnamdín fuera reconocido por la moyor parte de los cadies, que se alzaron con el mando de las ciudades, que antes gobernabas a nombre de los almoraxides.

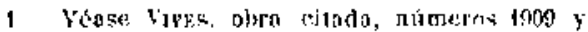

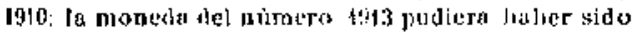

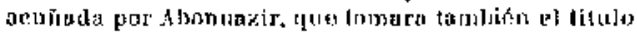

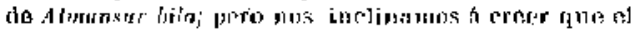
haber suprimido es nombre de Alienhamitit, aunque nosu lítulo, se dolico a ln circunstancia de que Abenuazir quiso poner en la monedis sa nombre propio $y$ do fomilia

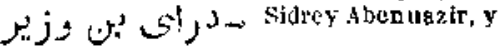
a quo liabla poco cospacio.

2 Dozy, Nalices, pág. 222. 
Poco sabemos te un modo concreto de lo que hiciera Abenlamdíu on Córdcba desde Kamodán de 5399 , en que fré proclimado por segunda rez, lasta el mes do Chumada postrero del oño siguicute, cn que liarado por los de Círdoba Xalya Abengrania, ge. bernador de Sevilla, Abeslandir le sule tl encuentro y derrotado en Ifejin, huye it $B_{i-}$ dajoz, entrando A isengranin vencedor en Cordobal el día le de Xabin le j40+ (24).

Do bos ance meses de rejratia the Abenhamdín, sólo tenemos noticiade give habiendo sido reconocito en Murita su compridor

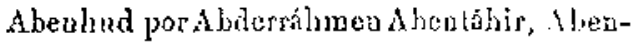
hamdín envió uno tras olro dos ejércitos, cl primero á las ordenes à sa sobrino Omali mad y el segundo á lus de su primo Alfolfolí, ncompañado de Abimohámed $A$ benal.

1 Adali (pág. 32) pine la entrada de Albengania co Cordoba á fines de robin de sit; pero sera "lror

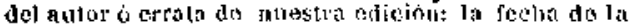

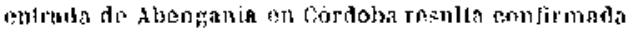

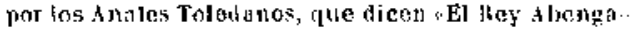
ma (por Alwuenanin) saco al Rey them frambin de Cordiba cen el mes te letureron gute en este ailo de

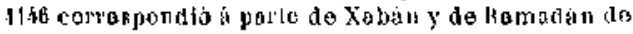
580 de la liégica. 


\section{$-60-$}

hach, de Abensinar y otros murcianos, que se le habín presentađo: ambos ejércitos fracasaron en su intento y los partidarios de Abenhamdín fueron pereeguidos, ó al menos buscados 1.

Estos sucesos debían tener lugar entre las fechas de fines de Rebia primero, en que fué proclamado $A$ bentábic y el 10 de Cluawada primero del inisino aũ., 540, en que, como reremos, hubo de abaudonar el alcázar mayor para dejar el puesto á Abeniyad.

Nada sabemos de las cansas que motivaron el disgusto de las cordobeses del gobierno de Abenhamdín: babiéndose refugiado en Badajoz, no renunció á recobrar su reino, paru to que creyó conveniente trasladarse á Andújar ${ }^{2}$, donde Abengania le sitió durante un mes: no conlando con fuerzas para resistir á las de Abergania, Abeuhamdín turo el mal acuerdo de pedir la protección del Em-

1 Duzy, Natices p. 219.

2 La generaliuad be los autores dico que al ser destronado so trasladó a Andíjar; preso el texto explfcito do Alenajjatily dice que se refutio en Badajoz y que despućs do algún licm $[0$ se traslado tijar. 


\section{$-61-$}

perador D. Alfonso, prometiéadole cuanto quisiera: uo sabemos lo que éste exigiría; es lo cierto que éste se presentó en Andújar, según los texlos árubes, aunugue segín la Crónica del Tomperador sólo envió al Duque Fernando Juámez: el Émperador consiguió hacer levantar el sitio de Andrijar y persiguiendo a Abcngania, al parecer eu auxilio de Abenhamdía, llegó á Córdoba, de la que se apoderó ayudado por los purciales de su protegido ': pero Abeagania se encierra en la almedina $y$ en ella se sostiene $y$ defiende hasta que nueves complicaciones le hacen aliado ó súbdita de D. Alf́nso.

Aunque D. Alconso ó sus tropas babían entrado en Córdoba como auxiliares de $A$ benhamdía, las cosas se prepararon de modo, que la conquista no fuora en provecho de éste, sino del Emperador, 6 de nudie; pues estando $\mathcal{D}$. Alfonso sitiando la almedino,

1 La entruda dol Errperadar y do Abenhambín en lordobă tupo lugar el do o ol 12 dol bitimen mes del

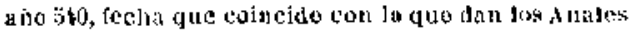

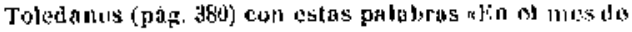

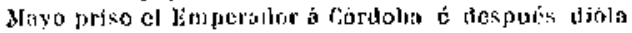
a Abenganta (Abonganiz). 
donde sc había hecho fuerte Abengania, le Jlegó la noticia de la entrada de los alinoleades y que los de Sevilla habían negado la chediencia á los almoravides: el Emperadcr, sorprendido y contrariado por los nuevos elemetrtos que entraban on juego, de acuerdo con sus cousejeroz, dice Abenaljatib, resolvis entrar on vegociariones con Abengania con objetn ile dejarle la posesiŕn de Córdoha, como efectivamente lo hizo, sin hue sepamos las condiciones que con él estipulara '.

Defraudado A benham dín re ans esperan\%as, despuís de haber contribuido á la tomn de Córdobu por los cristiunos, que sayuearon la parte oriental, segríla acuesdo anterior, labo de retinarse a Hojnchuelos o Badajo\%, $y$ deste ailí pasc á visitar á A budelurumen, quien le recibis, despidiémdole bonrosamente f́ invitándole a cue se volviese: ruelto á Espuña, Abeblamdín se establece en Malara, donde si lugarteniente y liechura Abuhháquern Ahosátin Abenhasút se ha-

1 Abenajatib cojita ci discarso djrigido por 1). Alfonso ol purblo do combloba al dejarlos bajo la obediencia de Abengania. 


\section{$-63-$}

bía rebelado conlra los almorayjes, y allí permaneció hasta su reuerte, no sin que aun intentara apoderasso de Córdoba, donde se dirigió, dice Abenaljatib; pero puesta de manifesto su debilidad. y declinando ya al ocoso su fortuın. hubo de volverse á Málagga, roode rnurió el 19 de Racheb del año 546 (I de Tovienbre de 1151) ', siendo enterrado en la parle de la alifuibla $z$ de la mezquita, donde sus liuesos no descausaron en paz; pues cuando los almoliades se apoderarou de Malaga 20 meses más tarde, deseulerraron su cadíver, y labióndolo enrontrado incorruplo, le crucificoron: consignan algunos historiadores que los astrólogos habían predicho que sería crucificudo: al menos esta era la tradición dal valgro eulre sus encuigos.

Veamos cuál fué la suerte de Córdoba después de la definilive expulsión de Ahenhamdin, o sea desde tines del año 540 .

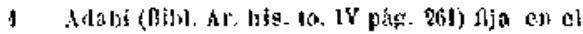
aìotsk ta muerto de hicstlutulin: pero parece mas areplable la fecla consignada por thetaljulits, que

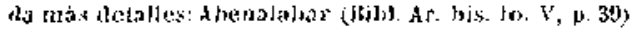
le supone muerto en

a Jarlo goue inira a la Mese. 


\section{$-64 \hookrightarrow$}

Establecido en elta Abengania por el Emperador D. Alfouso, sicudo por lo visto st feudatario, permancció en paz durante algŕn tiempo lasta fines del año 54], en cuya fecha, tomada Sevilia por los almodades cuatro meses anles, $y$ viêndose de cada día más hostigado por D. Alfonso, quien en una eutrevista en Audújar le exigió le entregara las ciudades de CTbeda y Baeza ', couro poco después le exigiera lo mismo respecto á Jaén. 6 que pagase mayor tribulo, Abangaia se puso secretamente de acuerdo con Barma, gobernador de Sevilla, y despues de uua entrevista en Ecija, le hizo entrega de ias cittdades de Córdoba y Jaén lacia mitad del año 543, retiráudose á Granada, donde murí después de una estancia de dos meses el viernes 24 de Xabán 2 (7 de Eaero de 1149),

1 bi nulur dol Cartas (pitg. Ith) stspone hecha

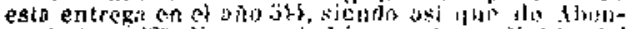
ganjo (pa:. l'aj) dice que habia muerto en Xaban del atho anteriol; trien que dor el toxto ingreso le llama

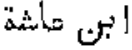

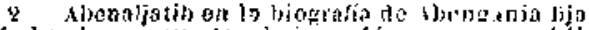
la recha do su mulerte el ritines $f /$, peco ecomo el it era martes, y el texlo del Cartas dice rilme $2 i$, seguimos esta indicacíon: ou ins levios arah:st lass feeluts 10 y 20 se confunden con mucina facilfald. 


\section{$-65-$}

siendo enterrado en el interior de la alcazaha, en la mezquita pequeña, que eslaba unida al alcázar de Ibadís, lijo de Habús.

Yalya Abengavia intentó inducir al gobecnador do Grarada, Mainón Myonbéder, 6 que cutregase la ciudad á los almohades. pero no pudo conseguirio ': seis años des. pués, ca 549. por fin Granada caýo en poder de los almohades por entrega del mismo Maimín Abenbéder".

Lutregada Córdoba á los almohades par Abedgana, 6 acordada su entregra, no renunció D. Alfouso á ser nuevarucnte señor de olla, y aprovechando sia duda la ocasión de que estuviera poco gruarnccida, logró sus deseos; pero los almoliades de Sevilia a las órdenes de Abalygomar Abenazrúu con los refuerzos suministrados por Yúsuf el Petrochí de Niebla $y$ los enviados por Abdelmumen bajo la dirección de Yaliga Abenyagmor la recobraron á los pocos días ${ }^{3}$.

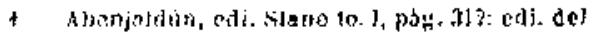
Cuiro, to. vi. pais. 325.

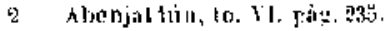

3 A benjaldúl, to, vi, pog. 23.

A SMORAYIDES 
En la relación de los aconlecimientos ocurridos en Alandalus desde que en 538 se inició la rebelión contra los almoravides, hasta el año 543, no hemos tenido necesidad de mencionar á los Príncipes de esta dinastia, porque para aada in lervienen en las cosas de mestra penínsulo, en la cque parece que ningúa eco tuvo su desapracición, á pesar de que oficialnente unu buena parte. quizá aun la mayor, de la España musulmana eslaba sometide al dominio de los almoravides.

De que en eslos últimos años do la diuaslía de Yúsư hijo de 'l'exulin, sus Príncipes eran reconocidos oficialmente on España, tenemos buena prueba ea los preciosos dinares que de ellos so conservan, acunados en Almería en los años 538 y 539 , de Sevilla de los años 538, 530, 540 y 541, y de estos. dos últimos aìos en Granada 1.

Muerto Ishac, hijo de Álí, último sultán, después y á consecuencia de la toma de Sarruecos por los almohades en el mes de Xaual

1 Yixfo, olma cilodo, mumeros 18 y y algumos. de Itss sighienteg. 


\section{$-67-$}

dol año 54l, si quedabau indivituos do la farnilie, parere que nadie pené́ en proclamarles al olro lado del Fintrecho: tn mpoco consta que se pensase en ello en las ciudades espanolas, que hista cutonces les habian permanecido adictas, ni menos en las que después de laberse rebelado contrn los nlmoravides, resistieron prestar obedicucia á los ahmohades: pudicramos decir que Córdobn y Granada, cu les monedas posteriores al año 54l la primera dá muestras de su arrepentimiento por laherse rebelado, $y$ la serrunda de su constancia en la adliesión á los almoravides; pues vo teniendo l'śncipe á quien proclamer, ponen en sus monedas...()) Dios, perdone á los Príncijues de los muslimes, los Benitexufin: !.

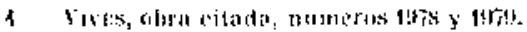




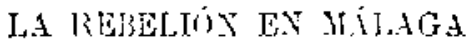

Se ba dicloa antes qua Alenhamdin despuéa de su expulsión definitiva de Cúrdoba se retiróá Máloga, y que allí murió en el จกัก วับ4 1 .

Fn el año 539, al liempo de la sublevación general contra lus almoravides, cra cadi de Malarra, desile el año anterior, Alhosáin, bijo de Athosiin, lijo de Abdala, hijo de Alhosáin, conocido más comínmente por Abuthityem thrmhositi, lombre de ilustre ascendencia y que se habia reriado en la holguta de su posición, llegando á adquirir nombre por su ciencia: cuando los cadies de las diferentes ciudades se pusicron en relacibn, sin duta para acordas sa conducta con log almoravides, se decluró independienie en Málaga, el sálbado 13 de Rusuedán de 539 (9 de Marzo de 11.15): sitiados los almoravides en la alcaraba durante siete meses, el

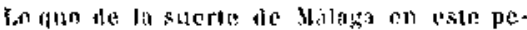

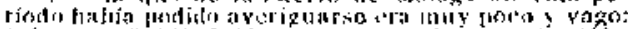

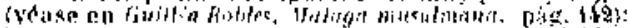

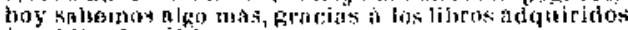
is publicados illimamelite.
} 


\section{$-69-$}

gobernador Almansur hijo de MIolkámed el

Hach, labo de caritular, insta lándose en ella A benbasún desjués de dos meses, tomando el título de mir y dándose el tono de los cadícs que habían asumido el mando: al frente del ejército puso á su hermano AhuJlısán, á quien, dice Aboualjulib, dió el gobieruo de Córdoba y su comarea; annque esto serír como aspiración ó puro látulo, pues no hay indicio de que llegrase is obtener tal mando efectivo.

Los almorasides vecinos de thenhasún no cesaron de molestarle procuranlo corturle las comnuicaciones y aprosistomfunientu, y esto le obligró a tomar á sla servicio 6 pedir auxilio a los cristiunus, compromedićndose a darles sneldo, jora lo que laubo do estrechar a los de Málega con impuestos: distristado al pueblo con eslo, nnidód la reprobación do su conducta, se pusieron de acherdo con un hombre sagaz de entre sus servidores, conocido por Li do Loja, y fijado el día, se rehelaron, sorprendiendo á los porteros y apoderándose do la alcazaba: eucerrudu A benhasún en el elcazar, allí se defendió; al convencerse 
tle cuo iba á morir (pues su liermano ja liabía sido muerto en la conmocibus, temiendo que sus mojeres llegaran à poder de otros, intenlo matayas eu el jalacio; pero ellas se defendicron en las gulerías y cuarios: agravada más la siturción, prendió luego á sus libros y lesoros, y lupró tomó un veneno que no produjo el efecto descado: en vista de esto, aruzó el licrco de una lanza y se precipitó sobre ól hasta que le salió par la espalda, sin que ni aun eslo acabara con su vida; usí que, al cutrar los almohades en el palecio, le encontraron revolviéndose en su sangre y ofreciéndose á la muerte: ann vivió dos días, muriendo el ll de Rebia primero dul ajo 548 (6 de Jusio de 1153): st cadfver fué crucificacio $y$, cortada la cabtza, fué llevadu à Marruecos, quedando Majaga desde esta fccha en poder de los almohades, quienes ya dijimos que habían crucificado también el cadáver de Abenhamdín, muerto veinte meses antes ${ }^{1}$.

- Abenaljatib, Ms. ar. ale In kerdenala, num. 37, frio äs, y fol. 49 do mi copia sobre el colice to la

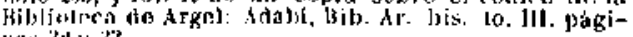

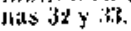




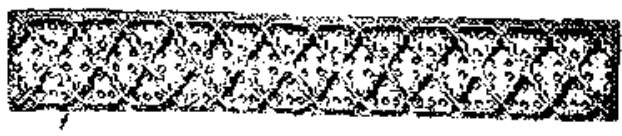

\section{IA REBELIGN FN FI, ORLWATt}

\section{DE ALANDALCS}

Como se ha dicho, uno de. los que más contribuyeron a expulsar de Alandalus, 6 mejor dicho, á que desapareciera de olla el imperio de los almoravides, fué Almosictasio Abmhal, llamado también Zafadohu, lijo do Abdalmélic Imadodaula, último rey de Zaregoza.

Nuestro Zafadolo, pues así le llamamos con los autores cristianos, á la muerte de sa padre en el año 524, le sucede en el señorío do Rueda y en al año 525 ó 5261,6 acosado

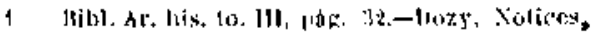
pógisa $92 x$, y abenaljatil., obra cisata. 
por las armas victoriosas de Alfonso $Y I J, 6$ entusiasmado con sus hazañas, como dicen nuestras crónicas, entrega el castillo de lìueda en cambio de la milad de Tútedo 1.

L'stablecido Zafadola en Toledo, allí permanecería lasta el año 539, en el que, iniciada la rebelión genera! contra los almoravides, se rebela en las fortaleza iamediatas á su pequeño dominio, y desde allí baja á Córdoha, donde entra sin resistencia por la connivencia con sus moradores $y$ el auxilio de los ricos?.

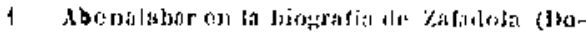

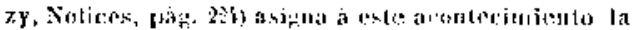

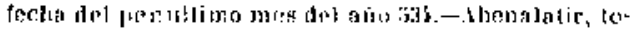

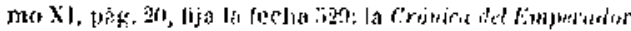

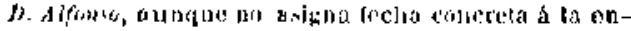

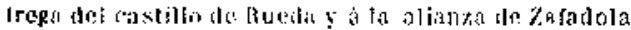

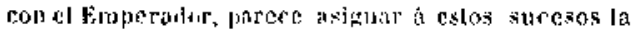
fecla thu acrplarmos o guy irsmediata, pues los re-

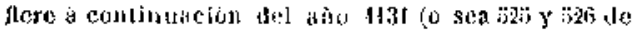

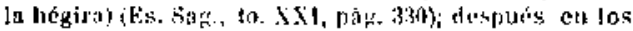

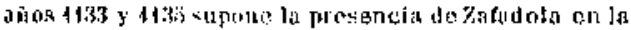
expealiciots contra dralalucía y er la proulamacion del Rmperador, por damin parece slebenus admitir

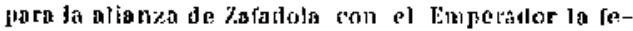
cha que pareco inftrirso de la Crimire.

2 Jésosu biografia en Dozy, Noliees, pag. 224. 


\section{$-73-$}

De las negociaciones gue para csto debieron mediar nos da alguua indicoción la Crónica de Alliuso VIL, a quien Zafudola acouparió en sus expediciones á codalucía en el вīo 1133, y probablemente en 114.

Rofficinclose al final de la primero de estas expediciones dice el autor de la Crónica 1: "Vicudo esto (los estragos causados por el ejércilo del Lmperadorj, los magnales de los ayarenos enviaban secretamente mensajeros al Rey Zafadola diciendole: habla con el Irty de: los cristiauos y con él líbranos de las mathoi de los Moabitas '; nosotros pararemis al Reg de León tributos reales mayores que los yue nuestros padres dioron á los suyos, y segurusos coutigro, Je serviremos, y tí y tus hijos reinaréis sobre nosotros". Oido este mensitjo por el Rey Zafadola, después de consultar con el liey y sus fieles consejeros, les contestó «Id y decid de mi parle a wis herumanas los príncipes de los agarenos (lo siguieute): a Apoderaos de algunos casti1 lip. Siag to . XXt, pate 33s.

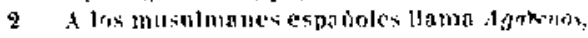
y Wortater a log allemorasithe. 


\section{$-74-$}

Jlos fuerles $y$ de alyuuas torres de las ciudades $y^{\prime}$ moved guerra en todo lugar, y al momento, yo y el liey de tecón os socorreremoss. Despuća de cslas pláticas, el Experador levantó el campo, pasó el puerto de Amarela y llegó á l'alavera.

Nada sabemos de los resultados practicos de las plálicas iniciadas en el aìo 11333 (527 y 528), ni aun si se siguib gestionando ó preparado el terreno para una sublevación general; probablemente no se consigrió más que fomentar el descontento coutra los almoravides.

Diez años despućs, la expedición dei Emperador hasta el corazón de Andalucía en 1144 (de Clunziada $2 .^{\circ}$ de 538 á Racheb de 539) debió de contribuir no poco á mover los ánimos costra los almoravides, impotentes para toda resistencia: por eso los moros andaluces volvieron naturalmente los ojos hacia los persovajes propiamente españoles $y$ de ascendencia ilustre por descender de estirpe real.

En Septiendre de 1144 (Rebiu 1." de 539) sc reunían en Toledo todos los Condes, Mag- 
nates y Dorgues del Fmperador, cada uno con

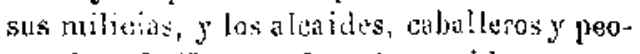
nes de loda lixtremadura 1: reuuido este numeroso ejército, el Emperador levantó el campo, dirigićadose al país encmigo, que devastó desde Almería á Calatrava, udestruyerou todas sus vinus y olivares; corlarou las higueras y muzanos; preudierou fuego en sus ciudadus, villas y aldeus, querairon con Ilamas sus castitlos; se apoderaron de lombres y mujeres y de sus hijos, haciendo gran botín de caballos, gegruas, camellos, mulos, asnos, bueyes, vacas $y$ toda clase de ganodo, oro, plata y objetos preciosos, que encontraban en los casas: lodo lo sobredicho fué llevado al Kmperador, Tue estaba acampado en tierra de Granada: después de eslo, el Ermperador se volvió á Toledos.

Exagrerada será sin duda la narración anterior; pero de todos modos se comprende el efecto que la campaña debió de producir en el ánimo de los moros españoles y que el

1 Sinun es elior de la croniea, Esirematciura

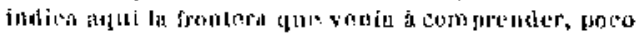
mas a modos, la cuelsca thel Tojo. 


\section{$-76-$}

autor de la C'rónica añade á continuación.

"Viendo los principales y jefes $y$ todo el pueblo de los Agrarenos los referidos males y que el Enperador y sus waguales se dirigrian todas las atios contra su tierra; que las luestes de Toledo, Serrovia, Avik, Salamanca y otras ciudades destrnían todos los dias algo Hel territorio unusulmán, se conrregraban en las plazas y asientos de las ciudades y en las sinagrogas (mezquitas) diciendo: «Qué vamos á hacer, pues no podemos sostener la guerra contra el kinperador y sus capitanes". A lo cual respondian algunos diciendo: «Los Yokbitas se comen lo mejor de la tierra; nos quilan nuesiras posesiones, oro y plata, y oprimen á nuestras mujeres é hijos; peleemos por tanto contra ellos; matémoslus y sacndamas de rosotros el yugo con que nos oprimex, yn que no tenemos parte en el palacio de Texufín, ni berencia entre los hijos de Alí y de su padre Yúsuf»: otros decían: «hagamos primero paz y alianza con el rimperador de Lébn y Toledo y démosle tributos de Rey, como nuestros perises los dieron á los silyos»: parecio esto bien y el que todos es- 
tuviesen pregarados para la guerra contra los Marroquinos ': vueltos inmediatameule á sus sinagogas, oraban pidiendo la misericordia de sla falso profeta Mahoma para que les ayudase eu lo que habían comenzado;,$y$, enviando meusajeros, llamabaa al rey \%afadola y á todos los descendientes de los antiguos reyes de los Agarenos para que fuesen hacia ellos Y peleasen contra los Moabitasa.

$\mathrm{Y}$ electivamente, en aquel mismo uño se lizo general la sublevación qute en Mérlola babía iuiciado Alnoed Abencasi, probablemente sin cosexión con estas tendencias; pero si Zafadola no lace el primero ni el más afortunado de los rque se levantaron contra los almoravides, lue indudablemente el de más nombradía $y$ prosligio ontre los mosulmanes cspañoles, y su autoridad fué reconocida en varios puntos, bien que de un modo poco duradero, pues probablemente no merecía el prestigio de que gozaba, más por su

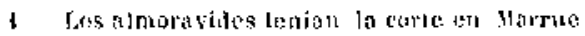
$\cos y^{\prime} \sin$ duda los moros espanolis cuptestrian al ju-

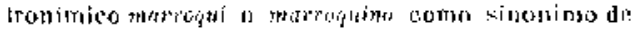
istimorartiet. 
ascendencia $y$ edad que por sus ruéritos propios.

Al fijar y discutir las fechas de los acontecimientos en que tomó parte $\mathbf{A}$ benhamdín, ha sido preciso apreciar lus indicaciones de los autores respecto á $/ a$ afadola: de ellas resulta, como hemos visto, que Abenhamdín fué proclamado en Cordoba par primera vez hacia el mes de Chumada postrero dol año 539 (Toviembre ó Dicienbre de 1144); pero no por cuesta propia, sivo como lugarteniente de Zafadola, hasta que éste eniró sin resistencia alguna en la antigua capital del califato en Euero de 1145 (Rarnadán de 539).

Si efímero fuć éste que se ha llamado primer reinado de Abenhamdín, tanto que los toledanos parece que no tavieron noticia de él, porcue no fuera proclamado con títulos pornposos, como lo fué después, no duró mucho más el reinado de Zafadola en Ciórdoba, á pesar de haber sido llamedo por el pueblo y ricos, con quienes se labría puesto. en relación desde que acompsinara al Emperador en las incursiones por territorio musulmán. 
Al decir de casi ludus lus historjadores árabes nue de ello lacen mención, sólo doce dins permuneció $7 a$ adada en Córdoba $y$, aunque aceptemos lo que dicen los Anales ToJedanos, siempre resulla qque su reinado fué muy corlo, pues que hobieudo en trado en ol mes de Enero, fricó a Gruacela an el mes de Marcio de 1145 y en tances fuć proclamado de nue. vo Aberhamdín.

De la que en Córdoba hiciera Zafadola an su corto reinado, nada dicen los autores árabes y poco nuestros cronicones: cuando tan pronto se disgustaron de él los de Córdoba, y lo mistno hicieron luegro los de Granado, no leudría zraudes condiciones de mando; $y$ el heclio de liaber dodo muerte á Farbx Adali, cl antiguo gabernador de Calatrava, que tuntas victorias había conseguido contra los cristianos, prueba al menos que la gloria adquirida en los combates no era bastante á garantir la vida de los que le contra riaban.

Fohado de Córdoba, Záadola hnyó a Granada, como dicen los Anales Toledanos. ó á Jaén y de allí a Grouada, lo cual no está en contradicción: en Jaén venció al cadí 
Abenchozay, que se habia rebelude, sin duda cantra los almoravides, deciusuduse independiente, 6 mejor dicho, nu reconociendo a Yafadola como representante del foder en Córdoba.

Habiendo dejarlo en Jaén por lazarteniente á un sobrino suyo. Za fadola se dirigióa Granada, adelantáudose á làs ruelzas que dbenlamdín enviabu cu auxilio lle slí Ahenadla; asi cque, las tropas rublutadas por Ali Omalimad, sobrino ó primo, serrín parece, de Abenhamdín, Lutieron de "riresar á Córdoba: sin duda Alroudta de Granada se habría puesto de acuerdo con \%alindila, tunque había proclamado a dbenlamilin, pues no ofreció resistencia á la entrada lé Zafadola !.

No es racil hijar la fecha concreta de ia

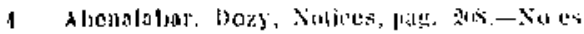
facil compreader lo gno pasa en tirasina Dhenala.

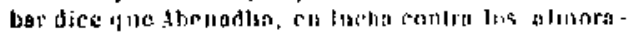

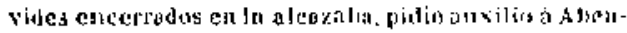

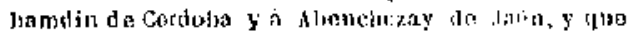

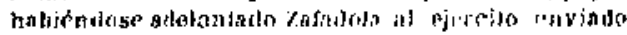
nor Abenliamdits, Abonndha y zaratola se thisiliaron mulunmeste. 
euirada de Zafadola en Crauada, ni tampoco el tiempo que en ella permaneció; pero puede fijarse de un modo aproximado, por la marcha de los acontecimitntos que se desarrollan en Córdoba y Murcia: los encesas de Granada en que interviene Zafadola lan de encerrarst precisanonte en los nueve meses gue median eutre Rumadín de 539 (Marzo de 1145), en que es echado de Córdoba, y el vierncs 18 de Racheb del año 540 (5) de Faero de 1146) en que entra en Murcin (25).

Instalado Zafadola en la alcazaba de la Alhambra, quedó reconocido como señor de Granada y su comarea, y por esto en el zaes de Dulcada le vemos nombrer grabernotor de Guadix á Alodelaxi\% Abonabuasio'

Lintre tanlo los almaravides de la alcazaba hacían sin durla frecuentes salidas $y$ an una de ellos, en un combate librato con los fuerzas de Zafudola, fú mortalmenle herido Iradodaula, su hijo, y los almorayides le envían su cadáer: en encuentro posterior, entrato ya el año $5 \mathbf{4 0}$, muere también alí

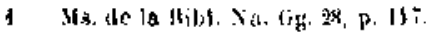




\section{$-82-$}

A benadhe, sucerliéndole en el mando su lijo Mohámed.

No contanulo Zafudola con fuerzas para someter á los almoravides eucerrados en la alcazaba, gestionería sin duda el que sus pa $\mathrm{F}-$ tidarios de olros juntos le enviasen refuerzos; $y$, efectivamente, despoús de la nuerte de $A$ í A benadha, llecraba desde Murcia $A$ benabicháfar, con ejércilo de algnna importancia; perofá́ derrotado y muerto ec la batalla de la Altnosala, bien porquo los aluoravides se aprovecharas do un desorden atciìntal producido al acampar, bien porque ucometicran dispuestos á ulu supremo esfuerzo y á morir, consiguicndo con esto desordeoar las laces cocmingas: es lo cierto que los que se salvaron del cjército do Ahenabicháfar se relira son jrecipiladamente a irarcia.

La batalia de la dlmosala y muerte do Abesabichtátar, tuvierou lugar el viernes, tres de liebia primero del oño 540 (24 do Agosto do 1145).

Después de esta dersola parece que Zafadola pudo eostenerse en Gravada durante un mes, y que desconfiando ya de poder sos- 


\section{$-83-$}

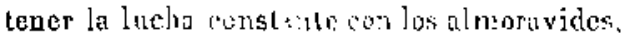

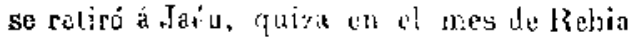

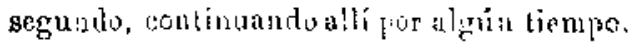

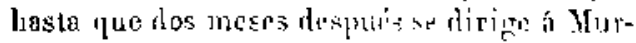

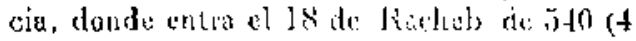
de Enero de 1.46 ).

Al retirarse \%afodolin de (ironadia, quelo con el mando de la cindad, como independienle ó como Seudalario suyo, Nohámed lijo de Alí dbetadha, quirn, úlos acho dias, faligado de haber do sostener combales manua y tarde contra los almoravidis de la alcozaba, setelira a Almunécar, volviendo sin duda el pucblo de Granta a la obediencia de los almoravides, a fuga causa permanecio fiel dexpyús durante hastanto tiempo, cuanko ya toda Alandalus reronocía á los almohades 6 á Mbemmerdoris de Murcia.

l'estimonio locuente de la adluesión de Granada á lo ceusa almoravide tenemos, coro quelo dicho, en un precinso dinar dol año 545, en el que, extinguicla la fimilia do los Príucipes almoravicies, se jide pora ellos la misericarliu de . lýa l.

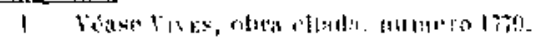


Hacia el mismo liewpo ea que Zafadola salia de Granada, tomaba posesión del gobieruo de Murcia, y probahlemente como vasallo 6 lugurteniente, un amiro suyo, llamado Abumohámed Ablala sbeniyad, quien, puesto de acuerdo con sus partidarios que saljeron á visilnale en Orilucla, en cuanto esta población le fué entregada por el valí Abenzanón, se dirigió á Murcio y se instaló en el alcarar nuyor, sin quc uadie tratara de estorbárselo: sucedia esto el 10 de Chumada primera del año 540 (29 de Octuhre de 1145) 1.

El reyezuelo de Yurcia Abubderrahman Abentáhir, que desde la muerte de su antecesor en la bataila de la Almosala de Granada, apenas había tonido tiempopara enterarse de los riucones del alcízar graude, si efeclivaineate merecía este nonbre, nada supo de las negociaciones del que trataba de suplantarle, y hasta se esforzaba por congraciarso con los que iban á Orihuela á cumplimentar al fuluro rey de Murcia: es lo cierto qua

1 Doxy, Notices, p. 214 y 219: segit n oto aldor,

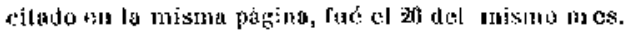




\section{$-85-$}

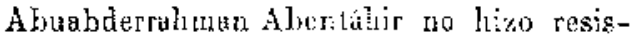
tencia, y relirándose, primcro al alcázar pequeño, y luego á sli costa, consiguió que Abeniyad, no considerándole temible, le dejase en paz. (26)

Iustalado Abeniyad en el alcázal mayor de Murcia, proclamó á $A$ benludud, contentáudose con ser su Jugarteniente; y Zafadola, en tanto que se preparaba para presentarse en su nueva capital, envió á Murcia á su hijo Abubéquer, á quien salís á recibir Abeniyad, mosteándose muy hon rado con su presencia: luesro se fueron anclos á Valencia, donde el pueblo, al eclitr de ella al cadí Meruan abenabdela\%ir. había proclamadóa Abeniyad, casi al mismo liempo rne el de Murcia.

Abeniyud entregró el mando de Denia á Abubétier $A$ bentud, $y$ raefto á Valencia, al tener noticia de la llegatia de Zafadola á Murcia, a los dos días se le presentó, prestando honenage, ó instalándose en el alcazar perqueña!.

Poco tiempo permaneció en Murcia /a-

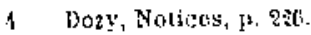


fadola, pues se acercaba el témino de su accidentada correra: aunque le vemus salir á campaña personalsaeute, era poco omigo de ocuparse en la grobernación del estado, pues nos dice A lienalshar que en tregó los negrocics á Abenjyad, conten tándose con el nombre de Principe.

No aparecen claras las circunstancias de la batalla en la que Tafadola pierde el trono y la vida: Abeualabar dice que á las pocas noches de haber hecho entrega de los negocios en poder da Abeniyud, se dirigieron ambos á Játiva, á doude ya se les había adelantado, con el ejéroito de Valencia, Abdala Abeusaad: luabía éste salido en persecución de los cristianos, que lalaban la comarca: eran éstos los soldados del tirano Alfonso (VII), y cuando se encontraron ambos cjérci los, despućs de laberse unido las tropas de Valencia y Murcia, trabeda la batallo, murieron Abeulud y Alrensand, salvíndose Aberiyed.

Esta batalla, perdida por los muslimes, se dí6 en el lugar conocido por Alloch (?), en la llanura cerca de Chinchilla, el viernes 20 


\section{$-87-$}

de Xabán del año 540 (5 de Febrero de 1146 ), aungue se dice que fuć el sábado siguimle: algunos autores le lloman la batalla do Albavete, y por haber muerto en ella ibensout, es conocido pos el de (la batalla de) Abetete'.

En los duales Toledanos se huce mención de esta botolla y de sus resultados cou estas lacónicas palabras: "Lidió Cahedola con Cluristianos é matáron! on en mes de Febrero, Lra $1184{ }^{2}$ : fecha que concuerda perfectamente con la que hemos lomado de Abenalubar. (27)

Estudizda la historia de la rebelión general contra los almoravides, e c el Algarbe, en Córdoba y en Granada, $y$ desembarazados ya de la narracióa de lo que se refieré á A hmed lijo de Yúsuf conocido por Zafadola y por Abenlud, y que como hemos visto,

1 En ol tomo XXxi, prig. 46: del butetin de Ju

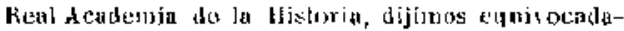

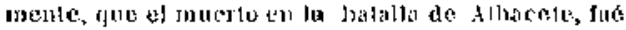

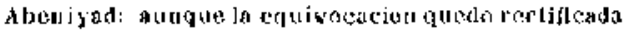

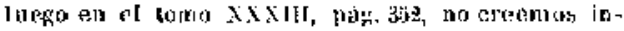
oport ano lacer cata reetificacion.

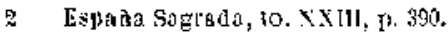


$-88-$

figura en primera línea,"lo mismo en la historia de la rebelión de Córóoba, que en la do la parte oriental, pasemos ya al esludio de ésila. 


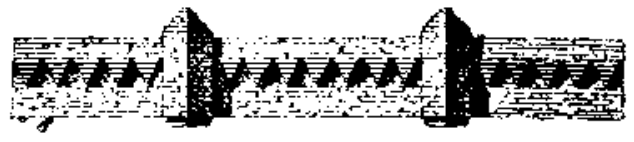

\section{REBELION EN HL ORIENTE \\ DE ALANDAITS}

\section{Gurein yalencia}

I.a listoria del oriente de Alandalus, principulmeste de Murcia y Valencia, en este período que examinamos, ofrece tal compli. cación que, á pesas de que nos dan muclia luz las biografías do alganos de los personajes que en este período obtuvieron al mando supremo, difícilmente podemos darnos cuenta de muchos de los sucesos: narración detallada y especial no hay que buscarla en los 


\section{$-90-$}

*ulores árabes y menos en vnestros historiadores particulares, rive poca 6 nisguna noticia turieron de largos períodos de la dominación musulmana, cabalmevle de arguellos que zás interés podían ofrecer para los historiadores de ciudades; pues cuando éstas formaban parte de la dominación peneral, lo quc á ellas se refirine, lalía de tener inlerís secundario, al paso qque lo tenía muy capital, cuando coda ciudad constituía una entidad independiente; tanto más si, como sucade en Murcia en este poríodo, el jefe de ella aspiraba, y lograba alsuna vez, ser el certio de casi toda la Espana musulmana.

La bistoria de Kurcia $y$ la de Valencia en este período se compenetron entre sí y, por fin, se refunden en la de los valíes ó príncipes re dominan en Murcia, donde en los dos primeros años de este período, 539 y 540, los reyes 6 valies independicntes fuecon muchos, $y$ de ellos apenas teceros más noticies que las que nos han legrado Abenalabar 5 Abens.ljatib, y por cierto que muchas de ellas se encuentran no en la biografía del personaje á quien se refieren, simo en 


\section{$-91-$}

la de algún otro, en la cual entran de ux modo más ó menos vatarul.

Tnciiada la sublevación contra los almoravides en el Alrache en el mes da safur del año 539 (Arosto de 1:44) y secuidada en Córdoba por Abenhandín hacia el nues do Racbeb (de 28 de Dicimbre de 1l44 á 26 de Linero do 1145), y luego cono ]erralizada con Ja proclumación de Abenhud ca Ramadán de este mismo oño (le $2 \bar{s}$ de Febrero á 26 de Harzo de 1145), por este mismo tiempo se propaga por Murcia y Valencia.

\section{Gablerun fle abenalinan

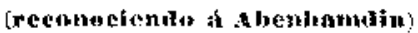

Los de Murcia, bien porçue alguien estuviese preparando el terreno en counivencia con $A$ benhamdín, ó como mavifestación espontánea del odio que los musultnunes espaLoles profeseran á los alnoravides, al tener conocimiento de lo ocurrido en Córdoba, se rebelan, poniendo al frente del grobierno á Abnmohámed Abderrahman, hijo de Chafar, 


\section{$-92-$}

bijo de Ibrabim, el de Lorca, conocido de ordinario por Mhenathrshe el cual proclumó á Abentamdín, por quien hizo la oración pública durante algunoz días de los meses de Ramadán y Xaunl 'de este aña, en que, como dice Abenalobar, abunderon los rebeldes en el oriente y occidente de thendalus.

No babía nacido Abezalhach para el cargo á que lo elevaron las circunstancias, así que, luego manifestá discrusto del mando $y$ desco de dejarlo, quizá porque le crearon dificultades los partidarios de Kafedola, quien, por aquellos meses, manifestabe prelcusiones de dominar en la parto oriental; pues dice Abenalobar set cosa corriente edtra los aulares que Zafadola envió á Murcia uno de sus capitanes Ilamado Abdula Abenfarech, el 'Tegrí ó Zegrí fol de la fronterti', quien á mitud de Xaual echó de Jlurcia y reemplazóá Abenalhach, que durante un mes escaso había ejercido el mando bajo la obediencia ó proclamando a Aberibamdín. (28)

- Dozy, Noticos, p. 21\%. 


\section{Gobiermo del arriez abdala el zegri}

Reemplazado en Murcia thenallach por Abdala Lbenfiach el Zergrí. quer después figrurará en las monedas con el títalo de critr: proclama la obediencia de Houllud á mitad de Xaual, pero á fáes del mismo mes es reenplazado por Abenabirlafar.

\section{Gobieruo de abenabichifar}

Abucláfar Mohámed hijo de Mblala, conocido por lbenebichalar, sucesor del Kegri, decia, respecto á su elección, que el mando no le cuidraba ni ann le merecín; pero que to aceptaba para proleger al pucblo y á unos contra otros, hasta que se prosentase quien fuese dicrno del mando'.

Abenabicháfar golernó á Murcia durante los trez últimos moses del atio $\mathbf{6 3} ; 9, \mathrm{y}$ primeros del 540 , pero aun este corto tiempo no lo pasó sin disturbios; pues labiendo salido de la capital con objoto de unirse al

1 Dory, Xalices. p. 217. 
ejército de Jeruán Abenabdelmélic, rév de Velencia, que en Játiva siliaba á lús almoravides, los de Aneia promovieron un alboroto, que Atemalich far acudió is sofoesr, volvienda luega á Játiva, hasta que esta ciudad cayó en poder de su aliado el rey de $V$ atleucia: en el mes de Safar del año 510 , vuel. to a Mircia Abenobichafur, pronto hubo de salir de nuevo, para no volver, pues habiendo saido en anxilio de Alí Abenadáa de Granada, 6 mejor dicho, de Abenhud $/ \mathrm{H}$ fadola cn lucha con los almoravides de la alcazaba, al de Murcia fó derrotado y mierto en lo batilla de Almosala antes de fin de Rebia prinero ', ya que es este día, lleredo a Murcia la noticia de su derrola y mucrea, se Je dió sucesor: el cjérciló á las órdenes de Aberabicháar se chice aque lleguba á 12,000 hombres entre peones y gincles.

I t mismo dbenalabar, dospués de referir la historia de estos des lattimos reyes de Murcia del mado que lo acalyamas de hacer casi con sus misnas palabros, pore otra tra-

1 ) $12 \%$, Notices, p. $\geqslant 18$. 


\section{$-95-$}

dicion ante, corforme con las feclias, difiere bastante en el fondo: es'a serrunda versión dice estat lomala de! inistcriador Abensálibasala, getieratmente mejor informato que

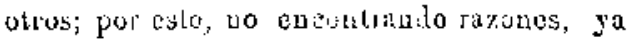
que no decisisas, de alguna fuerza para segruir una versiún más bien que otra, debemos consigiarlas andias.

Dico Siensihibasala cut Abdala el Zewrí estaha de apitín en Cuenca, cuasdo tuvo noticia de la jrocéomación de Alsenhandin en Córdobs y que se dirggró lacin d pertanecibrdo algín tiempo en su companív: couvienten los historiatores, añde, que thentamdía recibió menaje de los do Murcia sliciéndole que, hibiendio dada el mando a shaunchumed Abenallach (bajo su obediencia, por sapucsto), éste habia hecho remuncia del golberno, $y$ que entonces Alrenhamdín les enció de val.i a Abdala el Zecrrí, nombrando cedí á Abucháfar Abenobichafar: el Zegrí llegó á Murcia el naries anilud de Xaual del iño 539: luego, alunque Nhenabicháfar, en sia calidad de cadi, era realmente el sergundo, manifestó ó se vió que 


\section{$-96-$}

acabiciouaba la jefatura; pues labiendo reunido tropas, marchó á conbsatir á los almuravides de Orihuela, â quienes arillí pórfidemente foltando a lo que con chlos habia estipulado: desembarazado de esta expedicío, entró abierlamente en cabildeos con la gente de Murcia, proponiendo que le diesen el mando; rue el cadiangro, que él habia ejercido, pasase a manos de Abrabdala Abenaliallel; $y$ que Alydala el Zagrí luese nombraclo jefe de la caljullería.

No encoutrando Abenabictátar quien se opusiese á sue miras ambiciosas, fué proclamado sin oposición, y á seguida uecró la obediencio a thenhamdin, decisrándose independiente: como para sellar solemnemente este acto de rebeldía, no se contentó con menos que con tomar el tílula do $W T$ smir Atasirlidimula (el emir pratector de la religgión de Alá), desechando el que llevara astes de arai liamir almosimin (el que obedece al emir de los muslimes): necesilando $\sin$ duda preraverse contra los partidarios de Abenhamdín, encarcelo á Abdula el Zegrí, lo mismo que á dos cuñelos de éste, lijos de Masluca, dando 
el carro de jefe de la cahallería a Zanón, uno de los jufer del ejúroito I.

Deste este punto cstán conformes ambas narraciones con la única diferencia de cue A bensáhilasala indica cuál fueril el mativo del albaralo ocurriclo en Murcia, mientras Abenobichalur estaba en el sitio de Játiva: no fué otro que el de poner en libertad á Abdala el Zegrí y á sus cuîados, quiencs proboblemente huirían todos á Cuenca al llegar Aljenabicláfar, autquo el autor sólo lo aserara respecto á diduala el Zegrí.

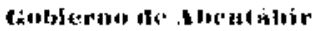

Muerto Abenabicliafor cu la descracia-

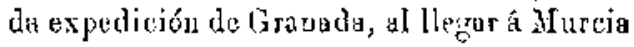
la noticia, los de la ciudad convinieron en dar el mundo á Abuabderralıman Mohámed hijo de Abderrahmun, hijo do Alımed, hijo de Abdermlman Abentíbir el Caisí, conocido generalmente por $A$ bealálir: sucedia esto á fines de Rebia primero del ino .5to (20 de Septionbre do 1145).

1 mozy. Notices, ping. : 1 is. 


\section{$-98-$}

Instalado Abenlábir en el alcázar, jrocla. mó la obediencia de Abenhud, á roserva, según parece, de aspirar ít sucederle en el mando: al frente da la cabal!ería, jefatura que resulta ser en este tienpo la mís imporlante, puso á su hermano Abubécquer.

Por ac[uel mismo tiompo, Abenhamdín quiso secobrar la inlluercia que lobín tenido en Murcia, $y$ al efecto envió ua tjérejto á las órdenes de un sobrino suyo llamado Cmalimad, quien liubo de volverse defroudado, habiendo suecdido io mismo con otro ejéreito á las órdenes de su primo, Ilomado Alfolfoli ', rcompenado de Alymobjued Abenalhach, of primero que se hisbia rebelaclo, ó mejor dicho, que había ejercido el mando en Murcia: acow pañabanles otros que Labian ido a prestar homenajc a Abouhandín, y á pesar de que lus expediciovarios debían de terer connivencias dentro de la ciudad, no padie-

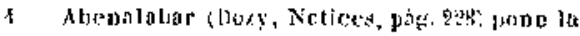

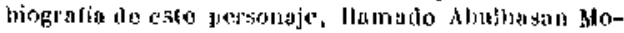

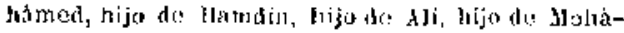
ned, lojo de Ahle:ariz Abenliarucliu. 


\section{- 99 -}

xon eatrar, $y$ los partidarios de Abenhem din hubieron de esconderse.

Ocupado y aun prevoujado dloculahir en perserguir á lus partidarios de Abestaradín. no advirtió que tenía on rasal obos enemigos, y su emirato dura muy poes timpo, pres los de Blurcia, escribieron á Abumoháned Abeniyad de Valencia para que fuera á cncargarse del mando, como efectivamente lo hizo.

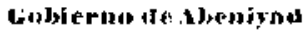

(á Mofibre de tafasiola)

Al Jlegar Abevigzd a Orihuelo, el valí Zanón le hizo cntrega de la ciudad, y vilí fueron á visiturle los cae le habían invitodo á que se aporlerase de Ifurcia: Abentáhirentre tento nada sabía de lo que contra él se tromala y lissta procuraba caplarse la amistad de los que iban á visjur á Abeniyad, quien, curndo Abentálir menos lo pensoha, entró en Hurcia, se dirigió al alćazar mayor y tomú posesión del mando, sin quo ondio se le opusiera: esto succdía 410 de Chumada

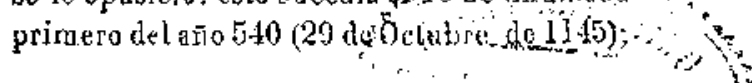
$\therefore$ a hiseo 


\section{$-100-$}

de modo eine Abontálier ejerció el nando nos 40 días; yues, como liemos visto, se había trasladado al alcázar gronde á fines de inebia primero de este mismo año y ahora se traslada alalcázar pequeño, donde no sabemos cuánto estuyo: pero yronto se trasladó a su casa, donde Abenjyad le dejó vivir lranquilo, conociendo sin duka que no era temible.

Vuelto Ahentálic á la virla priyada, no vemos que tomara parte alguna en los sucesos posteriores de Murcia, donde vivió durante largos años, hosta la muerto de Mohámed $\Lambda$ beosad, cuya antición y prudencia le tuvieron sienpre reccloso: muerto theneaad, se calinó el temor de Mbentáliis y habiendo entrado en la obediencia de los almohades. se trasladó a Marruecos, donde murió en el gกิ० $374 \%$.

1 Muxy, Nolices, phog. 220\%. 


\section{La RERBLIÓN las VALEACIA}

Durante los primeros meses de lia rebelion rencrul contra los almoravides, Valencia no tuvo relaciones especiales con Murcia, si bien pronto aparece como ejerciendo supremacía sobre ella; pues liemos visto que Abenabicháfar fué en auxilia de Abemabdelaziz de Valenciu, que sitioba it los almoravides on Jáliva; y parece que csthba como mero auxiliar, yi quie, tomada ésta, quedó agregyada á Valencia.

Nientros en liurcia se sucedían $e n$ ol maudo Abumolímed Abenalhach, Abdala Abenfarceb tl Kegrí, Abeoabicháfitr y $\mathrm{Al}$. derruluman Abentiair, Valencia estabu grobernada por Abrabde'mélic Deruán hijo de A bdula, hijo de Neruán, hijo de Nohámed, conocido más genoralmeate par Abcadbdelaziz. 
A benalabar 1 pone una biografía detalla da de Abenubdeloziz, de la cual exiractamos aquí lo más imporiante, refereute á este pumto, prescindieudo de lo que se utiliza en la narración relativo á otros personyjus.

Cuando llegó á Talencia, el sabado 5 de Ramadáu del año 539, la noticia de la prockamación de Abenhamdín y de que Abengania se hobía retirado de Niebla, desesperando de poderla recobrs, teniendo otras cosas más urgentes é importantes quc dominar, la geate de Valencia se alboroló: estaba de valí 6 gobernador un sobrino de $\Lambda$ bengania, llamado Abumohámed Abdala hijo de Moháned, hijo de Alí, y de cadi, este Abenabdelaziz, á quien T'exufín hijo de Alí había conferido este cargo el 24 del mes de Dulbicha del oño 538 \%. A pesar de la rivalidad que en secreto

1 Dozy, Notices, rág. 2iz y siguienles.

2 Ll mismo Abenatabar on st] Tuemilu (Rtbl. Ar. lisps., 4.0. Y, p. 382) en la rutu pone una biografia más corta de este mismo personaje, dice que según a]gunos este nombramienio tué en el año ă39; tosmhién en el Almontham (Bibl, Ar. Iis. to. IF, p. 191; pone otrs biogra fia con algun detallo poco importante, que no consta en ningura de las otras dos. 


\section{$-103-$}

Thabía entre el valí y el cadí, convinieron en obrar de comnin acuerde, prescindiendo de rivalidades, y lubiendo convocado á las gentes a la merquila aljama, tomaudo la palabra el cadí Abenabdelaziz, recordo al putb!o que los afmorasides hacían la guera eanta a los eristianos, habían ayudado á los musulmanes espuñoles, y singularmente habían libertado a Valencia del dominio cristiano, por lo que les exhortaba á permanecer fielcs en su obediencia: levantóse luego al palí, y hablando en el mismo sentido recordó la cordialidad que pocos años antes habih existido entre ellos y su lío, durante el tiempo en que había sido gobernador de Valencia: con esto se disolvió la asamblea.

No obstante cslo, llegó á oídos de $A$ bdala el rumor de algrún dicloo del cadí y de otros, que no dejó de inquietarle, y en la noche del miércoles 18 de Ramadán, envía su familia y equipoje á Játiva: ol día siguiente amaneció inquieto, y entre él y el ejército ocurrió algo grave que le determinó a retirarse con los suyos.

Cuando el valí con sug almoravides llegó 


\section{$-104-$}

á Játiva, envió su cuballaría contra las comarcas recinas á Valencia y los soldados áque日ron cuanlo encontraron: quejárorse Jos de Valencia ante el cadí Abenabdelaziz, rogándolo el r jército, los árabes y los magnates, que tornase el mondo; pero lehusó hacerlo, aconsejándoles ifue eljgiesen entre sus jefes uno que se encargase del gobierno: convinieron efectivamente en conforirlo á uso do los almoravides que hivbítn qucdedo en Valencia después de la fuga á Tátiva del gobernador Abdala, y las cosas continuaron bien durante algunos días; pero luezro este almoravid, en cuya elección liabían cunvenido, quiso apoderara del cadí Aberabolclaziz, y no labiendo conseguiclo su intento, amedrentado, se refiegió en Játiva acompañado de los drmás almoravides que hahían quedado en Valencia: recajó entonces la elección unánime en Abenabdeleziz; pero ésto se negaba á aceplar y se escondió, hasla que habiéndole hablodo á solos thumohámed Abdala Abeniyad, capitán de la Frontera, y Abdala Abenmerdanix, le hicieron ver la uccesidad de accplar y efectivamente acce- 
dió á encargarse del mando: slicedia csto el lunes 3 de Xinual del 533 । (29) de Marzo de 1145).

Los almorarides catre tanto seguía hacieudo incursiones por tierras de Valeucia, derastando las lanaras y furtalezas inmediutus; por to cual Aberabdeleziz hubo de llawar las tropas de las frouleras $y$, puesto al frente do cllas, marchó á sitiar á Jativa: al teper nolicia de ello, enojidos los almoravides, descendieron á la ciudad desde la aleazuba, rubaron las catas é licioron prisionceas a los mujeres: el rierecs 13 do Xaual, Aberabrlelazi\% llegó con susi tropas, y después de alonnos encucutros, en que salío vencedor du los aimoravides, éslos se retiraron á li alcazaba: á lines del mes, llego con el ejército de Murcia Ahenabicláfar, y ambus permarsecieron apretando el sitio, conformes en apariencia, unque rivales en secreto, pues cada uno de ellos aspiraba al dominio do Jáliva.

Eutre tallo, como bemos visto, hubo un

1 En la Teemila se dice que exto fué a fines do Hamadan o primeros de $\mathrm{X}$ aual (p. 3E?, 


\section{$-106-$}

alboralo en Murcia, á donde hubo de acudir

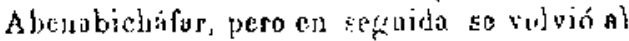
sitio de Játiva, á donde lleró también jor el misno tiempo theniyad con gunte de la frontera en auxilio de su erwir Abeubudelaziz, contra cuyo refinerzo no ereyó opurlutuo resistir ol jufe de la alcazabo, . Milala hijo de Nelramed lbengrania, y huró, refugrandose ел Almería.

'Tumada la alcareba de Jiliva nar capitulación después de la fuga del grobernindor, Abenaldelaziz la fortilicó y se volvió á Valencia, donde se dice que cutró montado en. un camello y rn traje de camjaña, reriovándose su proclatación, es el día de la eutrada, que tuvo lngar en el mes de Safor del a ño $510^{\text {t }}$ (he 24 de Julio á 22 de Agrosto de 114i).

lin virtud de la tora de Jutive, ésla y su distrito, lo mismo que Alicante, se unieron a Vulenciu, con to que Abenubdelaziz se enorgullecib, y como los tribulos no bastaban a las necesidades que kobrevenian, les tro-

+ Abenalabar hobla de osin all la Taremila (tomol, p. 34-2) como si ruese ta virsita proclamación. 


\section{$-107-$}

$\mathrm{f}^{\text {as }}$ be disrustaron y pensurou en testituirle, posicinterse de acuerdo con Alowiyid, quion por a fuellos días haljíu sido proclamado en Mumia, $y$ a quien escibieron pra que acelerose la marrha.

Narta arvirtió Abenobdelæziz tasta que el martes, 25 do Clumade primero (13 de Noviembre de 1144), como dice Abensuhibasali, las tropms rodearon el aldázar: pudo evadise, sin embnrgo, disfraziadosts y descolráadose del muro: sin guía $y$ andundo fuera de camioo, llecró á la montajia de Almería, reuniéndose con Mohimed Abemaimín, que se ypoderó de él $y$ le curatenó, parando con esto una deuda cou los Benigania, a ruienes Abeobbdelaziz labía cohado de Vuloncia y Jálifo.

Abenabdelaziz permaneció prisionaro de Moháreed A benmaimún, hasla qus labiendo llegudo a A imería con les galeres de Mallorca Abdala lijo do Mohámed (Abengania), ol mismo a quier Abenabdelaziz labia echacio de Yalencia y Jàtiva, fué eutresada áste. que se abstuqo de dersamar su songre y se lo lievó encadenado: la condueu de $A$ benmai- 


\section{$-108 \cdot-$}

mún con el fugrilivo zobernador de $\mathrm{Fa}$ ancia fué llevada muy a mal por el puebio. (29)

Al ser destronado en Valeucia Abcubdelaziz, Ios sublevatos pusierou al frente del gobiermo, como lagratesiegte de Abenigad, á Abdala lujo de Molámed Abeumerdanix, á quícn iustalaron en el alcózar.

Abenigad, que en virlud de la excitación de los de Valencia, se dirigía á ella desde Murria, supo en el camino su proclamación, llegaudo á fin de mes, y allí permaneció algún tiempo euidando de las upgocics de In capital y de encjorar el estado de las fronteras; luegro, dejando de vali de Yalencia á su crinadu? Abdab hijo de Siad Abenmerdanix, regresó a Murcia ${ }^{1}$, donde siçruió de emir, aunque brio la ohediencia de Almostánsir Abenizud, á quien encontró en la capilal.

Poco timopo perruaneció Abeniyud bajo la obediencia de Abenlud: pues habiendo salida ambos, como se lia disho, contra los crisliunos, Abenhud $\mathrm{y}$ el valí de Valencia,

1 Dozy, Nolices, p. 215. 
Abdala Alenmerdanix, furron muertos en la batalla junto a Chuchilla eu Iidreso de 1146 , como dicen los Inales 'loledanos.

Xuerto Zafadola, Abeniyad se declaró indepeutiento en Yalencia; peroen Nureia se le opuso $A$ bdala el Zegrí, quico, como hemos dicho, había ejercido ya é mando y se lubia retiralo a Cuenca después de laber estado

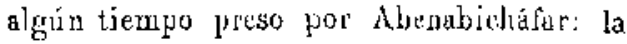
lucha entre Abdula el Zegri y Jlolámed hijo de Saad Abennerdanix, como lugartoniente de Alyeniyad, parece que terninó á priur ro de Dulhicha del año 540 (1) de Sloyo de 1146 , luyendo á Aliconta ó sefuspiándose en Valencia al ralí Mlohámed 1.

Det ruinado de Atrala el Zagri en Murcia deste principios de lubicha de 510 (15

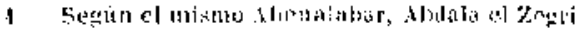

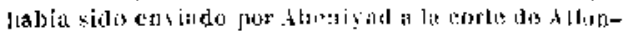

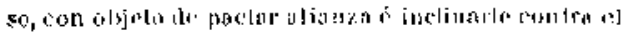

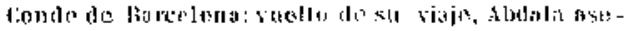

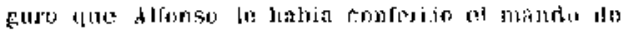

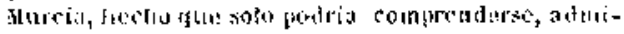

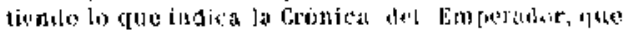

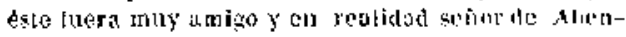

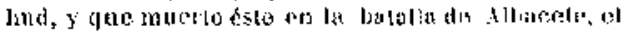

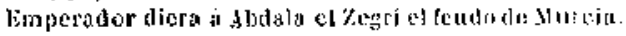




\section{$+110-$}

de Mayo de 1 l46) hasta al $\tau$ de Rachrb de 541 (13 de Dicicolse de 1] 46) en que fié muerto, sóles saberaos que acmón moneda de oro en los años 540 y 541 , tilutiudusc at artrez Ablala Abrefurech t: ni aun las cirentstancias de su muerte son conocidas, pues Abrrali bar sólo dice, como de paso, que fué nuerto en esa fecha y rue por segunda vez oempre el

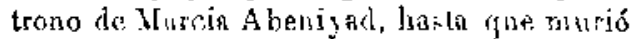
de la lasida que recibió en una batalla contra los cristionos el viernes 22 de Rebia primero del oño 512 (2l de Agosto de 1117 ), despućs de un reinado de un año, nueve meses y veiule dias.

1 Vixos, obra citada, numeros $192 ;$ y 1928 . 


\section{$-111-$}

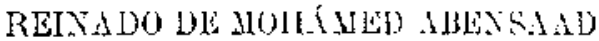

Mucrto Abdula Abeoigad y l'evado á enterrar á Valencia, donde estaba de valí Mlohámed Abensad, éste se aizó con el poder, como dice Aluenalahar, s sobiendo el fueblo que el dilusto Abenijad le babía desigruado para sucederle, le reconocia sin dificultad, aunque otros diven que Juć elovado á esto paesto sin nonbrumiento de su antecesor'.

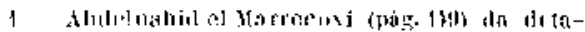

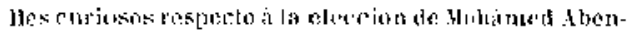

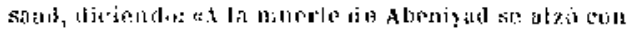

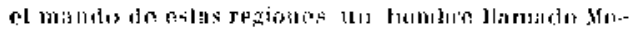

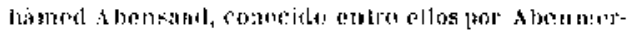
dauix, famitiar y esculero do Abenjydiestatudu esto para notir se reunicron en lojno sujo kes quine iqka-

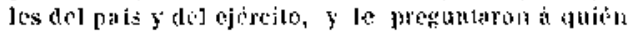

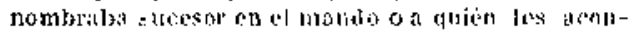

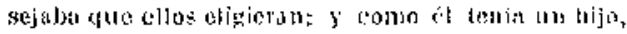

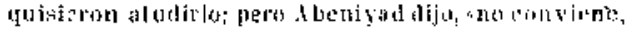

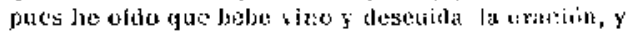




\section{$-112-$}

Los de Juarcia á su vez, dicron por terminada la Jugertenedcia de Alí Abenobáil, nombrado por Abeniyad, $y$ á fines de Clumada primero del mismo on̂ hizo enlrega de cuanto tenía en su poder, pertececiente al rey difunto, quedando en consecuencia Abuabdala Mohámed hijo de Saarl, hijo de Mohámed, lijo de Saad Alenmerdanix como rey independiente de Valencia, Murcia y loda la lispina oriental.

Dozy pirtando el caríter de este personaje dice 1: Después da la caída lie los almoravidos, dos partidos se disputoban la posesión de la Tspaña muculmaná; el de los beteberes, 6 sea almohades, que se consiteraban legítimos herederos de la dinastía ciestrona-

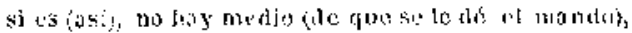

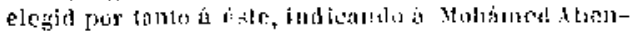

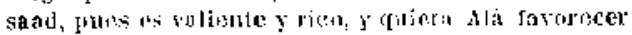

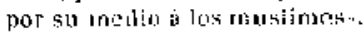

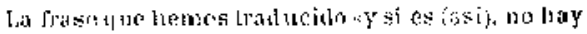

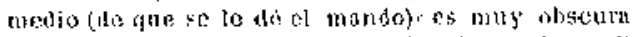

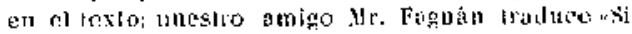

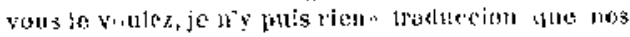

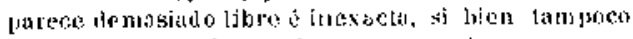

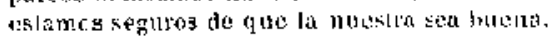

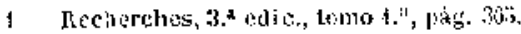




\section{$-113-$}

da ó extinguidn, $y$ al partido españal s nocional, que trataba aul de mantcner la independencia del país.

El jefe de este áltimo partido era Abuabdala Mohámed, conocido por thensnat of Abenmerdanix, rey de Murcia, de Valencia y de todo el sudeste de Tipaña: ena este personaje una de las figuras características y difíciles de clasificar, que produce á reces ol coutacto de muchas naciosalidades $y$ de diferentes religiones.

A qué nación pertenceid? lat pretendí. ser ásabe; segín unos, se decía de lu tribu die Chodam; segrín olros de la de Tochib; duda que demuestra su falsutad, pues los verdaderos áahes, lan pagados de su nobleza, nunea dobrabon en asurto tan ionportanle.

Aníduse á esto que el nombre de su tercer aluelo no es árabs, sino español: Mordanich ó Mlar.lenex es evidentemente Markínez (30): todo hace creer 'ue era de origen espenol y cristiano; que su ahutelo se hi\%o musulmán, $y$ true su familia, como lanlas olras que su encontrabon en condiciones pa- 


\section{$-114-$}

recidas, trataba de pasar como perteneciente a la noblèza árabe.

Lu sus maneras no desmentía Abenmerdanix su origren, antes al contrario: gustaba de vestir como los cristiauos, sus vecinos; usaba las mismas armas, aparejaba sus caballos del misino modo y gustala de hablar su lengua: sus soldados eran en sia mayor parte castellunos, uavarros y catalanes, $y$ para ellos edificó cuarkeles, y hasta buer múruero de cantinas cou grande escándalo de los buenos musulmanes: con sus larguezas se atraía á los jefes, y para ello tenía que nprimir con excesiros impuestos a sus rasillos. Hasta llegó á recumpenser á uno de sus caballeros, á Pedro Ruiz do Azagron, dándolo la ciudad de Santa Muría de Albarráńn con su ierritoria, ctue este cahalle ro laizo erigrir en obispado.

Ia política constante de Abenmerdanix fué estar íblimamente aliado con las príneipes cristiavos; d había comprado la pratección del rey de Aragón, del de Castilla y del Conde de Barcelona, compromotićndose a pagar un tributo: en realidad no era más que 


\section{$-115-$}

un vasallo, de modo que un cronista auglosajón de su liempo no se urarta mucho de ta verdad al decir uque el rey do Castilla rcinaba en Mírcia y Valencia, Para los cristimos no se llamaba llohímed, simo Yupo ó Tobo:

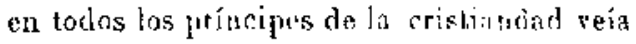
aliados, amigos y her:uanos: el envialsa marníficos regalos de oro, seda, cabalios y camellos al rey de Inglatera finrique II, y los recibía á su vez: su reputación entre los encmigos de su religrión era tal, que un sicto - después de su nueve un Papa le llamó el rey lope do ghorisel mimorit.

$Y$ bajo muches conceplos mercéa esle elogio; pues era lomjure de gran sacracielad, y segúu las circumitaucise sobín perdouar noblemente 6 rastign con severidod: dolado de una fuega prodicriosn y excelente caballero, era de una bravura á toda prueba: on los combates no seituia el policrro g exponía su vida de modo que ora preciso recordarle que el general en jofe tiene otros deberes que el simple solclado.

Para sus oficiales tonía además otras cua Jidades apreciubles: los lunes y jueves de to- 


\section{$-116-$}

das las semanas los conviduba, lo mismo que á Jos al los dignatarios, á un banqueteque se celebraba on uno de los salones de su palacio: pientras los convidados bebíau, sus csclaves bailaban y cantaban, y al cerruinor la fiesta, muchas veces distribuia entre los convidados los vasus de piata que labían servido en el convile, $y$ Iidsta los tapices gue adornaban la estancia: sieudo esto así, nada tiene de extriño gue lal capitán fuese el ílolo de sus guereros: la maicha de su carácter, aun pзra los mistoos rousulmanes, era su gran lujuria.

'Tenía el rey iobo por lagarteniente à su su suerro y vasallo, señor de Jaén, L beda y liacza, poblaciones que Abumerdanix le habíl darto: pmese Ibralim, hijo de A hmed, hijo de Jofarech, lijo de Memodico, lambién de origen cristiano, to yue él no ocultaba: Hemochica era din sob:enoxulare ó apodo de sis bieabuelo, un cristiano del ejército de los Bewihurd de Zaragroza; le llamaban Itemochico, por'pue le labían cortacio una oreja, $y$ les espauoles, cuando le véan en el combale, secían It: Wochio, es decir he apui d mo- 


\section{$-117-$}

cho pequeño: esle apodo rino á netr el bonbre de la familia, como lia sucedido an neuchos casos análocros con uncstras apellitirs: Thenochico ó su hijo reberó del cristiulenos laciéndose musalinán jor lia medisción de uno de los reyes de Zarigoza, do bodo que nusp tro Ibrahim fué criado eu cl is lamisuso; pelu no parecía musulinati: stos uverturis fuerou muchas, sirvicudo a unthos príncipes, hasta al mismo rey do Castilla y yuiza tutouces so lacía pasar por cristiano; yeco poco imposta: cra un capita y nada mis; como lul cipiláu, uwo de los mejores de sul liemprop pero $\mathrm{m}$ monstruo de cruclatial: se conplucia tu chenar vivos á sus prisionerse; en precipitarlos de lo alto dis las Iucutañas ó de lus torres, y

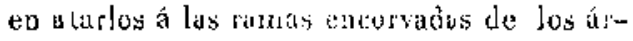

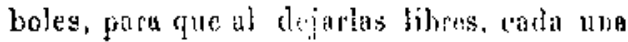
se llevase una parte del cherpo: ios verduteros musulmanes créian que loubía ido clerecho al intiermo, y se cuenta rgue despues to su muerte se aparecio cil suciós a th a devolo musulzúa pora decirle que en efecto eslabr sufriendo atroces dolotes scrbe efrbontes encendidos. 
Si á los ojos de la historia imparcjal tales houbres no pueden ser tezidos por buenos musulmanes (ui meros por buenos cristianos), ¿qué aversión y liorior no debia inspirar a los gluohades, ignoranles bereberes, animados del más ardiente faualisco? ': para éslos, tales hombres aran apóstatas é infieles de la peor clase: la guerra rue les hacian, era una grerra de reigión, una guerra santa, $y$ en cuanto les cuitalosn una ciudad, se apresuraban á puriticar las mezçuitas profanadas por la presencia de tales hombres.

Los cristiasos y los julíos, por el contryrio, consideraban de un modo mu diferente a los soldados de Abenmerdanix, y tenían para ello razones poilerosas: su suerle, ya bien desgraciada durante el imperio de los almoravides, se habra hecho intolerable bajo los almohades: hasla la sombra de tolerancia lıbía desaparecido: el califa Abdeimumen, inmediatameale después de la toma de Marruecos (1146), lez había anunciudo que no covsentíríd en sus estados sino á musulmanes,

1 En mi seotir el autor cxagura el espiritu rojgrioso do los almohades. 


\section{$-119-$}

y que por tanto sus icriesias y sinagoctas 3efían demolidas, y que debían rlecrir entre e] isjanistno ó lu muerlo: á lo sumn se les permitiría la cxpatriación: muclios optaron por este extremo: otros sufrieron è martirio, y los almohades se apresurason á apropiarse sus casas, sus riquezas, y hasla sus mujeres: otros, priacipalmente estre los juctíos, permanceiendo, en secreto, fieles á la relirion de sus mayores, se resignaron á profisar exteriormente el islumismo: gracias á esta transacción 6 anosistáa, conservaruu suts bienes; perosu posición era harto folsa, pues el gohierno, que sobía nuly bien lue su conversión no efe sinceri, les temia relerados, no - cousintiendo los matrimonios con los verda deros anusulmanes. de modo que estos desgraciudos debía ein dula desear verse libres

\section{- - - -}

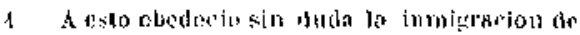

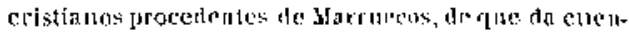

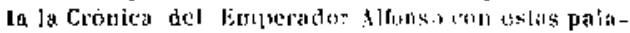

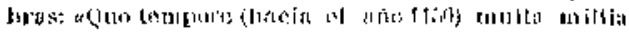

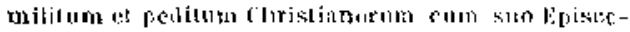

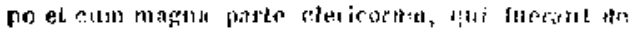
domo Regis Ilaly a filid ejus Texufiri. Ltatusierunt

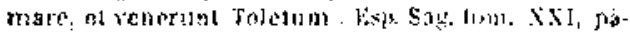
gina 399. 


\section{$-120-$}

del yugo que soire cllos pesaba, y esío sólo podían esperarlo de los soldados de A benmerdanix, en quienes véán á sus libertadores, y á quienes estaban dispuestos á auxiliar con todas sus fuerzas. como lo indica el autor conterupoźnco Aisersáăhibasala.

Hechas eslas iudicaciones acera del carácter de $A$ Jeamordunix, procureanos bacer Ia historia de su reinado, reuniendo los pocos datos concretos que licmos visto en diferedtes auteres, ya nue los listuriadores árabes. a un escribiendo su biegrafía, dan pocas nuticias refercutos á sa grobierno.

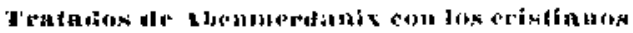

lil primero de los príncipes cristianos con quitu Abrumestaniv, que sepmos, enlibbló relaciones, fué el condo de Bascelona, I). Ramón kerenguer $1 \mathrm{~V}$, con quien consta que lizo faces por cuatro años, compromelicadase a parar un tiibuto de cien nil miscules de oro, de los stayos ', que por cierto

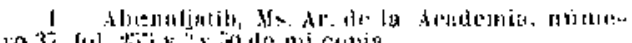

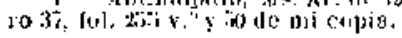


sou de oro muy bueno y abundan ex las cobecioces mumitmaticas: es de alvertir que. según atgún otro texto. Jos tien mil mis-

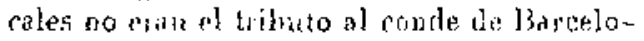
ra, sivo á iste y al rey de Castilla, cl l'mporador I). Alfous VII, a quien, como tueda indicado, quizá polia rousiderasse como el verdadero rug de Mureia y Faloncio.

Guno la alianzid ó amistad parada por Abeumerdanix, 6 l'ty lope, cun al conde de Barcelona eloséo jor cuatro yños, es de suporer fueris rencrabla al expirar el plizo, lat to más cuonto, sicezlo cosi ntr retonocimiento de vasmllaje par parte ded rey tope.

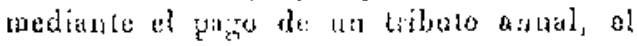

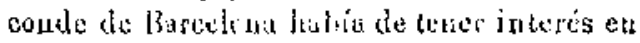

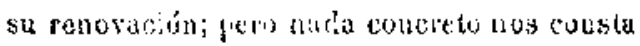

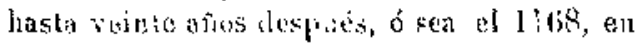

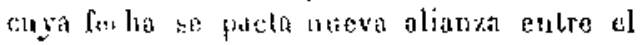

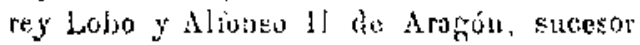

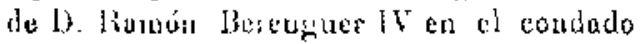
de Barelolu: el dia de las nones (díi 5) de

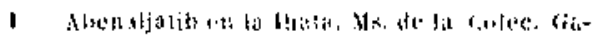
youstos, folio tidi $r$. 
Novienbre de 1168 , se firmo el documento correspondicute, en el cual el roy Toloo, por medio de su apoderado Creraldo de Jorba, se compromete á jagar á Alfonso II veinticinco mil maravedises antos del día de la Tatividad del Señor, y el rey Alfonso, por su parte, se conpromete á tener y hacer respelar la paz cou el rey Lobo desde 1. de Mayo próximo hustu tos añus después: por parte del rey Alfonso juran observar lo pactado Pelegrín de Castillazuelo, Rlasco Fomen, Mayordomo del reg, y Ximeno de A trosillo, su alféres ${ }^{1}$.

El rey lobo hubo de pagar tributo no sólo á los soberanos de Barcolona y liastillo, sizo tambicin á los de otrus estados: un el segundo año de su reinedo, el día 15 de Ramadán del a fo 543 (6́ sea el 27 de linero de 1149), firmaba un tratado por 10 años con la República de Pisa, $y$ luégo otro de mayor importancia con la de Génova, compromeliéndose con ésta á pogar diez mil morebitines, cinco mil cn el mismo aúo, y los otros

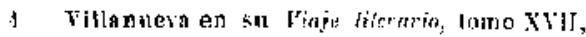
[rág. 328, publico el documento latino do esto trutado. 


\section{$-123-$}

cinco mil en el sicraiente: además del subsidiu, el rey Lobo, que eu el disumento figura con sus narubres norus àt: Aboarella Mordervet hbensul (por A buthdala Mohrmed Ahuensaud), ofrece á los genoyestis hubitaztes eu Valencia y Jeula ne fundacó mesón para e) comercin, pero con probibición de que otros babiten allí y ademis ies concede un bo no gratis cada sumans: los genoreses, por su juate, sólo se comprometen á do lícece daño á los subdites del g'y Lolo en l'orlosa y Al-

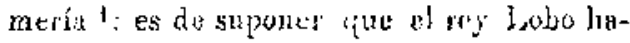
bríd te firmar lratados andoros eu otras fechas, atemis de las comocidas.

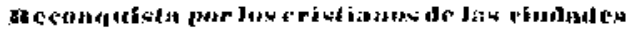

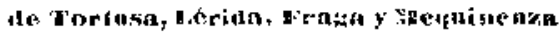

In los primeros años te su reinado, e] rey Loho, estreclarlo por el conde de l3arce-

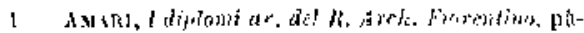

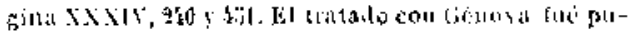

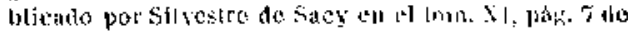

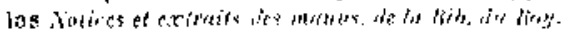




\section{$-121-$}

lona con los muchos extranjeros fite de lodes portes acudíal en su aguda para la ragra con los moros, pierde lu ciudades de Tortosa, Lérida, Frnga y Meruinoma: lia primera bubo de ser entregada hl conde 5y. liamón Bereoguter, despnés de un largo y podtiodo

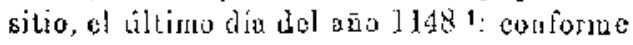
a conpromatios valeriores la ciuded fue donada tiu feuto, por leeceras portes, á sos fienoveses, a filillermo Ramón de XIncada $y$ á Guillermo de Nontyeller, quienes hatran

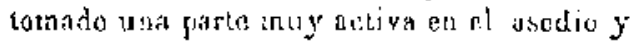
A taque the la ciudad: por las historiodures árulyes sólo sabemos ta ano en que Turtosa valió de su dominación: ni aun porlríamos aseguma que l'ortosa y su comarca formasen

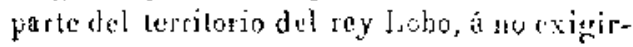

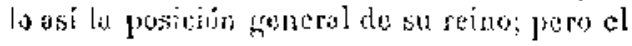

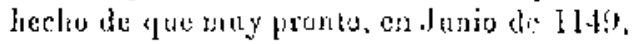

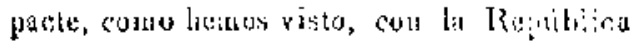

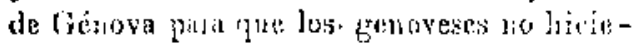
ran dajor á los monas labilantes de Tintoro. prueja que el rey lobo so abandond a sas

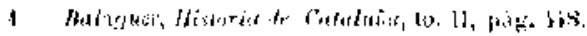




\section{$-12 \check{j}-$}

an iiguos súbditos musilmanes, tenioudo que sacrificar la zo despreciable suma de diez mil norabilines, en eujo pacto se incluía además á los moros residentés en Almería, en cuya conquista los genoveses liabían tomado también una parte muy activa.

Tomadi Tortosa por las armas de D. Ramón Berenguer y de sus a tiados, las ciudades de Lćtidn, Fraga y Mequinenza, que aun perlectecín al dominio musuláán, no podían ser defendidas por sus solas guarnicioncs, á quienes uo labían de atuxiliar los moros andaluces, como suerdiero pocos años untes cizando el sitio die lisatra por Alfonso el Batallador, sino que ni de Valencia podía esperar axıxilio, aubque el rey Lobo huhjera podido prestíselos: así pasece yque Lúida y I'roga sosterían el sitio con sus solus fuer\%us, y en el mismo año 513, en que fiać tomada 'lorlosa, caen en poder del conde de Barcelona; los antores úabes conocidos nada concreto nos diven de la pérdida de estas ciuclitles pas ol isianismo, fuem del hecto de la ruiriatista, juvulucrando la noticia de

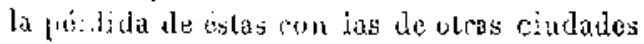




\section{$-120-$}

bien distanles, corno Lisboa y Sautarén 1.

Ins a utores catalanes admiten que lus tres ciudades, Lérida, Frarga y Mecquinenza, fueron tomatlas en el misma día, 24 de octubre de 1149.2

Por el mismo tiempo, y sin que conste de un modo claro que pertenecieran al dominio del rey Lobo, aunque Abenaljatib habla de pllo en la biografía de éste, los cristianos se apoderaron do Lelis $a$ y del castilio Serranía.

Si Abenmerdarix, ó el rey Lobo, pierde en los primeros anos de su reinado alounas pobjaciones importantes, en cambio incar-

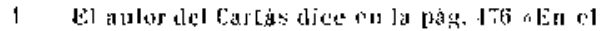

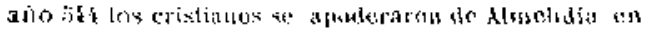

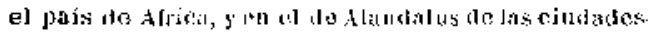

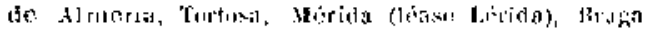

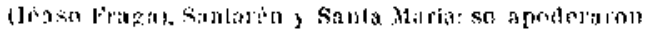

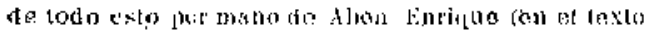
dico aven Yatrist,

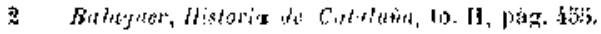

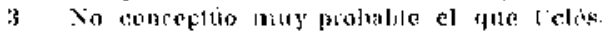

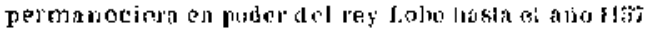
fanos at Emperador V. Altonso es parmuta por la vilba lie Aitrón, como se dices en an articulo aceres de Celés,

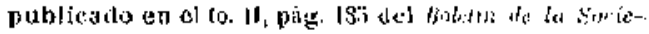
dete de tixirionistas. 


\section{$-127-$}

pora al reino de Alureia alras, que aunco habian protenesido a la región rsiental, apoderadose de Jaću, lbeda, litezo, Baza, Guadix y Carmova, liegando á poncr siliu á

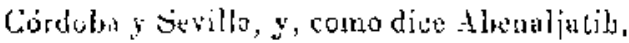
por peco llegó á clominar en loda Alacidulus.

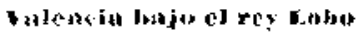

Contr vercuos en capilalos posterjoses, puede decise que el rey Lobo compratió el mas lo con indiriduos de su Camitia, parientes consampraineos, como su hermano Yúsuf, ¿que ejerció el mando eu Valencia y un prino suju del mismo nombre, Hohamed Abessaad, yuc suberaj cu Almwria, ó parjentos por afinitad, $y$ a esta misna circunstancia debió en zran parle, ei no por completo, su entronizhmienta.

larece qua, desile ol principio do su rainada, el rey lába corstió el maudo de Yálen-

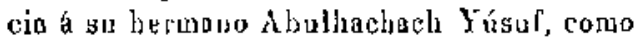
si Valewdia en esie período, en tue csta bajo la supremocía de Marcia, fuese, cono era 


\section{$-128-$}

razón, el pruto de residencia de lin autoridad inmexliata a la del rey.

Sólo iudicaciones muy vagras encoutramos respecto á la suerle de Valencia en estos años, iudicaciones que algunas, por lo incompletus y al parecer incoherentes, casi no pueden considerarse con valor histórico. (31)

Pn el ario 34 fo (de 20 do . Bril de 1151 á 7 de Ahril de 1152) huho on Valoncia una rebelián, que tardó isigún timpo en ser sofocada, dutonte la cual estuvo emancipadn del dominio del rey Jobe, por holerse rebelado en cila sludelmélic Ibensilláa, $y$ antes que é parece que labia hecho lo mismo un Atrubámial: la rebelión terminó en el alio siguiente, sufricudo Valencia us silio que jarece fuć bastante larfo. (32)

Desprués de esto tratescurren bastantes años sin que encontremos noticia al cruna referenle? a Yulencia, $y$ por cierto nolieia bastante vuga. pues se reduca a consignar la asistencia de Abulhachach Yísuf á un entierro el 18 de Kacheb dol tino 564 ( $17 \mathrm{de} \mathrm{Abril}$ de 1169): el eutor llarna sultán cntonecs de Valencis a Abullachach Y'úsuf, el hermuoo 
depl rey J.obo ': ¿os q the $A$ buhachacl se habia ya rebelado contra sul liernano, resla rándose independiente en Valcucis? Creo que no.

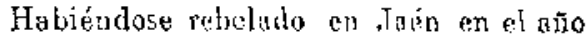
564 Abenlemochice, s en Almería un primo del rey Lobo, llamado ceno di, Molárued Ahensaad, el rey temí́ en Fa!encin hasta porsu persona, é hizo stlir te la ciudnd sus moradores, equanccíndola con cristianos y Io mismo se proponía hacer en otras ciudades: á esto, y quizá yor cslo, sirzue una rebelión en Alcira, donde un santón muy respetado, temiendo que el rey le echase de ellz, llamó á los almohndes, í quicnes el roy hubo de someter mediants un sitio, yue debió de ser laréro, secrín las indicariones queso

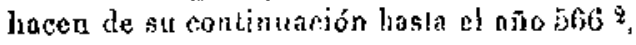
labicudo intorvenido en la sumisión Abulhachach Yísuf, á quien por pale tiemposo supone ya rebeladio on Valeucia contra sa

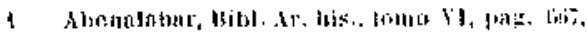

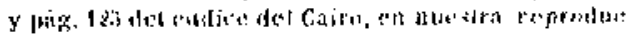
cien fotosesnca.

2 Dozy, Notices, pàg. 23\%. 
hermano, ó al mepos consta alguma indicación.

Eu los últimos años de su reinado, el rey Lobo livo el disgusto de que se fixeran al particlo de los almohades sus mismos parienles, que liabían sido el sostén de su estado: parece que el úlimo fuć su hermano Abulhachach Yúsuf, quien, segán Almacari, se

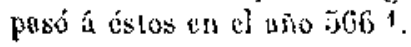

1Henjultín adelanta esta rehelión, diciento que Alulluchach Yúsuf silió a Valencia; que hizo en elia la oración pública por el califa Abasi, Almostánchid, á quien escribió, y que éste le contestó confirmándole en el mando y yue luézro reconoció á los almohades en el año $566 \%$ \%.

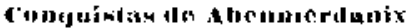

Al hacer al retrato del rey Lobo ó sea de Mohimed Abensad Abenmerdanix, queda hecho también, con ol brillante pincel do

1 Tomo II, jıą. iait.

2 Tomolv, pay. 166, ale la ediciól del cairo. 


\section{$-131-$}

Dozy, el de su suegro $y$ brazo derecho de su reino, Ibraling Abenhemorhico.

Ýa antes de que $A$ bensad fuera proclamado definitivamente como rey de Valencia y Hurcia, parece ine aprovechó les servicios de Abenhemochico, miándole á Segura contra Abensiuar ': muy pronto debió de llenar su cometido, ya que. IJegado $\Lambda$ beusand á Murcia en el mes de Chunada primero del año 542 , pronto llerróa ella Abeuherochico $y$, hecha la proclamación solemue, Abensaad se volví á Valencia, dejando en Murein de !ngarleniente á st knegro, que permaneció, dice el autor, en la obediencia de Alensaad en Segura, lasta que se levantó contra ál después del año 560 .

\section{Comejuinia de Gondix}

Rechazado el rey Lobo en la perte Nurto de sus estados por las armas del conde du Barcelona, pretende extenderse por metio-

1 El texto tie Adabi, lsibl. Ar. Mist. Inine MI, paz. 33, tonde se da exta notiria, esti falto, y no so ratiende to gue diec tor este neonterimiento. 


\section{$-132-$}

día : poniente, mermando el poder de los alunolades y el de los que so conservahan independientes de ćstos.

Al declararse independierto en Córdoba Abenhamdín en el año 534, haciendo to mismo otros jefes en sus respectivas ciudades, se declaró iudepeudiente en Guadix, no por ambiciún, sino por la fuerza de las circuustudcias, un personaje desconocito hasta hoy en nuestra historia ', y que á ser más conccido, sería el perzonaje más simpático de cuantos ficriraron en la lísaño musulmana en este periodo de revulotas.

Llamábase Ahused, hijo de Molámed Absumilháu: eru natırul de Guadix, de recoroeida suficiencia y mo considerado por siss obras: al decinrarse independiente, tomó el título de Ainotaayyud bila, y fortificada la alezazia se dedicó á proveer y gobernar con nano firme st perqueño sstado, sin encargar á otro el mando: la perturbación ge-

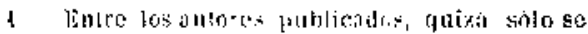
le oncuentra cisato por Abenalatir: Alonaljatb en el

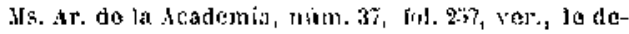
dica media f'agina. 


\section{- 133 -}

neral le impulsú, y ayudánalose de la agricultura y arboricultuma adiguirió grandes riquezas y tesoros, lleçando á ser el más rico de su tiempo, y a prevalecer sobre cuaulos estaban próximos à en ciudad Guadix, apoderándose de $B \mathrm{za}$, donde dice cl autor que en su tiempo (dos sicrios más tarde) se eonservalua descendencia de Abeminlhán.

Clando Abetsarad, que anbicionaba lo que poseía A benmilián le estrechó en el año it6, ayurlado, sectún parece, por el kimperador D. Alfonso VJ, de ruien dicen los A.uales Tyledanos que en este ño prosó solur Ciadiexy, Ahenmilhán extró on la obedieneja de los almohades, trasladindose á Marmecos, donde se encesgó de lu albuera ó paztano, de su construccion á roparación $y$ de la distribucion de sus aguas: rersegtido inego, no sabezues por qué caustis, perdió sus riquezas y murió en este ustado.

Durante su reinado en Guadix, $A b e c-$ milhán había sabido atraer á su servicio á los más célebres literatos, como Alubéquer Aben. tofäil y Abulháacem IIerodes (?)

Respeclo á la suerte de Gradix, no cons- 


\section{$-134-$}

ta si al ontrar su reyezuclo en la obediencia de los alinohades, eitró también en ella, ó habia caido en poder de Abessuad: parece fué esto ríltimo, pues en su biogyralía se menciona á Guadix entre las ciududes que le estuvieron sometidas.

\section{daen, nlyeua y Uarza}

Ẃ el año 5̃5ł, ó quizá ya en el anterior, Abensaad, acompanado, segín parece, do Abeuhemochico, sitia á Jaén, cuyo goberuudor almoliade Mobiued, hijo de Alí el Cumí le presta obediencia, lo mismo que UJbeda y Baeza I: luego si tiu á Córdoba y Sevilia en el mismo año 554 , apretando los ataques cantra Córdoba husta el punto do que los labradores hubieron de orar sus huer tos (\%) dentro de la ciudad: lo más recio del sitio de Córdoba, si no fueron dos, debió ser hacia fues dal año 55.j 2: por este tiempo, ó duran-

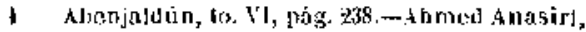
Iono $\mathrm{l}$, pris. 1 .'.

2 Bsla feclon resuléa fijada por la indicación de Abenaljatib ale que Moloámed Abringuamán murió 


\section{$-135-$}

te el sitio de Cúriloba se apoderó de Eejja, y un merodesdor, liaraulo A beusaruhil, le hizo dueño de Carmona 1.

Parece, sin embarto, taje Aluenmerdunix no llerró á apoderarse de Córloba, á pesar de que ea una salida labía muerto el grobernador Abenbocait :.

\section{Amuctia}

'Tomada Almerín por los cristianns (castellanoz, calalanes, navarros $y$ genoveses) el 20 de Chumada primero dol año 512 (17 de Ochubre de 1147), cabalneote por el miswo tiempo eu que Abenmerdanix era proclamada rey de Valencia y Mrria, anuque Al-

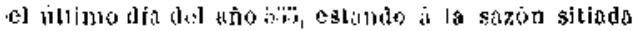

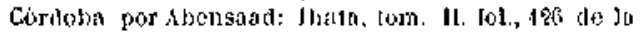
copia completu de la denbembin, nues en el ejemplar ade la col. Gayangos for. 209 ver." tallat uare polatra,

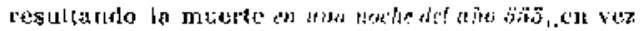

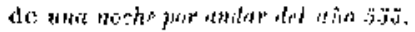

1 Abenaljatih, Ms. Ar. de la Atodemia, numero $3 \%$, fol, 256 r.

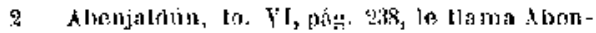
boeat: Almed Anasiri, 1o. 1, pag. fijit eseribe Abenyoenit. 


\section{$-136-$}

mería no había eslado bajo sia poder, Abensaad se creía sin duda con derecho á ella, ó al menos consicieraba que los moros españoles, que alli brbian quedado, debian considerarse como súbditos sayos.

Los a!maliates, ducinos de una buena parte de la Estrena musulmana desde poco antes de la courfuista do Alnería por los crislianos, habian de infestar apuderarse de poMacióit tan importarate, $y$ irabía de resultar difícil al tue los cristiunos pudieran defenderle de un wotio aticaz.

Fritregada (janada á los nuevos dominadores en cl biso :30, por stzmisión del ryobernador almoravid Naimín Abenbèter 1. el tobernador do: Alreciras y Málaga, el príaripe ó sira husasaíd Otmán, hijo de Abdelazuen. pulasiodor yo de Granada, recibe de su padre la vodeu le sitiar a Aloueria: formalizato el sitio jor mas' y liers, los cris-

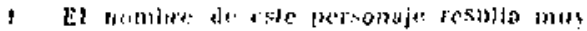

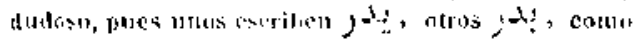
con esta lorma inatren maclsos seces como nombre propio, y nocon olra, ucejotomes la corwia ja: . 


\section{$-137-$}

lianos se reliran á la aledzabia, y Abusaíd acanpa su ejercito en el monte plue domina la ciudid, conslruyeudo 111 waro y un loso entie el monte $y$ el mar, da moulo gue la ciudad y fortaleza quedasoa cercatís por este muro: los cristianos, eu este estado. pidieron auxilio al limperador, "ricu se diriztó á $11-$ meria con 12.000 howbres, mis 6.000 que Heviba su cunstante aliado el rey lobo; pero, á pesar de lievar un ejórcito tan respelable, los aliados no punierou hacen levantar el sitio, y hubitron le retirarse, stpalríudose $-t$ ambos reyes para siempre, pues at limperador murió en el camino antes de llewarán d'oledos en liessueta, cerca del puerto de Muradal, el 21 de Arosio de 1157'.

Almerij, deficmlabia on sus esperanzas de vor levintado el silio, labjo de capitular, yolviundo al proder de los musulmanes después de hulyer estado die\% años en al de los cristianos: los autores árabes solo lijan el aĩo 552 de la hégira like 1:3 de lebreso de J157

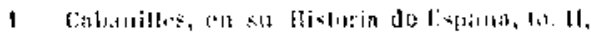

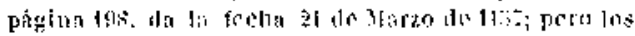

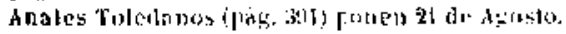


á 1. ${ }^{\circ}$ de l: ebrero de 1158 ), sin indicur el mes, ni mucho menos el día. (33)

\section{Círanu din}

Entrezada Grapada a los alızoliales por cl último gołeroador vlmoravid Mtrimún Abenbeder, puco 6 nada sabemos de lo que en ella sucediera de carácter foueral y político hasta nl año 5j7, aungุue crecmos que algo se encoritrará en la lhata de Aberaljatib, si llega á publicarse, y se extudia más detenidamente.

E.l príncipe Abusaíd YúsuṔ, hijo dol ca-

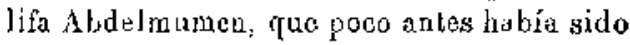
nombrado scoberandor de Cicuta y T'úuger, ó más bicn, de Cena, Algeciras y Malaga, fijândose en ésta úlliua, en ol misıno año 549, al pasar Granada á porer de los almohades, se encarga tambión, par orden de su padre, del gobieroo de Granada.

Hacia el año $55 \%$, bien porque los descontentos de Granada, judíos y cristianos, como dice el historiador Abensáhibasala, unidos al partido árabe español llamasen espontánea- 


\section{$-139-$}

mente a Ibrahim Alsenberuachico, 6 bien porque ésle, de acucrdo cou Abenmerdanix, entrara en tratos con puros y otros, es lo cierto, según resulta de los autores árabes, que Abenhemochico con sus parciales sorprendio de uoche la cindad de Granada con el auxilio, por supuesto, de los partidarios que tenía dentro, pudiendo, siu embargo, los afectos al partido almohade refugriarse en la ulcazaba al amparo de la guarnición 1.

Puesto el sueeso en conacimiento de Abenmerdanix, qque á la sazón se encontraba en Marcia, esperando poder someter la guarnición almolade de la alcazaba, enpió inmediatamente á Granadia dos mil ginetes cristianos, en tanto que hacía los preparativos necesarios para ir persoualmeute con mayores fuer\%as.

Fistablecido Abeuhemachico en la Allambra, frente á la alcazaba, comenzó á dis-

1 Lo marracion de estos sucestss la tumamos,

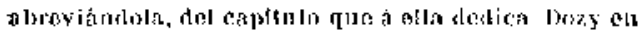

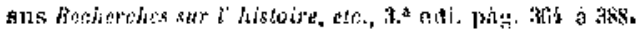
para la cual le sirve principalmento do guín el historiador contemporáneo Abensábibasalo. 
poner las catapilias para combatir á los almohades, quienes inmediatamente avisaron al ealifa y al robernador de Sevilla, pidiendo anxilio: el califa Abdelmumen, que estaba á dos jornadas de Rabat, recibida la uoticiu de la pérdida de Granada, se trasladó á Rabat para tomar disposiciones, y su hijo el príncipe Abusaíd, que estaba allí con su padre, salió inmediatamente para su gobierno de Málaga en la esperaliza de poder someter á Abenhemoclico, á quien por considerarle solo, crési poder combatis sin esperar la reunión de muyores fuerzas; así que, llegado á Mảlaga, avisó al folemertudor de Sevilla para que inmediatamente so le uniese con las fucrzas disponibles, y ambos so dirigierou á Grunads, doode estahan yn los cristianos enviados al Murcia por hijenmerdanix: Abenhemochivo con los suyos salió al encrentro del príncipe $\lambda$ Jusaid, cuyas tropas, atacadas de improvizo a cuatro millas de la cindad en la praciera llamada Huctiarocad, se dispersaron, cnyendo muchos ell las acequias de riesro, abuudantes vilí, sienda esto una de las principales causas de la derrota. 


\section{$-141-$}

Fil príncipe Alusaíd tuyo la suerle de poder escapar del dusistre y se retiró á MáJaga: no así el scobernutor de Sevilla, yue murió en la batidila con muchos ahmoliades y musulon nos españios: los alouoiades encerrados en la alcazaba, iestigos del combate, nada pudieron hacer en auxilio do los que iban a prestálialo á cllos, $y$ después de presemeiar el desastre, labieron de presentiar tambisin, secrún ol autor, las crueldades que Abenlempelico ejoentí con los prisioneras.

Guatudo el califa, en torto del cual se labían reusido muchos a!molades, boduinos y tropas rerulares, fuvo noticia de cota

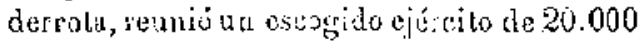
caballecos y pumes, y desimes de haberles arengado, recordanilo las recompensas prometiclis in lus fute haceu la gruersa santa, los despidió alando é maudo á su hjjo Abuyacub Túsuf, lacieudo que le veonpañase el general Abensolicun, jefe de su confianza por su mrande amistad, $y$ experiencia $y$ bravura en lik guerra: has tropas maccharon al principio eon la mayor rapidez, atravesande ol Estrecho, y llegadas á Algeciras, so dirigieron 
á Málaga, doude se reunieron á las fuerzas del príncipe Abusaid: aprovisionedas todas estas tropas, salieron de Málaga en busca del enemirro, pero en jornadas cortas segrín las disposiciones de Abensoliman, que de actzardo con sus guías, se proponía que aum la gente más lloja llegase con brios á Ciranada.

Lntre lanto Abeumerdanix habia llegado con los nuevos reluerzos, con sus eristianos, y había acampado en la montaña innediata á lo alcazaba: su suegro A benhemodico continuaba a la otra parte del Darto en la Alliambra, y con él estaban los cristianos (granadinos?) mandados por el Calvo, los del nieto de Alvar Fáiez y los de los dos hijos del conde de Urgel; el número de estos cristianos pesaba de ocho mil caballeros, sin contar los soluados de $A$ beulemochico $y$ las tropas de Abenmerdanix eran aún más numerosas: de un día à olro esperaban al ejército esemigo, que aranжaba lentamente, lasta que por fin llegŕ á Dilar, junto á Alhendín, donde hizo alto para descansar.

El jueves 27 de Racbeb del año 557 (12 


\section{$-143-$}

de julio de 1162 ) ul general lluxsoliman seusiú á los jefes y les hizo uris exlortación, explicinobles sin didu el pian de andque y dando las órdenes oportanus: comicada la oraciót del aledioçáa, matodó dar pienso á los cabailos, y dada la orden de macchur por la vuble, la gente se armó, y terminade la oración de la tarde, se pusieron todos en marctia: los nuias y la iufanteria atmoltade comenzaron á subir la monlatio, fue domina ei Genil, contiçua a lu ruontañ Asabica ýa la Aibawlora, dunde estaba el ejécicito de Abenismochice: ba subicla fué lesta durante toda la nocbe por camino tan escarpado; sin embargo, como durante la segunda nitad brilló la luna, los soldados veían donde puníau el pjé: al amanecer del viernes 13 de Julio los almohades cayeron sobre el campamento enemigo, $y$ como todos dormían aún, apenas habian montado sobre sus caballos, cuando pudieron convencerse de que Dios había resnolta sil derrota: dicrou algunos alaques, pero al querer huir couforme á su táctica, engroñados por efecto de la obscuridad producida por el polpo, y olvidando la. 


\section{$-144-$}

posición que ocupaban, se precipitaron en el río Darro, rodando por ias rípidas nendientes de los cerros, de modo yue sils escuadrones fueron anirfuilados: el cristiano de Granada llamodo el Calvo y el nielo de llvar líñe\% murieron en el combate, y la cabea de éste fué lleveda á Cúrdobo despuós de algunos dias: tumbira narió Abedaliaid. pariente de Abenmertanix y uno de sus incjores capitanes.

Abemerdanix, testigo de la derrata de los sugos, á ruienes le cra imposiblo prestar auxilio descie su posiction al atro lado del Darro, en cuanto vió destruído è ejercito de A benhemochico, y que los almohades halían entrato triumfantes on Granada, se comvenció de que codo estaha perdida y levantó et campo, ubandonoudo las tieadas y gra!n yarte de sus bagrajes: perseguido de cerca en su retirada, liutu de perder nuclat gente, preliendo salvarse, sabe Dios cómo. (34)

Fugitivos de Granada Abenmerdanix y Alenhemehico, el primero se dirige á Murcja y el segundo á Jaén, donde fué sitiado por los almoliades, aunque parece cue sin 


\section{$-145-$}

resultado inmediato, purs los dos príncipes Abusaíd Otmán y Abuyacub Yúsuf se adelantaron lasta Córdoba, de donde pronto fué llamado este úllimo para ser declarado Príncipe heredero en el año $55 \mathrm{~S}$, poco antes de la muerle de su padrc Abdelinumen 1.

Muerto Abdelmumen en al año 558 , en el mes de Chumada postcero ( 7 de Mayo a 4 de Jubio de 1163) 2, le sucedió en el mando su hijo Abuyacud Y'úsuf, rquien en el año 560 llama de Graciada á su hermano el príncipe Abusaíd Omám, que es recibido en Cicula por su hermane Abuhafs.

Durante la ausencia de Grauada de su gobernador el príncipe Abusaíd, quizá gobernador general de la lispaña almohade, parece que el rey Lobo, acompañado ó no de su suegro Abenliemochico, intento nuevomente apoderarse de Córdoba ${ }^{3}$, aunque en Cairo.

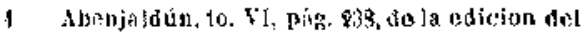

2 l.ns altores arabes rarlau en ol dia de la

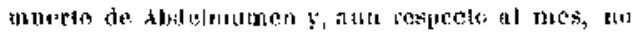
ostán de actecto toslos.

3 Alsenjaldili, lomo $\mathrm{YJ}$, rág. 23 s. A LNOR.AYIYFS 


\section{$-146-$}

vano, pues al tener noticia de ello el califa Abuyacub envió á Fispaña un poderoso ejército à las órdenes de sus dos liermanos Abusaíd y Abulafs: el ejército expedicionario, pasado ol Estrecho, so dirige hacia Murcia contra $M$ benmerdanix, que le sale al encuentro dispuesto á presentar la batalla: á pesar de que el rey Lobo había reunido sus tropas $y$ las de sus aliados cristiunos, ayistados ambos ejércitos en el llano de Murcia, se trabó un encarnizado cornbule, eu el que fué dersotado el rey Lobo con muerte de todos sus soldados cristianos, al decir de algunos historiadores árabes, que hacen llegar su nuimero a trece mil 't: la batalla tura lugar el viernes 7 de Dulhichra del año 560 . (35)

El rey Lobo después de su derrota huba de encerrarse en Murcia, que fué sitiada por el ajército yancedor, sin que los almohades consiguieran epoderarse de ella, porque sin duda no contaban can el material $y$ tiempo

1 Cartes, pog. 197; en el resumetr, patg. 177, no

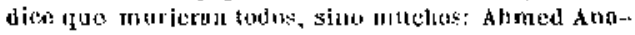

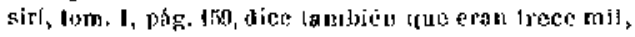
y 


\section{$-147-$}

necesarios para un sitio en regla: los príncipes Abusaíd y Abuhal's se limitaron a devastar la comarca, y en el año siruiente se volvieron á Harruecos, una vez extinguido el fuego de la guerra civil de Abenmerdanix.

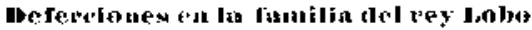

Hemos visto que los parientes del rey Lobo ejercieron gran influencia en su reinado, ayudándole en sus continusas guerras, principalmente su suegro Abenhemochico: ćste, que más que nadie contribuyó al éxito de las conquistas de Abenzerdanix, fué de los primeros en abandonarle en los áltimos años de su reinado: al menos de éste consta con bastanle seguridad el año de su defección.

Ea el año 564, estando en Córdoba el jeque Abuhafs, segrín $A$ benjaldún ", recibió un mensaje de Ibrahirn Abeuhemochico prometiendo obedicncia, ingresar en lá secta al-

1 Tomo v1, pig 230 de la ediclot del Cairo: to-

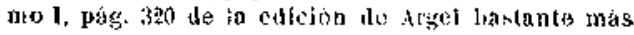
forrectu y ammpleta en riste levto. 


\section{$-148-$}

mohade y romper toda relación con su yerno Abenmerdanix: la causa de esta separación, según Abenajolib 1, fueron los relaciones entre Abenturdauix y su mujer, hija de Abenhemochico, a la que llegó á repudiar, devolviéndola á su padre.

Ei jefue Abuhas dió cuenta al califa de los propósitos de 1 benhemochico, quien sin dirla para termisar personalmente las negociaciones de la sumisión, ed el año siguiente, 565 , pasó á Marruecos á verse can el califa: éste, en virtud de lus graves noticias que te hulían sido conunicadas al mismo tiempo respecto al daño que los crislianos causaban á los muslimes, despachó para Alandalus á su hermano $y$ visir Abulafs, quien inmediatamente salió para su destino con un ejército almoliade, acompaiado de su Jermeno Abusaía: llegrados los herzanos á Sevilla, Abusuíd fué enviado á Budejoz, de donde regresó pronto, una yez pacteda paz con D. Alfonso

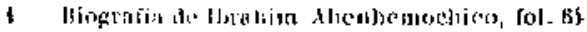
y siguionles del manuscrito bo la llanta oth la Colec-

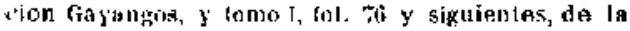
copir de la misma nbra procedento de Tuinez. 


\section{$-149-$}

Linríque\% de Portaral: incorporado Abuseid con su hermano el princip̣e 1 bulats. acompañdos de $A$ benhewoulico, se dirjogieron a Iurcia contra Abenmerdanix, á quien sł... tiaron.

Con la presencia del ejúreito a mohode en la región de Murcia. Jorca se rebela conIra el rey lobo y entra en la obediencia de Ios almoliocles: tomada posesión de Torca, el príbcipe $\Lambda$ buthafs eusiqulista a Bara, y por et mismo tionpo presta también obediencia á los almoliades un primo del reg Tobo, llamado, como éste. Nohamed hhenmerdanix. gobenador ó señor de Almería.

A este liempo se refiere sin duda la rebclión de Alcira por instigación de $A$ bulyéquer, hijo de Sufún, la cual fué sitiada á unitad de Xaual del ano 560 por uno de los copitanes del arráez Abulluekach Yúsuf, hermano del rey Lobo, sosteniendo un diro silio hasta milad de Dulhicha del mismo ario: antonces parece que hubo de ejcorgarse del sitio Abuayub Abenhilel, á quien Abensotián entregó la ciudad'.

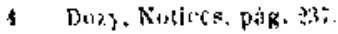




\section{$-150-$}

'También Jilcìe se rebeló contra Abenmerdanix en los źltimos tiempos, $y$ de ello tenemos una indicación concreta en el hecho de haber muerto mártir un lol Abenfaid, cuando jos de Tilche salían de la ciuded por miedo al emir Abensad, contra quien se habían rebelado, negandole lit obediencia ': no se indica cl día ni el mes, sí el aña 567.

Con la defección del gobernador 6 señor de $\mathrm{Almería} \mathrm{y} \mathrm{principalmente} \mathrm{con} \mathrm{la} \mathrm{de} \mathrm{Aben-}$ hemochico, hecha pública con su asistencia al sitio de Murcia por el ejército ulınohade, quedó cortada, como indica un autor, una de las alas del rey Lobo, $y$ aun que por de pronto no se conlinuó el sitio de Murcia, desde esta fecha era inminente la ruina de este reino $\mathrm{y}$ su desaparición como estado independiente de los almohades.

1 En al texto imprest, Bibl. Ar. Irist. lo. II, pa-

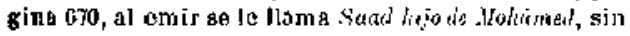
duda por arrala dei compalador, fiucs en la biouraria del nismo personsjo Abullasál, Ali, hijo de Holskmed, hijo de Ahmod, lijo de Faid, ol de cordoha, que so canserva la legra en el codice dol to. Ill de la Tecmila exlgtesto en el Cajto. y iel tjue canemos fologra-

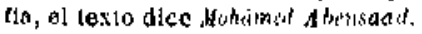




\section{$-151-$}

Comunicadas al califi las conquistas $y$ adhesiones obtenidas por sus dos hermanos en Alaudelus en ocasión en tque se lanbín reunido en Marruecos numerosas herzas procedenles de los áobiernos de Bugia y 'Tremecén, revisadas éstas, el califa Abuyacub Ýusuf se dirige á Fsparia, dejando en Morrueros de lugarteviente á su hermano A buimrán.

Llespado el califa Abuyacubá España, se instala en Córdoba entrado yo el año j67 y desde allí se traslada luego á Sevilia, donde le encontró su hermano Abuhats al volver de su campana contra la región de Murcia.

El rey I.obo, descie la defección de Abenhemochico, al ver que las fuerzas de éste $y$ su prestigio sc unían á los almoluades, comprendió la imposibilidad de que su ya mermado reino se sostrviese por mucho tiempo contra las fuerzas almohades, y aunque sin duda había nombrado Príncipe heredero a su hijo Hilel, pueg así consta en mosedas desde el año 564, al tener noticia de la llegada a Sevilla del califa Abuyacub, se dico que decryó su ánimo, y que habiendo entermado, murió el 29 de Racheb del año 567 


\section{$-152 \multimap$}

(27 de Mlarzo de 1liz): otrus dicen que le envenenó su malre', poriue habiéndole reprendido durawente su conducla con su founilia, servidores $y$ magnates del estado, el bijo llegó á amenazarle, y la madre, temiendo su violencis, le envenenó.

Había nacids tbennerdanix en Peñ́scola en el año sls; ienía por lanto 49 años cuando murió, dijazdo marios lijos varones. Abdeidathid (pig. Lsi)) pone los nombres de ocho, y hace ademés mención de dos hijas, de las cuales una casó con el calita Abuyacub Yúsuf, $y$ la otra con su lijo $y$ sizcesor Abuyísul Yucub.

Muerto el rey Abenmerdanix, su hijo $y$ sucesor Abulcámar Ililel, conlorme á las indicaciones que recilicera de si padre, entró en la obediencia de lus almolrades, á cuyo electo el príncipe Abuhaís se dirigió a Murcia de la que tomó josesión, siendo enviados á Śtuilia Hilel y su familia, á quienes el califa hizo moy buena acogida, como lo confirma el liecho de que luego se casara con

\footnotetext{
1 Aleojolican, colin. del cuiro, in. It, pág. Fu,

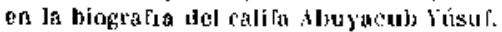




\section{$-153-$}

una de las hermanas de Hitel $y$ ol que contaru carsos importantes a rarios individuos de la familia.

Después de una expedición poco feliz contra C'beda ó Hrete (36), el califa se dirigió á Murcia, y vuclto á Sevilla, ja en el aino 568 entab:ó cordiales relaciones con el destronado ó dimisionario rey de Hurcia, y se casó con su hermada ', dando á su tío Yúsuf el maudo de Yalencia, que habia grobernado bastantes añes antes en nombro de sn hermano el rey Lobo.

$\Lambda$ ños despnés, en 575 , aparece nombrado jefe de la cscuadra, mandado una expedición contra Lisboa, Günim lijo de Abenmerdanix ${ }^{2}$.

1 Sugrin ol lanurlo smonimo de Copenlague.

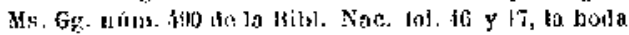
s" verificé el sábzato, cincen de Rebia primero del dionsto.

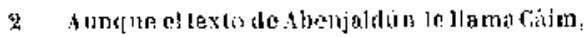
creo será fónim, ubo de los ocho hermanos, yuo menciona sbolubhid el Yarrecoxi. 



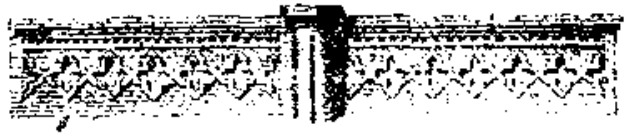

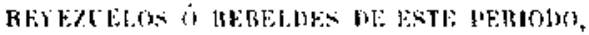

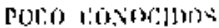

Abenaljatib: al dar cuenta de los rebeldes de este períndo contra la dominación do los alworavides, lace mención de alrzuos do

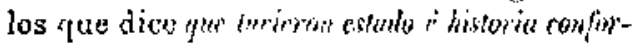
me a la importania de sit reyin, pero que no puede tratar do todos ellos, y que se limita a compendiar la listoria de Abencagi 1 que conan so ha visto, es el más importenle por haber sido el primero que so rebeló contra los almoravides, y el que simboliza la rchelion en el Algarbe, $y$ en torno del cual so

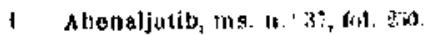


agruparou casi codos los demús rebeldes de esta región.

De alfunos ro estos personajes se dan olgunas moticias por jucjdencia. por su relación con los lıechos más inporantes de este período: de olros, como de I,elid, hijo de Abdala, señor lio Santarén, de Mlumed, lijo de Jachar el Nilinianí, $y$ de Merif, el Merodeador (s), no encuentro monción en parte alguna: 7ay olvos cque, mencionados también por incislencia, merecen alecín esturtio aparto, y por eso ponemos á continuación lo que de ellos hemes porido averigurs.

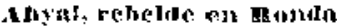

Ahyal, lijo de Jdrís, el de Rooda, fué secrelario de Abuchâfar Handín, mientras ćste fuć cadi; cuando Abeoranis entro en Cordoba echando a Abenhamiin, Ahyal se refugrió en Runfla, su país na ta1, declarándose independiente por my poco tiempo, pues los de Ronda entraron en negociaciones con Abulgamar, hijo de Asaib Abengarrín, que en Jerez y Arcos seguía bajo la obediencia 


\section{$-157-$}

de Abensandín: temniradas las negociaciones, Abujamar quedó dueño de la cilebre alcazaba de lioula sin combule, por habússele entregodo thyal sin resistenciu, fándose de cl y sarásdose con lo yla lexía to mano; sin embargo dbulgamar sayueú las casas de los partidarios le Alygal, y luego negó la obediencia á Abeuhamdín, obedecióndole las fortalezas inuncuialas y aserurándose su juando.

Respecto á Ahyal, hay quien dice que fué encerceiado por Abulgamar, pero que luego le puso en libertad, y que se neogió en Málaga juulo á Mbulbaupem Abevhasía y que desde alií pasó á .Iarruccos.

Por las relaciones con Abucháfar Abenalía, Ahyal recabró sus riquezas y despuŕs fué cadí do Córdoba y Sevilla, donde ruurió en el año 5606561 ' : era clocueate $y$ enlendido y se conservan de ćl algunos versos ó indicaciones de haber enseñado en Cúrdoba?.

1 nows. Viclices, par. 212.

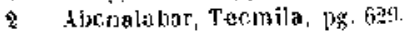




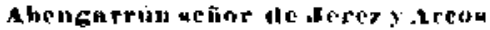

Entre lospersonajes de quienes dice $A$ benaljatil que en este período de revueltas tavieron mando independiente, cita á Abulgamar Abengarrín á quien llarna señor de Jerez.

Poces son las poticias que de este personaje encontramos: por lo dicho al dar noticias de Ahyal, señor de Ronda, resulta que Abulgamar, hijo de Asaib Abengarrún, como le llama thenalabar ' fuá señor de Areos $Y$ Jerez, bajo la obediencia de Abenhamdín. de la cual te separó cuando. echado Aben-

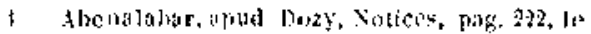

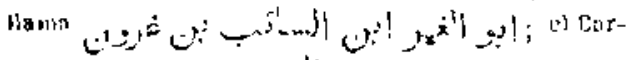

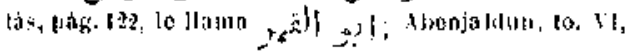
pats. 2is,

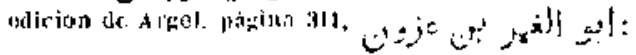

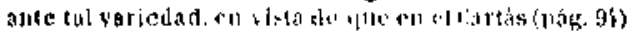
y Adabí (pag. 3i) enconiromos ritacios jos

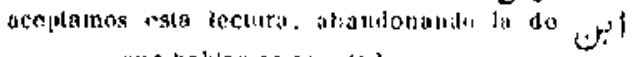
$c=1,20$

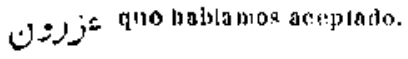




\section{$-159-$}

liamdíu de Córclcba por Abengania, A bengarrún se apoderó de Ronda, después del brovisimo reinado de Aliyal.

Mug poco tiempo debió de ser Alulyawar seño de Jeres, Areos y lionda, pues en Jere\% reconoció en al mismo año j 10 a los alcobades, sicado esta ciadad la primera que prestó obediencia á los nucvos conquisladores, por cuje circunstancia, cuando de Españis llegaban mensajes á los califas almohades, los coviados ó representantes de Jerez eru:1 recihidos los primeros.

Corno se lá dicho en la pán. is, al tralar de la retselión general en el Mgarbe. poco despuís de loberse sometido a los almohodes, Abujgamar fuc el único jefe que permanecí́ tiel y, unido a los hermanos do Almelidi, que labian teaido que refugiarse on Bobastro, contribuyó eficazmente a que los almoharles recobra ran a Algeciras.

Niste mismo personaje es el rut en el ano 545 estaba de alcaide en Cócdoba, cuendo fue siliada por el emperador D. Alfonso. cuya estratagrema de somprender al ejércilo rue iba en atxilio de los sitiados supo bur- 


\section{$-160-$}

lar AJulgamar con su perspicucia, comprendiendo la falsa retirada del enemirgo, por lo que hiza que el ejército auxiliar misase á deslora en Córdoba antes de que pudiera ser acometido por D. Alfonso. (37)

Rechazado de Córdoba D. Alfonso á la llegada del ejército de lus alroohades, mandado por Yahya itbengagnor, y gracias a las prudentes observaciones del alcaide A bulgamar, los jefes rebeldes del Algarbe se apresuraron á pedir el amán (la paz), quo Abdelmumen les concedió por mediación del reneral Yahya Abenyarrmor, presentándose al califa en Salé, renunciando ó sus mandos: allí. se presentó también Abulgamar, siendo la vilima noticia, que de él encuentro, lo indicación de haber mierto mártir á la vista de Serilla en el año 553, 1 donde también murí Abcalhacham, de cuien vamos á tratar.

\section{Ahenalhagliam roy de hatujos}

La porticularidad de que Abenaljatib, al mencionar de paso los rebeldes contra los al-

1 Abenjaldia, to. VI, pag. 237.-To. II, pán. 14x de la tradteclón de Slane. 


\section{$-161-$}

moravides, que en este período se declararon independienles, cite á Abenalhacham, llamándole Mohámed, hijo de Alí Abenallacham, nos ba hecho caer en la cuenta do una de las particularidades de este personaje, de quien tenemos pocas noticias.

No encontramos que figurara en los primeros momenlos de la rebelión contra los almoravides, $y$ podemos suponer que por de pronto vo figuró, ya que se cila como señor de Badajoz á olro de los personajes, que más figuran en este período, á Sidrey Alrenuazir: de Mohámed, hijo de Alí Abenalhacham, como le llama dbenaljatib ', no encuentro mención hasta el tiempo de la primera rebeJión de los jefes españoles contra los almohades, después que Abengania hubo recobrado de éstos á Alggeciras; puess entonces Mohámed Abenalhacham, como le llana Abenjaldún 2, se adhirió en Badajoz ul movimiento insırraccional; pero luego, cuando el nuevo ge-

1 Mз, Аг. de la Academia, X, 3, fol. 2000 yer. y 47 ale mi copia.

2 Tomo YI, do la edición del rairo, jáx. 234, y jág. आA del tomo 1, te ba edicion de Argel. 


\section{$-162-$}

neral Yúbuf hijo de Suleiman pudo tomar la ofensiva y hubo sometido a los rebeldes ó reyezuelos, el Pelrochí, señor de Niella $y$ Tejada, Ahencasi de Silves, é Isa Ahenmaimún de Sarta María, Mohámed hijo de Alí Abenalbacham señor de Badajoz envíó regalos, que fueron aceptados (es decir, so somelió como los otrost, quiźa anca volvieron todos á rebelarse; pues Abenjaldún labla de una anera pelición de amán, dirigida por los rebeldes por intermedio del nueva general Yahya Shenyugroor, al ver que el Einperador ó sus tropas se retirahan del asedio de Córdoba (esta ya en el ano 544 ó 545), y en 545.) Abenallacham y los demás reheldes mencs Abenessi eran recibidos por Abdelinumen en Solé, renunciando, patece que de un modo detivitivo, sus pretendidos derechos.

Ya hemos visto gue $\mathbf{A b e n o l h a c h a m ~ m u - ~}$ rí6 mártir á la vista de Sevilla ce el año 553 al mismo tiempo que Alyalganar A bengarrín.

Una prueba de que Abenalhacham se consideró como rey independiaute, la tenemos 


\section{$-163-$}

en los preciosos dinares que se acuijaron en su nombre un Badajúz eu el año 543 , conervando por completo el tipo $y$ leyendos de las monedas almoravides !

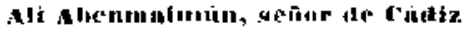

Otro de los jefes reljeldes, que tuvieron estado é historia conformo á la importancia de su rérion, es Alí, hijo de Jsa Abenmaimún, señor de Cádì, de quien sc ha hecho mención al tratar de la rebelión reneral en el Algarbe.

Aimirante de la escriadra do los almoravides en Cádiz? Ali, hijo de Jsa Abenmairaĺn, á la wuerte de l'exufín se rebeló en Cádiz y se presentó á Abdelıumen, cunando eslaba sitiado á ['ex, entrando er su obediencia en el año $5+0$.

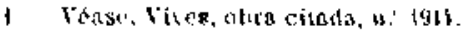

9 según Almacari, to. I, pág. 113 , era hijo do

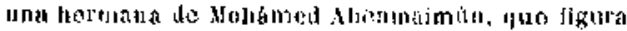

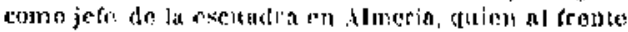

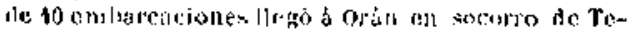

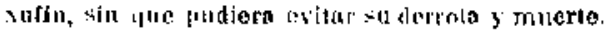




\section{$-164-$}

En este mismo año, y quizá despuéa de negar la obediencia a los almoravides, mandó derribar el ídolo de Cádiz, de cuyo hecho no da detalles el autor del Cartás 1 : ajyún autor dice que al derribar el ídolo, Abenmaimún esperaba encontrar en los cimientos un tesoro 2 .

Como Abdelmumen no hubiera querido conteslar al mensaje de Abencasi, cuando éste, enviaudo como mensojero á Abubéọuer Abenhabis, buscó por primera vez su protección, pero sin renunciar á sus ridículas pretensiones, al menos en cuanto al título, Alí Abonmainún, ardiente parljdario entances, segúa parece, de los almohades, aconsejó á $\Lambda$ beucasi que se presentase personalmente, como lo hizo, probablemeote con recomendación de Alí para el goberuador de Ceuia Yúsuf $A$ beumajluf, quien le prestó facilidades pura presentarse al califa.

Al tiempo de la primera sublevación generai contra los almohades, también entró en

1 Curicis, eti. Toinhers, jag. 1\%.

2 Alenzuist, to. II, páp. 370. 


\section{$-165-$}

ella Abennsimún, y es la última roticia que de ćl cacuentro, á no ser que esté confundido con Isa $M$ benoajmús. que podría ser su pal’re, y Ggura cowo señor de Sunta MTaría, y probablemente de Tavira pues une asescrta Abenjaldún ', que después de liaher sometido Yúsuf hijo de Suleiman á los rebeldes de Niebla y Silves, acometió á Tavira y le prestó obediencia Isa Abenmaimút, señor de Santa Marsia: cundo en 545 se presentan en Salé los rebeldes y renunciun sus derechos en robzos de Abdelmamen, no tiratia cutre ellos este Abenmaimún, que quitá leubisra muerto, ya gue hógura como señor de Tavira un Amil Abeumohib, que no encontramos mencionado en olra parte.

1 Tumo 1, da la edi. ales Argot, pog, ill: en la

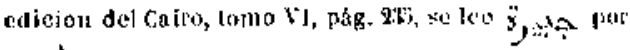
ât 



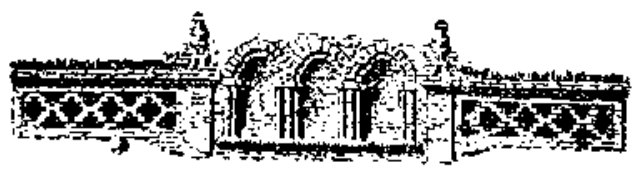

\section{JAS BALEARES \\ BA.TO LOS AI,MORAVIDES}

De los rcinos llamados de T'aifas, constituítos á la desaparición del califato de Córdoba, uno de los primeros y de los más jmportantes fué el de Denia $y$ los Islas Orientales, fundado por Mochéhid, cliente de la familia de Almanzor: muerto Nochéhid on el año 436 de la hégira, le sucede en el mando eu hjjo Alí, y al ser ésle despojado de su reino por su suerro Almoctadir, rey de Zaragoza, en el ano 468 (16 de A fosto de 1075 a 4 de Agosto de 1076), las Islas Orientales, sin que seprmos cómo, se constiluyen en 


\section{$-168-$}

reino independiente, cuya historiu no podemos estudiar en este capítulo, dedicado al estudio de la de las Baleares brjo el dominio de los almoravides.

En el año 1114 (507 y 508 de la hégira) reinaba en Mallorca Mobáxer Nasirodaula, cliente que había sido del rey de Denia, Ali t: con sus piraterías, cosa corriente durante toda la lidad Mcdia y aun Moderua entre los missulmanes de los Eslados mediterróneas ", infestaba las coslas de los Estados cristianos, por lo que Ramón Berenguer III, conde de Barcelona, Aimerico, vizconde de Narbona, y Guillermo, conde de STompeller, constituyeron en este año una liga pera reprimir á los corsarios de Mallorca; pero siu duda hubo de fracasar, y los atıos despoés, cou el apoyo dal Papa se constituyó

1 Baycin aimogrit), to I, p. 314.

1 En el aĩo nutcrior, en el mes to Rebia posErero, halian llegado a Almehdia icn la achal kosen-

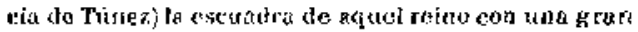
cantidar de esclayos o prisioneros ristianos, de chya llegada se olezró mu'ho el rey ranya, lijo do Te-

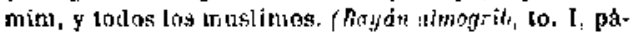
gina 316). 


\section{$-169-$}

otra con ce carácler de Cruzada 1, á la cual se adbirió por circunslancias imprevistas el mismo Rámón Beredguer I]T, ciýas armas, unides para este fiu á las de Génova y Pisa. se apoleran de Mallorca despnés de vil fuerte y largo sitio, dando muerte á la grarnición $y$ laciendo cautiros a las mujeres $y$ Diùos?

Como Hobaxer, al verse sibiado por los cristionos, había pedido auxilio al príncipe almoravid $\mathrm{Ali}$, éste, que ó no pudo ó no quiso auxiliar á liempo á los sitiados, muerio Mobáxer, y cntregada Malloren á los cristiaacs después de la plisión desu sucesor $\mathrm{Abu}-$ rcbia Suleiman, envió una numerosá escuadru, y los Genoreses, que parece habían quedado solos depués de sometida la Isla, bien porque no se creyeran con fuerzas para

1 Abenjastún, tom. If de la traduccion de : Same, pág. 206, nota.

2 Respecio a la recha de la conquigla do Mullorca puede verse to que so dice en la ilustracion N. 16: respecto a los prisioneros cogidos por los criatianos, phede consultarse la obra Bosquejar fistérito de

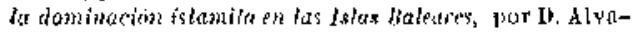
ro Campacer, pug. $\$ 1$ y zro. 


\section{$-170-$}

registir á las armas de los ałmoravilies, ó porque no tuviera interćs en conservar hajo su dominio las Jslas, abondonad á Nallorca, con lo que los almoravides vinieron a ser dueños de ella sin resistencia. (38)

Recobrada Mallorca para el islamismo por Alí hijo de Yúsuf, enría, ó entra cu clla Vanudía, hijo de Sir, en el mismo año 509 y la gobierna durade tres meses, sucediendole lueso en el mando Abubćquer Jieratat 6 Tecratar, á quien sucede Yabur 6 Linnur, hijo de Molıamed, contra quien se subleva la nobleza, dándole muerte, sin que el autor nos diga la causa; otros dicen que por haber intentado que se construyese ó reparase la ciudad lejos del mer, los de Mallorca se sublevaron y que ljanur dió muerte al jefo de los amotinados, quiencs le encercelaron $y$ enviaron mensajeros á dar explicaciones al príncipe Ali: después del mando de Ulanur, se encargŕ del gobierno de Mallorca Abubéquer lijo de Alí hijo de liarafe", "quea mu-

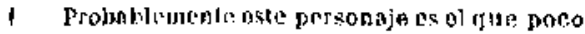
lespaes fyura como guberuador de valencia cor el 
rió tricuicado el mando, probablemente en el año 320 , en que se juagrira te: las Islas el gobiemo de los Benigania. (39)

\section{Mohnmed abenganion. S24 in 516 o 330}

Cuundo en el aj̄o 520 Alí lijo de Yúsuf dió el gobierno gederal de Alandalus ása hijo Texufin, éste se encargó del mando de toda la Fopañu musulmana menos de los Islas Orientales, para euyo gobierno fué nom-

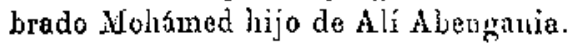

Muy poco sabernos de la historia de Mullore dusante el robjierno de Mlohámed, tunto en los primeros años, en que indudablemente se consideraba como simple gobernador, como en los posteriores, en que desapa-

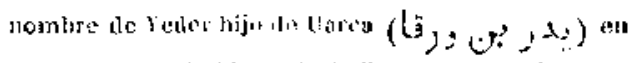
Abenaljatibula la bjonkrafio de Tahya Abengania, á cul. ya exaltarion contribuyo uo poco por labers rectatio-

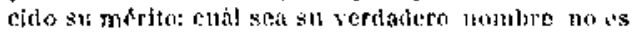
bacil fijarks, dodu la discrepancin de los dos textongen

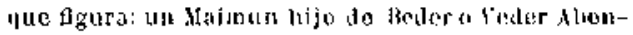

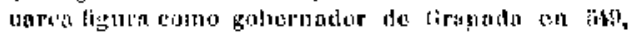

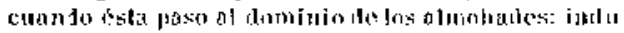
Najplenente es de la mismo familis. 


\section{$-172-$}

recida la dinaslía de los Renitexufín en el año 541, debió considcrarse, al menos de hecho, como verdadero rey, bien reconociera la soberanía espiritual de los Abasiclas de Oriente. como la habían reconocido las lienilexufín. bien gobernase como presidente ó jefe del Consejo!.

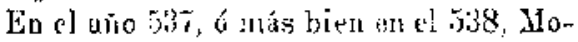

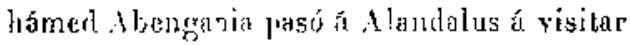
á su hermano Yuhya, nombralis goberuador gencral de lin Jispana musulnana con resiJencio en Sevillu ó Corrloba: dot robluerno de Mallorea quedó sin carcrado durntes su ausencia Abdala Abentimacadmat: pero labiéndose promovido ajguna sedición, Mohámed lubo de regresar á su srobierno, permaneciendo en el an despućs de la desaparieión de la dinastía de los Benitexulín $y$ de la

4 E1 senstor dmari, refiriéndsse à Isher, lijo

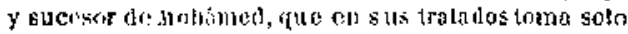

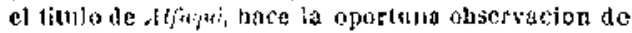

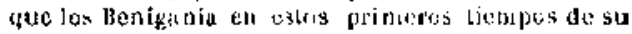

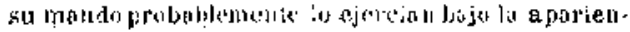

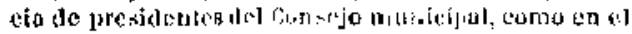

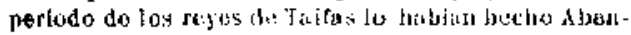

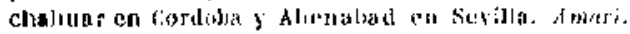

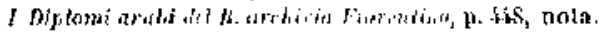


muerte die su hermano Yatyo. y desdo esta fecha, i mejor, desde que iste se retiró a Granada desposeído de todo mando, Molrámed pudo cousiderasse do laclio cono ry indepenticute de Mallorea, comis en parte lo indica cl haber nombrado para sucedcrle á su hijo meyor Abdala, pronavicudo el cuojo de в hijo Istar, que dio muerte a su harmano, y también a sa padre, sorgía algún autor, si hien se dice gua el padro murió márlir on guersa con los cristianos en el año äti 6 $5 \mathrm{~s} 0 .(40)$

Tenemos otro indicio de ilue Mohámed Abeggania oluraba en realidad somo rey on cl hecho da haberse eutahluclo en los íllimos bios de su vida rehiciones ofiejales eatro Mullorca y las Repúblicas de Ganova y Pisa. firmándose un tratado de comercio con la primera eu el eño $1149 \mathrm{y}$ en cl siģuiente con Pisa!.

Durante el roinado de Ilolímed Abon-

1 Anuri, obra cilada (post. XXVb) dies, ,i primi

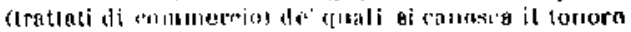

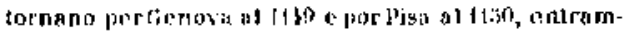
bi con yaiorea.." 


\section{$-174-$}

gania en Mallarca, su hijo $A$ brala estusso algún tiem po de grobernatior militar en Yalencia, donde ene encontraba cuanto la subleva-ción general contra los almoravides, la que no pudo contener ai aun en 'alencia, retirándose á Játi ca y huyendo lıego à $A$ lmería I como se dijo al tratar de la rebelión de Vilencia, pán. $] 03$.

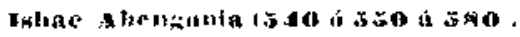

Poco y malo es lo que sabemos del gobierno ó reinado de Ishac, rue si jlepó á las gradas del trono por medios infones, dando muerte a su mismo puxtre ó al menos á su Jermano $A$ bdila, uzu vez desenbarazado de cllos, sospechando que los famtuníes, sus cómplices, hal,ian acordado deshacerse de al. como era verdad, según Abenjalchún, puesto de acuerdo con el almirante Lop Abonmaimún ${ }^{2}$, los sorpreadió en sus casas y los hizo morir.

Desaparecido por cusapleto al imperio de

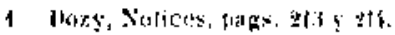

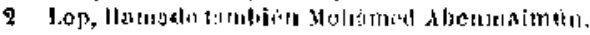




\section{$-175-$}

los almaravides en lipaña y en Marrueces, si ya su padre lohámed pukto de hecho considerarse como verdadero rej, con más razón podía hacerlo lskac, quien sin embargo en los tratitilos que celebró con Cínoro y Pina no sc dió lítulo de mirir, cono to lizo luegro su hijo y sucesor Abdalia, sino de al/otui, gobernandr quizá á nombre del Consejo.

De su reinato se conservan preciosas monedas do oro, actunadas en Muthora en los años 565 y 567 I, si bien en ellas ro puso su nombre, quizít por no darse oficialmento aires de rey: las monedis estín armunados. siguiendo el mismo tipo de las cle los almoravides, an lo sue podramos tener una prueba de que por este tiempo no tenía aun los tendencios almalades. tque on los allimos años de sa reinado le alribuyo Abenjaldún. al decir que enviaba ol califa Abayecub los prisioneros y cristianos?.

En los primeros años de su ruaudo Ishuc

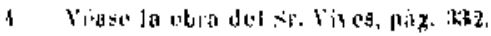

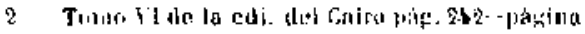

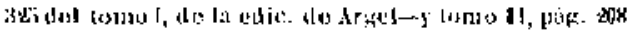
dt: la Iradarcion de' Slane. 


\section{$-176-$}

Abengrania se dedicó á las construcciones y plantaciones, cuya frase interpreta e! Barb́n de Slane, dicieudo que se hizo construir palacios y plantar jardiues: su gobierno debió de ser tiránico, pues se lice que angustiadas las gentes por lo mul que grobernabs, Lob Abermaimún, que le labía ayudado al principio en el sangriento custirro de las conspiredores, se pesé a les almohades.

lin los îltimos yños de su vida volvió su atención á las cosas de la gruerra, haciendo dos incursiones anugles en lerrilorio de cristianos, del que, como es consiguiente, apresaba muchos cautivos, que enviaba al colifa Abujacul, al cual se dice que llegro á ofrecer reconracerle, y poco antes del cual murió en el año 580 I. (41)

Couforme con estas indicaciones tenemos noticia de dos cxpediciones pirilicns llevadas á cabo por Ishac en los últimos años de gu mando, $y$ por una de ellas varmos cuán grandes eran su atrevimiento $y$ audacia: en

1 La particutaridats do atua su merta ocurriera

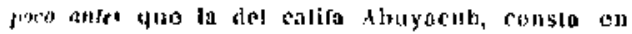

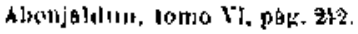




\section{$-17-$}

el año ll78 (574 de la hérerira) encontrsmos mencióa de dos de sus incursiones, la una en el mediolía de lirancia, la otra en las costus de Cataluñe: la primera dirigida por el rey en persona, la otra no lo sobemos.

Fin el año 1178 Abengania acomete $y$ toma la ciudad de Tolón, haciento muchos prisioneros, que fueron llevados a Mallorca, cucontrándose eulre ollos ligo Gaulredo vizconde de Marsella y su nieto.

En al mismo вño, en el dia 27 de . Iurio, los moros mallorquines, 'puisa los de la misma expodición, sopprenden la Jerlesia de Santa Maria de [ lia, en la actual provinciu de Gerona, cuyos canónigos unas fineron muertos, y otros blevados cautivos a $\mathrm{Ma}-$ Horea. (42)

Si Moliamed Mheugania labía llerrado a podorse considerar como rey, ya rque como dice Abdelualid so asemejuba á allos. y como tal liwo tratados con las liepriblicas de Génova y Pisa, en mejores condiciones se cncontraba su hijo Ishac, que entraba a gobernar un estado ga constituido y como reconocido, así que podia suponerse que las 
relaciones diplomáticas se habían de renovar con aquellas Repúblicas.

$\mathrm{Y}$ efectivamente hay noticia de que en el año 1161 trat́ó con los Pisanos, con quienes no se sabe que firmose la paz hasta el aúo 1173 y de nuevo en 1184 , siendo probable que á las negociaciones de 1161 siguiese algún tratado, desconocido hasta hoy, y del que fuese renovación el de 1173.

Del tratado de 1184 conocemos el texto arabe y un extracto latioo, publicados por Amari 1: tanto este tratado con Pisa firmado muy poco ontes de la muerte de Ishac, como al conclúdo con Gínoya tres años antes, en $1181^{2}$, son vagos y las partes contratentes sólo se obligan á no hacerse dano mutuajuente y á proterrer, ó más bien, á hacer respetor á los náufragos: en el tratado con Pisa se incluye lambrién a los nalurales de la IRepública de Luca.

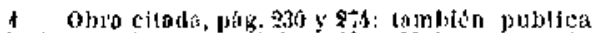
en árahe y lolín, on las popiugs is y 273 , jo carta on la que el rey conounca lo lifn:a le! tratado al Al\%obisto, coneulfi, anciatorg golables do pies.

2 Publicodo primero por 1) Sucy puede verso

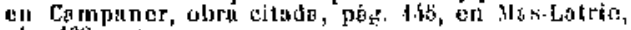
pág. la y otros. 


\section{$-179-$}

Quizí ya en eslos tiempos las Repúblicas comerciales del Mediterráco, para proteger su comercio, constantemente amenazodo por los piratas musulmanes, pagasen tributa on forma disfrazada de presentes ó requalos, como ha sucedido en los liempos modernos, casi liasta nucstros días. (43)

Las circunstancias de la muerte de Ishac son desconocidas: hay algues indicación do haber muerlo ó sido herido gravemente en una incursión en país eristiano; así lo dico Abdelúahid, auuque por lo menos equivoca la fecha diciendo fać á principios del año 579: secrín $t$ bemalabar parece que murió on une sublevación de los ceutivos cristianos, que liabía en pracio. (44)

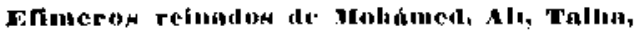

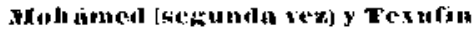

Muerto Íshac Abengania en el año 580 , como a ueda indicado, dejando varios hijos, la historia de Mallorea se complica en el interior, y en el exterior llega á toner gran importancia; pues acometiendo los inullortuines bajo la dirección de los hermanos Alí y Yál. 


\section{$-180-$}

ya, la parte orienial del imperio de los almohades, llegan á hacer bambolear á los sucesores de los almoravides 1; pero la historia de estas alrevidas expodiciones en el período do 53 años sale de los límites de nuestro trabajo, y sílo debemos ocuparnos en la invesligación de lo que á Mlallorea ó las Islas se refiere: esto no deja de ofrecer graves difieultades, pues las noticias referentes á los primeros sucesos que on Mallorea se desarrollan, son contradictorias, ó lo pasecen por incompletas.

Na resulta clara si Ishac Abeugania llegó á prometer sumisión al califa Ajuyacub Yúsuf, 6 fuć su lijjo $y$ succsor inmediato Moháned, quien en su caso delitó hacerlo inmediatanente después de su proclumación, toda yez rucurles de los dos meses muere el califu después de haber euviado á Mallorce a Alí hijo de lieverter.

Fiste Alí, cuyo padre lieverter, fué general de los almoravides en los íltimos tiempos, muy querido y cossiderado de Alí,

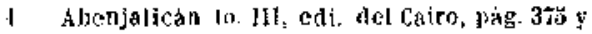
sizuicules. 


\section{$-181-$}

hijo de Tóisuf, y do 'l'exafín, su lijo y sucesor ', fué onviado por el califa Abuyacub a tomar posesión de las Islas, cuya sumisión hiciera cl nuevo rey Nohámed; pero an les de que se hiciera cargo del mando, disgustados los hermanos del rey de la sumisión al imperio de los almohades, se apoderan de $\mathrm{Ml}^{-}$ hámed y del enviado del califa, y encerrándolos en el alcázar, proclaman rey á su hermano Alí: esto debió suceder entre el 19 del mes de Safar, fecha en la cnal vivía aún Isbar, y el mes de Kebin 2. ${ }^{\circ}$ en que muere Abuyacub á consecuencia ó despliés de la batalla do Santa'én ?2. (45)

Llegada á Alí la nolicia de la mucrte del calin̂n Abuyacul, y la proclanación do su hijo Abuyúsuf Yacub, titulado Almansur,

I Respecto a esto singular perbonaje, puedi verse bozy, hewerches, 3." di. tomo sli, pag. 3 th.

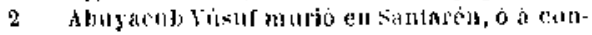
secucucia de la expedicion de sautaren ell Rebja $1 .^{\text {th }}$

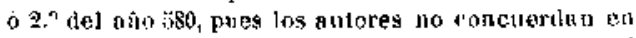

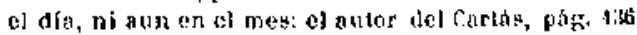

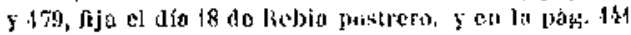
dice [u e e 2 del misno mis:-Amed snasiri, to. 1 ,

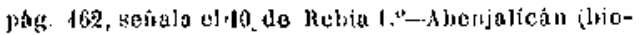
frafia 8: 
resuelse llevar la guetra contre los almohades á las recinas costas ofricanas, se prepara rápidamente, y en el mes de Xabán, dejando on Mallorea á su hermana Talba, que aigunos llaman rey, sale para Bugía, de la que se epodera el vicroes $t^{\prime}$ de dicho mes ${ }^{1}$. (46)

Alí Abenteverler, que liabía quedado preso ea Jallorca, al portir para Bugía los dos hermanos Yahya y Alí, á pesar de la vigilencia, que con él se tevía, consiguió sobornar á la guerdia y al pueblo, proclamando al destronado Mohámed, que sale de la cárcel para emupuña el mando por segunda vez ${ }^{2}$.

1 Abenjutdill, 10. I, pag. 3is. edi. te trkel,-

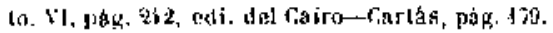

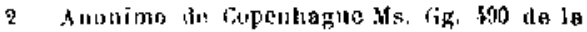

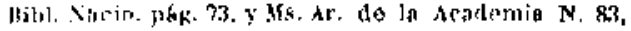

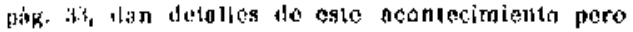
for slestaras paco concrotos respecto it personajes: fos mayores drsulles so rojleren a las megociociones

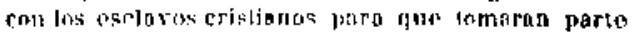
neliva en i mosimiento: rn al codice ale la Jiblialeca Nacional falta ta ruilad tel texto. A esta reledion pue-

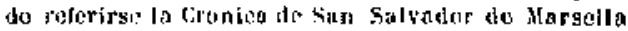

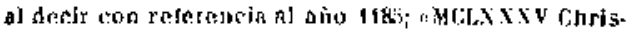
liani ceporum Palstitm civilntis Majoricarum at fuerunt flberoli a captivitate", sunque como so alice en la llustracion th pueda rejerirse a otra rebolion en of mismo ano, ol liompo die la muerte do lshac. 


\section{$-183-$}

Segría Abenjaldún I con la restauración de Molnámed fuć proclamedo el califa almoLade Almausur, quieu enció á Mallora una escuadra á las órdeues de Abinala hijo do Chamí para que tomara posesión de las Islas; pero Molámed, desaprobando to hecho por sus partidarios, $\delta$ arrepentido de lo acordado, se apuso á elto, pidiendo auxilio al Conde de Barcelona, quien le facilitó el que pudiora alistar un ejćrcito de calalanes: esto disgustó más á sus partidarios, quienes temiendo á Almansur, echaron do buevo a Mohamed, proclamando á su liermano Texufin.

Alí thengania, en realidad verdadero ray de Mallorea desde la prisión de $\lambda$ lí Abenreverier, al marchar á Bugía con su hermano Yahya, había dejalo on Mallorca de gobernador 6 lugarleniente suyo, á su hermano 'Tallia y en cusnto tuvo nolicio en Constantina ó en J'ripoli de la sublevación llevada á cabo contra éste y el restablecimiento de su hermano Mohámed, fuera ó no destituído de nuevo y remplazado por su hermano

1 Tomo I, pas. 2är do la edi, dito Arged. 


\section{- $184-$}

T'exufín, envió á Sicilia á sus hermanos $A b$ dala y Algaci, quienes desde allí se embarcaron para Mallorea, de la que, entrando en relación con algunos de la ciudad, se apoderó Abdala sin gran dificultad, quedando destronudo Texufíc, ó quizá Mobámed, pues no conceptuamos seguro el reinado de $\mathrm{Te}-$ xufía 1 .

Proclamado Abala como rey de Hallorea, probablemente yo entrado al aizo 583, ch califa Almansur intentó varias veees apoderarse de su reino, enviando sus escusadras contra $\mathrm{Ma}$ llorca a las órdenes de Abdala hijo de Chamí y lucgo á las de Yalyo, hijo del jeque $A b u-$ ibrahim el Hazrachí pero los de Mallorea se defendiecon con resolución y con ixito con muerte de muchos almohudes $y$ con esto se fortificó el poder de Abdala.

Por el mismo liempo en que se desarrollaban en Mallarea estos sucesos, hay noticia. vaga de haberse apoderado de Ibiza en el año 583 el capitán Abulabás el de Sicilia, haciendo prisionero al capitán Abennachal

1 Aborjatatin, Jo. 1, do ln edi. de drgel, p. 3.32. 


\section{$-185-$}

el de Iallorca: quien se había pasado de las banderes de Abegcrania á las de los almohades, con quienes babía roto después, enganando también à los de Ibiza, de cuya isla se lizio dueño!.

En el año 584 de la hégira, sin duda luego de quedar Abrala instalado de un modo definitivo como rey de Mallorea, firmu un tratado con la República de Génova; pero quizá no hizo más que copfirmar lo pactado por su padre poco untes de su muerte, y que probablemente no habría sido observado al meuos por parte de Mallorea, Atendidas las revueltas que en ella habían tenido lugar en el período do cuatro anios: la paz entre la República de Génova y Abdala como emir de Mallorca se firma en el mes de Chumade postrero del año 584 (28 de Julio á 25 de Agosto de 1188) y el plazo fijudo de 10 años, debía comeverar á contarse desde $10^{\circ}$ del mes de Safar del mismo año (1." de Abril de 1188).

$$
\text { (47) }
$$

1 Anonimo do Copenlague póg. Sh del contice de la Ribl. Nacional, $y$ pág. 37 del eodice do la tcaùemìn. 
Muerto el culifo Almansur on el ano 595. su hijo y succsor Mlohámed Anásir envia contra Mallorca una escuadra á las órdenes de su tío el sid Abulalé, $y$ del jeque $A b u-$ safd Otmán hijo de Abuha s; sitiado Abdala en Mallorca y abandonedo por su hermano Texufin, segrín Abenjaldín, murí́ en un combate!

Otros aulores fijan la fecha de la desaparición definitivo, dul poder de los almoravides en Mallorca en el año 5996600 ó 601, diciendo que el valifa Anasir salí de Marruecos en el año 598 y al llegar a Argel mandó construir (á organizur) aua excuadra y preperar los ejércitos contra Mallorca, la cual conquistó con muerte da su rey Abdala ${ }^{2}, y$ Juyendo al desierto su hermano Yab-

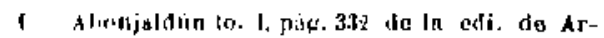
gol-Ahmed A nosiri, tomo I. phas. Th.

2 Serini Aldeluahid (jág. 231) al ser sitiada Mallorco y salju for una do las pucras de la cindac, sil rey Abdala cn estado de emhriagnez, cayo su calpallo, y le mato ar curdo llamado omar el Adolanlado: Ia tincrado do loy plmoliades el Mallorca, $y$ Ia muerte de Ahdala turieron lugar en el mes de nujhicha del ano 590 silu 11 de a gosto a 10 de Septicmbre 


\section{$-187-$}

ya: el conquistador uha vez dueño de Mallorca, acogió muy bien a los naturales dol país, que le reconocieron y ofrecieron sus respetos 1.

de 1203): á pesar do noticias lan larminantes, Horiry

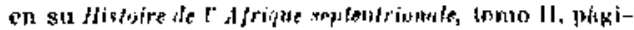
an 128 , sienta qua Abdala no murlo, y pudo ovadirso.

1 Alrondinor, pâg. 117.-Corlás, gog. $133-4 \mathrm{k}-$ med Anasiri, to. I. pág. 190.-Anónimo de fopenhoguto. Hy. (to la Mbl. Nacio. pag 135-Abonjatican. eti. del coiro, to. III, biog. del califa Abuyusus linculs, p. 陊之. 



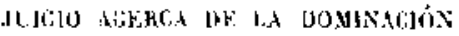

IU I.OS ALMORA YIIES EX ESUASA

Dado el imperfecto conocimiento que tenemos tanto de la historia de los almoravides como de la de los otros períodos de la dominación árabe en lispaña, no creemos ive se pueda formular un juicio definitivo, ni nucho menos, acerca del carácter do su dominación en nuestro suelo; pues un la historia externa hemos visto que está par dilucidar en gran parte: respecto a la historia interna, no menos importante, apenas si tenemos utra cosa que noticias sueltas referentes á instiuciones, costumbres, artes, agricultura, ciencias, letras, administración y demás manifes- 
taciones de la vida del pueblo: sólo respecto á las ciencias, y sobre todo, á las letras, parece que pudiéranos decir bastante; pero en rezlidad sería sólo de la parte bibliográfica, citando muchas de las obras escritas en este período y do las que se tiene noticia; pero siendo muy contadas las que hasta hoy hoyan sido oljelo de estudio, aún esta parte resultaría conocida en apariencia nada más.

A pesas de lo que se acaba de indicar, se han formulado juicios muy calegóricos $\mathrm{y}$ poco favorables respecto al gobierno de los almoravidey, y como no los creenos justilicados, a pesar de la gren autoridad de Dozy, con quien lagen coro casi todos los autores posteriores, recargando no poco les tintas, como suceda con frecuencia, creemos preciso decir algo por nuestra cuenta, ya que el juicio del sabio holondes, si al parocer muy justiticado con datos tomados de autores árabes y cristianos, en mi sentir rosulta muy parcial, sicndo esto en gran parte debido á su clerofobio aplicada al pucblo musulmán, y á su marcuda lendencia, muy común en nuestros dias, a qu uerer generalizar y deducir 
consecuencias con cscaso número du datos.

Ya al tratar de theumerdanix lemos tenido ocasión de indicar algu de lo que dice Dozy respecto al caricter taut. she la dominación almoravid, como de la almohade, principalunente cun relación a lus cristianos ó mozárabes: veamos lo gute lice al tratar de la expedición de Alfonso el Bataliador', que es quizá donde cita los ltechos más concretos en apoyo de sus apreciaciones.

-Hácia el tí del sirnto xa, cuando la Lspeña musulmana pasó del poder de los royes de Tailas al de uu príncipe a ricicao que había venido como aliado, y luego destlonó á

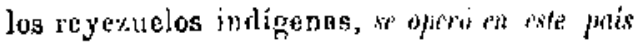

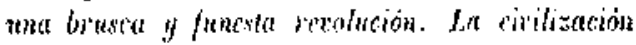

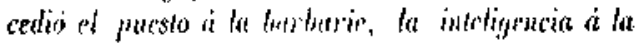
supesticion, lat tolmcit at fantismo. El país gemía bajo el régínen abrumador del clero y de la soldadesca: en lucrar de las eruditas é ingeaiosas discusiones en lag erademias, do los profundos discursos de los filósofos y de los armoniosos cantares de los poetas, no

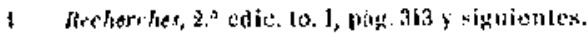




\section{$-192-$}

se oía más que la voz monótona de los sacerdotes $y$ el ruido de los sables, que arrastraban por el suelo".

«Pero si la situación de los musulmanes españoles era deplorable, la de los cristianos mozárebes lo era mucho más: con ellos los morabitos africanos no guardaban consideracion a) gruna: la tolerancia, que hasta entoncos se labía tenido col los cristiauos, les parecín criminal é impía: á sus ojos, las iglesias eran el oprobio de la Península ć iusistieron cerca del monarca en la necesidad de destruirlas: Yúsuf, casi tun fanálico como ellos, cedió pronto á sus deseas. ¿̨Qué más hicieron? Hs imposible decirlo, ya que los autores musulmanes no lo dicen y los moza. rabes de eutonces no escribieron; pero no debe presumirse que los alfápúes se dotuvicser en mitad del camino: su odio contra los cristianos era demasiado fuerte para tue no los vejaran y persiguieran de todos nodos».

"Durante largos años los mazárabes sufrieron on silencio; pero por fin, habiéndose llenado la medida hácia el año 1125, suplicaron al rey de Arazón Alfonso el Batallador 


\section{$-193-$}

que fuese á libertarlos del insoportable yugo que sobre ellos pesaba, y Alconso respondiendo á su llamamiento marchó hácia Andelucía».

El mismo Dozy, insistiendo en lo que había escrito en los párrafos transcritos, dice 1, hablando de los príncipes almoravides: "Los tres príncipes de esta dinastía, que reinaron en Espania, Yúsuf, Alí y Texufín ergn extremadamente devotos: rodeaban á los alfaquíes de toda clase de respetos y lomenajes, y nada hacían sin haber obtenido antes su uprobación: pero la palna en este modo de obrar hay que concederla á Alí: la casualidad se hajía equivocudo, haciéndole nacer sobre las gradas del trono: la uaturaleza le había destinado á una vida de reposo y piadosa meditación, paro el claustro ó para la vida eremítica en el desierto: durance siu vida no hizo más que orar y aphor: como era natural, los alfaquíes se felicitaban de esto: ellos manejaban al monarca como querían, gobernaban el estado, disponían de tados los car-

1 Hísticire des musulmans, 10. IV, pag. 2 is y sigruienles. 


\section{$-194-$}

gos, con lo que a tesoraban inmensas riquezas, en una palabra, recogían el fruto que se jabíau prometido de la dominación almoravide, y quizá la cosecha sobrepuịaba á sus esperanzas».

Más adelante, fijándose en el hecho más concreto de intulerancia, que nada tenía de particular, dice 1: «La intolerancia do los allayuíes traspasaba todo límite y sus miras eran rauy estreches: poco versados en el esludio del Alcoráa $y$ de las tradiciones relativas al Profeta, no conocían más upue los escritos de la escueja de Málic, que consideraban como autoridades infalibles, de las cuales no era lícilo apartarse: en realidad su teología no cra olru cosa rate uy conocimiento minuciosa del derecho conónico: en rano los teólogros un poca illastrados protestaban contra este exclusivismo en pro de cuestiones y libros secundarins: la persacución era la única respuesta y se les tachabo de heterodoxas, cismáticos ó impios: el libro que cu Oriente había publicado el célebre Algazalí con el

1 Ohro cilada, pág. $\tilde{2}$. 


\section{$-195-$}

tílulo de liesurecrion de las ciencias religiosas, causó un gran escándalo en Andalucía, y sin embargo no esa un libro heterodoxo... El cadí de Córdobe Abenlamdín declaró que todos Jos que habían leído el libro de Algazalí eran infieles y coudenados, y escribió usa consulta juxídiea (fctua) probando que todos los ejemplares de tal obra debran ser quemados:, suscrita la cousulta ó informe por los alfarquíes de Córdola, fué presentada á Alí, quien la aprobó. En consecuencia de este decreto el libro de Alrazalí fué quemado en Córdota y en todas las ciudades del imperio almoravide, prohihiéndose bajo pena de muerte y confiscación de bienes el conservar un ejemplar de la obras.

Hablando del estado del pueblo añade Dozy más adelade 1: "En general el pueblo (rousulwán espażol) no fué contrariado con la dominación de los almoravides, pero sc equivocá graudemente, si creyó que los nué- vos dominadores obtendrían victorias decisivas sobre los cristianos y valverían á la lís-

1 Pàg. 260 de la mikna gbra. 


\section{$-196-$}

paña musulmana el esplendor $y$ grandeza que había tenido en los tiempos de Abderrahman III, de Alháquem II y de Almanzor. Las circunstancias sin embargo eran favorables, porque después de la muerte de Alfonso $\mathrm{VI}_{1}$ eb 1109, la España cristiana estupo sumida por largo tiempo en la discordia y guerra civil; pero los almoravides no supieron aprovecharse de la ocasion: todos sus esfuerzos por recobrar á Toledo fueron inútiles y sólo consiguieron apoderarse de algunas poblaciones poco importantes; pero la pérdida de Zaragaza fué un gran golpe para contrarrestar las pequeñas ventajas obtenidas».

"Iil pueblo por lo demás no pudo felicitarse por mucho tiempo de la revolución llevada á cabo: grobierno, generales y soldados, todo se corrompio con asombrosa rapidiez."

"Los generales de Yúsuf, cuaudo llegaron á España, si no eran ilustrados. en cambio oran piadosoz, bravos y probos, y acostumtrados á la vida sencilla y frugal del desierto: eariquecidos con los tesoros de los prín- 


\section{-197 -}

cipes andaluces, que Yúsuf les dí á manos llenas, perdicrou pronto sus virtudes y sólo pensaron en gozur tranquilamente de las riquezas adquiridas: la civilización de Espeña fué para ellos un espectáculo completameule nuevo: avergonzados de su barbarie, yuisieron iniciarse an la civilización, tomando por inodelos á los príncipes destronados; pero por deggracia su epidermis era demasiado dura para apropiarse la delicadeza, el lacto $y$ las buenas maneres de lus españoles: todo entre ellos ostentaba el sello de una imitación servil y poco apropiadas.

Busta lo transerito para formarse idea del negro cuadro de la dominación almoravide pintado por el hábil pincel de Dozy, y recargado por los entores posteriores, que como se lea indjcado, se inspiran en el criterio del sutor bolandés, conocedor, es verdad, cual ningún otro, de nuestra historia árabe: creemos sin ambargo ser de estricta justicia el aclarar las tintas de tal cuadro, y esto nos proponemos en parte, sometiendo algunas indicaciones á la consideración de los lectores.

En la hiatorir de los musulmanes puede 


\section{$-198-$}

hablanse de teocracia y clero? Sólo de un modo muy impropio: en realidad el único sacerdote es el califa, cuyas funciones podemos decir que imprimen carácter, y aun éste tiene atribuciones religiosas muy limitadas por la tradición ó por las pocas exigencias de la religión mnusulmana, que parece no da lugar a consultas de doctriua ni de costumbres, ya que todo se supone determinudo por el Alcorán ó por las tradiciones referentes a Mahoma.

Por otra parte los individuos á quienes se confieren las funciones del culto musulmán, si así quiere llamársole, no son perpetuas, di imprimen carácter dentro de sus creencias, sino que pueden considerare como funciones civiles; así que el imam y predicador de la mezcuita al mismo liempo pueden ejercer olros cargros, ó pasen á ellos indistintamente: en realidad, más bien que los dedicados al servicio de las merquitas, pudieran llamarso saccrdotes los jueces; pues por la unión íntima, ó más bien identidad entre el derecho canónico, si así puede llamarse, y el civil y político, las ideas más 6 
menos amplias del juez pueden influir mucho en la práctica judicial $§$ penal, cuando se presentan ideas nuevas en el terreno filosófico teolórico; así vemos que los cargos de intolerancia se dirigen de un modo conereto contra los alfaquíes (jurisconsultos), de cnya clase, á la que pertenecían casi todos los hambres de letras, se nombraban los jueces.

Ahora bien, pueden sentarse las proposiciones de que con la venida de los almoravides se operó en España tma bruset "f funssia revolucion; que la cirilizacion cedierte sl petesto at la barbarie; It imteigencia a to supersticiun; II In interancit al fanatismo? En manera alguna: la vida de los musulmanes españoles siguí siendo la misma, "que había sido hasta entonces: podría retarse á cualquiera á que estudiando las hiografís de los personajes que figuran en los Díccionarios biográticos, marcase diferencias en el modo de ser do los literatos, ó mejor, hombres de letras hasta el tiempo de los reyes de Taifas y los posteriores: estudiaban lo que querían, y con los maestros de su elección, ya que la ense- 


\section{$-200-$}

ñanza fué entre los musulinanes completamen te libre, si excepluamos quizá los úl lizos tiempos.

En las biografías de los muchos personajes que figuran en eslo periodo, musulmanes españoles los más, almoravides algunos de ellos, poco 6 nada se encuentra que indique cambio alrzuni, y que los que babía conocido el golierno de los reyes de Taifas se viesen obligados a cambiar de modo de vivir: aduladores cortesanos y parásilos saldrían mal parades del cambio, ai no se prestaban a adular á los nuevos señores; pero esto sucede siempre que cambian los dominedores: del conjunto de dalos que se han aducido al tratar de la rehelión general contra los almoravides, resulta que ni liabia grandes guarniciones africanss, ni án que el mando de las pobluciones más importantes estuviese por completo en manas de musulinanes almoravides: nada por tanto juslitica el aserto de que con la resida de los almoravides se operó

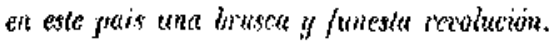

¿La cirilización cediu el presto á la larbarie; In intelifiencia a ta sipersición y la tolcrancia al 


\section{- $201-$}

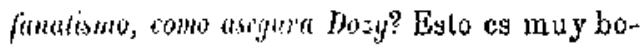
nito y de grande efecto eu un libro; sobre todo cuando á coctinuación se ponen frases tan grálicus, si fuesen verduderas, como éstas: «Li país gemía bajo el rćgimen abrumador del cjero y de la soldadesca, en lugar de las eruditas é ingeniosas discrisiones en las Academias... no se oía más que la voz monotuna de los sacerdotes y el ruido de los sables arrastrados por el suelo», pero necesita pruebas que no puedan lacliarse de hechos aislados.

Se parte del supuesto, no probado, de que los bereberes en sus diferentes tribus eran unos bárbaros por civilizar, cuando de entre ellos se levantan los almoravides y dominan todo el Almarreb: hablabon lengua diferente y por tanto entenderían con diticultad el árabe, en especial la poesía, y por esto nada tienc de extraño que Yúcuf Abentexufín no entendiese ó no le exaltasen los rebuscados versos de los poelas españoles, que on realidad la pedírn pan, aunque no lo dijesen en sus versos: Yúsuf era un bárbaro on este sentido para los poetas españoles, como lo era 


\section{$-202-$}

Oridio para los del Ponto, de quienes inuy bien pudo decir: eBarbarns hic ego sum, quia non intelligor ulli: et rident stolidi verba latina Geta." "Yo aquí soy un hárltaro, porque nadie me entiende, $y$ las necios Getas se cíen de las palabras latians. „ 1

No hay más que cehar una ojeada por las obras de Wusléufeld y Pons ${ }^{2}$, en las rque se da euenta de los historiadores por orden crobulógico para convencerse de que al menos los estudios listóricos no dejaron de tener tantos cullisalores como en cualquier otro período, $y$ en generul do no menor importancia: facilísimo sería, tomándolo de la obra de Pons, continuar una gran lista de historiadores polígrafos españoles de esie período. y ponderar la importancia de algunos de eilos, y no lo sería menos el anotar los muclos escritores de todo grénero, de quienes

1 Elegia X. lib-i Y. Tristims, versh 37.

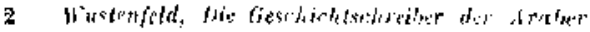

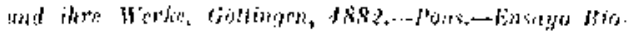

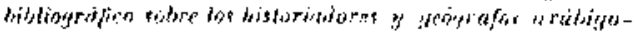

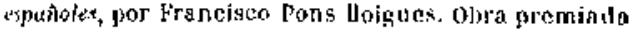

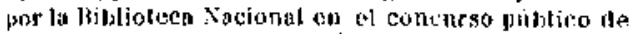

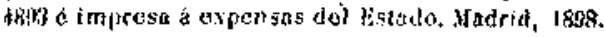




\section{$-203-$}

levemos datos hibliográficos en nuestras papeletas de esta close por orden alfabético.

T'enemos obras filosófico-políticas escrites en este período mar musulmanes espoñoles, $y$ que quizá cuando se puedan estudiar en buenas condiviones, pues al menos dos existen, dan luz pa'a conocer las causas de la caida de los almoravides.

I, a primera, litulada Adrertercia reerca de las carsecs quo prolucen la disidensia a discordiu chle los mulimes, está oscrita por el polítrafo, pero principalmente gramático, natural de Badajoz, Abumohámed Abdala, hijo le Sohámed, Abeuasid convcido por et de Buttijos: el título nos lace sospechar que lu obrid pueda ser interesante fara la ilustración de la Jisistoria de este período, pues que debía de escribirse en plena dominación almoravide, ya yque el aulor matirió en el año 521: de las muchas obras escritas por este autor, se conservan varias: tenemos nota do acho do ellas, conservándose varios ejemplures de la yuo es objelo de nuestro estudio en este lugar. (48)

locos años después debió de escribirse otro obro, que si no podemos decir que sea im. 
portante, pues lampoco está estudiada, prueba al menos que los esiudios no estaban tan decaídos en ja España musulmara, como resultaría de las palabras de Dozy, tomadas en sentido estriclo y segrún la mente del autor. Tn almoravid de pura raza de la tribu de Sinhacha, $\Delta$ trnlabás Ahmed lijo de SIoháned el Sinhachí, el Andalusí, conocido por $A$ bevalarif, de quien hemos lecho mencion al tratar de Abercasi, de ifuien fué maesico y pudiéramos decir cofundador de la secta de los moridín, escribió un libro titulado: Las tesoros, las bellestes de las sesiones, el cebo paite preader los con'cionrs y la contemplacirin do los amados, obra que se conserva en la Hiblioteca del liscorial 1.

Y por cierlo sue como queda indicado, coniendo Alí noticiu de fue propalabu doctrines sediciosas, ó se lacía muy popular, no tomó contra de y su compañero, Ahenbarrachán ${ }^{2}$ más medida que la de alejarlos de

1 Derendoung, balalogue des manuscrits arahes do l' Escurial, tainu II, ell preusa, pajg. 21, $x^{\circ} 7$. (o). 2ùt $r$.

$q$ Abonaljatib, Ms. dr. de la dcademia nóns. $3 \bar{j}$ : 


\section{$-205-$}

Almería y llevarlos á Marruecos, donde murieron en el año 536 , poco antes de iniciarse la rebelión reneral contra los almoravides, que contribuyó à preparar: por esto merecía dicha obra algún esludio, ya que tan poco sabemos de la secta de los moridín, que parece cantribuyeron en gran manera á la rebelión. (49)

Huchi Jalifa meneiona esta obra de Abenalarif con dos vitulos diferentes, Bellezas de las sesiones, ó simplemente Sesions, bajo los púmeros 11499 y 1138.1 .

T'a a bién Atrencasi, el discípulo de Abeualarif, é inicindor de la robolión, eseribió una obra acerca del sufasmo, la cual debió de tener importancia enlre las sufíes posteriores; pues como dice Hachi Jalipa, fué comentada por cl célebre sufí murciano Mohididu Abenaralri, quien dice do Abancasi, ó sea del autor de la obra, que comenta, que era literato excelente, gran falólogo y que no hablaba sino para pronunclar senteacius filośficas.

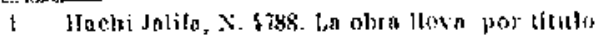

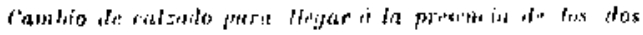




\section{$-206-$}

De lo dicho puede inferirse que en el periodo de los almoravides los musulmanes espoñoles siguieron dedicándose al estudio, cuyo aprecio indican bien los versos de Abenasid citados por Pons:

- Gal sahio vivira clernamente despuis de su mueric, nunque slix minmbros de emroupan bajo de la lierra; mas ol ixnoronte es un muerio gue ansu por

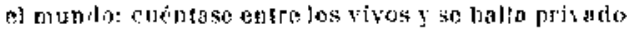
de vida..

Abenalabar en la biografía de Ibrahim, hermano de Als' dice que durante su gobiervo en Murcia fué discipulo de Abuelí Asadefi, para lo que hubo de ir á casa del maestro, pues éste se hizo el desentendido respectóa la pretensión no extraña, de que Abuali fuese á la residencia del gobernudor. $A$ benalahar dice terminantemente en esta fiografía cue duranle el mando de] liermano de su hiografiado (Alí Abenyúsuf, año 500

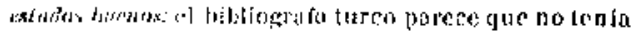
noticia la: la patria dọl oulor, a (juien solo llama

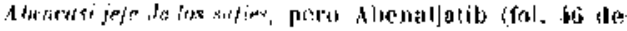
mi copia, al boblir the themsasi, clice yue r's el autor de Jn olyra meneionadia.

I Hiblio. Arab. tis. como tr, póg. ibs. 


\section{$-207-$}

a 537 ) estuvierun en predicamento las ciencias $\mathrm{y}$ las bel'as letras $\mathrm{y}$ abundacon los hombres célebres, principalmente los escritores; y que Alí había pedido la ichaza de todas sus tradiciones al salsio Abuabdala shoned, hijo de Molámed el Jaulauí por la nobleza de las autoridades (en que se apoyaba).

'́ambién ficura como discípulo de Abralí Asadafi y de otros maestros ilustres, Almansur, hijo del emir Abuabdala SLahámed, Abenallach Daud, de quien se ha dicho que murió en la expedición del Congrust de Martorell en el año 508 .

Almansur, que en Valencia fuś lugarteniente de Abnzacaría Abenganis durante lus expediciones de éste, era de elevada inteligencita, de alma pura, ansioso de la ciencia y apusiontdo de lus divanes (colecciones) antignos y originales preciosos, de los cuales llegó a teunir una colección admirable: murió en Ibiza ó en Mallorca en el ano 547, 6 Lácia el año 500 .

Dígase si tales príncipes 6 tales personajes mercen el dictado de bárbaros é ignarantes. 


\section{$-208-$}

Quienes tales aficiones manifestaban é iban á las casas de maestros particulares, siquiera fuesen tan célebres como Abualí Asadalí, no dejarían de tener 6 asistir á tertulias 6 reuniones literarias, mal llamadas Acodemias: pues con carácter oficial as casi seguro que nunca las hubo en la España musulmaDa, á no ser en los últimos tiempos; y en esas tertulias ó Academias se discutiría con la znisma liberiad y allura de miras, que en los tiempos anteriores.

\section{Persectelion de los mozturabes}

Par las anlores cristianos poco ó nada sabemos del estudo de los mozárabus en Andalucía durante los primeros años de los almoravides: sólo con motivo de la incursión de Alfonso el Batallador se dan algunas noticias acerca de su ostado, b más bien, de la persecución que contra cllos se movió á consecuencia de esta famosa expedición, poco conocida en sus causas y no mucho mejor en sus efectos. 


\section{$-209-$}

Por el testimonio de Abonasnirafi ", resulta que en el reinado de Iŕsuf en el año 492 los cristianos de Granadu fueron inquietados en el ejercicio do su culto, siéndoles demolida una iglesia anticrua, que existía en la que hoy es plaza del Triusfo: en realidad esto es lo único que se sabe; suponiondo que esto fué debido exclusivamente al funatismo de los alfaquíes y á so iciciativa, á la que de buen grado debió de asentir Yúsurf, Dozy supone y da por sentado quo los alfaquies yo se detuvioron en milad del eumino, y que, obtenido ol permiso de derribar una igrlesia, lo tendrían para todas, y que los crisitianos fueron atrozmente vejados por los musnlmanes hasta que habiéndose llenado la medida hacia el año 1125. suplicaron á Alfonso al Batalledor quis les ayuduse á sacudir el yugo y se apoderase del territorio sornetido al islam; y que en virtud de esto el rey de Ararón emprendió su famose expedición.

Admitida la demolición de la antigua iglesia de Granada, ya que ningtin dato po-

1 Sozy, nccherches, 2. edi. lomo J, pbg. 346. ALMonatioss 


\section{$-219-$}

damos aducir en contra, ni hay motipo especial para ponerla en duda, aunque mencionada en rigor por un solo autor, como éste noula dice de les causes que la molivaron, en buena crítica no cahe ampliar la persecución y suponer que los alfaquíes se ensañaron con los cristianos, lanto más, cuanto que el outor, al meucionar este hecho, no hace alusión algına a tirantez de rélaciones entre musulmanes y cristianos por este tiempo: Indica sí con preciosos detalles la alianza con Alfonso el Batallador y la consiguiente expedición de éste, despúśs de la cual y á consecuedcia de la mísma se juicia la persecación, que no podía menos de sobrevenir, como previeron los diez mil cristianos, según Orderico Vita], que se reunieron al ejército de Alfonso al regresar; $\mathrm{y}$ aun así se necesitó que á raíz de la derrota de Araisol y regreso de D. Alfouso, el cadí de Córdoba Abuluslid Abenroxd (abuclo de Averroes) se dirigiese á Marruecos á informar á Alí de lo sueadido y pedirle tomara medidas contra los cristianos, por lo menos la de desterrarios, como efectivamente tomó estr medida, pues 


\section{$-211-$}

en el mes de Ramadán del mismo año 520 muchos cristianos fucron deportados á Africa, sufriendo mucho en el viaje por el mul tiempo y los malos caminos: á los sufrimieutos ualurales del viaje, que confiesa el autor árabe dcl selato, hay que añadir, segrúc Orderico Yital, los atropellos de todo género cometidos por las musulmanes, irritados por la marcha de los que se habfan unido al ejércilo de Allonso 1 .

Estos parecen ser los únicos datos que nos sumiaislran los autores antiguos: falla ahora apreciarios en su verdadero valor, ya. que están poco conformes entre sí.

Dada la connivencia indudable de los mozárabes en general con Alfonso el Batalla-

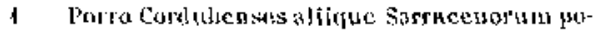
puli valde irali sutl, ut Ifuenavios cum fanjilis el telus bu is discessisso yider ant. (luapropter commiuni recrelo coulsn resicues insurrexerubl, rcbus omnibus pos rude]jer expoliavelunt, verberibus et vin-

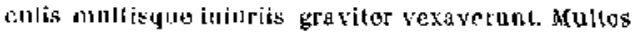
emum horenclis suppliciss interemerumt, ot ormes alins in Africam ultra fretum Athlanticum lelegave-

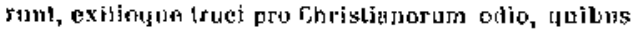
magna pars onrure comitala fucral condemnaserum.

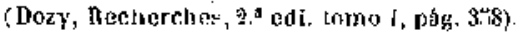


dor, no pueden tacharse de exageradas las pretensiones del cadí de Córdoba Abulualid Alenroxd de que lo menos que procedía era expulsar á los mozárabes, y por tanto bajo el punto de visia del gobierno musulmán, en mi sentir no es justo hacer cargos al emir Ali por esta medida; que produjo atropellos injustificados, no to dudo; pero probablemente no serían tantos como dice Orderico Vital; pues es lo cierto que en Granada quedaron bastanles cristianos, como dice el autor árabe, y coufirman de un moda indudable los graves aconiecimientos ocurridos en esto misma ciudad en el año 557, de los que se ha kecho mención ex la página 139 y siguientes.

¿. Wl llamomieato de Alfonso por los cristianos de Audalucío se dehí, como dice Dozy, á que la medida del sufrimiento de las mozárabes se hubiera llenado por este tiempo? Podra ser; pero lo dudamos: habían pasado 28 años desde cue habín sido derribada la antigua iglesia de la pnerta de Elvira, $y$ si la persecución de los alfatquíes can zquiescencia del príncipe hubiera sido tan violenta, 


\section{$-213-$}

no se concibe su prolongación por cspacio de 28 años.

Es probable, en mi sentir, que la expedición de Alfonso el Balallador partiese de su inicialiya $1, y$ tue como era natural procurary autes ponerse en relación con los mozárabes que habían de ver con simpatía sus triunfos y podíu servirle de mucho, aun sin tomar una partc activa $y$ directa en la lucha.

De que la persecución juiciada segrin Abenasairafí en el tño 492 y exacerbada hacia ol año 519 no tuvo ni de mucho cl alcance que le supnso Dozy y lan exagerado autores posteriores, encoutramos tun indicio Inśs, tuaque purarante negalivo en el silencio de los Acales Tolectanos.

El antor ó autorts de estos Anales, moy

1 Orderico l'jial ta alribuye al deseo de tlrom-

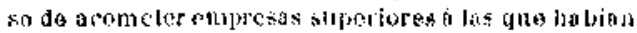

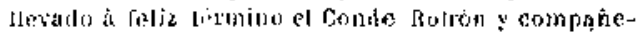
ros,-anno ah incartatione Domini MCXXY, past¿uam Rotro Comes cum slais sateltililus et nuxilinrijs jh Gatham romenvit, Arognonensis thex visig insignt-

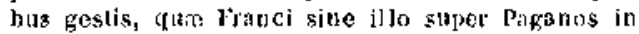
Hispamia fecerant, incidid: Jaudisume eupidus ingentenl sua: gentis cxerentum arroganter atsunasit. Espatus Sog. 1012no X, prat 607 . 
afecto á los moros, como oporiunamente indicó el Sr. Saavedra, nada indica de î destrucción de la iglesia de Granada ni de perm secución: quizá pudiera encontrarse algo de ésta en lo que se dice con relsción al año 499 . siete después de la demolición de la irglesia de Granada- «Ticé la hueste de Málarga cuando exieron los Mozarahes de Malagra, Era VCXLIV ", pero parece nucho más probable que mozárajos de Háloga salieran al servicio de los moros como supone el P. Flórez 1.

No consis en dichos Analcs Toledanos otra indicación reforente à los mozárahes hasta la entrada de Allonso el Batallador en Andalucía, que coma se dijo, refiere con eslas lacónicas pilabras: "Lintró el rey de $\Lambda$ ragrón con grand lucste en tierra de moros í lidió á verició a XI Reyes de Noros en Aranzuel, Era XCIXID, añadiento á continuación: «Pasaron los Mozárabes á Marruecos ambidos, Fra MLLXil), (año de J. C. 1124). La feclia está cruirocada, pues estos sucesos ocurrieron en los años 1125 y 1126.

1 España Sagrada como XXilt, jobg. 387. 


\section{Gucma de log lfbros de alganali}

Es indudable que la obra de Algazalí $L a$ rorsurrecion te las ciencias religiosns, fué prolibida en la Fspaña musulmana con la intervención del cadi de Córdoba Abuabdala Abeuhamdin: son muclios jos autores árabes que hacen iodicaciones acerce del hecho $y$ no cabe ponerlo en duda: de to que cabe dudar, es de la eplicación que del decreto se hiciera: probahlemente la prohibitión excitaría el deseo de leer la obra, y sería causa de su mayor circulación, cono resulu del hecho de que 30 ajos despres ibencrusi explicaba este libro á los sufíes, à duienes iniciaba en la idea de rebularse contra los almoravides: en jo que no están conformes es en los delalles de la proscripción, y en realidad, en el prícipe qute la autorizó, y menos, en las causas: podría muy bien sospeclarse que la acrimonia con quo según Dong, atacaba á los teólogos ó alfaquíes fuese la causa principal de la proscripción de la obra de Algazalí, que debió de alcanzar gran éxito en al mundo musulmán, si alendemos al nú- 


\section{$-216-$}

mero considerable de ejemplares que se han conservado en las bibliotecas: parece sin embargo que en Fspaña circuló poco en la época inmediatamente posterior, al menos de un modo público, pues Abenjár no le cita entre los libros que esludió !.

Las circunstancias y la fecha de la quema de la obra de Algazalí son destouocides por los zutores árahes: la fecha puede fijarse entre el año 500 y $507,(50)$ sa the en el año 500 subió al trodo Alí, $y$ en 5617 muere una de los que intervienen en el proceso.

$\Lambda$ hora bien, el unutema lanzudo contru un libro determinado autoriza para asegurar que

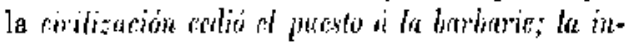

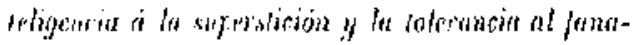
thame? lin mituers wlguma: de totos los periodos lisstórices de los musulmanes de lispaña se citan hechos analogros y lo misno ha sucedido eta todos 6 cusi todos los pueblos, y casi podria asegrurarse pue sucederá siempre.

Añade Dozy, «que grobierno, generales y

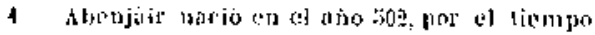

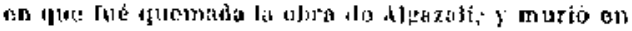

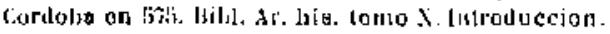




\section{$-217-$}

soldados todo se corrompió can asombrosa rapidez; que los generales sólo pensarou en gazar tranquilomente de los riquezas adquiridas y que avergonzados de su barbarie quisieron iniciarse en la civilización, pero que todo en ellos ostentaba tl sello de una imitación servil y poco apropiada", es mug sencillo $y$ de micho efecto el asegurar todo esto; pero hacen fulta pruebas, imposibles de aducir, porque en el estado actual de los estudios árabes no es aúv posiblo ver on conjunto los hechos y la marcha de los acontecimientos: pueden citarse leclros particulares de ceudillos ineptos 6 desgraciados en la dirección de los ćjércitos, como Temim el héroe por fucrza de lelés, que se retira sin pelear de los muros de Zaragaza; y del vencido en Cutenda, el príncipo Ibrahiz; pero también hemos citado no pocos que luchan con acierto y valor duran te largos años y que si por fin sucumben, saben hacerlo con honar.

Como por olra parte yemos que en muchos casos los jeles de poblaciones de importancia son españoles, y esto les proporciona el poderse rebelar contra los alworavides en 


\section{$-218-$}

los últimos tiempos, haciéndoles concebir Ia idea de independencia nacional ó de autonomía regional, no encontramos que los almoravides acaparasen pera sf los cargos militares, ai mucho menos los civiles, que si eran dados á los alfaquíes 6 jurisconsultos, sólo ha podido hacerse antipática esta conducte, tachándola sin razón de clericalismo y teocracia.

Queda probado que en lo militar y científico no cabe encontrar diferencia radical desfavorable a los ulnoravides: domás? Del esiado de ly arricultura, industria y comercio de este período como de los demas, poco 6 nada sabemos; pero hay un ramo jmportante de la administración, en el rue los almoravides son muy superiores a los grobiernos que les precedieron, y es el sistema monetario.

Ias monedas de los almoravides en belleza y en el sistema á que obedecen, sou nuy superiores á todo lo que se labía visto liasta sntonces: y cosa singular, el sistoma monelario almoravid viene de Marruecos, pues resulia implantado antes que Yúsuf Abente- 


\section{$-219-$}

xufín fuera llamado por los reyes de Taifas.

Lá perfeciós y abundancia de las monedas almoravides tasto tu oro como en piata pueden considerarse por una parte como un indicio de la prosperidad moterial en esto período, prosperidad que confiesa el mismo Dozy, como no podía menos de reconoeer con los a utores árabes ', (51) y por olra su buena $y$ hermosa acuéación nos prucban yuo en todas las poblaciones de inportancia se cultivaba al menos el arte del grabado, como no se había hecho antes, y que la reforma monetaria no se había hecho á la ventura y por descavolvimicnto espontáneo aislado, sino con plan fijo procedente del poder central. En efecto, las monedas de oro, muy abundantes en este período, son de peso muy uniforme, lo que no había sucedido antes, de modo que quizá sólo desde este tiempo la moneda de oro árabe española, tiene en realidad ol carácter do tal con peso y ley fijos: y aun en las mismas monedas encontramos indicio de algún cambio de peso, pero tan poca

1 Cartás, edi, Tornberg, pár. 10 : Anenalatir,

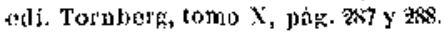




\section{$-220-$}

importante, que no ha podido hijarse á pegar de las muchas monedas que so conservan, bien que de muy pocas saberoos que pertenezcan al sisfeme antiguo, que probablemente indicará algún mayar peso '.

En todo el período de las reyes de Trifas puede decirse que no se scuñó moneda de plata: pues de que llevaba el nowbre de dirhem cra en realidad de cobre 6 do plata de pésima ley y peso muy diferente: con los almoravides se introduce un sistema mons:tario, con el cual reaparece la plata de buena ley, y las monedas fraccionarias del dirhera, fraccionarios que no se habín couocido en período anterior, y que en Jispaña trataron de introducir los últimos reyes de Badajoz, de quienes se conocon monedas pareridas.

Para facilitar las transacciones mercautiles al por menor, los almoravides acuãaron semidirhemes, cuartos de dirluea, octavos y dicciseisavos, llamando á estas microscópicas monedas, jarruba (algorroba): así lo dice Ab-

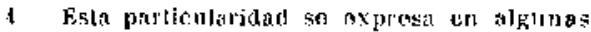

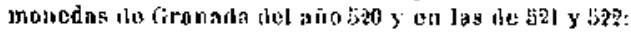
Fives, ohra eiladio, numerus $16 \mathrm{2} 1,1622$ y 1623. 


\section{$-221-$}

deluáhid ', $y$ así resulta de las monedas de este período estudiadas y dadas á conocer por el Sr. Vives. (52)

La perfección artística que aparece en las monedas de este período, resulta también en otra clase de monumentos no menos auténticos, en las inscripciones sepulcrales, en las que las letras dejan de aparecer en la forma llamada cúfica, para ostentar el caracter cursivo, mucho más elegante, y el conjucto de la inscripción se eucierra á veces en marcos elegantísinos.

Como, al menos para la Tispeña musulmana, Alí es el representante legítimo de la dinastía almoravid, dígase si quien vino a España cinco veces tomando en varias de ellas la dirección personal de las campañas y arreglando los negrocios, si un príncipe en cuyo reinado tanto florecen las ciencias y las artes, no hizo más que rezar y elykuzh, como dice Dozy y repilen en coro autores posteriores.

1 kbdęluánid al de Marruecos, pał. If8. 



\section{ILUSTRACIONES}

$\bullet$ 



\section{IILISTLACIONEA}

1

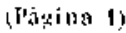

Ia generalidad de nuestros cronicones antiguos fijan de un modo muy vago y poco preciso la facha de la hatalla de Zalaca, que

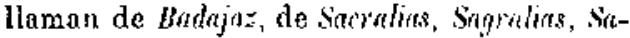
raliar ó Zagalla: la mayor parle tijan sólo el año y no siempre bien; pues son baslantes los cronicones que rclrasan un ano la fecha: algunos citan al mes de خoviembre: sblo en los Annalos Comphulenues (España Sugrada, tomo XXIII, p. 314) encontramos la indicación concreta de la facha con estas palabras: In Wra MCXXIY. Die sexta feria, scilicet $X$ kal. Novembris, die Sanclornm Servandi el Germani luit illa arrancada (derroto) in Badalozio, id est, Sincralias, el fuil ruptus Rex Domnus Aldelonsusi. 


\section{$-226-$}

Los autores árabes dan más detalles y son. varios los que de un modo concreto fja la fecta de la batalla en el viernes 12 de Tracheb del вйo 479, que caincide perfectamente con la auterior, correspondieado al viernes $23 \mathrm{de}$ Octubre de 1086 (Bibliotheca Arabico-bisp. to. III. p. 31.- Abenolcadi, edi. litogr. de Fez, pag. 343,- MIs. N. X. de la colcceion fougangos en la Acadernia de la Historie, fol. 39, v.), Otros antores árabes. ljando el mismo mes, varían en el día.

\section{$\mathbf{2}$}

(P'xtilla 3)

Las vevidas de Ýlisuf á España y el objeto de cada una de ellas ato aparecen bastante claros on los autores áralses: resulta que vino cinco veces, aunque la generolided de los autores solamente mencionan dos de sus viajes.

La prinera revida, conacida de todos, es la que de por resultado la betallo de Zalaco. 


\section{$-227-$}

el viernes 12 de Racheb del aù $479, \quad \delta$ sea 23 de Octubre de 1086.

Scrpamla cenda en el año 481: en Rebia 1." sale do Algeciras, se dirige a Aledo, que sitia durante cuatro meses (Cartás, p. 98,Shmed Anasiri, p. 119,-Allolal Almauxia, fo. 41 .

Terriri renida: Yúsuf pasa el war por tercera vez en 483: Jlega á Córdoba en Chumada 1."; Luego se apodera de Grenada y Malaga, destronando á los reyes Abdala y ' 'emim, hijos de Boloruin bijo do Sardís, $y$ en I kamadán pasa de nuevo el mar: segúu algunos, la toma de Granada y Málaga debería otribuirse á la segueda venide (Bibl. Arel.. lrisp., to. TIJ, p. 32.-Cartús, p. 98.-A benjalicán, biogr. de Yísuf, torno Ill, pág. 462. Ahrued Anasirí, to. I, pár. 120.-Alholal Almauxía, lol. 44).

Exarte venida: Yúsuf pasa á Espeña por cuarta ve\% en el año 490 (Alımed Anasirí, to. I, p. 121), aungue el antor dice por tercera: Alfonso se dirige contra ét, y Yúsuf e nvía el ejército á las órdenes de Mobámed, hijo de Albach, que derrota á los cristianos: 


\section{$-228-$}

según el Albolal, fol. 48, Yúsuf vino acompañado de sus hịjos Abutáhir Temím y Abulhasán Alí.

Quinta renida: Aumque Alumed Anasirí, p. 122, dice que Yúsuf pasa de nuevo en el Būo 497, y le llama 4." venida, es la guinata, y debió de efectuarse en el ā̃o 496 , en cuya fecha se verifić en Córdoba la proclamación $\sigma$ jura de Alí, como príncipe heredero, en el mes de Dulhicha (Cartás, p. 101.-Dozy, Notices, pág. 225,-Abenaljatib, fol. 22 de mi ejemplar).

3

(1)iging s)

Alí había sido proclamado Príncipe heredero por su p̧adre Yúsuf en Marruecos en el $u \tilde{n} 0495$, segín consta del documento que se inserta en el Ms. N. X, de la Col. Gayangos en la Academia de la Historia, fol. 50; en el año siguiente, 496 , se hizo la jura solemne en Cordoba por los magnates españoles: a esta jura hecha con mucha solemnidad 


\section{$-229-$}

asistió Ahdelmélic, hijo de Almostáin II, rey de Zaragoza, quien envió magnílicos regalos, en los que iban L-1 arrobas de ubjetos de plata, en los que figuraba en taracea el nombre le Almocládir, abuelo de Almosláin, cuyos objetos îeron convertidos en quirates (peyueñas monedas), que fueron distribuídos al público en la noche del día 10 del mes de Dullicha (Dozy, Notices sur quelçues nanuscrits ar. págr. 220\%.-Cartás, página 101).

i) nombramiento de Alí como príncipe heredero en el año 495 of rece algua duda, por lo que resulta del testinorio de las monedas, en las cuales Alí no figura como Principe y, X, hasta el año $497, y$ con el de Principc heredero hasta el mismo año 500 . Le Segelmese hay dinares hasta el aĩo 498 , inclusive, sin que se mencione al nombre de Alí: lo mismo se observa en las munedas de Agmat Jasta este mismo año, $y$ eu uat de Fez de 499 (?); el nombre de Alí con el lítulo s y forura desde el año 497 en monedas de Córdoba y Almería; desde 498 en las de Agmat y Denia; 7 desde 499 en las de 


\section{$-230-$}

Játiva, Sevillo y Yalencia: con el título de 2,gabl s) sólo aparece en monedas de Málaga del año 500 (Véase Ifunetlay de lus Dinastias Arábigo-españolas, por D. Antonio Vives, números 1449 á 1530).

\section{4}

\section{(Pàgina}

Cartás, pág. 101.-Según Abenjalicán, (tomo Ill, edic. del Cairo, pág. 460) Yúsuf murió el luncs 3 de Moharrem (4 de Septiembre de 1106) después de un reinado de 50 eños y 90 de vida.

\section{5}

(Paglna ;i)

Ali había nacido en Ceuia en el año 477. de modo que al subir al trono contaba 23 años de edad: era hijo de una esclava cristiana, que según algunos autores se llamaba مä Camar (Luna), 


\section{$-231-$}

gina 102.- Alholal Amaxía, folio 52 ;

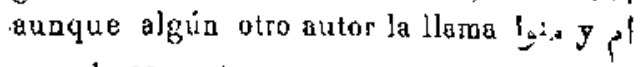

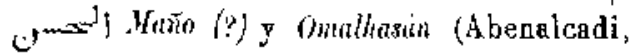
pág. 291, edición de Fez).

\section{6}

¡tging 5y

El imperio de los Almoravides se extendía desde Bugía hasta el extremo del Sus, por el mediodía desde Segelmesa hasta los montes del Oro on el Sudán, y por todo el país de Alandalus, desde Mallorca, Menorca é Ibiza, siendo proclamado en la oración pública en dos mil trescientos y tantos púlpitos.

\section{7 .}

(l'ogina (5)

No es fácil lijar con precisión las veces -n que Alí, durante su reisado, vino a Espar̃a, donde ya lrabír estado antes. 


\section{$-232-$}

Primera renida: En el mismo año 500 en que comenzó á reinar, vino a Fspana, sin que en los autores encontremos noticias concretas de lo que hizo: Abenaljalib, el rínico autor cn quien encuentro mención de esta venida, dice (Mls. ar. de la Acad, ním. 37, folio 250 r.) que slabiéndose renovado la proclamación 6 reconocimiento de la gente de Alandalus, se apresuró á pasar á ella á fines de este mismo año; traló sus negocios y ordenó el estado de las cosas. -Abenjaldún (edic. del Cairo, to. VT, p. I88), parece referirse á esta primera venida, cuando dice que "Alí pasó á $A$ landalus, deyastando el pais del enemigo, matando $y$ cautivandos ya que dospués liabla de la segnnda venida en el aūo 503 .

Segunda renida: Do este segundo viaje de Alí a Alandalus dan noticias más defalladas y concretas: á esta campaña se le llamó de Talavera, sia duda por ser la fortaleza más importante de Ias que en esta expedición cayeron en poder de los almoravides: Alí sale de Ceula el 15 de Moharrem de 503 (Ia. de Agosto de 1109); se detiene en Córdobe 


\section{$-233-$}

durante un mes: luegro se dirige hocia Talavera (da la Reino), que toma a viva fierza, cayendo en su poder hasla 17 ó 27 fortalezas de los alfoces de 'Toledo, entre cllas Ifatridy divadnhijura, y presentándose anto lus nuros de l'aledo, la sitia durante un mes, talando su campina, $y$ después de hacer uncho doño a lus cristianos se rolvió a Córdoba (Cartas, página 105.-Ahued Anasirí, posg. 125.Alsenjaldín, Y1, 182, 188.-Abeneliatib, Ms. Ac. núm. 37, p. 250.- A noles 'loidedanos. Esp. Sag, to. XXIJI, 388, - Bibl. Ar lispa.

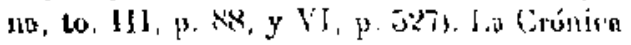
de Alomso Fll, confunde, ó mejur tilbo, refunda con esta expedición otra bastatuto posterior, en la diue el jefo no frí Alí, sino sil hijo l'exufín, quien por este tienpo no labia venido a bispana: segín ol autor, no pudiendo Ali apoderarse de Toloda, se diricrió a les ciudades y castillos yte babia al oteo lada do lu sierro, rompiendo los muros de Madrid, lalavera, Mmos, Canales y otros muchos, haciendo muehos cautivos, poro sill que pudiera apoderarse de las fuerles torres de dichus ciudades, que llaman chiareres: 


\section{$-234-$}

Guadalajara con otras ciudades y castillos quedó ilesa y sus muros no fueron dersuídos, (Chronica Adephonsi Imp. Esp. Sacr., tomo XXI, págs. 356 á 359). El autor del Alholal (fol. 54) añade que los musulmanes destruyeron a las pnerlas de Toledo una cálebre almunia, detalle que confirma y aclara el autor de la Crónica del Fimperador al decir que los moros prendieron fuega a ana fuerte torre que había á la cabera del puento frente a Sau Servondo.

La cronología concreta de esios sucesos no resulta clara, pues los Anales Toledanos, cugo autor en general estaba bien enterado dice: a Prisieron Moros Talayera en XVI días de Agosto, Bra MCXVII (sic)» (parece debería ser 3(CXLVII), cuya fecha corresponde a la que se da anteriormente como de la salida de Alí de Couta, y su embarque para vanir a España: los mismos Anales Toledanos indican el sitio de Toledo por Alĺ con estes palabras: «Posó el Rei Alí sobre Toledo é tórola cercada VIII dúas, Téra 1148.»

Tercera venida: Por los cronicones portagueses podemos determinar la teccera venida 


\section{$-235-$}

de $d$ lí, la cual aparece con pocos detalles en los autores árabes. Ahenaljatib (Ms. Academia, núar. 37, fol. 250 ) sólo dico que pasó por tercera vez, silió á Coimbra (el texlo dice as f.... : lo mismo se lee en el mauuscrito de la Miblioteca de Argel, según copia de uni pertenencia), y luego la abandonó: según el autor del Alliolal (f, 54) pasó por tercera vez en el año 5ll con propósito de hacer la gucra sunta; en este año con'juistó la ciudad de Coimbra (lexto à y sil que supouemos estará del misuno mado en el códice de Leiden, puesto que en el códice de la Colección Gayangos están avotadas las variantes por $\mathrm{Mr}$. Dozy, $\mathrm{y}$ de este nombre nadu se anota), conculcando el pais de los infieles con ejércitos innumorables, dejando en él muchas huellas". - El Chronicon Lusitano, (Españu Sag., to. XIV, 2." edic., P. 420) tijando el año y la persona del jefe dice: "Aira 1155 Rex Surracenocum Hati Ibeajuceph, veniens de ultra mare cum multo exercitl obsedit Colimbriam, adjuncto simul ol omni exercitu, qui erat circa mara, quoorum numerus erat inpumeralilis sicut arena maria, 
soli Deo tauturn cognitus erat. Obsedit antem Colimbrian viginti dicbus quotidic fortiter in toto exercitu oppugnans eam, sed per voluntatem Dei non potuit nocere el civitas illaesa remausit, et inhabitantes in eB., La fecha 22 de Junio de 1117 , correspondiente á 18 de Sufar del wio jll de la héreira, esta delerminada por el Clironicon de Coimbra (Esp. Siar, to. XXllt, p. 331) con estas palabras: $\therefore$ In bia 1135 absedil Kex tli Colimbriam $\mathrm{X}$ kal. lalii et luil ibi per tres hebdomados,

Cuark remida: lin el año 513 ó đquizá á principios de 5l 4 Alílubo de venir a Alandalus por euarta vez, no con el objeto principal de lacer la fruerra sanba, siso de calmar una sedición promovida on Córdoba, cuyos saturales, á causa de la insoleccia de uno de los siervos 6 criados del valí Abubíquer Yolya, hijo de liauad, habían echado de la ciudad á los almoravides: sabido esto por Alí, hubo de venir, los sitio, y por fin perdonó á los de Córdoba, gracias a la mediación de los alfacuíes (Abenalatir, ta. X, págriua 392). Según àgunos autores (Cartás, 


\section{$-23 i-$}

páarica 100.-Amed knasirí, to. I, p. 126), esta venida de Alí fuŕ motivada por la nolicia de la toma de Calatayud por Allouso el Bataliador: Alí pasó (por segutuda vez dice el tex to) con ánirro de lacer la guersa san arreglar el estado del país y useritror las fronteras: al llegur á Córdoba se hospedó en las afueras, y allí se enteró del estado del país por los mensajes que le herrarou: destituyó del cadiazgo a $A$ verroes, nombrando en su Jugar á Abulcásim Abenhamodín: hay que advertir que esta destitución y norbbramiento do cadí no aparecen bastapte cliras en los aulores, y quizá se reficran á tiempos algro posleriores: secrín eaios mismos antores, no olvido A lí la guerra santa y desde Córdobe salio para Sanlamaría ó quizá Santaréu, que sitió hasta tomarlo á viva fuerza. destruyendo en el occidente alquerías y monasterios: los detolles cn cuanto á la guerso mo perecen sospechosas, por no encontrar indicaciones on olros antores, ni alun en la obra A/holat Aimaurín (fol. 54), en la que se trata con más extensión de esta cuarta venida, que gor incorrección evidente del texto apnrece como 


\section{$-238-$}

del año 500, $y$ tiene por objeto arreglar las cosas de Córdoba, ante cuya población huho. de presentarse Alí con Iumeraso ejército, al que le fueron cerradas las puertas, habiendo declarado los ulemss (sabios) que era legítima la resistencia: prolongada la estancia de Alí delante de la ciudad, mediaron negociaciones de los principales de Córdoba, y por fin convinieron en pagar una jodemuización por lo que el pueblo había robado en el saqueo de las casas de los almoravides: nada se dice aquí de Abenroxd (abueio de Averroes). Parece que Alí prolongó en estancia en Alandalus hasta el año 515, en que se vuelve á Harruecos (Cartas, págs. 106 y 107. Almer Anasirí, to. I, p. 126), a unque algunos a atores le suponen alí en 5l4, en cuyo año luvo una entrevisto con Almehdí, que comenzaba sus predicaciones (Cartás, jáginas $111,112$. -Abenalatix, X, pág. 402), si bien este mismo autor (p. 414) le supone en Córdoba al salir las tropas para la batalla de Cutanda. 


\section{$-239-$}

\section{8}

(Priçina 50)

Bnialla de Vith. Autores árubes y cristianos den voticia de osta balalla, $y$ por cierto con bien diferente extensión, limitándose ésios à consignar el año del suceso con estas palabras del Chroticon de bargos (Lisp. Sagrada, tome XXIIJ, prág. 310): « Era 1146 Fuit la do ludés.s. Los thates Complatensce: "Sira 1134 (1146) et illum de Jjeles fuit fac:tum». Mós explícitos los Annales Tolectanos (Bsp. Sag. towo XX111, pâg. 387) diceu cou no menor laconismo: "Arraucada de liclés sobre los Christianos en el mes de Mayo. Era 1146.--Mrataron al Infant D. Sazcho é al Conde D. García cerca de Liclés, III día kal. de Junio Lira 1146.

Eu lre los aulores cristianos (antignos) sólo en la Hisloria del Arzobispo D. Rodrirgo Ximépez de Rada, autor de índole muy diferente á la de los anónimos de los Cbronicones, encuentro noticias más amp. lias, auncque no muy concretas. 
Los autores árabes, parafraseando unos, 6 copiando lo escrito por otros, dan algunos detalles inaportantes, que copiamos del Cartás, por estar la traducción francesa al alcance de los no arabistas, aunque en esta obra la fecha eslá algo retrasada.

Dice en la pagina 103 del lex to y 228 de la traduceión de lienumier:

aEn 502 (1108 J. C.). eut lieu l' alfare d Akelych 1 avec les Chrétiens Tcmy in beu Youssef était alors général en chef de l' arméa musulmane, et gcuvernait (Grenade. C' esi de cette ville qu it partit pour aller courir gur les terres des Chrétiens. Iitant arrivé sous les murs de la forteresse d'Akelych, habitée par une forle garnison de Clurétiens. il en fit le silere el y pénétre. Las Claréliens g ćtant relranchés daps la kasbah, expédièrent un courrier it Alphonse, qui so mil aussitit en mouvement. Au moment de son départ, sa femme l' arrîta en le suppliant d' envoyer san lifs it sa place is la rencoatre de Temyrn. «Observez, lui dit-elle, 'qu' il est

1 Cháten al Voliex. 


\section{$-241-$}

plus convenable d opposer it Temym, fils de l' émir des Musulmaus volre fils Chandja ', fils de l'émir des Chrétiens! Alphonse, se rendlant is cet avis, envoya honc Chuodja is la tetc $d^{\circ}$ une grande armée de guerriers qui s' avanca prompiement jusine sous les murs d'A lielych. A la nouvelle de l' approche des Chrétiens, Ternym manifesta le désir d' óviler le combat, en évacuari la place; majs Abd Allah ben Nohammed ben Fityma et Mohammet ben Aicha, ainsi que quelques autres kaïds Lemtounala, le dissuadicent, ef lui rendirent l' espoir et le courage, en hui affirmenl que l' enemi n' avait pas plus de trois inille cavaliers et qu' il était loin encoro. Temym crut it leurs paroles; et, lo soir mème, Jes Chrútieus fondaient sur lui par nombreux milliers; il voulut fuir, ne se sentant, point capable de combattre, mais il était trop tard, et il ne ponvail déji plus avaneer, ni reculer, Jorsque les liaids Lemtounah se précipilìreut sur l' onomi, suquel ìs livec̀-

I Chandjo, I imlant don Kanchu, flls at Alphos so et de zaida. 
rent un combal désespéré et tel qu' on n en avait jamais yo de pareil. Dieu tris-baut renvera l' enemi et donna la victoire aux Musulmans. Le tils d' Alphonse fut tue ainsi que vingt-trois mille Chrétiens environ. Les Musulmans entrèrent in $\mathbf{A}$ kelyoh par la force de leurs sabres, ol un grand nombre de Ciroyants périrent à l' assaul (que Dieu leur fasse miséricorde!). Jín apprenaut ce désastre, Alphouse resseatit un tel chagria iu' il tomba malade et mourut vingt jours apres 1 . Temym enroya un courrier a son pire ${ }^{2}$ Aly pour lui annoncer cette victoires.

A benaljatib (fol. 106 v de mi copia) califica la derrola de l'clés como una segunde batalla de Zalaca, aunque da pocos detalles.

\section{$\boldsymbol{9}$}

(Pigina 1)

El autor del Cartás dice, «Tn el año 504 (20 de Julio de 1110 á 10 de Julio de 1111)

1 Tardo basiante más en morir.

2 Temim no era hijo, sino hermano de A]. 
el príncipe Sir, bijo de Atubéquer, conquisto a Saytarén (en el terto impreso

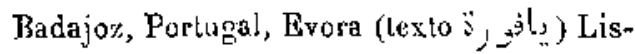
boa y todo el país del Algarbe en el mes dc Dulceda (11 de Mayo â 9 de .lanio de 111l), comunicando la vickoria al Príncipe de los muslimes Alí (prág. 105). Ahroed Anasiri, tomo I, págrina 125, dice lo mismo, aunạue con Ja variante de no indicar que se opoderase de todo el Algarbe, $y$ poniendo bien los nombres de Santarén y Erora.

IA Chronicon I.usitano (Esp. Seg. Lomo XIV, 2." edi. pág. 420) da menta da osta expedición con estas palabras: "Tira 1149 hex Cyrus cepit Santarem sept. kal. Junii (26) de Mayo). lil Chrouicon de Coimbra (Lspaina Sag. tomo XXIIJ, pág. 331) diec: «In Lirn 1119 (léase 1149 como dice el editor) pressa fuit Civitas Sancta Erene a Rege Cir VIII. kal. Junii». 


\section{0}

(19yona 12)

La fecha y lugar de la derrola y muerte de Almostán fuć lijuda por Dozy (Recherches sur l' histoire... 3." edi. to. II, pág. 15): a los documenlos aducidos por Dozy merece añadirse el texto de los Annales loledanos, que mencionan el lugar de la derrota, si bien en el texto se ha impreso ralentia por Falliorra, dice: "Nurió el Rey Almortayen en Valencia, Era 1148; (Esp. Ser. tomo XXIII, pás. 338).

Abenaljatib da noticia de esta derrota de los musulmanes con más detalles que los autores hasta hoy publicados ó conucidos, si bien equivoca ol año del suceso, que como probó 1)ozy, no cabe suponer anterior al 503 de la hégira.

Wate interesante texto dice:

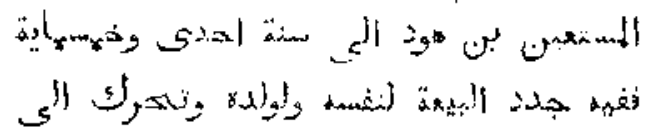




\section{$-245-$}

J

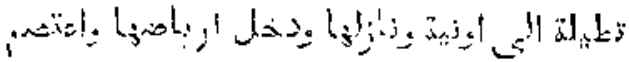

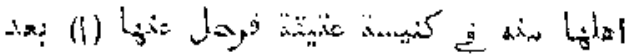

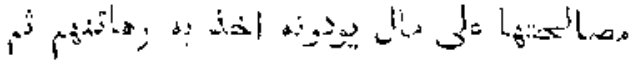

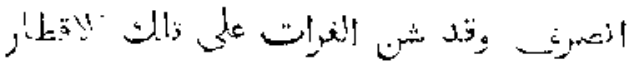
谟

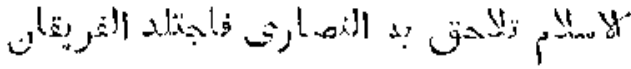

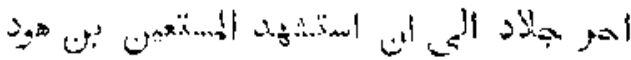

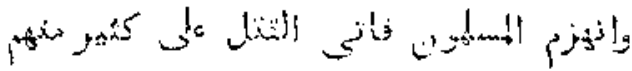

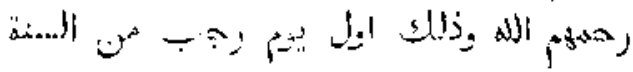

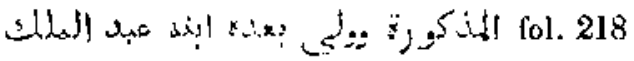
de la copia de la Academia y fol. 22 del ejemplar copia del de Argel.

"Continuó el reinado de Almostáin hasta el año 501 (léase 503): en este aũo, renovada su proclamación y la de su hijo, partí para

(1) En mi copia 
la guerra santa en el mes de Chumada postrero (de 26 de Diciembre de 1109 á 23 de Enero de 1110), y enirando por 'l'udela, basta Olite (f) ', la sitió, tomando sus arrabiles: suz moradores se defendieron en uar irrlesia antigua en la cual entró (ó de la cual se apartó) después de haber capitulado con dinero que le habían de pagar, y por el cual tomó reheses: luegro se marchó, pues ya hibía hecho incursiones por toda esta región, quemando, robendo y destruyendo: cuando estaba á punto de llegrar al pais del islam, le alianzaron los cristianos y pelearon ambos ejórcitos con denuedo (?), hasla que murí́ mártir Almostáin ben Ifud con derrota de los muslimes, $y$ miterte de la mayor parte de ellos, Dios los haya perdonado: esto sucedió el prixuer día de liacheb (21 de Euero de 1110) del mencionado año: después reinó su hijo Abdelmélicr.

4 Tol como aparece este nombra on al texto arabe, lo más natural serfa lecer oña un omile; pero su mucha diatancia sace quo ninguno do estus dos atrîbuciones resulte accpiable: por oso sospechamos pueda ser olite, como podria leerso sin gran canbia de lotras. 


\section{$-247-$}

\section{1}

(Paxina 12,

La fecha concreta $y$ decalles ilc in toma de Zaramoza por Alionso el I3atallador resultau muy vagos tanto en los autorez aragoneses cono en los árabes.

El autor anóuimo de 拍 Crónica do San Juan de la Peña, prinera fuedu escrita de nuestra historia greneral de $\mathrm{A}$ ragón, no de le fecha de la conquista, que parece referir al ano 1111 o 1112 , pues lo vago de la relación no permile fijar la fecho (jug. $68 \mathrm{de}$ la edición de 1876).

Blancas, lamentando la incertidumbre que reinaba en los autores respecto à la recho de la loma de Zaragoza, se propuso investig8r de un modo especial este pualo de nuestra historia, y contra la opinión de Zurita, que la fija en 1118, du como indudable la de $1115 \mathrm{con}$ estas terminantes palabras: «ly, pues, eqidente que recobró Alfonso la ciudad de Zaragoza ea al año 1115, que correspondo 


\section{$-248-$}

á la fecha del anterior privilegio 1153 de la era hispánica $1 . \gg$

Ni aun en estos últimos años se ha podido tjar de un modo definitivo la fecha de la toma de Zaragoza, al menos en cuanto al mes; pues el año resultaba ya fijado: así, el diligente investigrador de auestrus cosas aragonesas tice al hablar de ésla ?: Según Ebn Al-Abbar, on el mes de Ramadhan (24 de Abril á 24 de Hayo de 1lly): véase Abd-l' Halim; rreemos, sin embarzo, que fué á fives do nño por el mes de Dicientres.

Algo más explícilos son los autores árabes, y por ellos anbemos alygulas noticias de las cosas de Zaragoza durante estos años.

Muerto en 508 en la batalla del Congost de Martorell el valí de Zaragraza Mohámed hijo de Alhach, 'pue parece ser ol verdadero

1 Conendrios de las Costs de al ratgon, obra oscrita en lutil por forinima de Dtascus, cuonista del reino, y

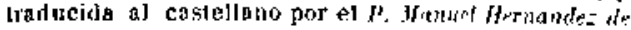
las Encueias Pirts, Zaragoza, 1878 , (156. 13 ).

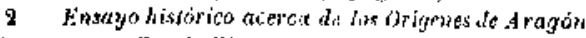

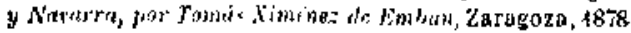
(j)g. 218 ). 
jefe, $y$ destitúdo por laberse vieito loco el príncipe Abuabdala, hijo de Lusuf Abentexufin, conocido por Abenaixa, fućsce reemplazado jor el Príncipe Abubequer, hijo de Ibrahim, hijo de 'Tíiluit ó '́efulat, valí de 3 Iurcia, cnñado de Ali, y pidre serrín parece del Yahya Abengania, de quien so lablará luego: el nuevo valí de las fuerzas musulmanes de Valencin $y$ Karagroza parece quiso 6 luvo encarro da vengar el desastro del Congost de Mlartorclt y llegó hasta Barcelona, que sitió durante 20 días; al refresar de esta expedición, se hizo cargo del gobierno do Zaragoza, doude dâdose tono de príncipe, perraaneció liasta su muerte ecaecida en el año J̆l0 (16 de Mayo de 1116 á 4 de Mayo de 1117) (Abenaljatil), thato, fol. 98 de la colección Gayanģos; Cartás, pági ua 104; Alimed Anasirí, tomo I, pág. I25; Bibl. Ar. his. III, pág. 55).

Muerto Aben 'lifiluit, y acosada Zaragoze por las armas do Alfonso, liubo de acudir en su auxilio el valí da Murcia, el Príncipe Abuishac Ibrahim, hermono de Alí, quien después de arreglar los negocios de 
Zaragona se volvió a Murcia (Abenaljalib, Ihata, fol. 98).

Pocu después, ya en 51l, se hace cargo del gobierno de Zuragoza Abdala bijo do Almazdalí, quien combatiendo á Alfonso, le hace retirar, según el autor dej Cartás, pero muere después de un año completo de mando, quedando la ciudad sin valí.

Parece que por este tiempo Alfonso, 6 quizá el Conde de Barcelove, silia á Lérida, en cuyo aurilio fueron fuerzas de los almoravides mandadas por 'Temim hermano de Alí (Cartás, pág. 106), quien una vez levantado el sitio, se volvió á Valencia: esta expedición pera levantar el sitio de Lérida, de la que parece que no hay noticia en nuestros autores cristianos, resulta de importancia según los autores árabes, pues Alfonso hubo de abandonar á Lérida, cuyo sitio había emprendido con grau empeño, así que no cej̄́ de su propósito hasta después de haber perdido 10.000 cuballeros en la exapresa: la fecha no resulta consignada on el Cartas, y aunque refiere la expedición despućs de indicar la muerte de Mazdalí, que murió en 
512 , como en esta expedicion hace intervenis al valí de Zaragroza, porece resultar que debió de lener lugrar algnnos meses anles, ya que por otra parte se indica que el fracaso de Lúrida flá causa de que Alfonso hiciera un llamamiento á los jefes de los francos, que vieuen como hormigas, $y$ con su auxilio se pone silio en regla á la autigua corte de los Benilud, que combatida con torres de madera sobre las que se monlan mátyuivas de guerra, y acusada por el lambre, tiese que pedir capitulación ofreciendo rendirse, si en plazo corto no le llegraba auxilio, que esperabe de parte de lus alraorapides.

I.os autores árabes, cue mevcionan la ioma de Znragoza por los cristianos, todos le asiguan la fecha de 512 (de 24 de Abril de 1118 á 13 de Abril de 1119): la generalidad no fijan el mes ni día; Almacarí (tomo II, página 767) y Abenalabar (apud Dozy, Nolices, pag. 225) señalun ol miércoles 4 de Ramadán, que corresponde a 19 de Dicienbre del año 1118 , fecha que de un modo menos concreto sólo encontramos eatre los autores cristianos en los Anales Complutenses, que dicen: 


\section{$-252-$}

aEra MCLYY1. Capta est Civitas Casurateguste ab Adefonso Rege Aragonensium mense Decembris" (Lisp. Sag. to. XXII, pág. 315).

Berganza (Antigüedades de España, tomo II, pág. 29) á continuación de nolicias peregrinas que no encontramos en otra parte, suponiendo que el a6 de Diciemabre huva ua muy reñida batalla con el rey de Marruecos, el rey de Granada, el rey Temin y su hermeno que huyó; que todos fueron vencidos, presos y muertos en el campo, añade: "y el 10 de Diciembre fué tomada la ciudad: ya hemos visto que la lecha 4 de Ramadún que asigran los anlores árabes, corresponde al 19 de Diciembre de 1118.

Cina dificultad grave contra la admisión de tal fecha resulta del hecho de que los Arales Toledanos $I$, cuyo autor, moro probablemente, y casi siempre muy exacto, dice: «El Rey de Aragón con ayuda de Dios y de sus Cihristianos, en el mes de Mayo, priso Zaregoza de Moros, Era 1157” (léase 1156 como observa el P. Flórez en su Esp. Sag. tomo XXIII, pág. 388): sin duda el autor de los tales Anales Toledanos I, consignó cono fo- 


\section{$-253-$}

cha de la toma de Zaragoza la del principio del sitio, que según Jos Anales Compostelanos duŕ́ VII meses, y por tanto debió comenzar hacia el mes de Mayo: este detalle de los siete meses de sitio no lo encontramos en otro antor ni moro vi cristiano $y$ nos parece digno de ser tenido en cuenta; dice así: - Hic (Alfoosus) in bellis expertus el audax in principio rogni sui Cassarangastam VlI mensinm olssidione cinxit, in qua obsidione septies cum Hoabitis dimicevit et devicil: landem ipsam urbem cum Caslellis et Villis sibi adjacentibus cepit sub era 1157\% (léase 1156 , como abserva el editor. Esp. Sag. tomo XXIII, pág. 32̇].

De las condiciones que los moros de Zaragoza propusieron á D. Alfouso el Batallador para entragar la ciudad en el caso de que no fuerun socorridos, nuda sabemos directamente por autores antiguos; pero el Sr. Ribera, con sacraz crítica, ha sabido descubrir el texto casi futegro de la capitulación en las de Tortosa y Tudela (Colección de Estudios arábigos, tono II.-Orígenes del Justicia de A.ragón, pág. 397 y giguientes). 


\section{$-254-$}

\section{2}

(rjagina 1,

Las circunstancias y liasta la feeha en que el último rey independiente de Zaracroza Abdelmélie. Imadodanla fué echado de le antigus corte de ins reyes Tochibies y de los Benilud, son desconocidas por la mayor parle de los autores árahes y puede decirse que por todos los cristianos: tanto unos como olros suponen que Alfonso el Batallador fuci quien desposeyó del teinóa Abdelmólic lmadodaula, que había sido destronado por los suyos ayudidos de los almoravides, ó más bien fué destronado por éstos, ayudados 6 byudondo a una fracción de los moros zaragozanos.

MLerto Abmed Almostáin II en la batalla de Valtiersa, el $1 .^{\circ}$ de Tacheb del año 503 (24 de Bnero de 1110), le sucedió en el trono de Zaragoza su hijo Abdelmélic. Imadodaula, de quien prece que los subditos exigieron el compraraiso de no aliarse con los cristia- 


\section{$-255-$}

nos (esta exigencia procedería sin duda del partido más exaltado en maleriss relicriosus, y afecto á los almoravines): Lbeualjutib (.lanuscrilo Ar. ㄱ. 37 de la Acadenin, Cul. 218) se hace eco de thiat radicióa, que no roe parece admisible, inticando que al mes de la muerte de Almostáis II, el valí de Folencia 1 Abdelmélic hijo tle ['itima entró en deseos de apoderará de \%uracroza, á donde se dirigió con su ejúceito, puro que al aproximarse. moros de la cindad (el parlido no nfeclo á los almoravides?) salicron á su encueutro y le suplicaron que se retirase y no promoviesa la guerra civil, sino que ayudose al l'ríncipe contra los cristianos y efectivamente so retiró de ellos"

Mas aceplable nos parce la versión do

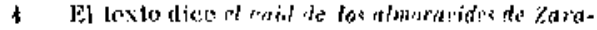

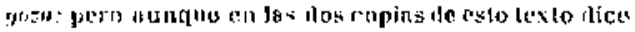
lo misins, cremos ylue el Abledmelic lijo do Fátima

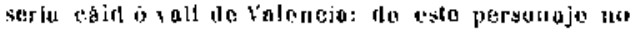

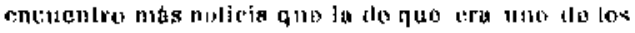
eapitanos quo ncomptioban al principe Tellim en la batalla do Ucles, si bisn delnemos novertir \{ue albi so fo llams dbdola hijis tlo Gohamed hijlo de Pialima. Y quizh no sea el mismo. 


\section{$-256-$}

que se hace eco el antor del libro Holal amanriá (Ms. Ar. Ac. Coleccián Gayangos N. X, fol. 62 ver.) quien dice que la gezte de estado había acousejado â $\Lambda$ lí que se apoderase del reino de los Benihud por convenir así á la religión, por sus relaciones con los cristianos: conforme á estas indicaciones Alí Ies onvió el Príncipe śbubéquer hijo de Tifiluit (léase Molámed Abenalhach segín veremos) con un ejércilo: Abdelmélic en vista del peligro, y como sorprendido por tal resoluoión de parte de Ali, se fortificó y escribió á óste recordándole la antigna amislad entre ambas familias, cuja carta copia el autor; pero si bien Alí revocó la orden, como al recibic la coutraorden, los almoravides eran ya dueños do Zaragoza, no parece que se pensara en deslacer lo hecho, y se aplicó la tenría de los hechos consumulor.

Según otra versión del mismo Abenaljalib, que tampoco creemos del todo aceplable, disgustados los te Zaragoza (el partido afecto a los almoravides) porque Abdelmćlic hubía hecho alionza con el rey de Castilla (cstaba concertado el matrimonio de D. Allonsa con 


\section{$-25 \%$}

D." Urraca, J por tanto hasta cierto punto era rey de Aragón y Castilla, pero no es creible tal alianza) contra lo que había promelido, Jlamaron al cáid de Valencia Mobámed thijo de Alhach, quien sin duda habría recibido órdenes 6 instrucciones de Alí, y habićndose presentado en Zaragoza, sus partidarios le abrieron las puertas de la almedina: Abdelmélic, según el autor, pidió auxilio a Alfonso, y habiéndose trabado combate con Abenalhach, abandonado éste por las gentes (por sus partidarios) nutrib (no es exacto), siendo derrotados los muslimes (los afectos á los almoravides) en la tarde del domingo 15 de Dulcada (aunque el texto pone aquí Dulhicha, que es el mes siguiente, esta indicación corresponde al hecho posterior; además de que suponiendo esto, resulta bien la fecha, pues el 15 de Dulcada era domingo, $J$ el is de Dulhicha fué martes).

Instalado Mohámed hijo de Alhach en la almedina $y$ Abdelmélic en la ciudad, habría sin duda batalla 6 batallas entre ambos parzidos, en una de las cuales, según 1 benalabar (Bibl. Ar. his. lo. VI, pág. 5555), muALMOR_V 


\section{$-258-$}

rió Abderrahman hijo de Molámed, couocido por Abencorreyax, y en la mañana del sábado 10 de Dulbicha la gente de Zaragoza echó á Abdelwólice, entrauto Hohámed liijo de Alhach en la ciudad: por lo que dice Abenalabar (Dozy, Notices, pág. 225) y aun el mismo Ahenaljatih al fin del texto anterior, podría suponerse que Mollámed bijo do Alhach entraba en Kararroza, llegando desde Valencia, pero creemos que entró desde la almedina, que sería la Aljaiería: la fecha. scibaro to de Duthicha do 20.5 de la entrada definitiva de los almoravides eu Zarargoza no cs exacta, pues el 10 fué jueves, no sábado, como dicen Abenalabar $y$ A benalijutib.

Despućs de todo, atendiendo á los muchos autores, tanto árabes como cristianos, que suponen el destronamiento de $\Delta$ bdelauélic Imadodaula por Alfonso, casi podría ponedie en duda el conjuato de la narroción an terior; pero tenamos monumentos, al parecer irrecum sobles, del dominio de los almoravides en Zaragoza, al menos desde el ario 504; se conservan dos monedas de cobre acuñadas en Zarggoza en los años 504 y 509 , á nombre de 
Alí hijo de Yúsul emir de los muslimes (véuse, Monedas de las diuzstías arábigo-espanolas por D. Autonio Vives, números 1832 y $183 \%$ )

\section{$\mathbf{1 3}$}

(Pàgiua 1?)

No es fácil fijar a qué población actual corresponde el aby, cras, al que hubo de acogerse el destronado rey de 7atagoza: que sepanos, se han asignudo t.res correspondencias diferentes: Rofo, on la provincia de IInesca, Rueda de dalon y Nonesterio de Ruedo, junto á Escalróm.

La opizión de que el Rota, donde se relugia el destronudo rey de Zarygoza, sea el Ihoda de la provineia de Huesea, y que se llamase Rotalyohud, Rota de los judios, no tiene fundamento alguno en cuanto a su primera parte, pues es absurdo suponer que los reyes moros de Zaragoza tuviesen su sitio real de recreo ó su punto de refugio á 30 leguas de la corte en medio de pás dominado por los 


\section{$-260-$}

cristianos: que el Thota se llamase Fotalyehud, que se ha traducido fola de los judios, casi creeríamos que es insezción de Conde, quien para les campaias de Omar hijo de IIafsún iuventara enlre otros pueblos este Rotalyehud, no mencionado de este modo por chinguno de los autores árabes que hoy conocemos: como nos hace observar amigo muy competente en estas cosas, quizá el Rotalyehud es pura y simplemente Rota Bemihud, Kota de los Benihud, por ser el castillo fortaleza-refugio de estos Príncipes. que Conde cregó identificar con Roda de la provincia de Huesca.

Que el Rota de los Benihud fut: el antiguo castillo, donde Alfonso II de Aragón fundó el Monasterio de Rueda, ha podido hacerlo sospechar la circunstancia de esta elección; el que al fundarlo fuera propiedad real el coto redondo de su jurisdicción, y el que el castillo y pucblo de Rueda de Jalón pueda parecer de poca importancia para haber sido buluarte del reino de Zaragaza, donde los Benihnd conservaran por algunos años un resto de su antiguo poder.

Fin verdad que en los autores árabes no 


\section{$-261-$}

encontramos indicaciones que puedan servirnos para resolver la cuestión: sólo una teníamos anotada que pudiera servirá este objeto, cual es la de que ca la porte superior hay una fuente; pero esta circunstaucia no resulta ni en el urtículo referente á Rnoda de Jalón, ni al Monusterio de Rueda, en los artículos geográficos respectivos del Diccionario de Madoz, en el que se acepta que Rueda de Jalón corresponde al Rota, fortaleza del reino de Zaragoza.

Argumento muy decisivo en favor de esta atribución podría creersc ol suministrado por el Diccionario geogrático de Yacut, que de las varias pobliciones que los antores ărabes mencionan con este nombre an Espa-

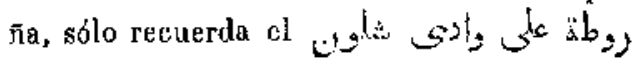
Roda (Rueda) sobre el rio ladón, de la cual, fijada su rocalización, sólo dice que era un castillejo 6 fortaleza muy pequeña, de los distritos de Zaràgoza: por tunto no resuelve que el Rueda de Jalón sea el Rota baluarte y silio reál de los Benihud.

Casi no merecía la pena de consignarse 


\section{$-262-$}

que Berganza (hutigüedades de España, tomo II pág. 63) identibica el Rola con Rueda de la Mancha, diciendo que «Zafadola descendiente de los antiguos reyes de Córdoba (léaseZaragoza), que tenía su asiento en Thueda de La Mancha, se hizo vasallo del Einperador...,

\section{4}

(Página 13)

La pretensión de los almoravides de recobrar á Zaragoza pareció tan disparatada á nuestros historiadores aragoneses, relativamente modernos, que suponicndo que la expedición tenía por objeto levantar el sitio de Zaragoza, adelantaron la fecha; pero hoy. merced al testimonio muy repetido de los autores árabes, no cabe duda de que la expedición $y$ derrota de Gutanda fueran posteriorệ en dos aũos á la conquista de Zuragoza.

Nuestros autores, no sólo ignoraban la fecha de la batalla de Cutanda, sino hasla los detalles más importantes: sólo tenían noticia 
exacta de que babía sido una gran victoria obtevida por Alfonso el Batellador.

La Crónica de San Juan de ta Peña dice al tratar de ella: aIste Imperator vincil unagnum prelium in Culanda, in quo fuit stremuus miles Comes Pictauensis, qui erat ibi cum sexcentis equitibus et in quo filius de Miramomelim fuil mortuus cum innumersbilibus sarracenis et inde ehitum (editum?) fuit vulgare proverbium «Peior est quam illa de Cotandà (pág. 68).

Zurita en sus Annales (lib. I, cap. XI.JV) suponiendo la batalla de Cutanda anterior a la toma de Zaragoza y posterior al fracasado intento de Temim, hermano de Alí, de hacer levantor el sitio, dice: "tornó à onviar un sobrino suyo con gran mucheduubre de gente para que entrasen en Zaragoza y la abasteciesen: el Emperador salió á ól, y dióse la batalla, en la cual los moros fueron rotos y vancidos, $y$ se dice que murió el hijo del Miramamolin».

No se muestran más cnicrados los autores de los cronicones contemporáneas 6 poeo posteriores al suceso: los Annalis Toledonos se 


\section{$-264-$}

limitan á decir: "Fué la hatalla de Colanda, Era 1159 (Ev Aragón junto á Daroca): algo más explícitos los annales Composictani (España Seg. to. XXIII, yág. 321), consignan la batalla en estos términos: "Deiude Calatayud (Allonsus) firme obsidione vallavit, et acceptis obsidibus una cum Guillelmo Pictaviensi Comile, qui in auxilium ejus venerat, ad Castrum Colanda contra Sarracenos pugnaturus, iter direxil, jbique Sarracenis expugnatis, Castra Ioubitarum diripuit, et. ipsum Castrum Cotanda cepit».

Mejor enterados los autores árabes dan idea más clara de la importaneia de la derrota y es de esperar que se llegue á encontrar relación aun más detallada: Abenalatir (to. $\mathrm{X}, \mathrm{p}$ 多. 4l4) dedicando capítulo aparte a la narración de este suceso, dice: "Relaciom del sitio $d e$ la ciudad de citunda. En este año (514, $=2$ de Abril de 1120 a 21 de Marzo de 1121) uno de los royes de Alandalus, llamado Abenradizair, salio hasta llegar á Cutanda, la cuul eslá cerca de Murcia en el oriente de Alandalus y la sitió y epretó: el Príncipe de los muglimes, Alí, hijo de Yúsuf, estaba en- 
tonces en Córdoba con gran ejército de musulmanes y los contingen tes de voluntarios, y los envíi contra Abenradimir: habiéndose encontrado, trabaron un gran combate, en el que $A$ benradimir los derrotó con derrota desconocida (ó dura 1), muriendo muclsos nusulchanes; entre los muertos estaba A buabdala hijo de Alfarre, cadí de Almería, sabio práctico y ascetu justo en el cadiazgos.

Abenalabar en su Almocham 2 es quien nos proporciona datos más concrelos, $Y$ por cierto donde nadie pudiera esperarlos, al hablar de la muerte de uno en el año 5.t. pero $\sin$ relación ninguna con la lratalla, de este modo: "murió en el año 514, y ca este año murió Abualí Asadafí (el grau maestro de cuyos discípulos lrata el libro) en la haialle de Cutanda.... cuya fecha concreta trata de Gjar, resultando discordia en los autores, que varían entre 18,19 y 24 de Robia primero y 17 y 23 de Rebia postrero (6

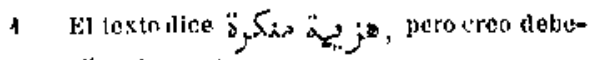

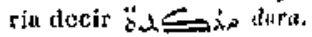

2 Bibl. Ar, hisp. to. IV, pág. 7. 
sea 17,18 y 23 de Junio y 16 y 22 de Julio de 11203: Abenalabar no dice de un modo explícito que la expedición fuera mandada por el Príncipe Ibrahim, hijo de Yúsuf rijo de Texufín, y por tanto hermano del Sultán Alí, pero lo dice Almacerí (to. II, pág. 759), que emplea en parte las mismas palabras con la particularidad de incluir alganas, que tomadas sin duda de in mismo autor, pero omi tidas por Alyenulabsr, alteras substancialmente el sentido, pues en éste resultaría que en la batalla había muerto el Príncipe Ibrahim asociado de Abuali Asadafi en la excelencia, siendo así que el asociado en la ercelencia, ó $t(\mathrm{t})$ excelente o mas que Abuali Asado/l, era Abuabdela hijo de Alfarre, que efectivamente murió en la batalla y era uno de los sabios y ascetas más ilustres: tanto A benalabar como Almacarí añaden que en la batalla murieron cerca de veinte mil voluntarios, sin que muriera ninguno del ejército 1.

4 Lo más concreto acerca de esta batarla lo dimos a conocer por primern voz on el Hotetin de la Jifrl Arratemia de la Historiz, tomn klil, pâg. 347 y sjguientes. 
La infuencia de la batalla de Cutanda en cl progreso de la reconquista de Aragón fué muy grande, y puede suponerse expresada con las palabras de los Anules Compostchnos, Post liwe, Alfunsus Daroca et Calalay atd et campum Arcilli cum universis eorum munitionibus sibi subjugavit: inde Tirasonam et Borgiam cepit, inde Leridam et Fragam peragravit..." pero por desgracia, al iusistir en apuderarse de Fraga, encontró el técruizo de su glorioso reinado.

\section{5}

(Pigina 18:

Aunque de la batalla de Fraga y de la muerte de Alfonso el Batallador heblan muchos autores moros y cristianos, coetáneos 6 poco posteriores, en genersl no fjan la Cecha sino eu chasto al año, $y$ esto no siempre con exactitud: y como por otra parte hay que fijar dos fechas, la de la batalla y la de la muerte, se la producido una gran confusión, de la que no es fácil salir. 


\section{$-268-$}

A pesar de haber sido la batalla de Fraga tan gloriosa para las armas musulmanas, pocos autores la mencinnan, así que noda encontramos en Almacarí ni en el autor del Cariás.

Adquí, al mencionar el año 5\%8, en el que muere alguno de los biografiados 1, dos veces dice: "y en este año fuć la grun batalla de Fragan. Abeualalir (tomo XI, pár. 2l), el autor que da más detalles, á quien hemos seguido en la narración casi por completo, conlundiendo quiza las fechas de la muerte y de la batalla, refíere ésta al año 529 ) (22 de Ostubre de 1134 a 10 de Octubre de 1135) $\vec{z}$.

tbenaljatib, en la biografía del hérne de la batalla, Yahya hijo de Alí, llamado Abenganis (el A bengama de nuestros textos, por no haber z̧nesto el punto á la i), dice poco y nada concreto de la batalla de Fraga: en la

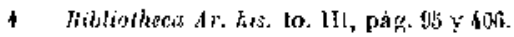

2 Ia tradueción del texlo la que nos tervimos, fué pululicada por nuestro amigo D. Tomas . Timine de Embtin en su Ensayo historico acorce do los oni-

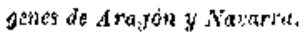




\section{$-269-$}

biografia de Abumoliámed Abdala hijo de Abubéquer, gobernador del oriente de Alundalus y luego de Granada y que usietí́ á la batalla de Fraga con cl convoy, dice que salí en el mes de Safar del año 525 (seráa 528 ) 4.

En la biografía de kúohámed, hijo de Sand hijo de líohámed Abenmerdanix, cuyo padre Saad cra gobernador de Fraga, también llace mención de ello, pero sin datos concretos.

A lgín detalie más da en otra de sus obras, que se conserva en la Biblioleca de $\mathrm{Argel}{ }^{2}$, aunigue tumpoco fija feclas.

Fntre los autores cristianos antiguos, el autor de le Crónica de Alronso VII, es quion da noticias más detalindas y concretas, fijando las fechas de la batalla $y$ de la muerte *

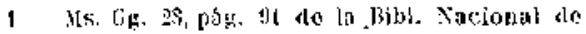
Madricl.

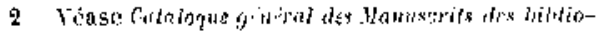

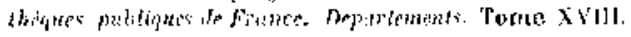

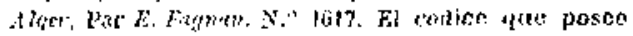
Ia linal Acudenia de la Misloria, no comprunde esia

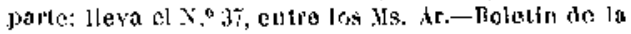

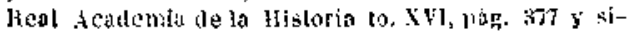
grientes.

3 Esp. Sag. to. XXl, warg. $393 y$ sigutrentos. 
respecto á la batalla le asigna la fecha scicto. decino hat. Augusti, y aunque no fija el año, como después refiere la muerte al 25 de Fnero de 1134, la batalla se referiría al año 1133, aunque nos inclinamos á ercer que la fecha sexto decimo hal. titg se refere efectivamente á la hathlla, $y$ al año 1134 '.

En al Martwinge de Solwnt, pablicado por Villanucra en sa Faje hteraro, tomo $\mathrm{IX}$, púg. 2:38, encuentro confirmación indirecta y pudiera decirse termiuade de la fecha mencionada; se lee: XVJ, Jal, Aususti. Ipso die inlerfectus fuit Rainundus 'Tuaballi, frater noster, a paganis apad Fragaw, anno M.C.XXX.IJIJ, incarnation is Xpi.;

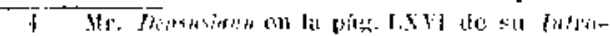

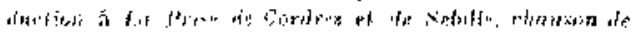

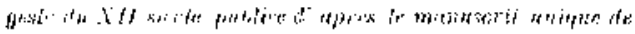

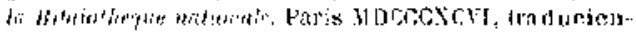

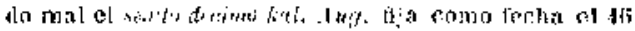
de agosto; esta olica, adomas to contener buenas bo. jicias bibliografiews, tiene jroiciciatles muy iniportaßtes para nossolros, co especial els lo reforente a lo que orderico vital sice del desquite tomado por Alronso después the la balälu, y lo relativo a la con-

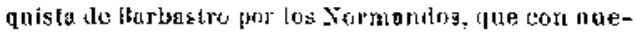

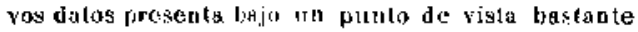
fiferento do convo la preseuto lrozy y acephibamos gencratmente. 


\section{$-271-$}

El año 1134 está fijado de un modo terminante por otros cronicones: así, los duzales Toledritus dicen: «Fue lit batalla de Prega, que tizo el Rey Dararon con Abengama (Abengavia) dia de Santa Rufina, é fue vencido el Rey Daragou, é perdiose allí, Era

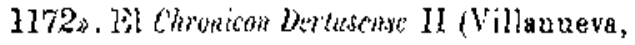
Viaje L iterario lomo V, pácr. 238) dice: «Era M.C.I.XXII, aneo MI.C.XXXIIlI, obviit Ildephonsus Rex Aragonit: apud Fragam, et Centulus de Biarn et Aimericns Narbon. et multi alii christiani pericrunts.

Parece ifie de los testimonios aducidos podemos inferir que la batalla de Fraga tuvo lugar el 16 de las caleudas de Agrosto, ó sea 17 de Julio de 1134 123 de Ramadia de 528 de la liérnira).

Respecto à la fercha de la muerte de don Allonso, hemos visto que sólo la Crónica de Aifonso VII, la fija en oclato tial. Foin. Fra chXill post millesintam, ó sea 25 de Enero de 1134, lo que no podemos admitir sin alterar la fecha de la batalta: algún autor árabe le supone muerto á los 20 días: los cristianos dicen en geveral que murió poco 


\section{$-272-$}

después: alguno concreta el punto, en $A \mathrm{~lm}$ niente (Esp. Sag. to. XXVITI, pág, 346).

El Sr. Ximénez de Enulún (pás. 229) indiea que segín algunos murió el 7 de Septiembre, fecha que ni admitimos ni rechazanos, pero que nos parece aproxionada á la verdad, pues parece indudable que vivió poco después de su derrota.

\section{6}

(])

La batalla del Congost de Martorell, como dicen los atitores catalanes modernos, $\sigma$ del Puerto, como dicen los autores árabes, tan ryloriosa para las armas catalanas, que humillaron el pader de los Almoravides en el período de su mayor pujanze, ha sido casi completamente desconocida, y aun hoy no presumimos p̧oderla poner completumeate en claro: en el tomo VJII del Isoletín de la leal Academia de la Historia, publiqué algunas noticias concretas relativas á la misma: aquí, con algrín da to nuevo, $y$ teniendo 
á la vista lo que encuentro en las cronicones anticuos, expondré las raxoues en que me furdo para exponerta camo se liace en el texto.

Que la expedición salió (prohablencale de Zarafroza) hacia principios del año 508 (7 de Junio de 1114 á 26 de Mayo de 1115 ), resulla del hecho de que las dos campañas parecen referirse por los aulores al mismo año, y que la jatulla, término de la primera campoūa, tiene lurrar en el mes de Safar 6 Rabia primero, que nos da Abenalabar (C6dice fotog. pág. 251. línea 17).

Lil dato de que la exjedición paseso por Cervera, sólo cousta, que scpamos, es la Grónira de Ripoll. publicada por Villauueva (Viaje literario, tomo $\mathrm{V}$, pág. 247); aunque la fecha está equivocada en el texto, es ovidente que se reflece á esta campaña: dice así: \&140... Raimandus Dax Provineice, et Comes Barchi. cum Pisis. Majoricas intrat. Moabita indignali hujus rei causa Barclinonam venerunt: á Cervaria usiue ad prafatam civitatem cuacta perderunt el vasturunt: Post hoc de a paucis (sic) devicti prulio AcMoltivites 


\section{$-274-$}

occiduntur in loco qui dicitur Martorelli, este mismo párrafo, más correcto, aunque mutilado, aparece en ol Croticon de Tortost, publicado por el mismo autor, diez párrinas antes y que dice: "Era M.C.LIII, anno M.C.XV... et capta est Hajorica civitas a Raymundo Comite Barchinonse et Pisanis. Pro hoe irati Moabila et multi ex eis perierunt in loco qui dicitur Martorcll».

Ślo en estos textos encoutranos indicación del nombre Mtarturell: de su redacción se infiore que el uno es trasunto del otro, ó ombos lo son de un tercero, descolacido para nosotros: los autores árobes le llaman batalla del Puerto, indicando que puerto es lo mismo que ?. merta.

Los delalles de las campañas y los nombres de los personajes están tomados del Cartás, pág. 104 y 105; Abmed Anasirí, autor que raizá vive (véase Boletín de la Real Academia de la Historia to. $\mathrm{XXX}$, pág. 25l) dice lo mismo y casi con les mismas palabras, aunque el texto resulta más correclo, y Ahenalabar, Bibl. Ar. His. touno IV pág. ó. 334, 193 y 309. 
La fecha 508 de 7 de Junio de 1114 â 26 de Mayo de 1115) consta en los textos árabes indicados: el Crohicón de Tortosa ser̃ala el año 1153 de la Líra, y 1115 de J. C., de modo que coinciden sólo en parte, $\mathrm{y}$ en mi sentír hay error de un año al asignar la fecta 1115 de la derrola en Martorell, pues en ella, según Abenalabor, murió Yahya hijo de Mohámed el Omuui de Lérida, en el mes de Safar ó Rehia primero ${ }^{1}$ (de 7 de Julio á 3 de Septiembre de 1114), y aunque esta fecha, constando en un solo punto, $y$ de un modo vago, no sea completaruente segrura, podomos admitirla provisionalmente.

¿QQuién mandaba el ejército cristisno vencedor en el Congost de Martorelle Ni los autores árabes ni los cristianos lo indican: cuando tratamos de esto por vez primera, admitimos, siguiendo á los autores catalanes, que

1 Esla bingrafia figura en la Biblisthera Arab. his. tomn IV, pág, 309, sin la julicación del mes, que consta en otra obra del mismo autor, la Tecmila, tow. mo llI, codice folografiado por b. Juliàn llibera, paginu 25 , línea 17, si bien haj que advertir tjue en vez

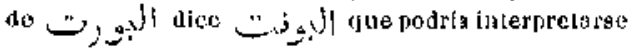
Alpuente. 


\section{$-276-$}

D. Ramón Berenguer, al yolver de la conquista de Mallorca, fué quieu sorprendió á los moros: para eslo Jubimos de suponer quis la batalla turo lugar hacia tines del año s,08, ya que constalba que $D$. liabló Berenguer estuvo en Malforca al inenos lasta primeros de Abril de ].115, y el año 508 de la liegrira termin6 el 26 de Mayo.

Tistudiados mejor los textos y con la indicación de que la batalla fué anterior, creemos hoy que D. Ramón I לerengruer para nada intervino en lo de Mastorell: quizá mi su mismo lugarteniente, ó como quiera cue llamemos á quié en su ausencia gobernase en Barcelona: la sorpresa, siendo pocos los moros, pues el trueso del ejército iba escoltando al bolís, pudo muy bien ser llcyada a cabo por los pajsanos de Martorell $y$ pueblos inmediatos, a prasis devicti, como dice el texto indicedo.

¿La expedición, cuya primera parte termina en Hartorell, fué mativada por el enojo que en los almoravides cansara la toma de Mallorca por 1). Ramón Berenguer y los de Pisa, como indican los tertos copiados de los 


\section{$-277$}

cronicones? lin nanera alcruna: los autores arabes nada dicen, $s$ se comprende; pues los almoravides nada tevíau riue rer cou los de Mallorea, con quiejes sólo temían de común el ser musulmanes: además de que, como acabamos de ver, resulta casi seguro que la batalla del Congosi de MIartorell fué anterior en algunos meses á la completa conquista de Mallorea, cujo último recinto fué tomado, según el $S_{l^{\prime}}$ Carnpaner, el 3 de Abril del año 1115 : cospeclo quc en el texto primitivo, de donde tomaran la noticia los dos cronicoIes conocidos, que de esto tratan, la irritación de los moros se referíría á la primera parte de la campara, tinica que consta en el texto actual, $y$ gue en el primitivo tupicra dos partes como en los textos áruhes, en los que, si no se laabla de irritación, sí de ln tristeza de Alí por la muerte de Abenalhach; y en virtud de esto, habiendo perdido la razon su hermauo Abuabdala Jlobámed, conocido

1 Campaner. Biwenejo histirtict, patg. 119: olros adolaritan los sucoses y otros los retrasan: veane lint-

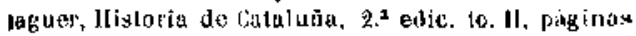
$309 \approx 315$. 


\section{- $278-$}

por Abenaixa, jefe de la expedición, innediatamente nonbró nuevo jefe, á quien sin duda daría b́rdenes de emprender nueva campaña, que los autores árabes consideran como continuación de la anterior.

Esta segunda compaña, ó segunde parte, dehió de tencr lugar á fines del año $508 \mathrm{y}$ quizá entrado ya el 509, y á ella dió fin don Ramón Berengruer con las tropas del llano de Barcelona y del puís de tor del Cartás le confunde con Alfonso el Hatallador, llamándole Abenramiro; Almed Anasirí eñade que era pariente de Alfonso, sea que haya visto esto en ejemplar wás completo y correcto del Cartás, sea que lo tome de otro autor, ó que se baya permitido alģuna pincelada por: su cuenta, lo que no creemos probable, dado el carácter de los histuriadores árabes.

\section{$x$}

(Jง่gำ 22)

Ofrece dificultades el fijar quién fuera el designada por Alí para mandar la seguada 
expedición contra Barcelona, ya qque las maticias que encontromos en los autores son escasas y contradictorias.

lil autor del Cartás (pag. 104) y el historiador marroquí moderno Alumed Anesirí (to. I, píg. 125) dicen que llegada fí of́los de Alí la muerte de Abenalhach on la batalla del Puerio, nombró para reemplazarte á Ábubéquar hijo de Ibrahim Abentifilujt'.

Ábenalabar (Bibl. Ar. his. to. IV, pátrina 5.5), ev la biografía de Ibrahim hermano de Alí, dice quo Ibrahim fuć el nombrado parh este cargo.

Aubque nos paruce que debe setguirse la indicación del autor del Cartás, ya que Abenalabar en la biografia de Ibrabim hermano

I Lil sobrenomber con cue era conocido eslo personaje, resulta escrito de dos motos muy diterentes: el antor del Carlḱs y cl moderno historiador ma-

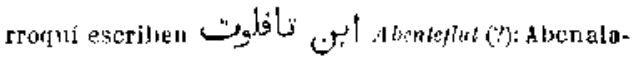

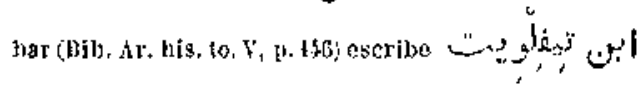
Abentifituit (in]: thenatjatib no menciona esto solurenombra en sul hiogtafia: conforme a la vocalizaciór ¿que consta en sbenalabsr, adoptanos lia marlo dientifluis. 
de Alí no sr muestra muy bien enterado, $y$ por otra parte el texto indudablumeale está fulto en algo, no deja de extrañarios tl que Abenaljatib en la biografía del emir Abubéquer hijo de Ibrahim nada diga de la expedición á Barcelona, siendo así que da noticias hasia delalladas de su gohiermo en Zaragoza.

No debe exiranarnos el que hoy no podomos resolver estas dificultades, pues ya Abenaljalib indica que los autores referían á Ibrobim, hermano de $\Delta$ lí, algín suceso referente al cuñado.

TAl emir Abubétquer hijo de Ibrahim Abentifiluit, uno de los jefes almoravides, era cunado de Alí, por haber casado con una hermana de éste, llamada franu (?), de la cual tuvo al célebre Yalya (el conocido por Abengania).

Venido á lispaña, Abentifiluit fué gobernador de Granada desde el año 500, siendo después trasladado á Zaragoza, según Abenoljatib (Ihata, Ms. de la Col. Gayongos, fol. 98) al salir de ella Almostáín Abentuud; pero en realidad en el año 508 , después de 
la muerte de Abenallach en la batalla del Puerto.

Abentifiluit gobernó en Zaregoza dándose aires de rey y visticndo como tal, hasta que murió en el año 510, estrechado ya por el rebelde Alfonso, que luego se apoderó de ella.

\section{8}

(Fuging 2f)

La Crónica del Einperador, retórica y pomposa como siempre, da noticias detalladas de esta incursión de los de Toledo (Esp. Sag. to. XXI. págr 365) con estas palahras: «ā3. Post moriam Grateri Hermenegildi Tolelanc militix Principis, sjeut superins dictow cst, Cossul Rodericus Gundicalvi invenit gratiam in conspectu Inperatoris; Imperator fecit eum Principem Toletana militia et Dominum totins Extrematura, qui congregans magnan militiam Castalle ot $\mathbf{l i x}-$ trematurx, insuper milites et pedites Toleii, et aliarum Civitatum, qua sub conditione Toleti sunt, ascendit in terram Sibillie el 
destruxit totam illam regionem, et fecil multas strages et incendia; ol omoia arbusta fruclifera fecit inceudi: et accepit magna spolia eormm et captivationem hominum et mulierum et parvilorum, quorum non erat numerus: aurum et argentum, vestes pretiosissimas abuudanter: greges equorum et equarum et asinorum et boum et vaccarum; et omnia pecora campi sine numero. Hoc videns Rex Sibillia convocavit multa millia Moabitarum, et $A$ rajum el Agerenorum ab Insuljs maris, et maritimis, et vicinos, et amicos, el multos Principes et Duces, et perseculus est Castra Consulis. Hoc autem non latuit Comiti: el Consul movil exercitum de castris, et stelerunt Sarracenis ohviam, et, divisi sunt pedites Christianorum in duas acies, et viri sacritarii, et fundibularii cum eis, el primi certaminis omues potentes, et deinde acies militum Avilee contra acies Arabum; secunda acies Secovia contra acies Moabilarum et Agarenorum: Consul vero stabat in norissima acie Toletana militia et do Trans-Serraun, et Castellm, ut auxilium ferret imbecillibus corde et consolationis, 


\section{$-283-$}

vulneratis. Inito autem certamine, Sarraceni clamabant tubis areis, el lambribus, et vocibus, et invocabant Mahomet. Christiani aulem ex toto corde clamalant ad Doninum Deum, et ad S. Mariam, ot ad S. Tacobum, ut eorum iniserereutur et obliviscerentur peccata Regum, et eorum, et parentum, el ceciderunt yulnerati multi ex his, et ex illis. Novissime vero quia vidit Consul firmiorem partem exercitus Regris Sibillice, convenerunt cum ipso in bello omnes constantes corde, et irruit in eunt: et Rex Sibillin cecidit in bello, et mortuus est, et multi I'rincipes ct Duces cum eo; et omnes acies Paganorum contrilie sunt, et fugeruat. Consul rera persecutus est eos usquc ad portam Sibilia, accepitque spolia corum, et prudam, coepitque reverti in sua castra.;

Mucho más que la Crónica del Fimperador, que olvidó decirnos el año y lugar del suceso, $y$ el nombre del gobernador ó rey de Sevilla, nos dicen los Anales Toledanos en tres líneas. «Entró el conde Rodrigo Ganzalez con gran hueste en el Axaraf de Sevilla, é lidió con los Moros, é venciólos é mató 
al Rey Omar en $\Delta$ zareda. Era 1170.» (Esp. Sag. to. XXIII, p. 389).

En dos autores árabes encuentro noticia concreta de la fecha de la batalla y de la muerte del grobernador de Sevilla: Abezulabar en el tomo IIY de su l'ecrnila (códice fot. pág. 210, lín. 16) menciona por incidencia la muerte del emir de Sevilla Omar Abenmacur, a quien mataron los cristianos en el mes de Racheb del año 526 (de 18 de Mayo á 17 de Junio de 1132): Ia noticia se da con motivo de la biogralia dol que eseribió al Sultán Alí de parte del pueblo de Sevilla, dándole noticia de la muerte y pidiendo auxilio: la misma fecha de la muerte del emir de Sevilla Omar Abenmacur, ó Macín, se da al fol, 26 re. del Ms. N. ${ }^{\circ} 1682$ de la Biblioteca del Escorial.

\section{9}

(Pägina 2:5)

Abenalatir (to. XI. p. 20) supone esta alianza en fecha posterior, en el año 529 


\section{$-285-$}

(22 de Oclu. 1131 á 10 de Octu. de 113ă): Abenalabar (Dozy, Notices, pág. 225) aun la retrasa mas, fijando la fecha 534, a mitad del mes de Dullicha (1 de Agosto de 1]40): la marcha de los arontecimientos narrados por la Crónica del Emperador parece obligar á aceptar la fecha indicada: la fecha dada por Abenalabar resultaría ser la verdadera, suponiendo equivocada la decena treinta por reiner: con esta tendríamos que Zaladola se labía puesio de acuerdo con Don Allfonso, a los tres meses de la muerte de su padre en Rueda, en el mes de Xaabín de 52i (Dozy, Notices, pág. 225).

\section{0}

(Página 3G)

La feclia de la muerte de T'exufín resulta muy dudosa por los autores á pesar de las muchas noticias que de ella dan, y de que la marchu de los aconlecimientos parece que debía Gjarla de un modo claro.

Tres son las fechas que ae asignan á este 


\section{$-286-$}

suceso: el 27 de lamadán del año 539 , el aกto 540 y el año อ̆ 41 .

La major parte de los auiores árabes frjac la fecha de 27 de Ramadán del año 539, con la particularided de que alsunos al fijur el tiempo de sa reinado, le señalan la duración de dos thros menos dos meses ó menos mes y medio, que efectivamente corresponden al tiempo transcurrido desde el 8 de Racheb del año 537, en que fué proclamado, hasta el 27 de Ramadán del 539.

Puedo verse esta fecha en Alimed Anasirí (tomo 1, pág. 127 y 142).-Abenjaldún (tomo VI, pán. 231, tomo VII, pág. 7\%).-Fil Alholal almauxía (fol. 82 de la Colección Gayangos).-Abenalcadi (pág. 106).-Abenaljatib (Ms. N. 37 de la Academia, fol. 250 rec).-Ahenalatir (to. $X$, pág. 409).-Abenalabar (apud Dozy, Notices, pág. 199).Cartás (108 y 122). - Abenjalicán (tomo III, edi. del Cairo, pág. 461).

Is facha 541 como la de la muerte de Texufín la encuentro en Aberjaidún (to. I, pág. 247 de la edición de Argel, $\mathrm{y}$ tomo VI, de la del Cairo, pág. 189); pero como este 
mismo autor, en otras partes ciladas antes, señala la lecha 27 de Ramadán de 537, su testimonio tiene poca autoridad, por més que alguta le presta pl autor del sirglo pasado Aburás Mollámed hijo de Alımed Abenalcádir, quien, ul fol. 34 qer, del códice 1235 de la Bibljoteca de Argel, ses̃ala la fecha $10^{\circ}$ de Xauai, 6 sea al amanecer de la noche de la ruptura del ayuno del año 5414.

La fecha 540, que en definitiva deberá aceptarse, no la encuentro consignada expresadnente más quo en Abdeluáhid, autor que por sí solo nos haría poca fuerza, pues incurre en bastuntes inexactiludes, aun en la narración de este suceso; pero tiene en su favor el testimonio indirecto, pero de indudable autcnticidad $y$ al parecer terminante, de las rnonedas acunadas á nombro de Texufín en el ā̄o 540 .

Dice Abdeluáhid (pág. 146 del texto $\mathrm{g}$

1 Acrica da este aulor del ciglo pasodo puedt: vetsc el trabajo pululicoto por el orientalista Liorfuos, que tradojo parte de esta obra bra lo Becue 2 fritom, tomo $\mathrm{Y}$, correspondicnte al año 1861: st texto ca fue nos ocupamos rstá trałucido en In joug. 38i 


\section{$-288-$}

176 de la traducción por Fuguán) : A la mort de son pèrétuchefin se dirigea sur $\mathbf{T}$ !emcer, mais l' espoir qu' il fondait sur les habilazts de cette ville agant élé dẹcu, il gagna Orau, a trois étapes de Tlemcen. Les Almohedes l'y assiegcrent el le pressicent si virenent qu' il en sortit tout armć et monté sur une jument grise, ef se precipita dans la mer oit il trouva la mort. On dit que ses enemis repêthreut son callayse et qu' apres l' avoir crucjfić ils le brûlèrent. Dieu sait ce qu' il on est. Tùchefìn avait régré, depuis le jour de la mort de son pire jusqu' it ce que lui-même perit it Oran duss les circozslances que nous venons de dire en 5404 , trois ans moius deux mois. Pendant tonte cette période, il ne put se lixer oulle part, car le pays le repoussait toujours at les révoltes étaient incessantes». Según esto, para que tuese exacto que Texufin hubiera reinado tres ahos zacnos

1 En 539 selon les Berberes (IS, 178) ort ikl (ibi. 83); en 3.39 selon le Cartis (páp. 122) et lim Aluir $(X, 809)$, qui donne des detaj)s sur la mort de ce prince. Zerkechi (pág. .j) donne aussi la date du 27 Ilamadìn de l' ün 533 . 


\section{$-289-$}

-dos meses, debió de morir en Chumada 1.0 del año 540, ya que comenźs a reinar en Racheb del $53 \%$.

Parece que las moaedas som las 1lamadas á resolver la cuestión: de plio no vivió l'exufín lasta el año nacte las monedas del año 510 acunadas por su hermano y sticcsor mediato ó inmediato, Ishac !.

De que 'Texufín vivin a prineipios del auo 510 nos dire testimonio cazlro clinares, acuirados en Xul-Tamta, Segelmesa, T'remecén y Sevilla, descrios en la obra del señor Vires en los mimeros $1856,1860,1865 y$ 1869 y conter rados respeclivamente en las colerciones tel aulor (hay en el Wuseo Arq.), Nuseo Británico, Museo Arqueol. y Huseo Brit.

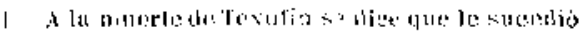

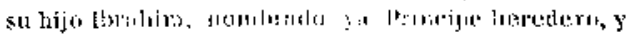

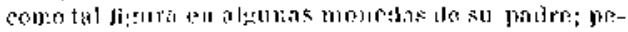

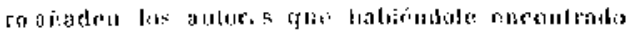

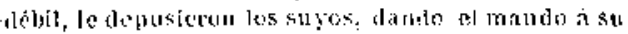

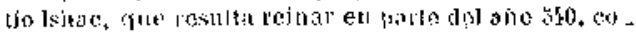

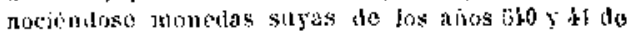

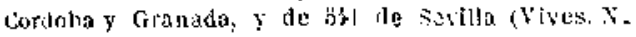
Isis a 1894 ). 
Mienlras no conocíamos de estas monedas más que el ejemplar existente on el Museo A rqueol. de Madrid, podía quizáa ocurrí la dida de que fuera una errata, posible y no desconocida aun en movedas; pero habieudo cuatro ejempleres de diferente población, desaparcee loda duda.

I moneda de 'Tremecén liene valor especial para la resolución de esta cuestión; pues por lo que resulta del conjunto de los hechos, muerto Texulín, Abdelmumen se dirige a Tremecén, compuesta de dos cindodes, distantes entre sí la carrera de un caballo; el gohernador militar con las tropas abendona la parte que ocupaba y ze retira á Fez, cntrazdo Abdelmumen en 'Tremecén, si bieu los de la otra parte se apercibieron á la defousa y hubicron de ser sitiados: la toma de la ruilad de 'Tremecén fué muy paco posterior á la muerte de Texufín, y según los autores, desde allí, ya en el ono 540, Abdelmumen se dirigió á Fez.

A pesar de todas estas razones que pudieran tomarse por decisivas, no debemos omitir un argumento en contra, que nos hace. 


\section{$-291-$}

sospechar pueda haber en estos acontecimientos alguna circunstancia especial imposible de deterninar.

Para nosotros tienen mucla fuera las indicaciones ivcidentales: eu el to. II, pág. 4 do la obra de Almacari, 0 -

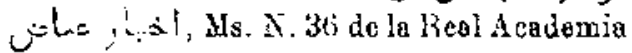
de la Historia, hablando del cedí de Cento Abulfádal lyad hijo de MLuza, encuentro la noticia de que á fines del año 530 fué nombra ${ }^{-}$ do cedí de Ceuta por Ibrahim hijo de 'T'exufín hijo de $A$ lí hijo de Yúsuf hijo de 'l'exufin i" ولى رغ

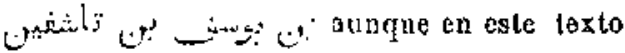
podrá suponerse una erpivocación, imitudablemente más fácil que en las monedas, de todos modos nos hace dudar, hasla que aparezcan nuevos datos, que do seguro existirán en algún texto desconocido por nasolros. 


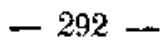

\section{$\$ 1$ \\ (Pagina 3?!}

De Abulualid Mobaned hijo de Omar Abenalmóndir, da noticias detallades Abenalabar en su biografía (Dozy, Noti. p. 202), incliyendo los más importantes de esie período de revuchis, culce el\}an aldonos referentes a Abencasi. Sidrey $y$ Abenlud, que quizá no constan en otra parte.

Parece que Abenalmóntir para poderse proclamar en Silves liubo die ser ayudado por Sidrey Aleculazir, ya ya se labía rebelacto en livora: haeso, Abembándir se dirigrio al castillo de Marchic (?), del distrito de Silyes, dondo se habían heolo fuertes los almoravides, $y$ se apoder bu castillo matando a sus defensores: on vista de esto, los almoravides que había en Becha, pidieron el amáu ó salvoconduclo para dirigirse á Sevi1la, y en cuanto salieron de la cindad, entró en ella Abenalmóndir con el ejórcito, que le bahía dado Sidrey, al frente del cual iban su 


\section{$-293-$}

hermano Ahmed y su amigro Ahdala hijo de Alí Abensomáit: todo esto parece que acaecio autes de principics de Rebí primero de 539 , en cuya fecla Sidrey y Abenalmóndir se presentaron en Mlérlola.

\section{9}

(Pèsina :̈fi)

Los textos árabos están unánimes en referir la proulanación de Abenliarndín al mes de Ramadar del ario 539 , fijando algunos el dia, jucres, cinco dol mes: suponen que Abenliud llegó á los 12 6 14 dias y se apoderó do Córdoba, huyendo Abeuhamdín a Lornachuelos (Do\%y, Narices, pág. 201): que pasados 12 ó 14 dérs, Abeuhamdín fué llamado de muevo a Córdoba, huyendo Abenkud a Jaćn y luego á Granada. El uutor de los Axpales Toledanos (pár. 330) nos pone en camino de aclarar estas fechas diciendo, arué Cahedola (Zafadola) en el mes de Yanero á Córiobo é mató á Farax Adali é fuxó á Granada, é pues que fuxó Cahedola, le- 


\section{$-294-$}

vantaron a A henhamdín Reg en Córdoba en el mes de Marcio Era 1183». De este aserto de los Annales Toledanos resulta que después del reinado de Zafadola, que duró de Enero á Marzo, en este mes fué proclamado Abenhamdín, $y$ como el mes de Rumadán de 539 comprende desde 4 de Febrero de 1147 a 5 de Marzo, los Annales Toledanos coinciden con los textos árabes en cuanto á la proclamación de Abenhamdín; si bien éstos nos Larían suponer que se trataba de la primera proclamación: de los Annales Toledanos, por sus lacónicas palahiras, pudiera creerse que al llegrur á Córdoha Abenhud nada luviera que ver con Abenhamdín, el cual sergín esto habria sido proclamado una solu vez: pero como los autores árabes hoblan varies veces, $y$ de un raodo terminanto do dos períodos de raando de Abenhemdín, tenemos que la proclumación de cinco de Ramadán fué la segunda $y$ más solemnc, en la que tomó los títulos de Almansur lmir almoslimin, como dicen algunos autores, y que diffcilmente hubiera aceptado gingún arabiata, á no encontrarlos en muchas monedas, 


\section{$-295-$}

que de Abenkamdín se conservan (Vites, Monedas Ar lns Din. 16. rsp., mímeros 1903 á 1908): el título de Anrisir titinaín, que lo atribuye Abenaljatib, omitiesdo el de Almansur, suponemos será una equivocacion. Valta t.jar la fecha de la primera proclamación, que de un modo aproximado fijan los Anrales Toledudos al decir que Zafadola fué a Cordoba en el mes de Laero (7 de Racheb a 7 de Xaabán): como los autores arahes están casi contesles en que $A$ bezhud llegó á Córdoba á los 12 ó 14 díes de la exalteción de Abenllamdín, ésta debió tener hugar en el mes de Finero 6 en Diciembre del año antorior, ó sca rn uno de los dos meses árabess Racheb ó Chumada postrero, á los tres 6 cuatro meses de la rebelión de $A$ bencasi en Mértola.

\section{3}

(legina :3,

Para sospechar que Abenhamdín no obraba por su cuenta en su primera proclamación, 
nos apoyomos en las indicaciones de Abenaljatib, quien en una parte dice que Aben-

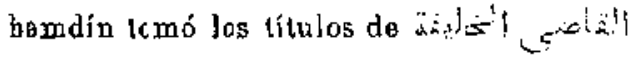

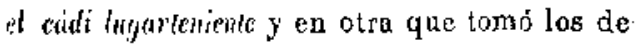
A niv almasliming defersar de la religion, títulos que deben referirse á difureute tiempo, pues quc en realidad son incompatibles: no puede suponerseque el tílulo en la suepción de Pontifice sumremo, sivo en el modesto de hiyfotenimite te otro, lo qut caradra bien con la primera parte del títalo, el calli, thymentente. Por otra parte, el autor de la (tronica dit Finperator D. Alfonso, aungue no siempre bien informado de lo que pasabe en Córdolya, dice (páger. 394) con relación á la expulsión de Aberloud, "que un secerdole mahomelono, llantodo thenfundi, el más rico de Córdoba, llamó á liarax Adalí de Calatruva y á los magrates, y trataron de matar á Zafulola, y reemplazarlen: esto prueba que Abeuhandin seguín en Córdoba después de haber cesado en el mando por primera rez, y aun ejerciendo el cargo, pues dice: habtit cum ris consilum ministerii sui; por tanto 
parece seguro gije el fin del primer período no fué violento ó debido á fucrza, g que los autores áralies lian atribuido al fin del primer mando su fuga $y$ retirada a Hornachuelos, á doode segín algrín untor se refugín al fin del segundo período, como veremos luego.

\section{4}

\section{(1)inina}

Con la sulida de Córdoba de tbenhamdín aparece on escrna olro personaje, Abulcásim

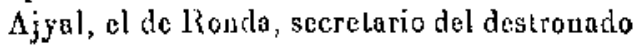
cudi, quien no queriendo ser menos que su anliguo señor, se declara independicnte en su ciudad natal, ameque por nuy poco tiempo; pues sus paisanos, disgustados de él, antraron en relaciones con Abulgomer, hijo de Asaib $A$ bengrarán, señor do Jerez y $\mathrm{Ar}$ cos, que lesta entonces liabía dependido de Abenhaudín: Abengarrín consiguió hacerse dueño do la alcazaba de Rondasin combatir, salvandoge Ajyal, aunque con dificultad, lo que no libró del sequeo las casaa de los par- 


\section{$-298-$}

tidarios de ésle, que vivió aún bastantes años, siendo en los últimos de su vida cadí de Córdoba y Sevilla, doade murió en el año 560 ó 561, según Abenalabar, que copia versos de varias de sus composiciones (Dozy, Nolices, pág. 222).

\section{$\mathbf{2 5}$}

(1'aging 81 )

Por el contexto de alguna de las relaciones de los autores árabes pudiera creerse que la entrada de Zafadola en Gravada tu vo lugar después de la muerte de $\Lambda$ benabicháfar de Murcia en in batalla de la Almozala en Rebí primero de 540; pero ulguna indicación de Abenaljatib nos hace ver que el de Murcia fué en anxilio de Abenhud 7afadola, por más que Abenalabar no lo indique como parecía natural.

Como en el mes undécino de $539 \mathrm{Zafa}-$ dala dió el mando de Guadix á Abdelaziz hijo de Abuásim, es de suponer que en este tiempo fucra ja señor de Granada, pues de 
otro modo no se compreude facilmente que lo fuera de Guadix (Abenaljatib, Ms. Gg. 28 de la Biblioteca Nacional, p. 147).

Fn la bingrafía de Alí hijo do Omar Abenadha, dice Abeualabar 'que dbenhud entró por la puertu del Mauror, acompoñado de su hijo Imadodaula: Abenadha, que al tiempo de la sublevación general había proclamado á Abeuliandín de Córdoba, salióa á recibir á Zufidola, y después de haberle saludado y lasperlado, como éste pidiese egua, Abenadla mand que la presenissen iın vaso preparado para perder á quien bebiese de ćl: al sucar la copa, el pueblo, temiendo un mal rcsultado, exclamó: "Yo behas, oh Sudtin»; por Io que abochornado Aberadha tomó el vaso y belió de él, $y$ con esto quitó loda sospecha; pero á la nocleo siguionte murió: A benhud permeneció diez días hospedada en unos jardines á la vista de Granada y después se trasladó á la alcazaba Alhambra: los combates entre los almoravicles de la alcazaba (del Albaizín?) y los reboldes de la ciudad no ce-

1 Moz,y, Nolices, pág. 210. 


\section{$-300-$}

saban y en uno de ellos fué herido y hecho prisionero el hijo de Zafadola, muriendo de las heridas á la noclie siguiente: los almoravides tuvieron la consideración de amortajar el cadáver de Iwadoduula y de eniregarlo a los de la ciudad para rue le diesen honrosa sepultura ó se lo llevasen: después de esto, Zafadola no permaneció en Granada sino cerca de un nes en... 1 injusticias é imponiendo tributos, Irasta que el pueblo quiso matarle $y$ hubo de huir de noche, dirigiéndose á Murcia, aunque otros dicen que huyó a Jaén.

Eu Granade rued6 con el mando de los rebeldes Abubéquer Mohámed, hijo de A benadha, pero á los ocho días, cansıdo de combatir á los almoravides, abardonó la ciudad y se retiró a $A$ imunécar y después al castillo de los Benibaxir ": sneedía esto, secrúu el antor, á principios del aĩo 540 (en esta hay error manifiesto): abandongdos por Abenadha los de Granarla, hicieron paces con los de la alcazaba, en la que estaba de valí Maimún

1 Falta lana palatira en el lexte.

2 Dozy, Nolices, píg. 209 . 


\section{$-301-$}

hijo de Yádar, que había sucedido al emir Alí hijo de Fono (esta Fono era hermana de Alí el emir de los muslimes), aunque se dice que como ingarienieute de Abeugania hobía tenido que apoderarse por luerza de la alcazaba, en la que pernaneció hasta el año 551, tn cuya fecha la ontrerú á los almolrades.

No puede aduitirse en todos sus detalles la dranática relación de los sucesos acaecidos en Gronacla durante los illimos meses del año 539 y prinera mitad del 540.

El mismo Abenala jar se liace uco de otra versión, que parece udmisible en cusi todas sus parles, y que secuimos on el texio, al mesos en su corjunto: supone al historiador de los almoravides, A hersáhibasalo, qua la muerte rle Abenadla fué posterior a la del lijo de Zafadola, quitándole tode la parto dramática: Abenaljatils dice que murió sitiando á log almoravides de la alcazaba, en el año 540 (Ms. de la Bib. Na. Gg. 2\%, página 578); é unistro autor, Albensálibasula, supone la llegada de Zafadola á Grauada anlerior á la batalla de la $\mathrm{A}$ lmosala y muerie dal cadí de Mureja Ábenabicláfar, quien iría 


\section{$-302-$}

a Granada en auxilio de los rebeldes al dominio de los alnoravides, es decir, en última término, en auxilio de Zafadola.

\section{6}

(Prginu 8)

El historiador Abdeluálid de Marruecos hace un pomposo elogio de Abenizad (pácina 1.19), el cual traseribimos, á pesar de que el autor no parece mny bien enterado, pues además de no der fechas, lo cambia el nombre, llamándole Abderrehman por $\Lambda$ bdala.

"Los habitantes de Valencia, Murcia y. la España orjental se pusieron de acuerdo para reconocer á uno de los principales del chund (ejército regional ?) llamado Abderrahman Abeniyad, qque era de lo más puro $y$ mejor del pueblo musulmán: supo (dice) por varias referencias que sus oraciones eran siempre oídas: entre lo mús notable que á él se refiere está el que era muy compasivo $y$ muy propenso á dersamar lágrimas: cuando montaba á caballo y tomaba las armas, no 
había quien le hiciese frente y ningún $\nabla a-$ liente podía salirle al encuentı: los cristianos contaban á él solo como cien ginetes y al ver su bandera, decían lati está ibeniyad: por la bendición de este hombre puro guardó Dios esta región y apartó de ella al enernigo, porque el temar, que se esparció en los pechos de los cristieoos, fué bostanto a reclazarlos del país: hlbeuiyad permaneció en el oriente de Alacdalus, defendiendo esta región hasla que murió no sé en qué fecha».

Podrá ser merecido este elogrio de Abeniyad; pero los cristinnos no le teudrían tanto miedo, cuando le vencieron en la batalla do Alloacete, camo verewos luego, con muerte del Rey Zafazola, á cuyss órdenes estaba, al menos de nombre, $\mathrm{J}$ después le vencieron otra vez, hiriéndole mortalmente.

\section{7}

(Pagina 87)

A pesar del perfecto acuerdo que en cuanto a la fecha de la batalla de Albacete hay 
catre Abeualabar y el autor de los Abales loledanos, es probalile quc las noticias que uuo y otro tuvieran del sucpso, fresen laslante diferentes: en la Crónica del limperador 1). Alfonso, cuso autor farese también loledano, se dan delalles que dificilmente pucten ponerac de acuerdo reu los que nos saministra Aluenalutat

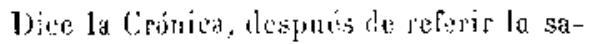
lida de: Ahetlitel de Cifroluba liulunces el

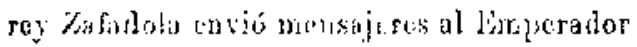

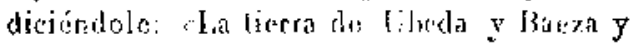
sus costillos no quieren ubeilererme ni pa-

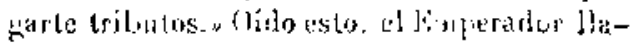

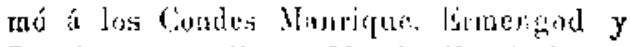

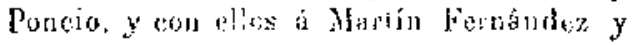
les dijo: Alel y sujetan á mi douninio y al del

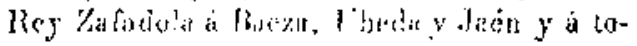
dos los relre]des; que vuestra cipar a no perdone á wingruno de eltos.; bu virtuel do esta orden, marclando con un gran cjécito, destruyoron aquella tierra rebele é hicieron grandes presas y inuclos cantivos.

Pero cuando loa ciudadauos de arucila región se vieron muy oprimilos, envizron 


\section{- 305 -}

una embajada al Rey Zafadola, diciéndole: "Yen, lilrranos de las manos de los cristianos $y$ te serviremos en paz a Al punto llero él con un grande ejército, y habiéndolo dejado á la vista de los cristianos, se dirigío en ademán pacífico al campamento de éstos y dijo a los Condes: Volvedme los cautivos y bolín que habéis hecho y con rosotros iré al Empersdor: cuanto me mande, yo lo haré." Respoudiéronle los Condes: elacjos esto de nosotros: tú enviaste mensajeros al Emperador diciendo: slos de ['beda están rebeldes a mí y á tí; ahora pues, envía un ejército. que destruya á ellos y á sn tierray-por eso hemos hecho lo que tú $\mathrm{y}$ ol Timperador nos hahéis mandado, - y Zafadola les contestó dicienda, $-\mathrm{Si}$ no me diereis todos los cautiqos y el botín, armado pelearé contra vozotros"-ahora es tiempo y ocasibn, contestaron los Condes, y al punto, ordenadas las haces, travaron la batalla, que se ggravó mucho: por fin volvieron les espaldas los Agarenos, declerándose vencidos $y$ el Rey Zafadola fué hecho prisionero por los saldados de los Condes: toníanle para llevarle á 


\section{$-306-$}

sus tiendas, cuando Jlegaron los soldados. que liaman Pardos, y habićndole conacido, le dieron muerte: Viendo esto los Condes se entristecieron mucho y cnvision mensajeros al Emperador que estaba en León, para que le anunciasen todas las palabras de la gruerra: Iuego que le dijeron, tu amigo el Rey Zafadola ha muerto, el Rey, muy entristecido, dijo: "Amigos míos, $y^{o}$ estoy limpio de la sangre de Zafadola -Cistianos y Sarracenos, desde la Arabia, que está junto al río Jordún, hasta el mar Océano conocieron que el Emperador no había tepido parte en lu nuerte del Rey Zafadola 1.

Qué relación debemos aceptar como más. probable? La de Abenalabar, que fija lugar y tiempo de la batalla y zada dice que no sea muy natural, ó la de la Crónica del Emperador, lleza de detalles minuciosos y dramáticos y que nada concreto dice del lugar $y$ tiempo del suceso?

No lo sí: en la Crónica del Emperador veo la pluma do un historiador, que preicnde

1 Chronica Adefonsi mpercomis. Esp. Sag. tomo XXI, pAg. 395 Y 395. 


\section{$-307-$}

ser clásico, cuidando más de la frase y del efecto que de la verdad histórica: es tal el prurito que tiene por darnos las palabras de los aclores de este y otros dramos, que no parcece, sino que á cada uno de los personejes acompañaba un taquígrafo, que transcribiera íntegras las arepgas y conversaciones de cada actor.

Mr. Mercier, en su Mistoire de $T$ A/rique Sepentrionale, tomo II, pag. 90, al tratar de los acontecimientos de la España musulmana relacionados con los almoravides, dice que al querer Zafadola licenciar sus auxiliares castellanos, ésios se rebelaron contra él y le mataron en un combate (año 1146): aunque la fecha resulta exacta, el hecho, como muchos de los que pertenecen á este período, está muy mal entendido.

\section{8}

(Pagina 92)

Adabí (Bibl. Ar. his. to. III, bio. 1005), que pone la biografía de Abumohámed $\mathrm{Ab}-$ 
derrahman hijo de Cháfar, hijo de Ibrahim, hijo de Ahmed Abenalhach, sólo labla de él como literato y asceta, indicando cono de paso que obtuvo el mando de Hurcia á la caída de los almoravides: en esto se refiere á lo que anteriormente habia dicho en el interesante compendio histórico, que forma como la Introlucción de su libro; pero por desgracia la línea correspondiente á este suceso en el manuscrito del Liscorial, único conocido, está ilegible y hubínos de dejerla en blanco en nuestra edición, pág. 33.

Abenalabar en su Almoclom (Bibl. Arab. his. tomo IV, pág. 233) pone también su biografía muy detallada, de la que se han tomado la mayor parte de los datos utilizados en el texto, y dice no haber leída la fecha de su muerte; pero que creír haber sido en la decena de 550: Adabí tampoco sabía la fecla concrela, y se limita á decir que fué después del 54\%. . 


\section{- $309-$}

\section{9}

Pagina los:

La fuga de Abenobdelaziz, cuando el ejército le hizo traición en Talencia, hasta que llergó a Almería, es referida por otros autores de nodo muy diferente, cou detalles que no tienen interés.

Al huir de Valencia, el alcázar fué soqueado durante alronos días y sus partida rios ó personas más adictas, fueron perserguidos: llevado a Nallorca desde Almería. A hesaudelaziz fus encerrado en Jóbrezo calabozo, donde no se distinguía el día de la noche: más de uoa vez fué dejado sin alimento alguno y su prisión se prolongó hasta diez años; en tan largo espacio de tiempo habo alguna vez de consolarse componiendo versos, al runos de los cuales copia Abenalabar.

Al cabo de largo liempo salíb de su prisión, merced á los buenos oficios de Abucháfar Abenatía, y como fuese partiderio de los almohades, advertido de ello Ishac, rey de Mallorea, le deportó á Bugía, de donde 


\section{$-310-$}

se trasladí á Marruecos: Abenalia, a quien debía la lihertad, gestionó su presentación al Sultán almohade, ante quien Abenobdelaziz recitó unos versos, que se dict fueron una de las causas principales de la muerle de Abenatíu. Abenabdelaziz murió en Marruecos en el año 578 á los 72 de eded.

\section{0}

(Pogrina 11:3)

No parece esto ten claro como supone Dozy: que el nombre no es árobe lo admilimos sin difieultad: para ludar de que sea Nartines nos mueven varias razones: si hubieren querido transcribir Hartines, probable-

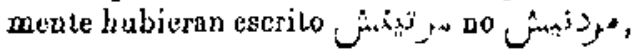
como escriben constantemente: es vordad que el uso do la s por $\$$ no es muy riolento, pero lo es fonélicamente el que pusiesen s de prolongación después del ;, si no se había de leer Martines, que nunca ha podido pronunciarse: el cambio de la vocal tónica $i$ de $\mathrm{Nar}$ linus on $a$ o e también parece poco admisible. 


\section{$-311-$}

No son gran autoridad cn cuestiones alimológicas los autores áralues; pero algruna hay que concederles, si no para la cuestión directa, al menos para fijar la pronunciación: Abenjalicán, guiado por la pronunciación del nombre, que pora él sería Merdanir, admite la etimología, poco limpia, que se da al sobrenombre de Constautino Coprinimo. (Abenjalicán, edición del Cairo, to. 1Il, página 466 .)

Quizá se haja cambiado ła vocal de la $>$, y pudiera sospecharse que se trata de un Mardonius, descendiente 6 nó de los antigios bizantinos de la parte de Cartagena: hesta pudieran sospecharse reminiscencias de raza en lo qua de las hijas de $\mathrm{Abeumerda}$ bix dicen los autores árabes, ponderando la especic de fascinación que sus rubios cabellos y ojos azules ejcrcieron sobre ulánimo de los dos califas que se casaron con ellas, principolmente la que casó con Ahuyacub Yúsul. 


\section{$-312-$}

\section{ax}

(lígín to 128)

Según Abenjeldún (to. IV, pág. 166 de la edic. del Cairo), "dlmudáfar, hijo de Isa, hijo de Almanzor Abdelaziz, hijo de Anásir. hijo de Abuámir (el Almanzor ministro de Hixem 11), al volverse al reino de Jáliva $y$ Murcia, se apoderó de Valeacia durante algún tiempo: luego murió en el sño 555, volviendo Valencia á poder de Abenorerdanix ». Sospeclıo que esta noticia está por compléto fuera de su lugar, y correspoude en parte á I00 años antes, pues parece se trata de Almotáfar Abdelmélic, rey de Valencia desde 453 á 457 , según la cronología recibida: si no es esto, $y$ no hay error en el texto, se trata de na personaje desconocido para mi.

\section{sa}

(1)ăgiou (28)

Esta rebelión en Valencia sólo nos es conocida por Abenalabar (Bibl. Ar. Hist. to- 


\section{$-313-$}

mo V, pág. 228), quien en la biografía de Abenalfáris, presidente que labia sido del Cunsejo en Wurcia, dice que lué nombrado cadi de Valeucia en el mes de Racheb de 546, y quéa privcipio de Xaual de este mismo año hizo dimisión de su cargo con motivo de la conmoción de Abdelmélic, hijo de Silbán 6 de Abenhámid antes de él, contra el emir Yrotamed Abensand, cuya solución fué el fuerte sitio de Valencia en el a iro siguiente.

Del mismo rébelde Abensilbán dice el mismo aulor (pág. 196), que en el dìo 547, duante su rebelión, dió muerte á un primo de Abenabdelaziz, el que había sido rey do Valencia en ol año 539, durante cuyo mando había sido cadí de Valencia y lo fué tambicin despuśs por nombramiento del rey Lobo.

Otra indicación encuentra en el mismo autor, quien al hablar de Asim, hijo de Jálaf el Tochibí, dice que murió en la cárcel en Claumada primero del año 547 duranto la rebelínn de Abdelmélice, hijo do Sabán (antes le llama Silbán), conocido por Abencholuna: aūade que fué enterrado en la muralla, 


\section{$-314-$}

lo que parece indicar que la ciudad estaba sitiade.

\section{$\mathbf{3 3}$}

(P’ąina 138)

Then general los autores árabes dan pocas y contradictorias noticias acerca de la toma ó reconquista de Almería por los musulmanes en tiempo del califa almohade Abdelmumen: y cosa singular, doude los hechos aparecen más claros y exactos, es en Abenalatir, historiador oriental, tomo XI, pág. I47 y 148, cuya narración hemos seguido por más aceplable.

El autor del Carlás, hacicodo intervenir a los mismos personajes, refiere este suceso al año 547 (pág. 126 y 177): el autor moderno Ahmed Anasirí, dice lo mismo, tomo I, página 149 .

A benjalưún (tomo IV, pág. 236 de la edición del Cairo, $y$ tomo I, pág. 315 de la de Argel) involuera la toma de Almería con la de Granada, refiriendo, parece, embos 
acontecimientos al año $549, y$ de todos modos poniendo lo de Almería antes del 552, pues que inmediatamente pasa á tralar de acontecimientos del año $55 \mathrm{l}$.

Que la fecha indicada por Abcnalatir es la verdadera lo prueba la conformidad di su relato con el de nuestros historiadores, que convienen en que asistió á Almería el Emperador Alfonso VIL, y murió en esta fecha al regresar de esta expedición, que es lo que también consigna el autor anónimo de los Anales Toledanos al decir: «Fué el Timperador con Minest á tierra de Moros, é tornóse ende en XXI días de Agosto al puesto do Muradal í murió y, Lira 1195\%.

Yr. Mercier, en la obra citada, pág. 96, también se expresa de un modo harto inexacto respecto á li muerte de Alfonso VII, y de la toma de Almería por los almohades, pues dice, que habiendo llegado á Abdelmumen la noticia de que los cristianos se habian apoderado de Almería (eayant appris que les Chrétiens a étaient emparés d' Almerie»), enyib á España á su hijo Abusaid: hacía 10 años que los cristianos eran dueños de Alme- 
ríu, $y$ lo dice el autor poco antes: respecto á la muerte del Emperador, muerto de enfermedad al regresar de la fracasada expedición de Almería, dice que encontró la muerte, combatiendo á los infieles.

\section{4}

(Papina Ifb)

La qreneralidad de los historiadores árabes dan muy poeas noticias respecto á estos acontecimientos, y casi todos equivocan la fecho, que difícilmente hubicra podido fijarse á no haberse servido Dozy del tex lo del historiador Abensáhibasala.

15) autor del Cartás, muy mal enterado de eslos sucesos, contra lo que podía suponerse, dice (pág. 127), que en el año 551 (por 549) los almohades se apoderaron de Grunada, haciéndosc la oración pública por Abdelmumen, quien envib un gobernador, pero que faltando al reconocimiento hecha, los de Granada mataron al gobernador, levantándose en ella Abenmerdanix, Abenhemaxico 


\section{$-317-$}

y al Calyo; pero en el año siguiente Abdelmuщeu cuvió contra Granada á sus dos hijos, Yúsuf y Otmán, quienes tomaron la ciudad por fuerza, matando al Calvo y á los cristianos rque estaban con él, buyendo Abeuheuochico y Abenmerdanix; añade el autor, esto dice Abenmatruh, pero Abensáthibasala dice que fué la toma de Granada en el año 557 , pero Dios sabe la verdad.

El mismo eutor del Cartás, más adelante (pág. 177), al hucer el resumen de la historia do los almohades, sin duda por la imperfocción de los códices de esta obra, dico que los almohades se apodcraron de Granada en el año 550; que luero sus moradores licieron traición á los ulmohades y los mutaron, y que en el eño 556 se apoderarou de nuevo de ella después do un fuerte sitio.

Abenabidinar reliere estos acontecimientos al año 551 (párg. lill del texto árabe 1).

1 Esla obra, interosante para ol conocirntonto de nuestra historia, está traducida al fratucés, haco muclios anos, y aponas es conocidia entro nosotros. llistoire de l' afrique de Mohammod-lien Abl ol-ltainiel Kairoudni, traduite de l' ataho por M. M. E. Pelligsier et hemusat. París HyccoxLr. 


\section{$-318-$}

Abenjaldín (to. VI, pág. 238 de Ja edición del Cairo, tomo I, pág. 317 de la de Argel) refierc esios acontecimienlos del mismo modo en el fondo y con menos detalles, que el. historiador Abensálibasale á quien hemos aeguido con Dozy.

Abenalatir (tomo XI, pág. 186) se mazifiesta bien enterado, dando en parte los mismos detalles que Abensáhibasals: en una circunstancia importante varía, al asegurar que $A$ benhemochico, cuando fué invitado por los de Granada á que fuese a ellos, y que le entregarían la ciudad, ya se labía hecho almohade; era por tanto de sus partidarios y súbdilos $y$ to excitabe contra Abeninerdanix: el autor ha confundido aquí los sucesos posteriores.

La fecha de la batalla de Asobica, arx.....J. el viernes 28 de IRacheb del año 557 está también indicada por Abenalabar (Dozy, Notices, pag. 230).

I. os Anales Toledanos con su siempre lacónica redacción confirman el año de la batalla de Asabica, que se acaba de mencionar, con estas palabras: "Lidió el Rey Lop 


\section{$-319-$}

con los rebeldes en Grupada y mataron a Pedro García, lira 1200. (l'robablemente este Pedro Garcíe, sería de Toledo.)

Mr. Mercier lepriversa también estos hechos, que refiere :1 año 1 lofi (pág. 96 del tomo citado).

\section{5}

(Pónina Istis

Los autores árabes menciouan esta bata-

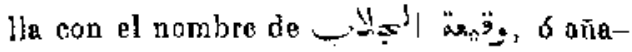
diendo el nombre vasio llkmo ó ceff, dicen ب.

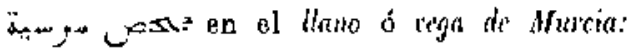
Ahenaljatib, Ms Ar. de la Academia N. 37,

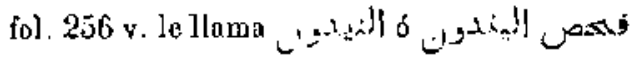
A benalabar (apud Dozy, Nolices, página 230) faja el día del mes, el lugar y su proximidad á Murcia.

La fecha y lugar de la belalla y a un la particularidad de haber muerto en ella muchos cristianos resulta confirmada de un 
modo indudable por un documento publicado por el P. Villanuera en su Viaje literario, tomo IX, pág. 239. En el Martyrologrio ó Necrologio Celsonense leemos: iddus Octob. In hoc die interfectus fuit Guillelmus de Spugnola a paganis cum multis ahis Xpianis, apud Murciam, anno M.C.LXV incarnationis Domini".

La fecla, Jos idus ó 15 de Oclubre de 1165 carresponde perfectamente al viernes 7 de Dulhicha del año 560 de los autores árabes.

Abdeluáhid el Mrarecoxá á su vez fija la orlografía del nombre del liggar de la batalla, escribietudo queda advertido, es autor no siempre bien informado, 6 guizá dijéramos mejor, que tergiverso con frecuencia los acontecimientos, da dotalles dignos de tenerse en cuenta respecto á la conducta de Abenmerdanix: recomendamos á los no arabistas la traducción de esta obra por el distinguido profesor de la Escuela de Letras do Argel, Mr. E. Fagnan, Histoire des Almohades d' Abd el-Whid 
Morridechi, haduite of mmotse por E. Fugnan. Alger, 1893.

\section{6}

De esta expedición dan noticia los ustores úrahes y de un modo parecido los Anales Toledanos (pác. 393) con estas palabras: $\mathrm{El}$ Rey de Xlarruecos tbenjacob yino á corcar á Huepte, é lidióla, é fue en hora de se perder la Villa por sed: más el día de Santa Justa envióles Dios agua del cielo cuanto uvieron menester é fue ka arora tan grand, que desvarató las tiendas del ling Horo. E era el Cardenal de Romn en Toledo, é daba grandes solturas: a ayuutaranse todos los de Thepaña, é fueron en acorro, é allagaronse azes con azes é uon lidiaron é fuese el Rey Moro; uns de tornada que tizo, ganó el Iiegno del Rey Top. Rra 1210 . 


\section{$-322-$}

\section{$\mathbf{3 7}$}

(Pagina IBo)

Abenalatir (to. XI, pág. 99): casi las mismas palabras emplea Almacari, 10. II, pág. 296.-Aberjaldún (to. VI, pág. 235 de la edición del Cairo, tomo l: pácr. 313 de la de Argel, y pácr. 188 del tomo 11 de la tradurción del İuron de Slane) da alyunos otros detałles de este sitio de Córduba por el Emperador.

Nuestros historiadores, poco entersdos de estos sucesos, pues no disponían casi de más datos que los que suministra la Crónica del Emperador, y los escuetos, pero en general exactos, de los Anales l'oledanos, 6 no liacen mencibru de esta campaña del Limperudor 6 la confunden con la del año 5,40 en ajoyo do Abenhamdíu contra Abengania.

Sandoval habla con alguna extensión de esta campora, conviniendo en que sno lay historia que di nalicia concretu de ella; esí. dice, que los alutores todo lo confunden sin orden ni concierto de los tiempos, ni aun 


\section{$-323-$}

saber las jornadas que el limperador hizo coutra Jos moros ': con el auxilio de los privilegios de este año cree aclasar la cuestión, pero incurre en Jos mismos escollos ea que tropezaron sus predecesores, confuuctioudo también esta joruada con la del az̃o 040 , evgañado por un docomento del Mouasterio de Eslonza del año 1188 de la líra (1150 de Cir. y 545 cle la légira), documento, ó falso o raal iulerpretado, en el que se lee, según al antor, como fecha: Post rulitum fossati, quo prouominatus Imperutor principem Hurorum Ahingawiam sibi vassulium fecit, et quandam pariem Corduba deprardavil cum Mezquita maioris. Fsta resena evidentemente se reliere á la expedición del año 5.10 de la liégira, pues que eftelivamente el limperador se apoderó, como hemos visto, de parte de la ciudad, que suqués con la mezquita, y Abencrenia le prestó homenaje.

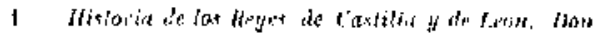

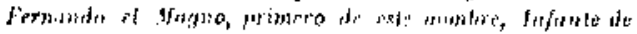

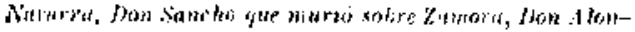

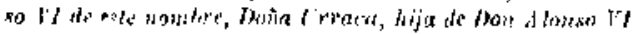

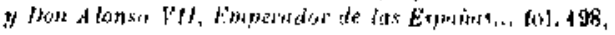




\section{$-324-$}

Por fortuna, Sandoval apoya su aserto con otro documento de más valor por su congruencia: del libro Becerro de la Iglcsia de Astorga copia una donación heclta en este año por el Emperarlor, y en ella se dice que esta hecha, «quando Imperator tenebat Cordubam circumdatam et pugnavit super eam cum XXX milia Nuznidis et eum aliis Andaluciis el devicit eoss: el antor deduce que la victoria sobre los Maznuditas (almohades) tuvo lugar el 23 de Julio tel año 1188 de Ja Era: la victoria que se atribuge al Lomperador, sería más 6 menos efectiva; pero si se dice que la sitio, y no que la tomase, parece puede darse por segiro '[ue no la tomó, y coinciden con lo que dicen los a u tores árabes.

Ios Anales Toledanos confirman esta expedición del lisperador con estas lacónicas palabras: CCeréo el Jimpcrador Córdoba, Era 1188, (Esp. Sag. to XXIII, pag. 391).

\section{8}

(Pagina ITO)

No resulta claro por los textos á çuién se debió principalmente la conquista de $\mathrm{Ma}$ - 


\section{$-325-$}

llorea; en general los autores árabes hablan sólo de cristianos: Abenjaldún (to. VI, págine 188 y 2.2 de la edición del Cairo, to. I, pág. 216 de la de Argei) la alribuyc á los genoveses: uuestros Crovicones mencionan el primer término a Ramón Berenguer III Conde de Barcelona, ayudado de los P'isanos y ś́lo dejan á los genoveses el papel poco honroso de haberla entregado: la toma do Ibiza es alribuída excilusivamente á los Pisanos. Nas-Latrie, Trerités de pris... Introduccióv, pág. 35.

\section{9}

(1) (1)

Estos sucesos y los nombres de los personajes almoravides que en ellos intervienen basto el вño 520 , resultan muy enredados tn los pocos antores que de ellos tratan.

Abeajaldún (to. I, de la edic. de Argel, pag. 246, tomo VI, de la del Cairo, pág. 188), á quien siguió el Sr. Campaner en su Bosquejo histórico, supone á Mallorca recobrada de 


\section{$-326-$}

los cristianos por el capitán Abentafartasat,

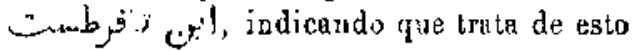
en otra parte, al hablar de los Reyes de Tajfas, y efectivamente (en el to. IV de la edición del Cairo, pagr. 165) trata de la conquista de Mallorea y dice que el sitio duró diez meses y que les auxilios pedidos á Alí so llegaron hasta despucs de haberse apoderado de Mallorea los cristinnos: que al llegar Ja escuadra, el enemigo abandonó la ciıdad; que Alí dí el mando de ella á Lonur, hijo de Abubćquer el Lamtuní, quien oprimió a los nalurales del país, queriendo que edificasea otra ciudad lejos del mor, y que labićndose rebelado, consiguieron prenderle $y$ encarcelarle; luegro enviaron meusajeros á Alí, explicando sn conducle, y el Príucipe paś por lo hecho, 6 lo aprobó añade el autor que los envió ó unió al robierno de Johámed. (léase) Yahya hijo de Alí Abengania, valí del $\Lambda$ lgarbe de Alandalus, quien les enví á su kermano Molámed, palí de Córdoba, el cual al llegar á Mallorca, lomando a Uanur. le encarcelo y envió a Marruecos; y Mohamed permaneció en Mallorca durante diez 


\section{$-327-$}

años, hasta que murió su hermano Yahya $y$ el Sultán Alí.

Como se ve, Abenjaldún confunde lastimosamente muchos sucesos, $\mathrm{J}$ por tanto no podemos dar gran crédito á los datas que nos suministre, $y$ que no constau en otros autores.

Yahya Abengania no era por estos tiempos (año 520) valí del Algarhe, de donde no lo fué hasta el año 538 , vi aun del Oriente de Alandaliss, donde gohernó antes que en Sevilla: ademís, desde el año 51660220 hasla el 538 habían pasado más de dicz años: Abdeluáhid, por el contrario, relrasa la ida de Mohámed Abeugania á Mallorca hasta después de la muerte de su hermano Y'aliya, incurriendo tambiéa en oiros errores $z$.

Se necesitarían muchas páginas para rectificar una á una todas las inexactitudes de los autores árabes respecto á este punto.

1 Avenaljatib, biograria de rahya $a_{1}$. Gg. N. 20 de la nibl. Nacio. pág. Job, y Hs. Ar, de la Aendemia N. 34 tomo JlI, Tol, 172.

2 Vuso pag. 231 y slguiontes de la llislolite les

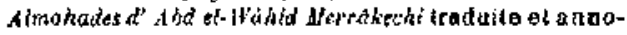
tée par E. Fagnan. Alger, 1893. 


\section{- 228 -}

El mismo Abenjaldún (to. I, de la edición de Argel, pág. 324 y 325, tomo VI, de la edición del Cuiro, pág. 242) da otra versión algo diferente, aunque no contradictorja, suponiendo que al ser abandonada Mallorca por los cristianos, Alí envió como gobernador á Lonur, de quien aquí dice que djó muerte al jefe de los rebeldes, quienes le prendieron y enviaron mensaje á Alí explicando su conducta, $y$ sin que diga nada de Yahya Aheogania, supone el nambramiento de Mohámed para el mando de Mallorea, hecho directamente por al Tríncipe.

É olra parte, como veremos en la Ilustración inmediato, da $\Delta$ benjaldún la verdadera fecha del nombramiento de Mohámed para el mando de Jallorca.

\section{0}

(iàgina 17\%)

La fecha de la muerte de Mohámed A.benganiu resulta muy dudosa: nos inclinamos á seguir la cronología del llamado Anónima 


\section{$-329-$}

de Copenhague, que en general da noticias coucretas $y$ exrctas respecto a este período de nuestra historia, poco esiudindo: MIs. (ig. N. 490 de la Biblioleca Nacional, y Ms. Ar. n." 83 de la Acad.

Abenjaldún (tomo IV de la edición del Cairo, pág. 166) pone como fecta de la muerte de Mohámed Abengania el aûo 567, si bien hay que; tener en cuenta que el lexto parece alterado con palabras que deben referirse á olro suceso: en el tomo VT ide la misma edición, pag. 242, y 325 del to. I de la de Argel, tomo II, pág. 206 y siguientes de la traducción de Slane, refiere la muerte de Mohámen al sño $546, y$ que tunto él, como st hijo Abdala, nombrado Príncipe heredero, fueron muertos por sediciosos movidos por so hijo Ishac, descontento, como se ha dicho, por el nombramiento de Príncipe heredero hecho á favor de su hermano.

La misma fecha del año 546 resulta consignada por Abenalabar (Dozy, Notices, páginas 215 y 216) al decir que Ishac Abengania gobernó á Mallorca después de haber sido muertos su padre Mohámed y su her- 
"mano Abdala ea el año scis, ó mejor dicho en el 547; pero á pesar de palabras tan terminantes de Abenalabar y de la conformidad de estos dos testimonios, nos inclianomos por hoy á seguir al llamado Anónimo de Copenhague, quien dice de ua modo cancreto qृue Ishac, hijo y sucesor de Molámed, reinú en Mallorca treinta años, siendo el primero el 550 y el úl timo el 580 .

\section{1}

(Pagina 176)

Tratando Abenalatir (to. XI, pág. 147) del año 552 , y de la desaparición del poder de los aluoravides, dice que en este año desapareció su imperio, no quedándoles mâs que la Isla de Mallorea bajo el mando de Hamo Abengania: el uutor confundió á Пamu con Ishac, 6 mejor dicho, al autor 6 algún copista suprimió el nombre propio y los de algunos ascendienteg, pites Hamu es uno de los ŕltimos, si bien puedo emplearse inmediutameate después del nombre propio 


\section{$-331-$}

como lo hace Abenjalicán (tomo III de la edición del Cairo, pág. 385), llamándole Abuibrahim Isluac Abenhamu.

\section{4:}

(Pagina 17)

De la incursión del rey de Mallorea en Tolón da cuenta la Crónica de San Víctor de Yarsella con estas palabras:

"MCLXXVIL. Tholonensis urbs a Rege Majorice dejsellaia et capta est, et Ugo Gaurredi Vicecumcs Massiliensis et nepos ejus et multi alii capti in Majoricam ducti sunt.» (Fspania Sagr. to. XXVIII, pág. 346).

Fll P. Villanueva en su Viaje titerario (tomo XV, pág. 16 y sigr.) da noticias de la Colegiata de Santa María de Lilla, pequeña villa situada junto a Torroella de Mongrs; de un Necrologrio y de una pequeña Crónica de esta Colegiata publica los textos que siguen:

VI. Kal. julii obitus duorum fratrum, seilicet Guillermi de Iemona, pbri., et Be. rengarii de Palegreto, subdiachoni, qui si- 


\section{$-332-$}

mul in hac ecclesia a Sarracenis, prolt dolor! fuerunt accisi anno MCLXXYIII.

VI. Nonas julij oodem die memoria vel obicus duorum Cratram Beratadi de Pulijano, phri., et Guillermi de Curtada, quos hinc duxeruat Sarraceni captivos et sauciatos, el martui sunt in mari. (pâg. 2liš3).

Anno XV. Kal. julii, Deo permitlente, capta fuit a Paganis ecclesia S. Marite de Tliano, et omaibus bonis suis penitus spoliata: cujus ecclesia canonici alij gladio ibidem perempti alii Maiorichas transducti fuerunt. (páfina 216.)

Puede consultarse acerca de estos puntos la obra citada del Sr. Camponer, pág. 144.

\section{$\$ 3$}

(1'egina 179)

El tratado de Pisa en su texto latiuo, casi único conocido, está publicado con alguna variante en la fecha: en el texto publicodo por ol Sr. Companer se lee: "et fail hec 


\section{$-333-$}

carta seripta nono decimo dio mensis saphar anno predic. hlameti Dl.XXX, hono yero Domin. Incarnat. MCLXXXY. Iud. II. Kal Tnaii ; c los publicados por Mas Tatrie $y$ Amari se lee eAnno a predicatione Sacumeli quingentesimo octuggesimo, anno vero Dominice Incarnationis MCLXYYY, indictione secunda, ipsa dio Kalendarum Jurii.»

Hay que advertir que el lexto latino en realidad no es tradncción, sino cxtracto del tex to árabe, cu el cual no cabe duda respecto á la fecha que dice: "l9 de Safar del año 5 \& de la predicación (re la hésiro) de Mahoma. y que corresponde al primero de $\mathrm{J}_{\mathrm{u}-}$ nio de los cristianosis: estando todo en lelra en el texlo árabe publicado por tmeri i no cabe erquivocacion, correspondiendo perfectamente la fecha 19 de Safar de 580 con el primero de Junio de los cristianos (del año 1184): no hay por tanto necesidad de suponer que Ishac muriern en el año 581, como supuso el Sr. Campaner por la inexactitud del extracto latino de que se sirvió.

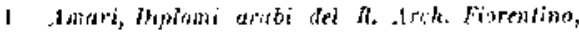
pak. 13. 


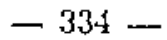

\section{4}

(1)

Hay muy pocos datos para conocer las circunstancias $\mathrm{y}$ aun la fecha aproximada de la muerte de Islac: la coincidencia de dos testimanios, cristiano el uno, árabe el otro, parece resolver la mestión, á pesar de que ambos son poco explícitos: la Cróniea de San Salvador de Harsella (Espana Sarrada, tomo XXXVIII, pág. 346) nos da un tato precioso de la historia de Mallorea en las siruientes palobras: MCLXXXV Christiani ceperunt Palaliun civilatis Majoricarum, et fuerunt liherati a ceptivitate.»

Lor otra parle, Abenalabar (Bibl. Ar. his. to. FI, pár. 401), en la biogralía de Abdala, hijo de Mohámed A benuacrs, natural de Mallores, nos dice que murió ráatir en la batalla del alcázar de Mallorca al tiempo de la muerte clel emir lyhac, hijo de Mohámed, en el año 580.

Nadie fija el mes de la muerte de Isliac, que debió de acuecer poco después de bober 
firmado el tratado con Pisa el 19 de Safar de 580, pues en Tabán del mismo año su hijo y jesegundo? sucesor Ali, salía para Rugís, de la que se apodera el día 6 del mismo (Cartss, pág. 179). Ccro entre la muerte de Ishac y la salida de su hijo pera Bugía debió de mediar algún tiempo, je que Alí proclamado á continunción de la muerte de an pedre, 6 despuŕs del corto reinado de su hermano, hubo de ocuparse en las cosas del gobierno, puede suponerse que la muerte ocurrió muy poco después de firmado el tratado con Pisa.

Aun puede precisarse más la fecha: secrún a]gún autor ', Isliac murió poco antes que el califa Almansur, muerto en la expedición de Sinterén ó á secruida de ella, en Rebí I." 6 $2 .^{\circ}$ de este mismo año 580 , luego Ishuc murió á los dos meses ó antes, después de haber firmado el tratedo con Pisa.

La toma del aleázar por los cristianos $y$ su libertad puede roferirse á otra sublevación poco posterior ocurrida en el nismo alcázar,

1 Abotualdsin, to, V], pag. 2h2. 
segúa entienden los textos Campaner (página 150) y Dazy"; pero de todos modos la muerte de lshac en su palacio con motivo de una batalla librada en el, resulta del testimonio de Abenalabar, desconocido antes, a no ser que diéramos á la prepasición tie en

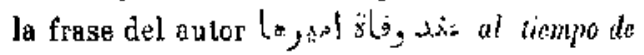
la muerte de sit cmiv Ishas, la acepción de desmese, que dudo pueda aseptarse gramaticalmente; pera que quizá no sería muy de extran̆ar, dadas las muy vagas acepciones de alguuas de las partículas árabes.

Siendo tan raro el que resulten das sublevaciones graves en el palacio de Miallorea en el mismo año, y arabas con resultado satisfactorio para los revoltosos, conslad a adeinás por otra parle que los autores que de estos sucesos tratan, están en general poco enterados, es muy posible que hayan confundido los sucesos, baciendo dos sublepaciones de una sola, en cuyo caso habría que adinitir la posterior, respecto á la cual se dan más noticias, tigurando en ella personajes, que

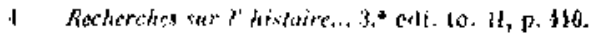




\section{$-337-$}

no pueden figurar en la primera, viviendo Mohŕmed.

\section{5}

(l'agina 181)

La narración más concreta de estos sucesos, al menos de parte de ellos, se encuentra en el llamado Anónimo de Copenhague (Ma. Gg. 490 de la 3ib). Nacio. pág. 63, 64 y 65), tcxto que no se encuentra en el códrec que, procedente de la biblioteca de Dazy, posee la Real Academia de la Historia: en dicho texto, muy incorrecto, como casi todo la contenido en dicha obra, dice expresamente que Abulhasán Ali (hijo de leverter) fué enviado á Mallorca por el califa Abuyacub después de la muerto de Ishac: que aunque muy bion recibido $y$ obsequisdo, se le tuvo como prisionera, dando largas al asunto de la obediencia á los almolades: rue aun antes de romper con él, se apoderaron de las saves que había llevado desde Ceuta, isstalando en ellas equipaje islez̃o, y trasladáadolas al arsenal: que cuando tuvieron molicía de la 


\section{- 338 -}

muerte del califa $A$ buyacub, le detuvieron prisionero en su morada, evcurgándose de él los guardias y centinelas, de modo que no le fuese posible meqquinar cosa algruna: el texto no hace mención del nombre del rey Mohámed, ni del hermano ó hermanas que promovierou la resistencia: parece inferirse que esta fué debida al mismo IIohámed ó quien fuese el rey pronlemado á la muerte de Ishec: sólo se bace mención del rumi liaxid, dirigiendo la prisión del hijo de Reverter, $y$ después la conducción de fuerzas á Buyría.

Como este texto puede ser interesante por otras indicaciones que en él se conticnen, y quizá no conslé en otra parle, to incluímos á continuación para couocimien to de los erabistas, á pesar de su incorrección manifiesta, que, al menos para nosotros, hace iniutelicgibles alcrunas frases.

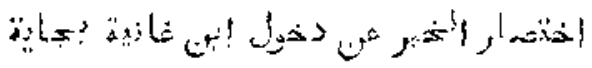

$$
\begin{aligned}
& \text { }
\end{aligned}
$$

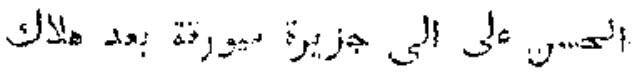


$-339-$

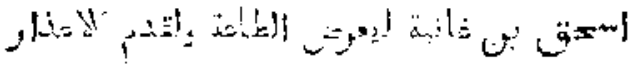
5 ظق "

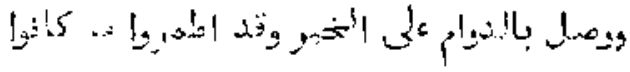

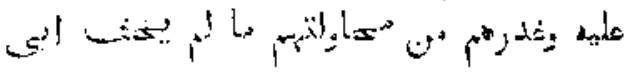
الح

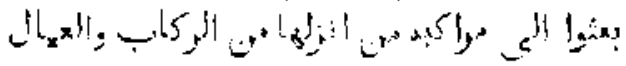

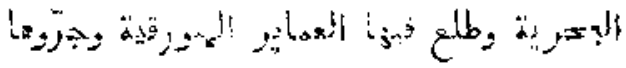
1)

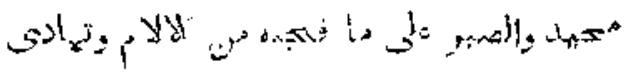

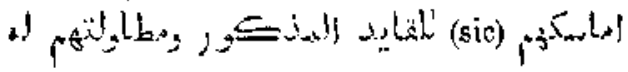

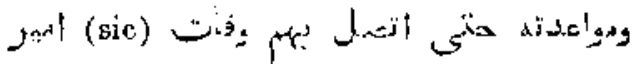

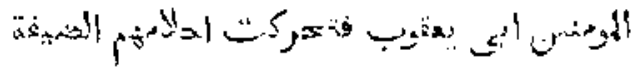

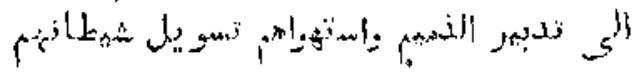




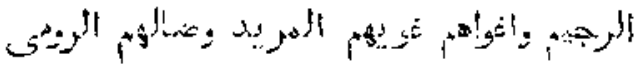

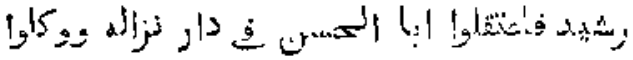

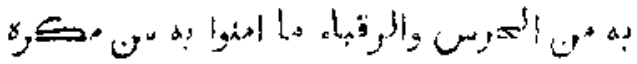

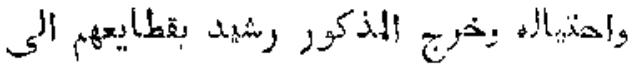

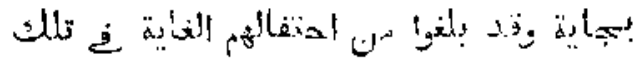

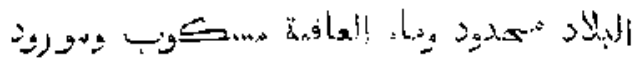

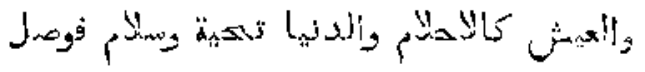

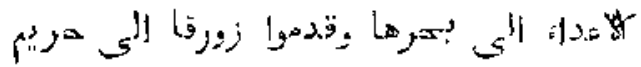

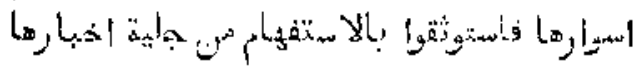
(pág. 65)

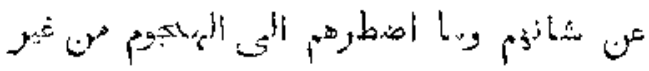

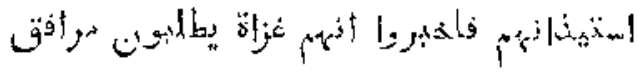

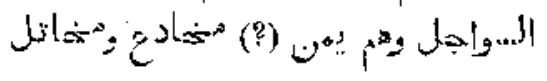




\section{$-341-$}

\section{6}

(f) 3 gina 182 ?

Segúc otra versión del mismo Abenjaldún (to. IV, de la edi. del Cairo, pág. 166), «Tallha, hermano de Ishac, le sucede en el Inando y reconoce á los almoliades ya en el gL̃o $58 \mathrm{I}$, yendo una comisión de Mallorca á prestar obediencia: los almoliades enviaron con los comisionudos á Alí hijo de Reverter; pero al llegar éste á Mallorea se rebelaron contra Talha sus sobrinos Yabya y Ali, hijos de Ishac, y combatiendo a $A$ lí A benreverter, echaron á Tallıa: luego, habiéndoles llegado la noticia de la muerte del califa Yúsuf, salieron para Africa\%.

Difícil es darse cuenta de lo que pueda. haber de verdad en esta versión, que en la fecha al menos está equivocada, pues tanto la muerte del califa, como la salida de Alí y Yahya para Africa, deben referirse al año anterior $\breve{80}$. 


\section{$-342-$}

\section{7}

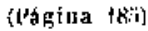

Aunque en el texto se ha procurado dar idea lo más exacta posible dol contenido de éste $\mathrm{g}$ de los tratados anteriores firmados por los reyes do Mrallorea, por ser el más corto, y más concreto, insertamos á continuación la traducción latina anligua publicada por Silvestre de Sacy, quien considerándola bastante exacta, no añadió traducción francesa, como en otros: no publicamos el tex to árabe, por vo recargar la impresión, sin gran vtilidad.

In nonime omnipotentis $p \mathrm{ij}$ et miscricordis. Carta pacis firme et slabilis, faclec bona et spontanea voluntale, ab clmir sublimi, Abo-Machomet Abd-ella, filio Isaliac, ebn Machomet elon Ali (quem Deus manu teneat!), cum alto et erregio legato Januensium Nicola Leccans unplias (quem D. in.t.);

I En el texto so la impreso que la duración del tratado drbia ser de 10 anos, en sez de 20 , que flja el texlo. 


\section{$-313-$}

quam pacem fecit at recpil idem legatus, per archiepiscopum et consules et sapientes Janux, qui propterea eum eum multa legalitate miserunt, observadarn inviolatam per Januenses omnes et de districh Janua (q. D. m. t.) Qui Nicola, legatus lauva, cartam Janueusium consulum detulit, iv qua contincbatur ut verbis suis fidem haberctur, tanquam ab ore Januensium consulum prolatis et omnium Januersium iatus et exterius ( 1 . D. In. t.); (qu? pax facta fuil per bonam fidem et legralitatem ab utrargue parte, sicut in caria inde facla continetur. Et rex ille Abem Machomet Abdella, eborn Isaac ebem Maclomet cbam Ali (q. D. m. t.), de pradicta conventione fucta cum $\mathrm{Ni}$ cola Jaccans nuplias legato, et cum arcliepiscopo et consulibus et omaibus Januensibns el de districtu Jantur, tenetur serundum quod scriptım est in eaden certa sic. Nulla persona sui districtus debet venire, nec offensionem ullam facere, in Januenses vel districlus Janua; el otnnes ejus et galea ipsius non debenl offendere Januenses, in terra vel mari, nec olfensionem faccre 


\section{$-344-$}

* Corvo usfue issulam Sancta Margarita: super Canebam silam; et juod omnes naves Janueusos debent salyari et custodiri $\mathbf{a b}$ ho-minjbus sui districtus et a galeis suis, per tolem terrom suan, el per Garbum el Xspaniam, et per universas partes, ubicumique inventas, ubicumaue vadant rel undecumque veniant; et si quando aliqua navis Janaensium in partibus suis forte, juod Deus advertal (sic), noufugina passa faerit, quod debcant ab lominibus sui districtus pro parva et convenienti quentitate (sic); nec ultra quod convenerint invicem delent accipare homines sui. Lloc antem promisil rex, pro honore et anore Januensium et houore ipsius. Jum nulius Jantecsis qui X[ajoricam venerit cemsi mercandi, aut forle iverint (sic) Garbrm vel l'spaulom, vel inde redierint, ullum drictum dare debel; el promisit illos salvase el gruardere el eis exlathere honorem. lesn promisit lare .Tannensibus fuudicum, ubicunaque Januensibus placuerí, el faroum el baloeum, in unaquaque septimana per diem unum, sino aliajuo driclu; ct ecclesizm unam in qua orare debeant Januenses, et 
facere misisterium Dei; et hoc pro emore Januensium (4. D. un. 1.) facit et donat Ebo Nacomel Abd-ella eben Isaac ebo (sic) AIacornet eben Ali (a. D. m. t.), per legatum Jnnua, Nicolam Leccans nuptias, qui ex parte archiepiscopi et consulum Jankensium at omnium Janteasium (q. D. n. t.) hav quasivit. Hade conventionem firmam ef illibutam promisit rex Mnjorica olservandam per se ct homines suos. Jlac sual ea quit sibi convenil vicola, ex parte archiepiscopi et consulum Janua et omnium Januensium: Janueuses non debenl facere alicuod malum neque offensionem in terra sua, nec adjuvare inimicos ipsius contra ens, neque per factum, ant per dictum, vel per personam, seu per pccuniam; et salvare debent et gruardero terram suan, el homines swos, et res earum, mari el terra, el ia omaibus partibus ubicunque invenlos. Bt (sic) superior rex forte invenerit blipuem Javucosium cum suis injmicis, eum ofiondentem, quod ipse faceret inde visdictan si ullum (sic) habere et $\mathrm{ca}-$ pere poterit. Lit firmum et stabile debel haberi et teneri per archiepiscopum et consules. 


\section{$-246-$}

Janua, et consiliatores et omnes Januenses. Et ita continebetur in carta quam Yicola Leccans nuptias ex parte ipsorum addixit regi Majoricre, quod firmum et ratum debebat permanere usque annos viginti, secundum quod ipse conpenerat, tauruam si per consules faclum esset.

Actum apud Majoricam, mense jumedi lachar, in augusto videlicet, anni Jlacomet DLXXXIII. Facta fuil hwe pax et convenio inter regem Jajoricht el Cominue Jinue. Testis sit Deus solus, qui bonus testin est. melior et potiar omnibus testibus, inter regem Majoricx et consulus Janukx, socundum legem amuium hominum. Fi Deus velit et illi placeat quod hene observeturabs ulraque parle, et qui contra fecerit, Deun ollendet, et seipsun, nisi illara firmen el illibetan servabit; et qui bene illam servaverit, Deum serviet, et fuciet inde bene placitum Deo, at suam et suorum honestatem servahit, quia Deus testis bonus est inter homines, ot specialiter inter regem Majoricas et Januenses. Expleta est carta, Boulile, id est, per gratiam Dei, firma el stabile permanere debente. In 


\section{$-347-$}

meuse Aigusco. Etemmer cullero tite gel ant, id est; Deus qui est melior omuibus robus, et babet omuium potestatem. Sotices ol extraits des manuscrits de la Bibliothinue du Roi et antres Biblidhinues, publies par l' Institul Ragal de france. '1.o. XI, parr. 17).

\section{8}

(5)agina zon)

Abumolámed Abdala bijo de Mohámed, Ahenesid, natural de Badajoz, donde nació eo el año $44-4$ conocido pror de te Manjos. gramatico, filósofo y literoto distinuruido, tanlo que algrin a ulor llesa á calificarle de superior á Moharrad 1, vivió en Valencia. donde murió á mitad de Racheb del oño 521 (2T re Julio de II27): en dicha ciudekl, y '[uizá en otrus, fué muy celebrada su enseñanza por la facilidad con rue se latía compreader, de modo que las gentes se rounían para las lecturas hajo su dirección, como dice s.benjalican ${ }^{2}$, y prueba de los muchoo

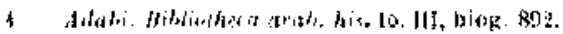

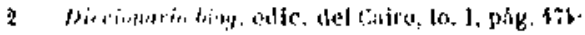


discípulas rue tuvo nos la sumiristra Abenalabar con las nouchisimas reces ique le menciona con los solos nombres de A humohamed el de Badajoz.

A henasirl escribió muchos obres cuyo can fálogo no es fácil completar. y nos permitimos poner algin tanto detallado.

A beopascual, ipue escribiósu liografía ', sólo cita tres de sus abras, inclıyendo la que es motivo de esle estudio, la cual por cierto aparece en este aulor como on otros, con alguna varianic que pucte hacer formar de la obra conecpto muy diferente: lítulast el libro 足 el mismo tílulo le da Aburjulicán y beeptado por el Sr. I'ons : , he traducido lid libra del despertumiento 6 del byiso (4ue versa) sobre las cuusas necesatias para la oposición á rebellía del pueblos: lil lículo puesto osí pudiera nuy bien comarso por indicación de una obra eminentemente polílica, en la que se exominasen ada menos cuo lás causas en

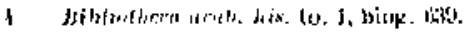

2 Obra cilala. 


\section{$-349-$}

virtud de las cuales se justificara el derecho de rehelión contra la autoridad: sin variar mucho lo material ila las palabras, cl tílulo aparece de modo vuly diferente en olros antores.

Abenjair ', con quien coinciden, al menos cu lo fundomental, las notas bibliográficas de los catálogos de la Bibliateca de Túnez $y$ de dos de Coustantinopla, lama a

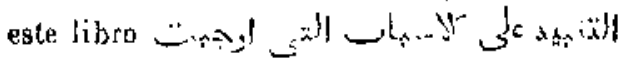
c.

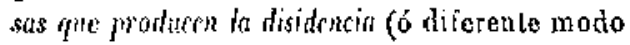
de pensar) intre los mustiman's: anuque la

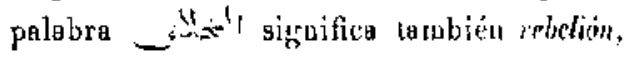
como cn alguna de los notas bibliográficas,

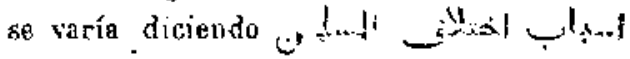

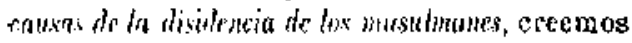
que casi no cabe duda de que se trata sólo de las causas de la disidencia ó diferente modo de entender al gunos textos ó tradiciones. Confirma esta interpretación el hecho de que el mismo autor tiene otra obra do título

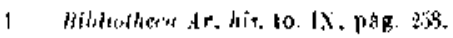




\section{$-350-$}

parecido respectóa la disidencia en lo escuela de Abuhanifa, en cnyo títslo se emplean en parte las mismas palabras أس بـ a cansas de la disidenciat que eciste en la religion ó secla $H_{\text {antr }} i$, obra que le atribuye Hachi Jalifa.

Ja importancia de esta obra puede sospecharse que esté en las indicaciones que el autor haga respecto â las cosas y horubres de su ticmpo; pues por cl solo lítulo de los obras no es fácil calcular la importaucia de las mismas, además de que resulta difícil y casi imposible la traducción de los títulos, mientras no pueda estudiarse la obra; de aruí que distinguidos biblígrafos modernos, con quienes estanos de acuerdo, al no dar las traclucciones de los tílulos, parecen indicar que el hacerlo tiene más inconvenientcs que ventajas.

Por la ciscunstavcia de ser Abeusid autor español zuy celebrado y por si esta obra diera noticjas inportantes relativas á Fspaña, convendría que so publicase, ya quo existe ejemplur de la misna en Constanti- 


\section{$-351-$}

nopla y una Frpasición en la Biblioteca de Túnez'.

Las bibgrafos de Abenasid de Badajoz le celebran sólo como gramático, literato y filólogo; pero por los títulos de sus muclias obras podemos inlerir que trató puntos muy diferentes, y en cspecial que no fué agenóa los estudios históricos y tilosóficos.

Como historiador, el Sr. Pons cita un

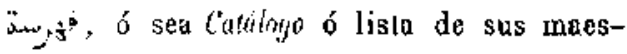
tros: es casi seguro que al mismo género per-

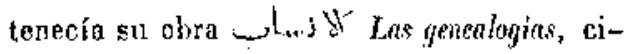
tada por IIachi Jalifá en el vúmero $13 \overline{3}$.

Abenpascual y Abeujalicáu mencionan algunas de sus obsas; pero quien de un modo indirecto nos da más nolicias es $A$ benjair ${ }^{2}$, que menciona hasta quince, aunque algunu parece estar citada con tílulo doble: de éstas sólo encontramos cinco citadas por Hechi Jalifa, quied en cambio cita otras que

1 Véase fatidago de la Rily. the ta mezquita

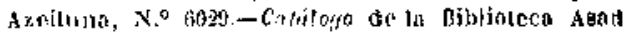
Efondi. Constantinopia, a iro 1300 (do la begira), en 8.0 33 prags.-pág. 3iy.

2 Biblioleca drabico-hisp. to. X. pag. räb. 


\section{$-352-$}

no conoció Abenjair, cuya listu completamos á continuación indicando las fuentes:

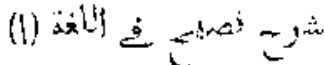

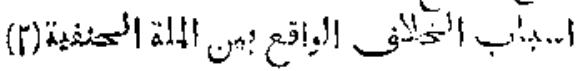

$$
\begin{aligned}
& \text { (") } \\
& \text { (c) (c) } \\
& \text { (c) ش } \\
& \text { (i) } \\
& \text { (i) } 14(x)
\end{aligned}
$$

\footnotetext{
1 Hachi Jalifa, j. 9110.

$2 \Rightarrow \quad \because 578$.

$3 \Rightarrow \geqslant 1353$.

$\triangle \Rightarrow \Rightarrow \Rightarrow 4192$.

$\Rightarrow \gg \Rightarrow 5051$.

$6 \gg>10049$.

7 \% $>13437$.

8 Bibl. Arab. hisp. to. IIJ. pág. 522 .

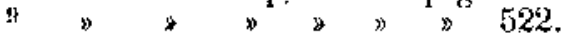




$$
\begin{aligned}
& -353-
\end{aligned}
$$

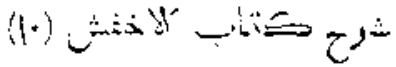

$$
\begin{aligned}
& \text { (ii) } \\
& \text { (i) }
\end{aligned}
$$

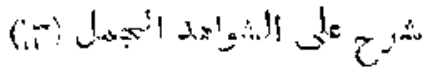

$$
\begin{aligned}
& \text { (if }
\end{aligned}
$$

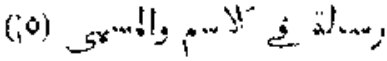

$$
\begin{aligned}
& \text { (i) (1) }
\end{aligned}
$$

De las treinta obras escritas por nuestro Abenasid el de Badajo\% se sabe que se conservan ocho en diferentes bibliolecas.

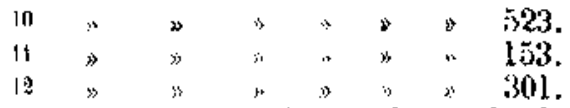

13 Cardoryo de la Bìis de Tínez N. 4194.

It cataligye d' une Col de la XIaison Brill par Houtscrit, pág. 78.

15 Catilogo de la libl. de 'Thínez, N." 1844.

16 Catalopue de la Biblio, de Asad Efondi, Consl. pás. 301 . 


\section{$-354$}

\section{9}

(Pápina 20ij)

Aunque son muchos los autores que dan uoticias dic Abenalarif y de su companero Abenbarrachán, eu ningudo encoutramos nolicias tan concretas como en el modernísimo historizdor marroqú Ahmed Anasirí, y por eso lo traducimos á continuación ${ }^{1}$ :

4En el año 530 murío el alfaquí Ahulabás Abmed, hijo de Molríned, hijo de Muza, hjjo de Atarla el Sanluachí, conocido por Abenalarif: era de los que luabian llecrado al límile de la perfección, religión y ascelismo en este mundo y cntregado far completo al bien: diringase a di bas gentes y familiarizáduse con él, colebraban su compañia: acusado ante cl emir do los creyeules Alí, mandó luese conducido á la corle de Marmecos, donde murió en la noctio del viennes, 23 del mes de Salar del año mencionado $(27$ de Sepliembre de 1141): habiendo elluído la gente pera su entierro, el emir de los mus-

- Tomo I. pák. 129. 


\section{-}

limes se arrepintió de lo que había hecho con él tu rida, $y$ se le hicieron obsequios (?): fué enterrado cerea de la aljama antigua que habia en medio de Marruecos, en el jardín del cadi Mluz, hijo de Alomed el Sabhochi." « Su sepulero es hog muy conccido en el zoco (mercads) de los perfumistas de Marruccos: sobre él hay una esmeradaconstrucción."

"Hu este misno año murió Abulhácam Abenbarrachan, de qujen dice Aboujalicán aque se llamaba A bulluaram Abitesalum, hijo de Abderalman, hijo de Molámed, lijo do Abdicralima el Lajmí conocito pror Abenbarrachán (indica la vocalización del sobrenombre): era sitrvo virlueso, y lisoc una Tafsira del Corán el zoble, y escribió mucho (muliplicó sus pilahras) acerea de il conformé a la secta de los sejiores de los estatios J sesiones.;

"Dice el aulor del libro Alaxanuf (B) Atavío) "Curudo Alublhácum Abeuharrachán fuć canducido desde Córdoba á la carte dio Merruecos, en ocusión en que los alfacquíes le habían presentado aigunas consultas, dijo: 


\section{$-356-$}

por Alá, no riviré, ni vivirá después de mi muerte el que me ha liecho conducir; referíase al emir de los muslimes Alí, hijo de Yúsuf: habiendo muerlo A bulhácams el emir de los muslimes mandó que fuese abandonado en un estercolero $y$ que no se hiciese oración sohre ól, ḋdesignnando quien hablase do esio de parte de los alfaquíes? Liacontrábase entonces eu Marruecos Abulhasán Alí i.Abenharzaham\%, y presentandosele un negro que le labía servido, y asistía á su lertulia, le conto lo que el sultán había dispuesto acerca del entierro de Abullacam: óda la relación, Abulhasán dijo al nér ro: "si quieres comprar tu alma á Alá, haz lo que te voy á decir "; a lo que con lestŕ el negra: "manda lo que quieres, $y$ lo hure ; dijale: ve gritando por las calles y mercados (lo siguiente): os diec Alenharrabau, asistid al estierro del jerae, sauto y contiacnte alfaquí hbuthácam Ahenborrachán: quien pueda asistir y no asista, sobre ćl la maldición de Alá. Hízolo el nedro como se lo labía mandado, y cuando llegó csto á noticia del emir de los muslimes, dijo: aquel cuya bonded sea reca- 
nocida y no asistiere á su eutierro. là maldición de Alá será sobre él."

"Dice Abenohdeimúlic on su libro ylew

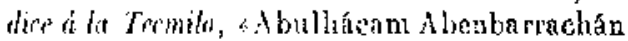
está enterrado en Narrueros en la liaza del trigro: es el que el fueblo llama riefi thorichal.

Pora más nolicias refcrentes á eslos dos personajes, véase, respecto á A benalarif, Alirnjulirin, erli. del Cairo, lom. I. pag. 93-Bithother Ambioths. Lom. 1. biogr. 175-tosoo IIl. biog. 36n-lom. [V. bion. 14; $y$ respecto al secrundo, hibl. tr. his tom. II, bionr. 1797: es de advertir pue Abenalabar en csla obra lc llama Abenborrichán ó Aberherriclún. ciláudale vuries veces por incidencia además de poner su biorrafía.

\section{0}

I'utina 2lrit

Fl mismo outor moderno, yque nos ha suministrado los datos más concretos para la ilustración anterior, nos da en la misme púgina a grunos dalos acerca de la fuema do 
los libros de dbuhámid el Gazalí; con molivo de tratar de la muerte de un cétebre alfuquí, dice: «En el ar̃o all3 murió en Culathamad Abulfadal Yúsuf, lijo de Hohârned, hijo de Yúsuf, conocido por Abenacahuí, el cual había acompañado á Abulhasán el Lahmi y á otros jeques: este Abulfádal ora hombre de ciencia y relirión por la direccion de una buena ascendencia, $y$ era oído en las oraciones."

"Cuando los alfaquíes del Almagreb hubieron dado la cousulta acerca de la quema. de los libros de Abuhámid cl Gazalí, complázesse Alá de él, y el emir de los musliunes mandó quemarlos, este Abulfádal tomó la defensa 1 do Abuhámid, Alá le haya perdonado, escribiendo al emir de los muslimes acerea de esto."

"Cuepta cl autor del libra El Atavio, $\mathrm{Abu-}$ gacub Yúsuf bijo de Yahga el de Tedela, y Marroquí por la estancia, conocido por Abenaiyas, tomándolo do Abulhasán Alí Aben-

1 La trase puliera otrecer didda on su sentido a lo ser por lo alltoridad del Suplentento de Dozy. 


\section{- 359 -}

harzabam, que dice: Cuando llegóá á Fez la orden del emir de los muslimes Alí Abenyúsuf de buscar con solicitud el libro de la Resurrección (de las ciencias de la religión) y de que las gentes prestasen los grandes juramentos de no tener en su poder tal libro. zo dirigí a A bulfádal pora pedirle suscribiese la consulta con estos juramentos, y me contestó que no procedían: á su lado había unos libros, y me dijo: éstos son del libro La Resurreccín y deseo no ver otros en mi vida: A bulfidal había copiado al libro de Algo zalf en treinta partes, y cuando entraha el mes de Ramadán, cada día leíu una parte: sus virludes eran graudes, álá le haya perdonado.z

(Dice el autar moderno:) «Durante al imperio de los Almoravides no ocurrió cosa más abominable que ésta, á saber, la quema del Libro La Resurrección, pues cuando llegó al país del Almagreb la copia de él, to examinaron muchos alfequíes, entre elioz el cadí Abulcásem Abenhandín 4, $y$ habiendo elegido algunas cosas corno cargas contra el

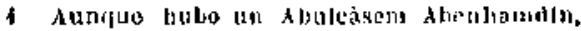
Ius posterior on poco: el que intervino en fester flact 
jeque Abubámid, las comunicaron al Sultán con la cossulta de que conscuía quemarla $\mathrm{y}$ que no se permiticse su lectura...

eAlí hijo de Yúsuf, lo mismo que su padre, estrba soruetido al consejo de los alfaquíes y sabios, á quienes babia deruelto todos los fallos, $y$ cuando dieron la consulta acerca de la quema del libro, escribibá la geute de eu reino en los lemás poíses y regiones, mandando que se buscasen con solicitud lus copias y que se quemara cuanto se encontrase: en virtual de esta orden se reunieron muchas copias en Alandains, $y$ puestas en el palio de la ajjama de Córdoba, se derramó accite subre cllas y se prendió luegro: lo nuismo se hizo con las copios que so encontraron en Marruecos, continuándose la quema en los derás países del Almarreb.:

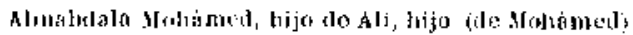

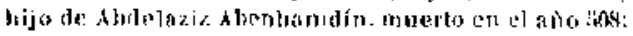

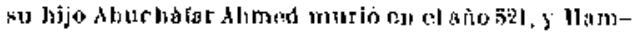

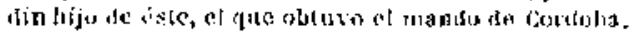
murió a is 3: pueden verso resperta al primero Bits. Ar. His. 10. If. hiok. 1138 y to. 11\}, hio. 230. l'a ra at se-

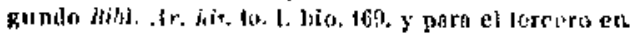

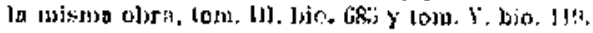




\section{$-3 i 1-$}

-Se dice que psto fur en vida del jeque Alulámid, y que por esto hizo oreción para que fuese destruido el poder de los almoravides, $y$ que le fui otorerada su petición acerca de ellus: si fué asi, la fucha de la quema sería en el intermedio entre el ano jon $\mathrm{y}$ el 50.5, pues la proclamución de Alí fućá prineipios dol año ino y la muerle del jeque Abulímit cl Crazalí acaeció el lunes 14 de Chumada postrero del año $505 \mathrm{x}$.

Como se vi, ia fecha de este suceso queda raga, y tanto más, si no admitioos la auécdola de que thizhímid twviese notivia do la condenación de su libro y de su maldición contra el imperio de los a! moravites: de todos modos la fecla es aproximada y se infierc de la coexistucia de los personajes, que intervinieron en el asunto.

Yo hemos visto que Abulfadal Yusuf Abenanahuí, muarto en el año 513 , lomó ia defansa del libro de Algazali; por consiguiente la quema lúé anterior á esta fecha.

El personajét quien nás iutervención se alribuye en este suceso, es $\Lambda$ bublodalo Mohámed, hijo de Mlís(bijo de Mohámed) lijo cie 


\section{$-362-$}

Abdelaziz, Abenhanadín, cadi de Cótdoba desde el mes de Xobán del año 490 hasta el de Moharrem del 508, en que nurió: Mbenpascual y Adubi en su hiografía nada dicen de su intervención en la quero de los libros de Algazalf; pero mencionu esta circunstancia Abealabar ${ }^{1}$ en la biografía de Abulhaeán $\mathrm{Ali}$, lijo de Mohámed, bijo de Abdala el de \erja, nuerto en el año 509 ; dice que éste exigrió (?) la quema de los libros de Algazalí y la iudemaización de su valor, cuando los quemó Abusldale Abeuhamdíu por orden

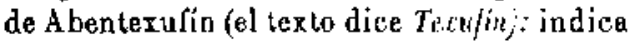
que is consulta fué suscrita por Abubéquer Omar hijo de Ahmed Abenelfasih, por Abulcásim Abenuaró y por otros alfatuies de Almeria, y que con motivo de la quema de Ios libros pasó historia extratia cntre Alí el de Berja y el cachí de Almería Abuabdelmélic Meruán, bijo de Abdelmélic: to mismo viene á decir, zunque con diferentes palabras, en la biografía de este áltimo ${ }^{2}$.

1 Bith dir. his, tomo Vt, biog. 1851, y tomo IV, Jiog. 253.

2 bith, Ar. hir, to v, biog. 1088. 
Mluerlos en los anos $513,512,509,508$ y 507 jus personajes mercionados, Abulladal Íisul Abenanahuí, Abumeruán A Idelmélic, Abulkasán Alí el de Berjo, Abunbiala tbenhamdín y Omar Abatsalfasib, que intervienen ó se indican con motivo de la proscripción de las obras de hlyuthanid el Gazali, resulta que el suceso acaeció entre los años 500 y $50 \%$.

lin el tex to (pdig. 216), dijimos ytle Abenjair uo cila a Algazalí eutre los butores coyas obras estudió; hay que rectificer la noticia; el nombre de Algazalí no ligura en el índico de artares cilados, prorque sólo se incluyeron un ćl los autores de quienes se dan los nombres de las obras.

De las de Abuhámid Mohámed hijo do Molámed el de 'lus, conocido por Algazalí. dice Abenjair que las estudió teniendo por maestros al cadí Abubéquer śbenularalí $y$ Abullasán Abad Abensirhán el Jiagfiri, naiural de Játiva, quienes las oprendioron del mismo Algazalí.

Ambos esturieron en Orienle, donda fueron discípulos de Algazalí, $y$ enseñaron on 


\section{$-364-$}

Alapdelus, especialmente Abecalarabí, de quien los antores dan noticias muy detalladas, transcribiendo la hiografía, que escriłi 6 su discípulo Abenpascual, quien dice (biogrefia 1181) que le encontrú cr Sevilla en el año 516; respeclo á las relaciones de Ahenelaralí con Alcrazalí dice que le encontró en Ragrilad, cuando fué á aquella ciudad por segrunda vez, y que de ćl y otros sahios tomó lecciones y estudió derecho.

Almacarí es quizá quien lá reunido más noticias acerca de Abubeiquer henalarabi, á quien dedica diez y siete páginas (tomol, pag. 477 a 489): en este autor encontramos los nomlyres hasta de 33 obras de A benalarabí, en alguva de las cuales: $\mathrm{C}^{1}$

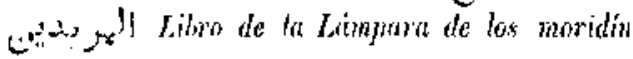
( 6 adeptos), quizá encontráramos algo referente á la rebelión contra los almoravides.

Como los aulores mencionan muchisimas veces en la cadena do las tradición literaria, tanto á Ahad libeusirlhán como 5 Abubéquer Abenalarabí, $y$ sabemos por Abenjair que ambos enseñaban las obres de Algrazalí, ca- 


\section{$-365-$}

balmente en el período más florecicuto de los almoravides, pues ambos murieron de edad muy a vauzada cn el año $54 \%$, tenemos un indicio más de ciue el anatema lanzodo contra las obras de A!razalí no sólo no estorlío su circulación, sino que quuiáa la fomentó.

\section{1}

Arigina

Ya que hernos creído oportuno insistir tanto vindicando la unemoria de los príucipes olmoravides, no estará demás el insertar literalmente algo de lo que en pro 6 en contra resulta en los autores árabes nque tenemos anotados.

Lit texto, que más ha servido para el cepílulo de cargos forruniado por Dozy, está tumudio del historiador de los limohades Abdeluabid el de Marruecos, autor no en todo bien informudo, romo hemos tenido ocasión de probar máz de ana ye\%.

Para que no se crea que damos al texto árabe más ó menos fuerza de la que le corres- 
ponde, tomamos la traducción lal como la pone Mr. Foggáa, y por más que la creemos algún tanto vaga, renuuciamos á ponerle notas, pues resulta lo de siempre, que al querer dar forma literaria 5 la traducción á nuestras lenguas, hay que variar el culace de ciertas cláusulas, y onitir palabras que quiza fuera bueno conserrar en pro de la exactithd: dice así en la pág. 179, traducido al castellano:

"Después del reinado del Príncipe de los muslimes Abulhasán Ali, bijo de Yúsuf, la situación de la Península española vino á ser de las más perturbadas. porque Ios Alinoravides abandonáudose los unos á los otros, cedieron á su azor de reposo y tranquiłidad y cryeron bajo la autoridad de las mujeres. Convertidos en objeto de desprecio $y$ lesdén de los habitantes, excitaron la audacia de los enemigas, y los Cristianos se Hicieron duenos de muchas plazas fuertes próximas á la frontera. A las cansas mencionadas de alteración, hay cue añadir la revoluciori de $A$ bentumart en el Sus, que distrajo la aleneión de Alí de las cosas de Lspaña. Eavalentouados 


\section{$-367-$}

los margnates espoñules por cl estado de debjlidad en çue veían á la dinaslia almorayid, echaron á los guerreros, que estaban instalados entre cllos, y cada uno pretendió ser senor de su propio lerritorio: poco faltó para que el país cajest en al mismo estado, que después de la desaparición de la dinastía de Ios Omeyas.:

El autor del Cartás nos presenta un cuadro muy dicercute lijándose en otras consideraciones: en la pás. 108 dice lo siguierte, que tomamos de la traducsión frascesa de Beaumier, pág. 238:

«Les Lemtouna étriegt un peuplo des camparges, religicux et houvite; ils suraut conquérir un immense empire en Andalougie é au Maghreb, dont ils régrulerisìrent le gouvernement, et ils firent la guerse sainte. Ben Djenoun rapporte que les Lemtoune étajent religieux, clesritables, justes, el que leur culte était pur; qu' ils gouvernèrent l' Andalousje depuis le pays des Franes jusqu'a l' Ocian, et le Traglireb depuis la ville de Bedjaia jusq̨u' aı Djebel el-Díeb du Soudan. Leur rigne fut tranquille et ne fat trou- 
blé par aucuae révolte, ni dans les villes, ai dans les campannes; on fit les holbah en leur nom dans plus de deux nille chaires. Leurs jours furent heureux, prosperes et tranquilles, el durant leur période l' abondance et le bon merché furent tels, que pour un demiducal on avait quatre charres de blé, et que les aulres urrains ne se vendaient ni ne $\mathrm{s}^{\prime}$ achetaient. Il n' $y$ avait ni tribut, ni impol, ni contribution pour le grouvernement, ai ce a esh l' aumine et le dime La prospérité à aumenta toujour's, le pays se peuyle, et chacuo put s' occuper librenent de ses propres alfaires. Leur rigge fat exempt the mensonge, de fraude et de rivolle, et ils fu. rent cheris pour tout le monde justu' an moment oit El-Yohedy. I' Almolade, se leva contre eux en 5]...

Ya que el tex to citado de Aldeluálid. ampliado por Dozy, ha llegacio á creas atmósfera entre los escritores molernos conlra la funesta inllueacia de los meijeres en el gobierno de los almoravides, bueno será incluir aquí la memoria de dos de las ilustres damas de que encuentro noticia, y que si res- 


\section{$-369-$}

pecto á la cuestión de intluencia en el gobieruo nada prueba, para la de cultura de los bereberes no deja de ser importante.

Ibenalabar al fiu de su leetrilu pone los biourafías de alguvas mujeres ihustres, $y$ auncue en el compendio que huhimos do publicar, falta la kiografia de Temima, lijia de Yúsul Abentexufín, se conserra íntegra en el tomo III de la misma obra, que existo en el Cairo en poder clel distinguido bibliótilo Sulciman Pucha Abaza y del cual tonomos copia fotogrática: en la pár. 308 de dicho códice antigno lecmos la siruiente biografía, que con las mismas palabras copia Abesaleadi en la pán. 106 de la olira varias veces citada.

"Temima hijo de Ýssuf hijo do Toxufin, hermana de Ali, y que por sobreuombre so llamaba Ocootallia (Matire te Tallo) era du grande hernosura, de excelente inteligencia, celebrada por lo elezancia do costumbres y doctrina, y por la generosidad; vivía en Fez: vióla cierto día un su secralario, á quien habia mandado randir cuentas; en cuan to ella la vío, conocís lo que lo había ocurrido, y com- 


\section{$-370-$}

prendió porque le labía sobrevenido aquella, y se lo indicó con los sigruientes versos:

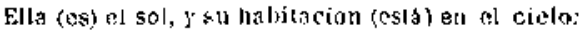
vence el ánimo cob paciencia i]usire:

No poldráa subir á clla, nł ella podrá liajar á ti .

El mismo Abeualaber pove á continudcír. la biografía de otra dama, hija y mujer de dos personajes de cuienes heroos tenido ocasión de halliar, pues era hija de Ibrahim hijo de Tifiluil (gobernador de Zaragoza), y mujer de Abutáhir Temim, hermano de Alí y gubernador poco afortunado de Alandalus durante bastantes años; por descracia la biogrufía resulta incompleta por el estado del códice; pero se lee que era buena, casta, dadivosa y limosnera y que sebía de memoria muchos versos: cua tro cita el au tor dirigridos á ella por un thuishac, cuyo nombre esta illegible en ol origrinal.

La noticia de ostas dos ilustres damas es una prueba más de lo infundado del colilicativo de birburos, que en general aplica Dozy á los almoravides, y quo autores modernos recargan, couvirtiéndolo en salucics almoravides. 


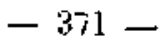

\section{5}

(Pógeinat 201:

Las monedas de los almorarizae, la serie más numerosa y variada de chantas se actiinaror en Espatta por los musulmenes, sou indudablemente las más perfectas como sistema monetario, las unis artístiens las que más laan ivfluido en el sistema monetario do España duraute la Lidad Medir.

El Sr. Yives en la citada obra describn 2200 moncelas arábizy-españolos: to istas pertenecen al tipo almoravid cuarta parte, siendo la más antigna una del año 450 , acur̃ada en Secrelmesa por tbubéquer Abenomar, primer jefe mililar de los olmoravides.

Durante más de 30 años los almoravites parece que sólo acuíaron su moueda en Segelmesa, $\delta$ al menos no conacmos ulma reca hasta el año 484: por este licmpo, poro después de loberse apoderado de parto do la Ixpeña misulmans, aparecén ya monedas de oro de las diferentes ceces espaiolos o 


\section{$-372-$}

marroquíes; en 181 Ceuta,-186 Agmat y Córdoba,_Játiva $189, \ldots$ Marruecos 490,Sanlúcar (?) y Sovilla $491,-$ Almería 492,Granade 493,-Yálaya y Fez 494,-Valencia 496-y Denia 497 .

Desde las primero. tiempos las monedas de los almoravides aparecen con su pr:so uniforme las de oro $\$, y$ las subdirisiones en las de plata, al menos las fracciones de medio dirhem ó quirate $y$ medio qujrate, au conociradose hasta thora los fracciocarios inferiores de los jurimeros tiempos, probablemente

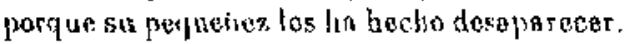

Como es de suponer, las monedas de los primeros aĩos, acuñadas todos cn Segelnesa, no son más artisticas que las que por el mismo tiempo se acuñaba en Ĺspuña por los

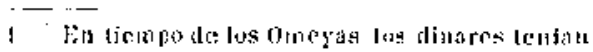

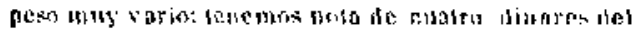

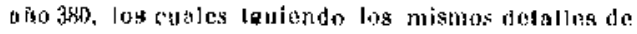
adernes, tanto dats de tres de ellog examinatos al mismo lompo anolamos la porticulariand ale dug parecian del mismo cuno, to ano snrede pocas veces, pesaban 3 ar. ;

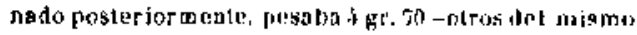
sino, pero con otros adornos, pesaron $3,5,3-3,60$ y $\$, 10$ : monedos tan diferentes hubian do aceptarsie al pesa. 


\section{$-3 \% 3-$}

reyes de Taifas, pero tampoco son inferiores a la generajidad de tistas bajo el aspecto artístico y son superiores en la acuinación 1.

For los datos publicados liasta hoy, conocemos monedas con fecha, de Abubécquer Abenomar, de los rùos 400 á 478 inclusive, si bien faltan de alnmos años, con la parlicularidad, para nosotros incxplicable, de que hay dinares indudables de Ihrehim hijo de Abnbéquer, de los años 462,465 y 466 , faltando estos dos íltimos en las monedas de Abuhérquer Abenomar.

Las monedas conocidas de Yúsuf comienzan en el año 480 , siendo la serio de Segolmesa casi completa hasta el año 498 , síndolo desde el 486 to de Agmat.

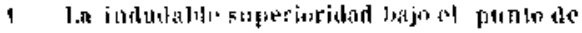

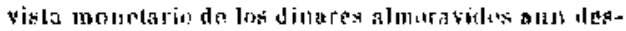

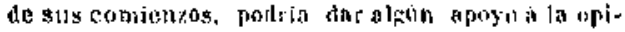

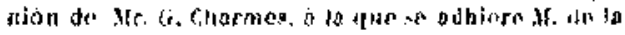
Martiniare, segun la cual en al perioto brillante

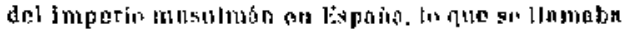

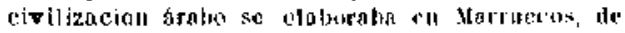

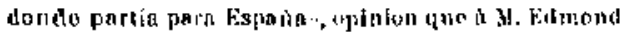

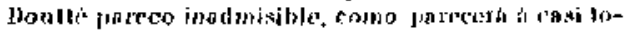

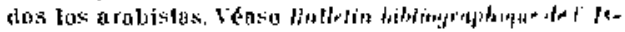

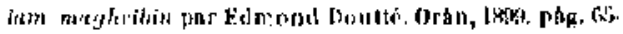




\section{$-374-$}

Como se ve, la cronología de las primeras monedas almoravides, no deja de ofrecer complicaciones en releción con los datos conocidos, con los cuales no es fácil ponerlas de acuerdo: así el autor del Cartás dice ( $\mathrm{pá}$ gina 92) que el año 473 cambió Yúsul la. moneda en todo su réíu, y puso en ejla su nombre, lo que no está conforma con los datos, que éstas nos suministran: el historiador moderno Ahmed Anasirí emplea las mismas palabras que el autor del Cartás, al repetir este dato, variando sólo en el empleo de diferente verbo, aunque con el mismo significado.

Como prueba de la perfección artística de las monedas de que tratamos, y como muestra de las que tuvieron curso ordinario en la España cristiaua, principalmente en Toledo, portemos á continuación y reproducidas cu lánninas las que nos ha parecido más importante dar á conocer de visu, no haciéndolo de mayor número, poroque, como qreda indicado, la serie es numerosísima, y curiosa en extremo por la variedad de aspecio y leyendas la sorie de las moneditas de plata. 


\section{$-375-$}

N. I. Moneda de oro de Segelmesa del año 450: es la más antigua que de los almoravides couocemos, teniendo yt el aspecto y leyendas que tienen todos los dinares de esta dinastía.

I. A.

$$
\begin{aligned}
& \text { a-b y } \\
& \text { ه } \\
& \text { كالها } \\
& \text { ots } y \text { ? }
\end{aligned}
$$

No hay Dios sino A lá:

Jahomà es el mensajero do dlá:

El emir Abubiquer

Benomatr.

M. dis

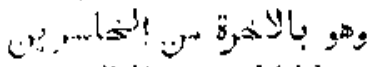

$Y$ al que signiese otre religion freera del islan, no le será revitido, y il en la otra vida sera de los descarriados.

II. A.

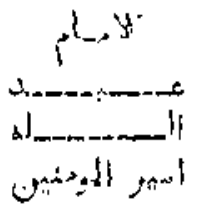


$-376-$

El imam (pontífice)

Abd-

ela.

emir de los creyentes.

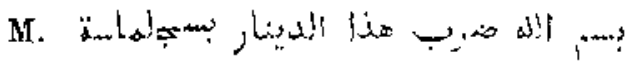

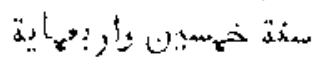

Kin el nombre de al lic fee aceñado este dinar cu Seyplinesa año cinctienda y cuatrociones.

Vives. N. 1425. peso, 4,10 gr.

N. 2. Dinar acurado en Agmat: acunación elegantísima: tiene las mismos leyendas que la anterior con la sola diferencia de

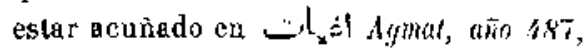
$y$ variando el nounbre del príncipe, pues ya perlenece al reinado de $E$ emir lisul bon Truplin.

Vives. N. 1460 peso, $4,15 \mathrm{gr}$.

N. 3. Monedita de plata (quirate) acuñade en Córdoba en el año 502.

I. A.

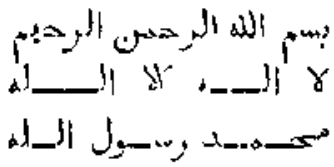


En el nombre de Alá, el clemenle, el misericordioso:

No hay Dios sino Ala:

Mahoma el mensajero de Alá.

1. No tiene orlas.

Il. A.

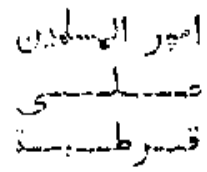

Emir de los muslimes

Alí.

Córdoba.

M. وخx

En el nombre de Ali fur acuinado este dirhem año dos y quiniculos.

Vives. N. $160 \%$ peso, $1,10 \mathrm{gt}$.

N. 4. Quirale de Córdoba del año 505.

I. A.

$$
\begin{aligned}
& y \text { a } \\
& x_{x}=0 \text {. } \\
& \text {,Lt) b.- }
\end{aligned}
$$




\section{$-378-$}

No bay Dios sido

Alá: Mahoma

mensajero de Alá.

I. Sin orla.

II. A.

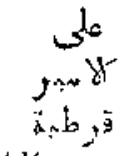

Alí

el emir.

Córdobra.

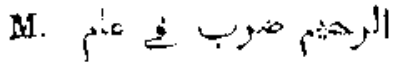

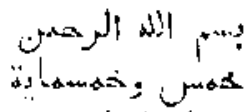

En el nombre de Alh, el elemente, el misericor.

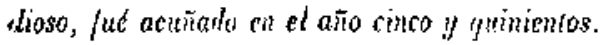

Vives. N. J668. jeso, 0,9 gr.

Se cunocen ejemplares de estas elegrantes monedilas de los oilos 505,506 y 507 , con la particularidad de que en unos ejemplares se lee la palabra ain y en olros palabra año 4.

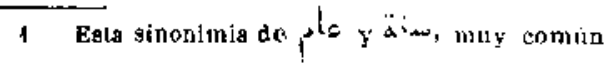
en las monedas de los almoravides, aparece ya en

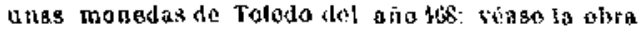
col Sr. Vives, N. 1117. 
N. 5. No tan eleganles como las moneditas de Córdoba, las acuñadas en Sevilla por Alí presentan singular perfección artística y variedad de lesendas.

I. A.

$$
\text { X. } 319
$$

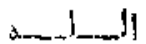

صلموات المات ant:

No hay Dios sino

$$
\text { تئ - }
$$

Alá:

Las bendiciones de Alá (sean) sobre él

Mahoma su sieryo y mensajero.

II. A.

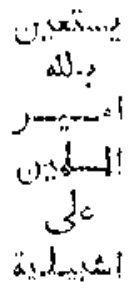

Pide la prolección de

Alá

el emir de

los muslimes 


\section{$-380-$}

\section{Alí.}

Sevilla.

Vives. N. 16r6. peso, 0,85 gr. N. 6. Quirate de Córdoba, elegante y caprichoso en su distribución.

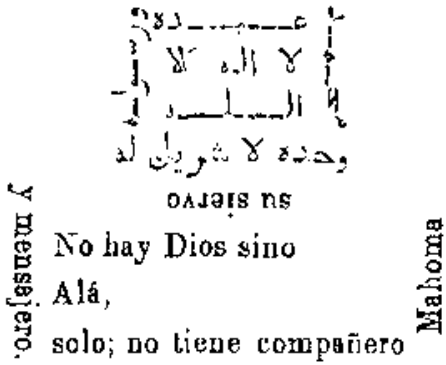

Vives. N. 1706. peso, 0,99 gr.

II. $\boldsymbol{\Lambda}$.

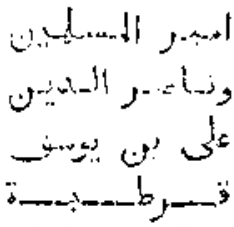

Emir de los muslimes

y defeusor de la religión

Alí hijo de Yúsuf.

Córdoba. 


\section{$-381-$}

Encima à manera de resello dll 8 i, Ayudele tha.

Vives. X. 1706 . peso, $0,99 \mathrm{gr}$. N. 7. Por la elegancia de la acujación merecen lugar especial aquí y que se reproduzca al menos una de las monedas de Foz de los tres ciltimos años del reinado de Alí.

I. A.

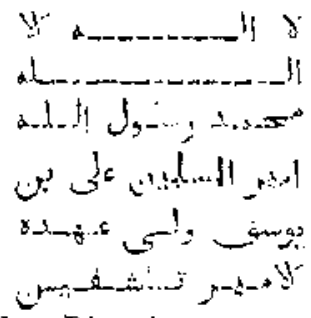

No hay Dios sino

Alá:

Jahoma mensajero de Alá:

Emir de las mustimes Milijo de

l'resu: prineipe heredero

el emir Texufin.

M. Después de la leyeoda ordinaria, el grabador aun tuvo espacio pura añadir allit, creo en Alí. 


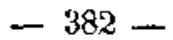

I\}. A.

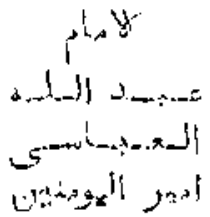

\section{El imam}

\section{Abdala}

\section{el Abasí}

emir de los crejentes.

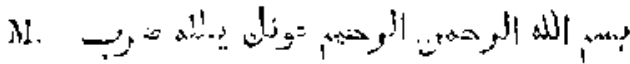
ن.

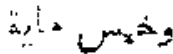

En of nswbin de dí, el clements, of misuricor-

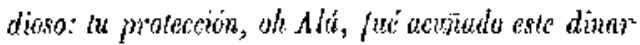
en la civded de Fe, reño seis y toninta y grixientos.

Yives. N. 1808 peso, $4,20 \mathrm{gr}$.

Parece que el yrabador eneargado de abrir los cuños de las monedas de Fez de los años 535,536 y 337 formó empoño cu hacer alarde de que al incluir en la ioscripción circulur la leyenda coránica ordinaria, nada corta por cierto, a un le sobraba espacio: en las dal año 535 pudo añadir las palabras 
en las del 536 allu. تisl y en las del 537 Ah p...! : estas mismas palabuas se leen en las monedas acuñadas en l'ez á nombre de Texufíu en los años 537, y 538, y probablementc en la única que se conoce del eño 539 , existente cn ol Museo do París, annque Mr. Lavoix, que hace notar detalles menos importantes, co advierte esta particularidad, como tampoco la nota respecto al dinar del año 538 , en el que, como resulta del grabado, se nota lo mismo que en los ejemplares que hemos visto.

N. 8. Los dinares acuñados en Almería, que induchblemente son las monedas más toscas de este período, distando mucho de la perfección y elegancia de las de las otras cecas, se modifican visiblemente comenzado ya el año j36: las acuñadas por Texufin en el año 538 alcanzan ya la perfección ordinaria: esles monedas, que parece debieron acuñarse en grandes cantidades, habiendo circulado en 'loledo durante alcrunos años como la moneda legul, ó usual, presentas su mayor per- 
fección en las acuñgdas en el año 539 , consiryando el nombre del Príncipe hesedero Ibratim; la reprodicimos con el número 8.

I. A.

$$
\begin{aligned}
& \text { 此 } \\
& \text { 每 } \\
& \text { (1) }
\end{aligned}
$$

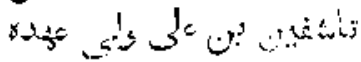

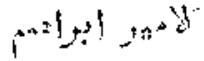

No hay Dios sino Alá

Mahoma mensajero de Alá: emir de los mustimes $y$ defonsor de te veligitin, Texufin hijo de . Ali; ste prineipre herdero, cl emir llowhin.

M. La leyenda ordinaria, más las palabras all

II. $A$.

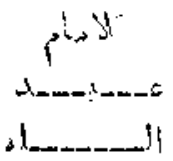

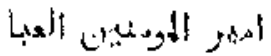

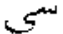


iij imam

Abd-.

ala

emir de los cresentes, el tha--

sí.

M. La levenda ordiuaria con la fecha 539.

Vives, $N^{\top} .1870$ peso, 4.20 gr.

De los cortos reinados de l'exulia $y$ do su hermano Tehar, en especial del primero, se conservan nuchos ejemplares de los yuira4's, medios de guirate, enerros, gitaras y dies $y$ seisroe, quiri por la coincidencis do haber podido adţairir cosi toto un tesoro de monedas descubierto en Córdoba hace al trunos años, tesoro que debio de esconderse en al à̃o 541 , pues no salió ningruma moneda posterior á esle año.

Por su elegancia cu tau diminu to lomaño, merece publicarse el siguieute carto do quirate.

N. 9. I. A. Idorno.

II. A.

$$
\begin{aligned}
& \text { أ } \\
& \text { (1) } \\
& \text { | }
\end{aligned}
$$




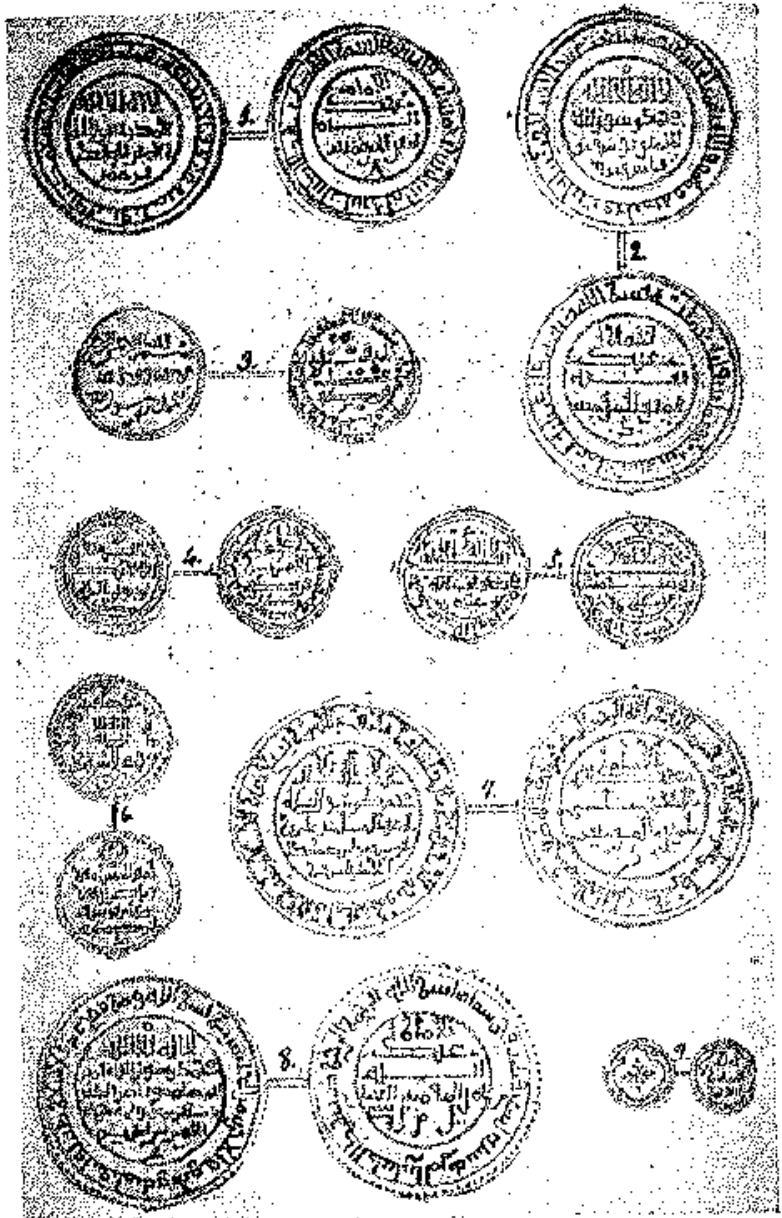




\section{$-387 \rightarrow$}

Limir de

los muslimes

Ishac.

Vives, N. 1899.

Muchas son las monedas acuíadas por diferentes poblaciones al separarse de la obediencia de los almoravides: merecen ser reproducides por su elegancia é inlerés, y aun por su curiosidad, las siguientes de Cordoba. N. 10. Linar de Aben hemdín.

I, A.

$$
\begin{aligned}
& \text { y. }
\end{aligned}
$$

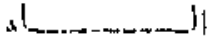

$$
\begin{aligned}
& \text { pat de ; ; } \\
& \text { की } \\
& \text { was }
\end{aligned}
$$

No hay Jius siuo

\section{Alá}

Almassur lite esuis

do los muslimps Montin, hijo

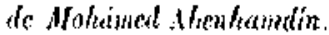

M. La misión profética de Malıoma.

II. A.

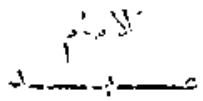




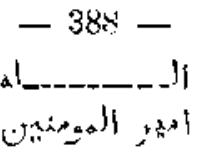

Til inam

Abd-

ala

emir de los creyentes.

M. إ'

En al nombre de llit, far acoũado scle dintr en liondola, año cutrenta ty quinimtos.

Vives, ‥ 1905 . peso $3,95 \mathrm{gr}$.

Hay dinsres con las mismss leyendas, aunque con ligera variante en lu distribución, de los años 539 y 40.

N. Il. Perucina moneda de plata; ó sea greirate.

I. A.

ע. a

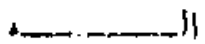

औो

قز طجة

No hay 'Dios aino

Alá: 
$-389-$

Maboma mensajera de Al

Córtoba.

II. $\Lambda$.

$$
\begin{aligned}
& \text { wh } \\
& 20 \text { : }
\end{aligned}
$$

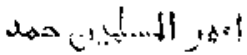

$$
\begin{aligned}
& 3_{x}=0 \text { : L.? }
\end{aligned}
$$

bila

Almansur

emir de los muslimes Hand

ín hijo de Mohámed.

Vives, 1906. peso 0,95 gr.

Hay otros ejemplares con pequeña variante en la distribución de las leyendas de la II. A.

N. 12. $1 / 2$ quirate.

I. A. Sin leyenda: adorno.

II. A.

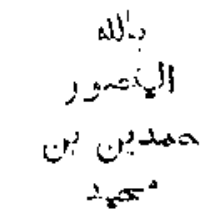

bila

Almonsur 
$-390-$

Hamdín hijo de

Mohámed.

Vives, 1908. peso, 0,487 gr.

Como procedentes del tesoro mencionado al tratar del N. 8, pueden suponerse de estog raismos años las dos moneditas siruientes N. 13. $1 / 8$ de dirhem

I. A.

$$
\begin{aligned}
& \text { ها” } \\
& 1 \times 2.31 \\
& \text { قمب }
\end{aligned}
$$

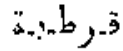

II. A.

Vives, 1 . 2013. peso, 0,245 gr.

N. 14. $1 / 16$ de quirate.

I. A. sin loyenda.

II. A.

$$
\text { ق }
$$

Córdoba.

Vives, N. 2012. peso, 0,0474 gr. Es casi seguro que están acuñadas en 


\section{$-391-$}

Córdoba en los años 542 ó 543 las dos monedas siguientes

N. 15. Quirate.

I. A.

a)

$$
\begin{aligned}
& y \text { d } Y \\
& \text { all }
\end{aligned}
$$

So hay Dios siuo Alá (arrib)

Mahoma mensajero de Alá.

II. A.

$$
\begin{aligned}
& \text { a.t. } \\
& \text { (r) } \\
& \text { : }
\end{aligned}
$$

(3h Alá, ten compasión

de los emires de los muslimes

los beniterufin.

Vive, N. 1981. peso, $0,99 \mathrm{gr}$.

N. I6. Semiquirate.

I. A.

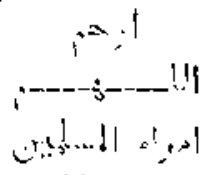

Ten comprsión

oh Alá

de los emires de los muslimes 


\section{$-392-$}

II. A.

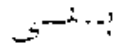

ن

los Beni -

texufín.

Vives, N. 1983 . peso 0,50 gr. Acunadas estas dos últimas manedas, prabablenente co Córbolys por A henganio despuís, de la muerte del tíltimo Principe almaravid, pueden ser consideradas como un piadoso recuerdo dedicito á la buena mezoria de la extinguida dinastía: se conocen monedas de oro con esta leyenda acuñadas en Córdcba en 542 y en Granada en 545 . (Vives, N. 1978 y 1979).

Queda indicodu que de Abenmerdanix ó sea del rey lope ú Loho se cooseryan muchas monedas: parece fuerou conocidas de los cristianos con el noubre de lapines; unal del año 553 reprodujimos en nuestro tratado de Numismatica aribigo-españolx: por su singular elegancia reproducimos aquí dos de estos precioson dinares.

N. I7. Disar de Volencia.

I, A. 


$$
\begin{aligned}
& -393- \\
& \text { (1...... ปู }
\end{aligned}
$$

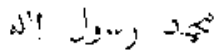

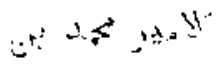

$$
\begin{aligned}
& \therefore \text { a... }
\end{aligned}
$$

Alấ:

No hay Dios sino

Mutouna mensajero de Alá:

Bl comir Mohimed, hijo de

Salad.

M. La leyenda ordinaria de las monedas almoravides.

II. A.

$$
\text { = }
$$

Ell inam

Abd-

ala

emir de los creyentes.

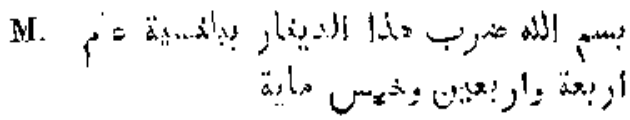




\section{$-394-$}

En el nombre de Ali, faé acuñado este dinar et Valencia año cuatro y cuarenta y quinientos.

Vires, N. 1937 . peso, $3,90 \mathrm{gr}$.

N. 18. Dinar de Murcia.

I.

$$
\begin{aligned}
& \text { 8 }
\end{aligned}
$$

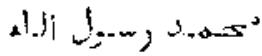

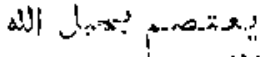

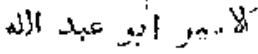

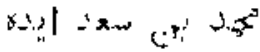

No hay Dios sino Alá,

Mahoma mensajero de Alá;

se apoye en la protección de $A$ lá

el emir $\Lambda$ busbedala

Mohamed Abensad, ayúdele

Alá.

M. La leyenda ordinaria de les manedas elmorovides.
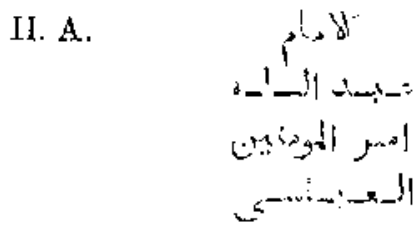
El imam

Abdala

emir de los creyentes

el Abasí.

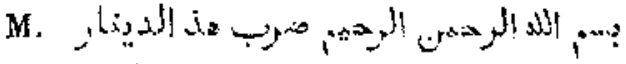
罗

En el nambre de Alá, el clemente, el misericordioso, fue acuñado este dinar en Ifurcia año ocho $y$ cincuenta y guimientas.

Vives, N. 1957. peso, 3,90 gr.

Fn esias monedas Abensaed reconoce explícitamente la soberanía espiritual del Califa Abasí, como lo hizo hasta el fin de su reina. do desde el año 547 , poniendo en las de algunos años el sobrenombre ó título sultánico all?<smiles>[AsH][AsH]</smiles>

Entregada Bueza á Alfocso VII en el año 542 de la hégira, vemos que por estos años se acuñan en ella monedas árabes con tipo de las de los almoravides, sin que sea fácil determinar las causas que á ello contribnyeron: toles monedas circularon mucho, siendo por algunos at̃os la moneda de oro corriente 


\section{- $396-$}

en Toledo: por esta circuestancia, pues parecen haber sido las que sirvieran de tipo inmediato para la moneda alfonsi, ponemos á continuación esta singular moneda, que Bolo encontramos acuñada en el año 548.

N. 19.

I. A.

$$
\text { Y. }
$$

Alá:

No hay lios sino

Haltoma mengajero de Alá:

Alá (es) omigo de los que creen.

M. La leyenda ordinaria de las monedas almoravides.

II. A. Isa leyenda ordinaria como en la moneda N. 18, con ligera variante, $y$ en la orla

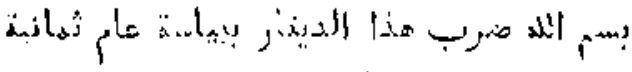

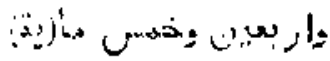




\section{$-39 \%$}

En al nomber do whe fur acuroto este diner

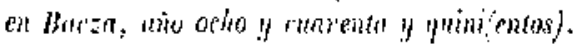

Vives, N. 1996. peso, 3,90 gr.

De los años 54t, ati) $y$ ith so conocen dinares muy parecidos en la legenda de la I. A. é igual la do la 11. A, en los que parece leerse, ccennado para (?) Baeza (?), Jaén (?) y Seville.

N. 20. Moneda de Alionso Yill ó sea dina" alponsi.

I. A.

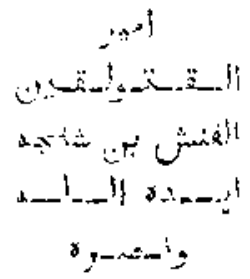

Fmir do

las católicos

Alfonso hijo do Sucho,

ayúdole Alá

y protćjale.

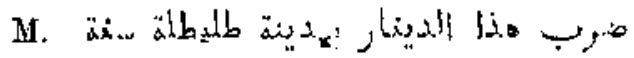

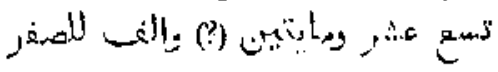




\section{$-398-$}

Fut acuñado este dinar en la ciudad de Toledo año 1219 de la cra española.

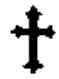

II. A.
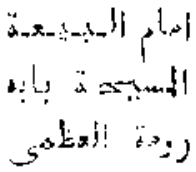

lmam de la religín del Mesías, el Papa de Roma la graude.

M. SW!

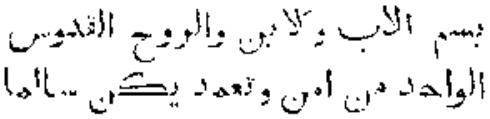

En el nombre del Padre, y dri llijo y del Fspirio Santo, Diss iniro, quiest creyere y fuera baudisalo, serie satio.

Viv̌es, 2021. peso $3,90 \mathrm{gr}$. N. 21. Dinar alfousí del año 1222: en la I. A. en vez de las palabras sobs't äs, aparece la abrcviatura de Alfonso, ALF: todas las posteriores siguen este wodelo.

Vives, N. 2022, peso $3,72 \mathrm{gr}$. 
La acuitación de estas monedas de f'oledo es en general tan mala, y las letras están trazadas de un modo tan losco. (jue aun sabiendo lo que en elles debe decir, es difícil durse cuenla de las lelras y seguir su lectura; por eso nada liese de estrano que no acertaran los primeros que intentaron su jectura!.

La acuñación de la tneveda propia de los reyes de Castilla y León comienza en tiempo de los almoravides con Alfonso VY. La de oro tomó el nombre de ellos. Jlamándose morabiti 'moneda almoravid;: onteriores a $\mathrm{Al}$ Conso VIII, sólo se cunocen nutiedas de aro (las marazedises) de Fernando II de Joón $\mathrm{y}$ Alfonso 1X.

Alfonso Vlli no se contenta con imitar en el sisterua moneturio los dinares almoravides, sino que los acuña en ârabe, imitando en la distribucióa de las leyendas al tipo

1 Puediv verse lo gisa decimos en huestro solle-

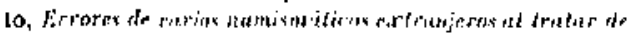

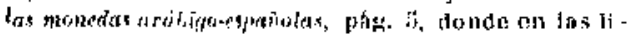

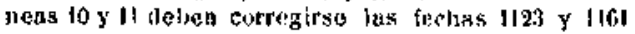
nor 1223 y 11 is. 


\section{$-401-$}

consagrado por el uso, si bien poniendo leyenda cristiana.

Y cosa singular, las monedss acuinadas en Toledo á nombe de Alfonso VUI se continuan después de su muerte durante dos ó tres años, habiendo reinado desde el año 1158 al 1214, se conocen dinares alfonsíes desde el aĩo 1174 de J. C. ul 1217, ó sea desde el año 1212 liasta el 1255 da la era de Safar, como dice on ellas.

Aunque hasta aluora la moneda nás antigua que conocemos de esta clase es del año 1212, comenzaron á acurarse antes, pues se citan los mizcales de oro alfonsí en dounmentos de Toledo desde el año 1210 ': con este mismo nombre tuvieron circulación en Toledo al menos hasta el oño 1260 de la era española.

En los añoi 1182 a 1190 se citan miscales de oro almurarit de la real acuñación de Aimería, y como el 1182 de la era (1144 de J. C.) corresponde en parte al 539, la moneda de Almería de este año que publicamos

1 Pons, obra citala.

ALMOR.YIDES

2i) 
con el n." 8 será la designada en tales documentos de Toledo.

Jesde el 1194 al 1210 de la era encontramos citados los mizcales de oro ribryesi, que remplazaron en Toledoá los mizcales de Al. mería, hasta quéa su vez fueron dados al olvido por la acuñación de los miacules de oro rl/onsi: por las rnouedus de oro albayesí deberán entenderse las monedas de Baeza, como la publicada con el n. ${ }^{\circ} 19$, que es del año 348 (de 24 de Marzo de 1153 á 17 de Marzo de 1154 de J. C. 6 sen 1191 y 1192 de la era espeñolo).

Duranle todo este período cncontramos citados en los mísmos documentos de Toledo mizcales sin determinación especial, 6 mizca$l_{p,}$ de on bient $y$ justo jreso. que suponemos serían simplemente los corrientes en las fechas respeclivas: son pacos los documentos publicados en dicha obra, anteriores al 1182 de la Err. 
ÍNDICE CRONOLÓGICO 



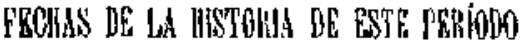

Dis LAS 4 STS

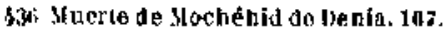

tro Atmoctarlir ray do Zaragoza despoja de sil rebro a su yerno alj de Denia. 137.

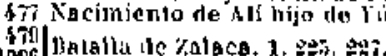

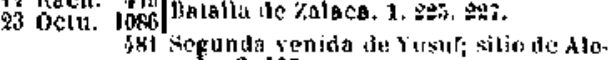
do, 3, 887 .

483 Tercera Yenida de rusuf; desirona a los

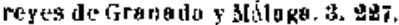

49) Cuarta venjula de Ýusuf, ge8.

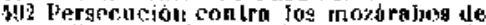
Gransos: degatruccion to una iglesin antigun. $\mathrm{E} 18$.

\$95 Alf proclamado Priaclpo boredero en Marruecos a:sio.

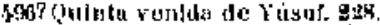

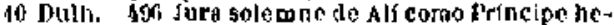
rederto, un Curtoba. gyw, yyt).

son Mozarabes do Malaga gn Ion para Marruecos. ㄴ.

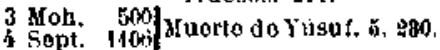

Dulh. $\$ 00$ Primern vonlda de Alf́ a Espana (como emir de los muslimes), n. *. Sist.

t00 Ahemitiluis, cuinado de Ali, goberna-

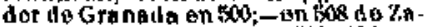
ragoza, fonds muere on 5io. 2800 . 


\section{Dis $\frac{\text { Nes }}{17 \text { Xaus. }} \frac{\Delta \mathrm{ic}}{i 01}$}

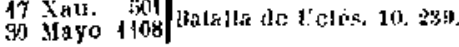

30 Junfo 1109 Herte te Allouso v. 10.

1 Julio 1109 Dona lirroca sucede á sn patre Alfolsa YI. 10.

503 Segundir ranida de All. 11. 282.

16 Agos. 1509$]$ Taina de Talaveria. 1s. $23+286$.

1 Racli, 503 Mruerte de Almostwin bl in Za ragaza en

24 Encr. 1410\} Yialtierra. 12.244, 254.

fi. Dulc. 503 Combate dentro ile Zarkgoza. an que parece son derrotados los a fectos á los almoravides. 257 .

10 Duth, So3 los de Zaragoza ectuan cir la ciadad al

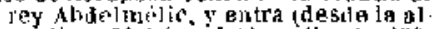
medina) Mohámed abcralhach. Lis.

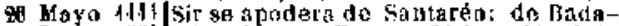
I5 Dule. Solf joz, Oporto, Evora y Lishao. 11, : $\$ 3$. $50 s$ soneda do los altnoravides en Zaragoza. $\mathbf{3}$.

som/s tramim ge retira de Maria? 12.

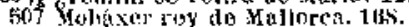

11 s lifia da principes cristianos contra los $50 \%$ corsal'ios de Mablorea. $10 \mathrm{~s}$.

Jutio ths dhennlsach sale de Zstrogora de expe-

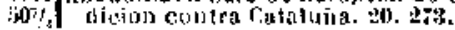

Safar íobjiatalla sel Congust de Mariorrell y

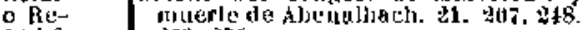
bit.o $25 \%$. 27\%.

3 Abril. Il I; Toma del altimo recinto tho Vallorca. 6 Dulc. 508 ) 275

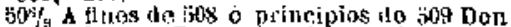
Ramen Berenguer dercota á jos noras obl of llano do Harcalonn. 478.

509 Lanudin Valj de Maltorca durante ires meses despirís do ia concurtista. 170.

bog Abuberuer valf de Mallorca después do tianudín. 17s.

sta Suere ol principe Abubéquer Abontifluit en Zaragoza. 240. 
Dis Les $\Delta$ 范

49 Solar 3̈l|Tercera venida de Ali: sitio de Colm-

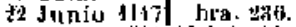

3j) Abưato Aluenalmazialí vali de Zarngo. 2a. 270.

sif i Temin hermano de sli huce lavgntar el silio ho Lerida" *ton.

Mayo 118 tcomienza bl sibis de Zarigoza, puo du$5 / 2$ ta 7 incses. Why.

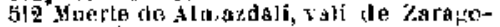
2.8. \$ٓ心.

it9 Dici.? H18 Toma de Zaragoza por difonso ol Bata-

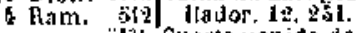

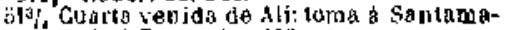
ría o Sanderen, 2.34.

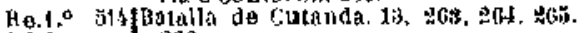
o 2.0

515 Muerte de simehại. Fundator da la sertí A Imohale. 3ils.

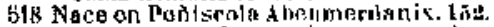

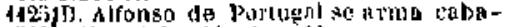

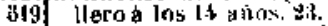

599 Los almoliades; sll apnridion, wh.

1 Sept. 11) big lucia. 14. 200.813 .211$.

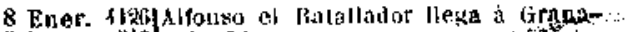

5 lpalh. $5|9|$ da. Jf.

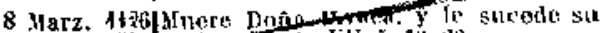
siol

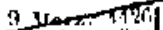

|latibla do Arimsol, 15.

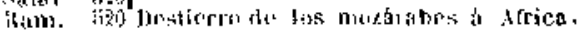
et1.

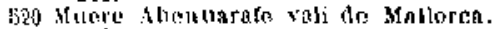
ITI.

:iela Ali cla el mando de clandal us a su

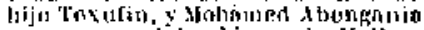
sc encarga del gohierno de Malloren. 171.

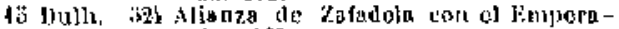
dor. $15 i$,

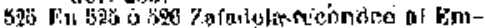

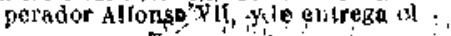




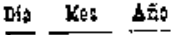

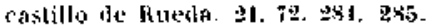

Hach. Saj Las milicias te Toleldo blegan à Savilla y metall en wh encuentro al valj imar. 24, 284,

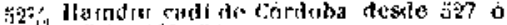

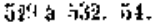

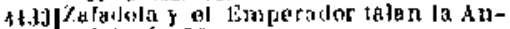
$32 \%$ latucla. 26.

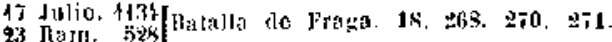

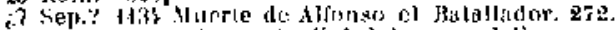

grta hlianza te Kafarbia con el Emperaसlar, sefize al

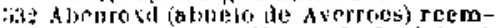

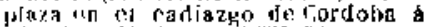

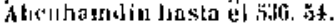

Siegri. 11,39|furna de oroja gor el fimperador. 30.

93 Safar. alarik, cundatinr de la secta de los moridin. $35 \%$.

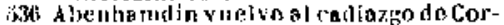
dolia. ist.

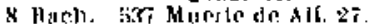

27 rivir. lik3\} Materen en latalia coutro los cristia-

9 Xabia. ist nos Azllel y Avencela.

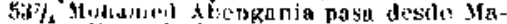
llorca a visilar

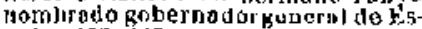
goìs. 172,327 .

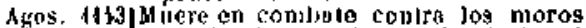

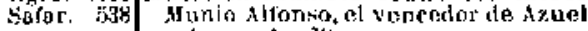

I. y A tencela. Zt;.

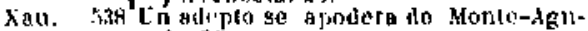
do. 36 .

25 Dulh. in alsennbelezis nombrodo cadi de ra. lertia, lot.

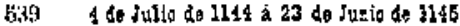

Safar. " Principio de a rebolion un el Algarbe. 01 .

42 Snfar. * Toma de Stitriola nor Abcuslcabilo. 33.

Sorar. "Aulos de Itebl $10^{\circ}$ Sidroy se rebela en 


\section{$-409-$}

Dia Yes Az:

Evora. Abenatmondir se apockera te

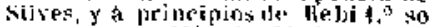
presentan en Mertola. 39. 29?.

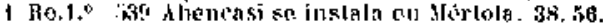

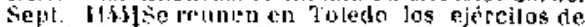

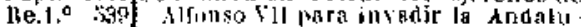
cim. 71 .

Abenalmondír se apodera de littolva. 10.

" Derrolado Abenalmoutir eered do sevijls es perseguido por abengania, que sitia à Jiebla, deftrodid u por Yे ssif el Petrochi. 41.

Rack. " Abenliamain proelamasto por prímera vez en Cordoha. so. is. 91.

tenor. ldiglzaratola sis presenta on fordols $y$ as

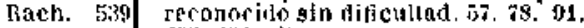
넥. 베) 4 . (i)

¿ Ram. "Jafadola es echado de Córitoba: se-

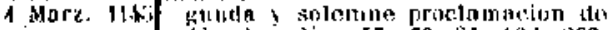
Abenhomdin. 57, 70, 81, 10ㄴ, ב98. :21.9.

339 Slezt a Yalencia la noticia de la proclamarian da thenhamdin: nlhoroto. 102 .

Ram. "Ahrnallacls proclame en Murcia a abonjaudin, por agien so tuce ln naciots pijJlica en parta de thama-

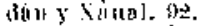

13 Ram. . dhenhasun se declara independtonto en Málogra Mis.

18 Rata. "Alenganid do Falersia envia su famtlis í Jativa. Ints.

27 Ham, "Muterte do Texusin segun la geuerali.lad he los nulores. 30, 296 .

3 Xau. "Abenalydelaziz se bice cargo det gobierno de lalenriz. tos.

$13 \mathrm{Xau.} \mathrm{"Abenabdelaziz} \mathrm{de} \mathrm{Valencia} \mathrm{llega} \mathrm{da} \mathrm{Ja.}$ tiva contra dbęngania. 10*.

(1) Corrjoso en las prig. Zs. ty. \$of. Io indicado en la fe do errnias. 


\section{$-410-$}

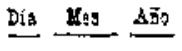

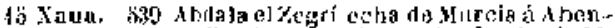
a]luacli y proclatina á Alıenbud, 00.

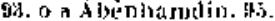

fin Xara. n Abenghichalar echa de Murcia a Ablala el 7.egrí. Ak3.

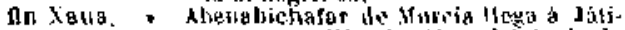
va en auxitio de Abenabdelaziz de

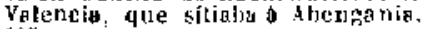
10 i⿱宀.

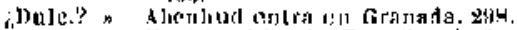

, Jjinibiro, hija de Texufín, a fines del año nimbira carji cla Ceula a Iyad hijo da Vtaza. :th1.

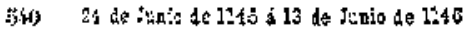

30laa. * Muese en tiranacla Ali Alonadia. S1.

- Ali djejmaimur se rebela en Cádiz,

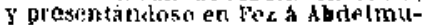

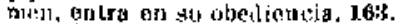

Salar. „ Abenabide] aziz eatra en Faloncia des-

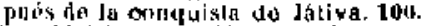

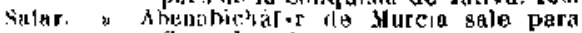
firangla. gli.

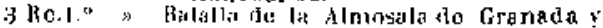

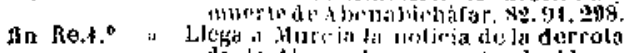
dr ! a truosala y muerte de dben-

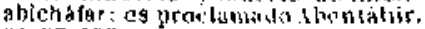
1). HT. 1Md.

Me.2. " ¿Zafalula se retira de Granada? WB.

Iro.2." "Ahencasi sa presenta a Abelmumen. 4 í.

* Moneds de Tremecón á romblede Te. xuliu. $2(00)$.

Ch.t. $\rightarrow$ Muerio lse Texulin.

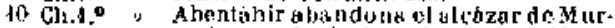
cjo, a poderadodose del mandó Abrnivact et 10 a 26 de estes ises. (4) H. (i) $10 \bar{i}$,

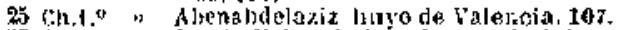

25 Ch.1." " fos de Valencia inștajun en el glcizar (mo Jigarteniente de Abeniyad ryy

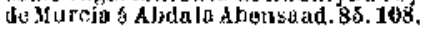




\section{$-4 ! 1-$}

Dia Kea

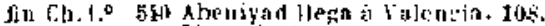

Ch. ;." J,1amado flimgania por los do fordoha, le sale al cueventor abiriliamdis, lute ps derrestado en Ecija. üst.

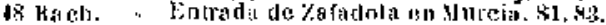

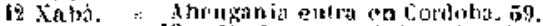

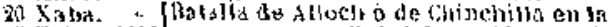

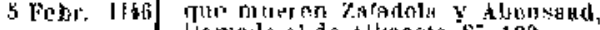
Liapialo ol do Altanceto.si. 10h.

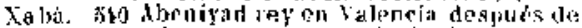
in unuerte de dbe nbud. 10!.

Xaba. "Abrala ol Zegri en Llleba on Murcia curt arenisad. 100.

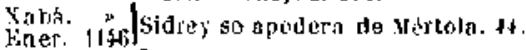

1 Dulia, ajgo Jas almoleadrs pasan a Espana. 4 b.

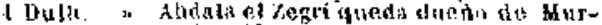
cia. 109.

" Aba fimar, sejior do Jerez, Arens y Rorkla reconoce do los almoliates. 1 igg.

16 Dulb. * El Lmperador y Abentandio olstran

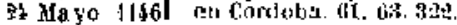

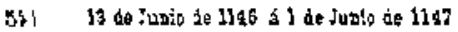

$10 \mathrm{Mol}$. "Isega a lídoba la noticia de lo entradio do los a lnolindey edl tisyaina. tis.

i lhach, "Abdalo el zerí es muerlo y Aboniygd

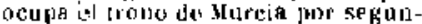
divez. 1 (1).

19. Xobé. o Tomá dle sesilla por los almolundes. 4(i., 61.

"Pl'inera rabelión general contra los

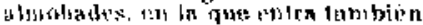
Abenmainu u de cátlix. 165.

a Hecolorada theciras por Abengania, thenalhachnm se adhiere ea liadajoz al movimionto insurreccional eontra los almoliadis. 161.

1 xaua. "Muerte de Texurín, segitn algein auIor. $288 \%$.

Xama. " sfuerte de ishac, iltimo principe almoravid después tle la lom do Ma-

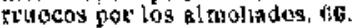




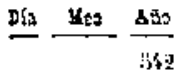

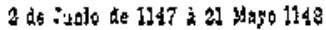

22: lle.1." Abenigad muere à consecuencia de beridas en halaliz ronira los crístianOS. 110.

22 Re. $1^{n}:$ thenmerdanix, muerto Abeniyad, es reconojde como rey de Falencia. 111.

C.t. 1. : Abenmerdanix llega à Mncia. 131.

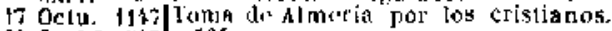

20 Ch, 1. 512] T35.

In tig. "

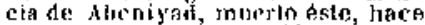
enimen del mando a dienmerdanix, 112 .

d) inar yeunatlo en Córdolia con piadoso lecuerdo a la memoria de los almorarides, isn:2.

it3 28 de Kago áe 1143 a 10 de Nago do 1140

Mohámed hija do dif Aienalhachars actuña monella de oro en ladajoz. IA3.

Ch. 9." "Alucoganik (lisgustado con D. Alfonso bil, se avista nn bijije con Rarra $z$, y entriega a los almohades Cordoba yoin. $\$ 4$. 16.l.

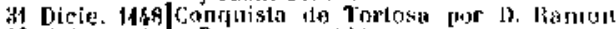

16 Xaha. :34) Berenguer. 124.

\&. Yaha. ¿A Alenganía muere en Granoda. (34.

17. Ham.

Safar "5th Tratado del rey Lobo con Genova. 124.

19 ch.2. 5rsfConquista de ledrila, Faga y Mequi24. Oelli. 1149 nenza. 195. $1 \geq 2$.

1.150 Tralado de naz ertre Nbengania do

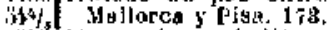

53 A trencasi en rejuelión contra los almothadog. 60.

" Abulgomar ajcaide de Coritoba evith 


\section{$-413-$}

Dis Mes

con su presision la sorpresa gua

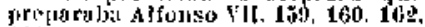
3 is.

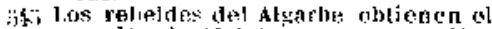
perdón ate Abstelutumen nos medja-

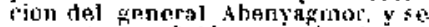
prosentan ea Sęlé, renuinciaurlo sus prefendiatos forechos. 160. 162. 1 15.9.

34 ; Dinar lo Gronada, piatosa recuerdo de los Benitexilill, 83, 89:

19 Hach. !jн; din. 63. 68,

Clı. 1." 海 bs muerto h hencesi. öI.

\$26 Alenmerdanix actidado por Allouso Ill sapodera de litudix. 133.

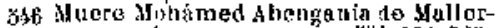

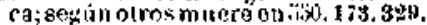

listi Rebalion en rulencia contra el rey l,obo. 125. th:

ijt7 Coulitula la reluclion en Faloncin, Bat.

s lostle eske àno ol ley lohio reconoce an las inonotas la soberalla espirilual do!l Califa do Oplemste. Jels.

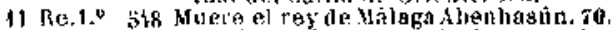

3 Momeda de lineza on jube y con lafentla misumana a pesat da cstar un porler to los cristialias chesdo ol

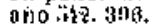

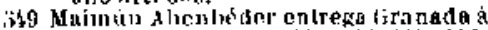
los almolnales. din. 130. 13:, $315,316$.

; Fotroga cie firatbetla ả los alinoliades,

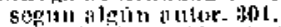

zijl Los da Sevilla piden j dodelmumen

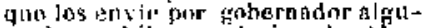
Ito des sus lijos: es desipuado Abuyrcish. is.

[ï̈ Almerita perdian por Jos cristianos. 13i. $31 \vec{i}$.

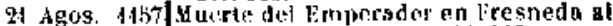

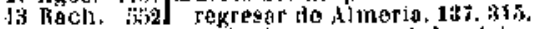

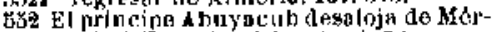
lola a texufin el Lambut, is.

bot3 sueren in lasta de Sevilla en contbate contra ios cristianos, Jos exre- 
Día Les Año

Yas Abulgamar y dbenollachsm. 160. 1h:.

fin

int Ja ch prests obedienciasl rey Lnbo. 184. itho Cordolsa sitiada por el roy Jobo. Tis. 16 If El rey de Mallorca trala de paz con los 5iN/ Pisanes. I78.

ivi thenbemorhicen se apodera de Grata(1) 139. $21 \pm, 35$.

557 Derrola de los almohudes ath la prid(iera de Marcharocad a ta millas de Graniala. 1 iq0.

28 sach. anj Baliba de la Axabica y dermta de

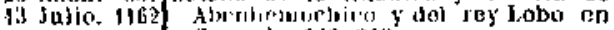
(itanitura 143. 318.

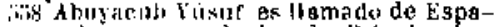
ìn para ser declarado Príncipe heredrro. 145,

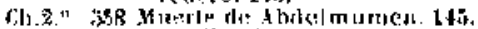

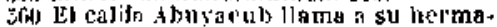

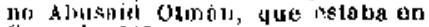
Ǵranada. 145.

: $x$ 0 A benheme chico illanta apoderarse do Cordoha. 145.

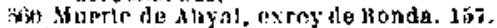

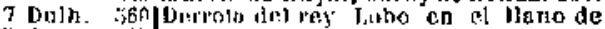

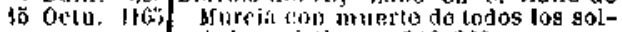

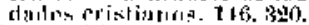

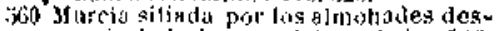

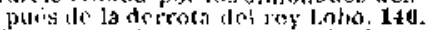

ibl alinlipinochico entra en relacioves con los almalizdes, ofreciendo soinelersm. 147.

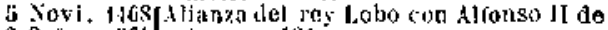

q Salar. inis Aragon. 121.

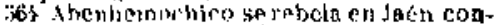

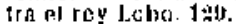

i66t Su reliela en Almería contra cl rey lobo, su prino Mohamed. 199, 149.

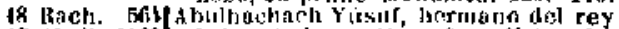
17 Abril J69 John independiecte? en Falencia. I내.

5isililel es proelangdo Principe heredero del rey Lobo, según Jas monedas, 151 . 


\section{$+415-$}

\section{Din Yes}

Setj Compuista cle Baza ror ef prinejpe dhutafs despues de tomar posesion de fistea. 149 .

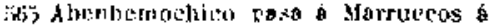
irnes una tulrevista colb el Califa. 1 its.

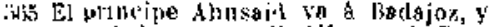
paclada paz con 1). Alfonso de Portugal rexresa a Sesilla. 14 A.

bes retielion de dicira contra ol res l,oho. I니.

Sab Konoda de Islac Abengania en Mollorea. L75.

wij Aluluacharh Yusúr, hermano del rey Letho, se yosa a los almohades. 1810 .

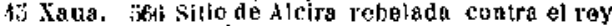
I.obo. 1.1\%,

15 Dulc. i'a y le es entregada. 14 .

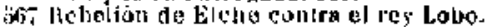
1 in).

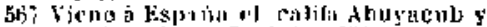
re itrstala on Co riluna. Cót.

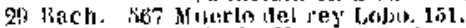

367 silta de Huele por los almohades, $y$ Pracaso de éctos. 173. 381 .

at Moneda do Ishac abengania de Mallorea, 17\%.

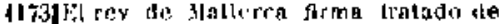

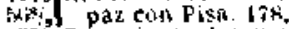

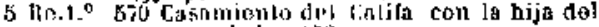
roy lolun. 15 is.

$1178 f$ til rey do llathorca ocnmete y toma in

5 T. thatud te Tolon, en Francia. 177. 3)1.

97 Jnio Jij8|Los mores mallorguina's samuenn la

9 Moh. ind ialesis de santa laria de tilla (jecand\}. 17\%, \$:31. 3:3:4.

75. Hucre en Alarmecos Abontahir oxrey ite il urcia. Ith.

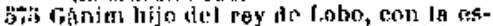
cuadra almoluade acomete a Líshoo. Lint? 


\section{Dia Nos Aic}

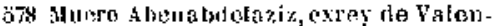
cia. 310.

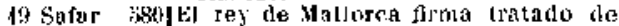

$\checkmark$ junjo t18i paz can I'isa. 178.

Fy Yuerle do Jshac de Mallorea poco antes de Ja muerte del ralina Abuya-

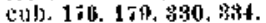

¿Re.2."? 380 Mure al culja dbuyacub a ennspcuencia de la derroía de Santarén. 181. 343.5.

700 Los the Mallorea se subjevan curlin Millamed y proclaman a su hermano Ali. 1:1.

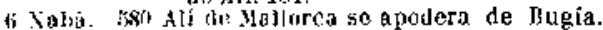
140

1183 Los cijsalanos cautivos se apoderan 5xif tel palesia do Mallorez, 189.

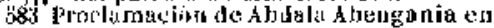
Moslorea. INt.

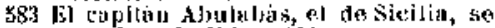
gpolera de lbiza. 1.S4.

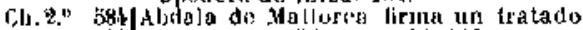
Agos. 1188 de paz con Génova.

69.5 Muerla del califa A lmansti'. 180.

ing lit caliria Anasir salo de Malruecos rontra Yallorea. 1 Ket.

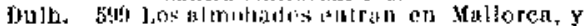

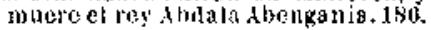




\section{ADDENDA ET CORRIGENDA}

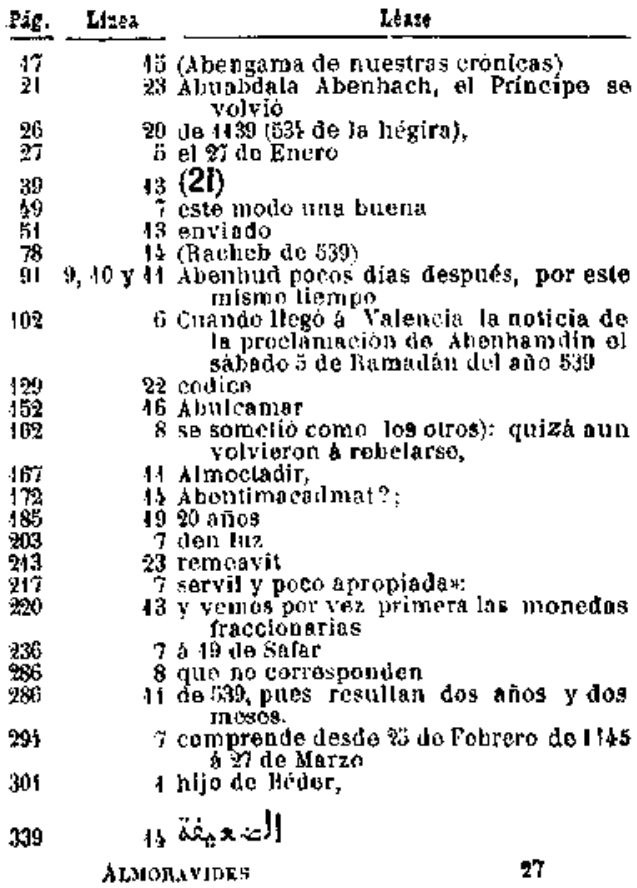





\section{INDICE DE ESTE LIBRO}

P4.

th

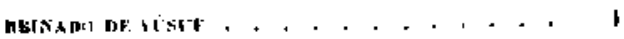

RESTADO DE , , . . . . . . . . . . . . 3

Arogón: Tudela, Zarggozs, Culanda ..... - Iz

Experlicion a Adodolncía. . . . . . . . . . 13

Ratalla de Frapa. . . , . . . . . . . . .

Jos almoratides en Calaluita: hatolla to Mtatlorell, , , . , . . , . . . 20

Porlugal j Cabilla.. . . . . . . . . , 果

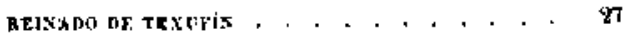

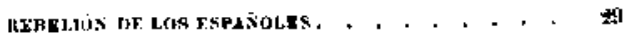

la Helrolion en el Algatbu. . . . . . . . . 33

La Rebelión en Cordolkn. . . . . . . . . . 53

I.n Aobellón on Mblage , . . . . . . . . , fR

La Reholion en al Orionto de Alaukalus, . , 70

En Murcia Y Yalencía. . . . . . . . . . . \$ \$ 
Rág.

Gobierno de Abenalhacli

del arraez kbdalik is Zegri. . . . , 933

"de Ahenabichafar . . . . . . . . $\$$

$\therefore$ de Abentálìr . . . . . . . . . 97

, de Abeniyat . . . . . . . . . . . 99

La Rebelicin en Vulencia. . . . . . . . . . . 101

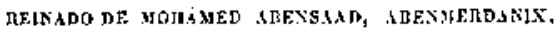

(i EL NEY LORO. . . . . . . . . . . . . HI

Tratados da dbenmentanis ento los eristiatuos. 120

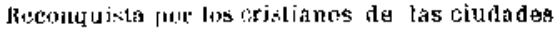

de Tortoss, Lérida, Fraza y Mequinenza . . 123

Yajencia hajo el rey loho . . . . . . . . . . 127

Conquistas de Abenmerdanix. . , , . . 130

Conquigta de Guadix . . . . . . . . . . . 131

Jaén, Ubeda y Baeza. . . . . . . . . . . 134

Almería. . . . . . . . . . . . . , 135

Miranada. - . . . . . . . . . . . . . 138

Defecciones en la ramilia del roy Loho. . . . 147

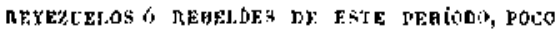
coxchisos . . . . . . . . . . . . . 6ï

Ahysl rebolde en frondin. . . . . . . . . . 150

A bengarion scinoy do Jerce y Konda , , . . ta8

Aheraltucham rey dat Badajoz . . . . . , , 160

Alf Alonmaimia serior do Cáaliz . . . . . . 183

GAS BALEATUS HAJG LOS ALYORAYIDES , . . , , 167

Mohamed Abengania. . . . . . . . . . . 17 s

lshac Alengania. . . . . . . . . . . . . 178

EPIMEROS MEINADOS DE MOHAKWD, ALi, TALHA, , vO-

"Á,UEO (Q. vEZ) Y TEXLFÍN . . . . . . , 179 


\section{$-421-$}

Juicio acorca de la dominación de los almoraFide en Españo . . . . . . . . 19 Persecución de los mozárabes . . . . . . 208

H.ESTRACIONES. . . . . . . . . . . . . . 928

Cromologia detallada de la contenido en este

libro............. 403

Adden da el corrigenda . . . . . . . . \$17 



\section{OBRAS DE ARABISTAS ESPAÑOLES}

que estin de renta et los librerlas 



\section{Bibliotheca arabioo-hispana}

To. 1 y II, ADEx PAsccxlis asslLA (Dictionarium biographicum) ad tidern codicís Escurialensis arabice nune primurn cdichit et indicibug locupletissimis instruxit Fratreisewe Cottero in liniversifate

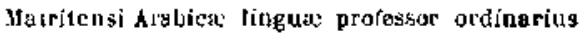
el Regia IIisloriene Academbe Sodalis. Matrili, 1882 et 1883 . hos tomos en 4. $^{\circ}$ eon toliacion unica, $\mathrm{XX}$ y tô? rágius,

4 plas.

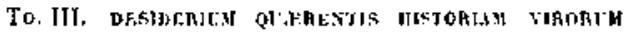
poptil ANDAtCsL: (Dlctionarium blographletm)

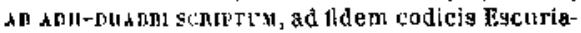
Jensis arebice nunc primum ediderunt indicibus additis Franeisens todera in Lniversilate Matritensi Arabica linune proressor ordinarias el Hegín Ifistorien Actiemiz: Suxtalis el Jwhum Rivera. Matrili, MDCCCLXXXY, on $40^{\circ}$, XXY y 642 peginas y un facsimila del códice,

34 ptas.

To. 1Y. ALMochas (Dictionaritu ordino alphabetico) IE DISCIPUT,IS ADE ALL AERADAFL AB AFFA ALABHAR scriptum, ad fidem codicis Escurialensis aralico nunc primum edidic indicibus additis, Francisets Codera et Zaydin. Mairiti, MuCCCLXXXY, en th, $\mathrm{X} I \mathrm{X}$ y $38 \mathrm{~s}$ j pag. 19 plas.

To. V y V]. COMFLedentrtia haRa assliall (Dictionarium biographicum) Ag slBR AI.ALBAR SCRIPTL'M, 
partem qum superesi ad fidem codicis Escurialensis. arabice nunc primum edidit, indicibus additis, Francisout Codera. Matrili, MDCCCLXXX1X. Dos tomos con roliacion conlinusda, Xil y obs Deginas,

SC plas.

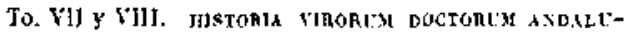

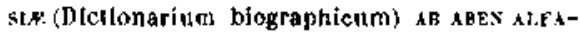
rabu scripla, ad niem codicis Tunicensis arabice notnc primum edidit, indicihus alditis. Frath-

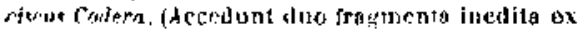

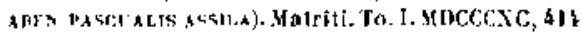
paginss y to. II. MDCrexcer, coto un facsimiledel original, XII y zis páge.

35 ptas.

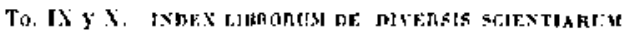

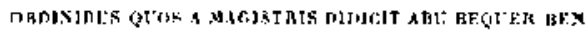
BHAlA al fidem codicis Escuriotensis arabice uunc primum ediderunt indicilste at ditis Frencisese $\mathrm{Co}$. dera el $J$, Bibern Tarrazo. To. I, Matrili, YDCCC.XCIII. thi phg. to. II, intices ef introductionem contiMrDs, XIII, 119 júk.

18 piss. 


\section{Obras de D. Francisco Codera}

Catedrático de leng:la drabe en la liniversidad de Madrid

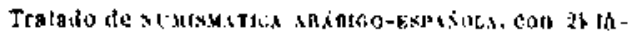
minas $\{23$ alluoclipngrafiadas por ol alutor. Ma-

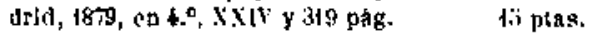

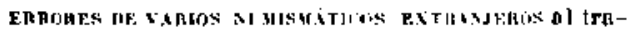

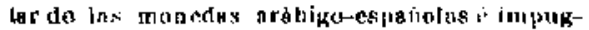

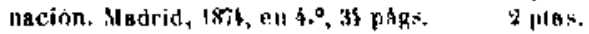

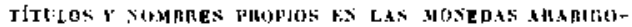

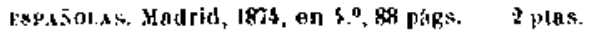

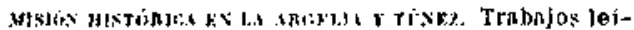
dos amlo la Peal xcademia de la Ilistoria. Matrid, IRgs, en $4.2,207$ pags.

7.50 ptas.

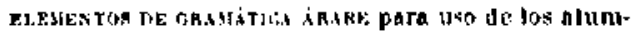
nos de 13. F. C. ' Z. Segunda ediclon. Mails ld, 1892 litografadn, en \{.", 11,3 pags.

2 ptas. 


\section{Obras de B. Loopoldo de Eguilaz \\ decano de Ia Faculad Je Fitosetia y Letras en la linivecsidad \\ de Granada y correspondiente de Jas R, R. A, A. \\ de la lengua y de la bisturia}

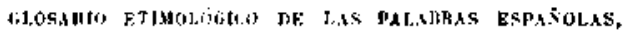
(costellanes, chlolanas, gallegos, mallorquinas, por(ughesas, valoncianas y bascongadas) ne oRTasx ontexisal (brebr, hebree, malayo, persa y

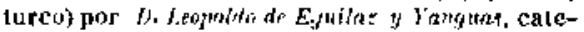
as bitico de bo Universiliad do Granade y corres pondiente las R. B. A. A. de la Lengua $y$ de la

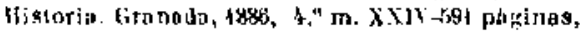
2i plas.

RESEYA HESTËRCA DE TA CONUL'JSTA DFL RENNO DE GRA-

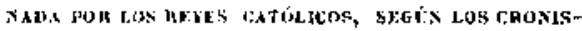
Tas inaties, pur ol misme autor. 2. edicioll, Granoda, 189s, con ol folegrabado de ur autogrofo do Honbiti,

3 plas.

Para los peditos de ealas dos obres, lay cue dirigfrse al eutor, Carrera de Darro, Na, Granads. 


\title{
Obras de D. Francisco Pons Boigues
}

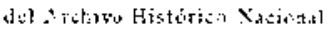

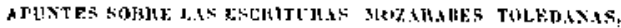
qub se custodine en el Arehivo llisturjo Nacional. Mallriu, 1897, en $82^{\circ}, 320$ pís. Librería do D. Hariano Murillo, 3 ptas.

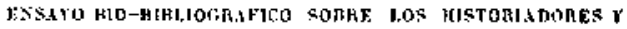

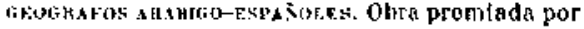

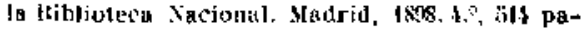
ginas,

to plats.

\section{Obra de D. Antonio Vives y Escudero}

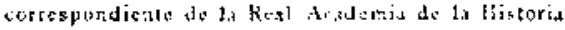

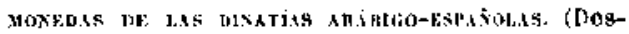
cripción de todes las modedas de esta dinastiag.

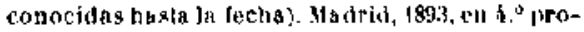
longado, X y iẳ póginas, l,ibrerla de M. Marimao Murillo, precio.

to ptas. 


\title{
Obra de D. Eduardo Saavedra
}

\author{
de la Real Academa de la Flistoria
}

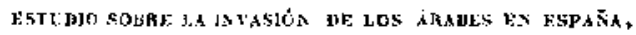
por D. Eiduavio Sacterira, do la Keal Acadernja de la Historia. Madrid, 489:. Vendese en Ia Jibrerla de Farnando Fe.

2ะงั) plas.

\section{Obras de D. Julián Ribera}

Catedrático de leagua ásabo e: la Lniversidad

$$
\text { de Zaragozat }
$$

OUIGENAS DEL JLSTIGIA DE ARAGḰK,

5 pesetas.

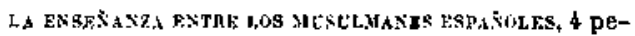
setas.

B]MUǴFI edición (extracto), 1 ptu.

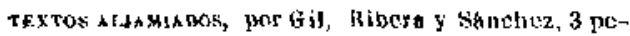
setrs. 